\title{
Synthese von Tetragastrin-CC-1065-Konjugaten und verwandten Verbindungen für eine selektive Krebstherapie
}

\author{
Dissertation \\ zur Erlangung des Doktorgrades \\ der Mathematisch-Naturwissenschaftlichen Fakultäten \\ der Georg-August-Universität zu Göttingen
}

vorgelegt von

Xiong Chen

aus Shanghai, China

Göttingen 2006 
D 7

Referent:

Prof. Dr. Dr. h.c. L. F. Tietze

Korreferent:

Prof. Dr. U. Diederichsen

Tag der mündlichen Prüfung: 04.07.2006 
Die vorliegende Arbeit wurde in der Zeit von März 2003 bis April 2006 im Institut für Organische Chemie der Universität Göttingen unter Leitung von Prof. Dr. Dr. h.c. L. F. Tietze angefertigt.

Mein besonderer Dank gilt meinem Doktorvater, Herrn Prof. Dr. Dr. h.c. L. F. Tietze, für die interessante Themenstellung, das stete Interesse am Fortgang der Arbeit, die hilfreiche Diskussionen und Anregungen sowie seine Unterstützung und Förderung während dieser Arbeit. 


\section{Inhaltsverzeichnis}

\section{ALLGEMEINER TEIL}

1 EINLEITUNG

2 MEDIZINISCHE GRUNDLAGEN DER CANCEROGENESE..................................................... 3

3 KONZEPTE DER THERAPIE MALIGNER ENTARTUNGEN.............................................. 5

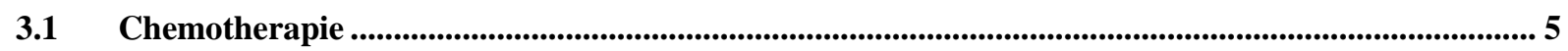

3.2 Immuntherapie....................................................................................................................................... 9

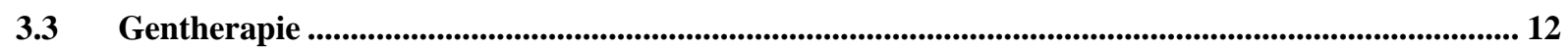

3.4 Das Konzept der reversibel detoxifizierten Prodrugs für eine selektive Krebstherapie..................... 13

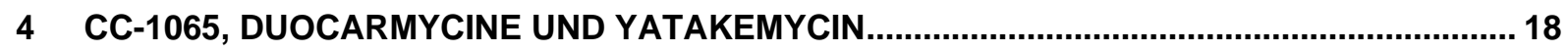

4.1 Analoga von CC-1065 und Struktur-Wirkungsbeziehungen ................................................................... 20

4.2 seco-Verbindungen und Prodrugs der CC-1065-Analoga ........................................................................... 22

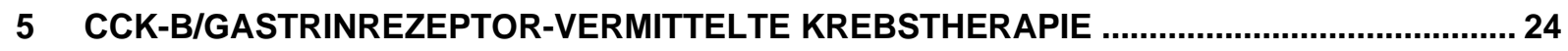

5.1 CCK-B/Gastrin................................................................................................................................... 24

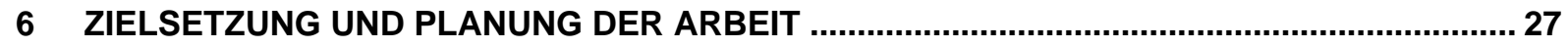

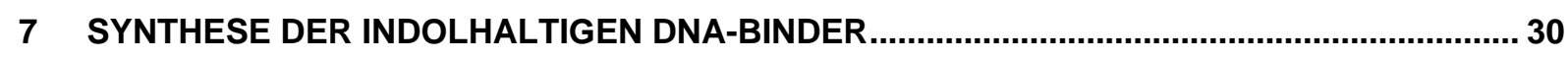

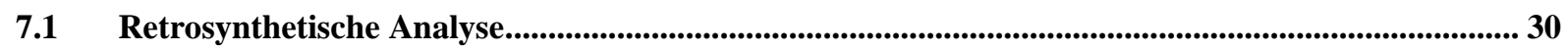

7.2 Synthese von 5-(2-Chlorethoxy)-indol-2-carbonsäureethylester (49) ................................................... 31

7.3 Synthese von 5-(2-Iodethoxy)-indol-2-carbonsäureethylester (50) ........................................................ 33

7.4 Synthese von 5-(2-Hydroxyethoxy)-indol-2-carbonsäureethylester (53) ............................................... 34

7.5 Synthese von 5-Allyloxyindol-2-carbonsäureethylester (57) und 5-(2-Azidoethoxy)-indol-2-

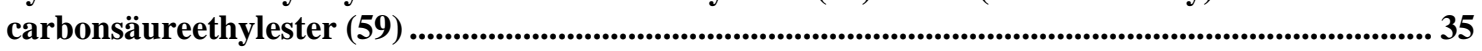

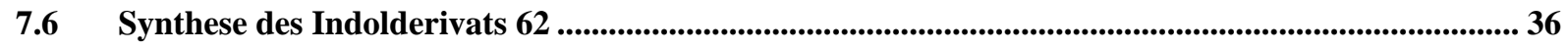

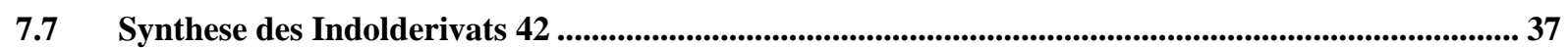

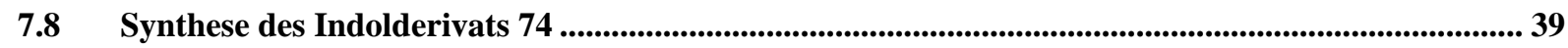

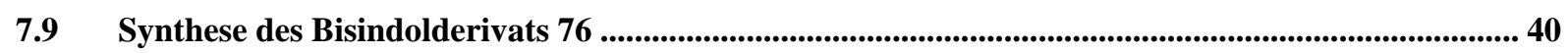

7.10 Diskussion ausgewählter spektroskopischer Daten von 49 und 42 .................................................... 41 


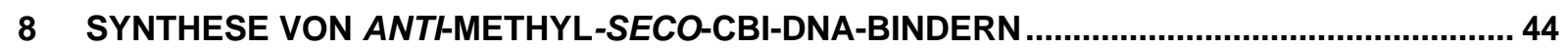

8.1 Synthese des anti-Methyl-seco-CBI-Grundgerüstes 82 ........................................................................ 44

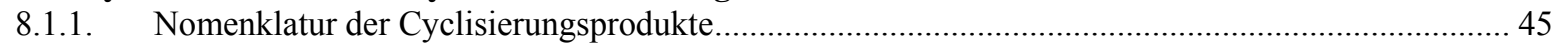

8.2 Synthese von anti-Methyl-seco-CBI-DNA-Binder....................................................................46

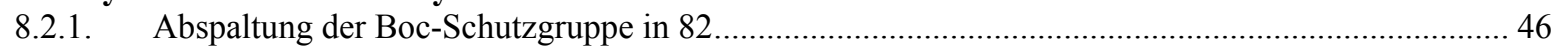

8.2.2. Kupplung von 84 mit unterschiedlichen DNA-Bindern .......................................................... 48

8.2.3. Modifikation der gekuppelten Verbindungen ........................................................................ 50

8.2.4. Überführung zu den Drug-DNA-Bindern durch Debenzylierung ........................................... 52

8.3 Diskussion ausgewählter spektroskopischer Daten von 91 und 101 ................................................54

9 SYNTHESE DER ANTI-METHYL-SECO-CBI-DNA-BINDER-TETRAGASTRIN-DERIVATE..... 57

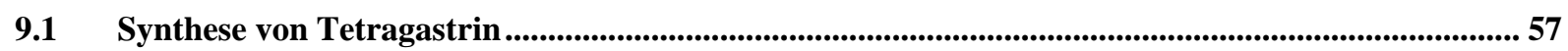

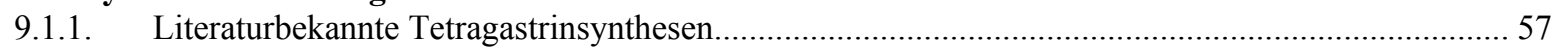

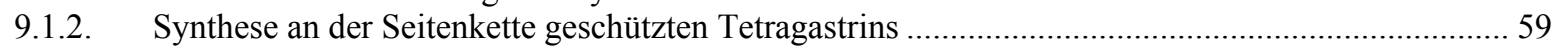

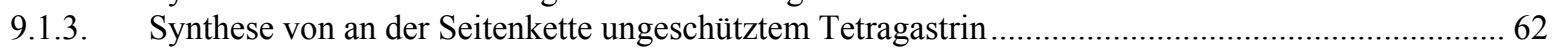

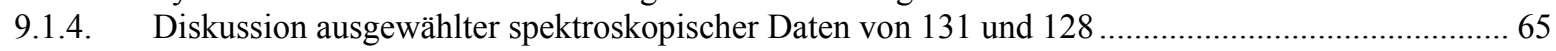

9.2 Synthese der anti-Methyl-seco-CBI-DNA-Binder-Tetragastrin-Derivate........................................67

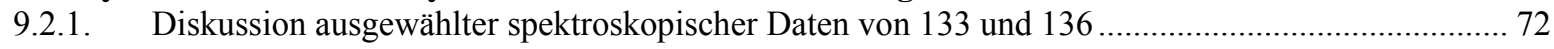

10 SYNTHESE DES ANTI-METHYL-SECO-CBI-DMAI-CARBAMAT-DERIVATS .....................74

11 IN VITRO-ZYTOTOXIZITÄTSUNTERSUCHUNGEN ...................................................... 76

11.1 Der HTCFA-Test zur Bestimmung der Zytotoxizitäten .......................................................... 76

11.2 In vitro-Zytotoxizitäten der anti-Methyl-seco-CBI-DNA-Binder-Derivate ........................................... 78

11.3 In vitro-Zytotoxizitäten des anti-Methyl-seco-CBI-DMAI-Carbamats ............................................. 79

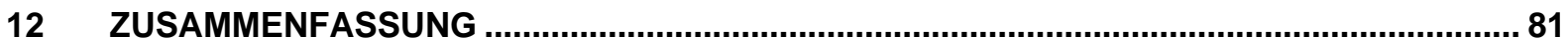




\section{EXPERIMENTELLER TEIL}

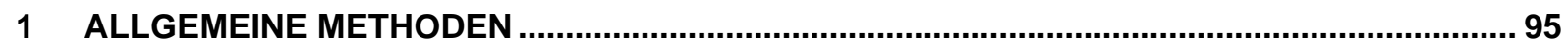

1.1 Präparative Methoden ............................................................................................................................. 95

$1.2 \quad$ Instrumentelle Analytik und verwendete Geräte ...................................................................................... 95

1.3 Chromatographische Methoden .............................................................................................................. 97

$1.4 \quad$ Materialien für die in vitro-Zytotoxizitätsessays ........................................................................................ 97

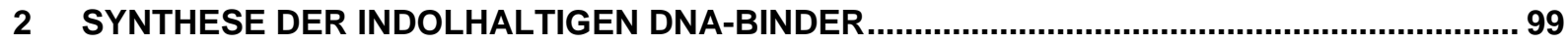

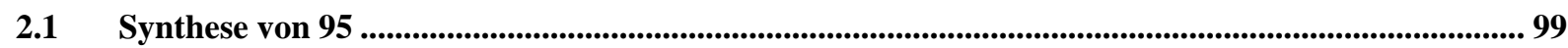

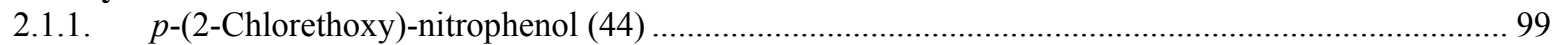

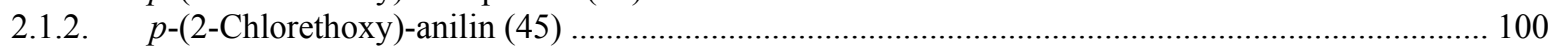

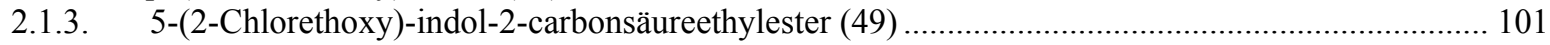

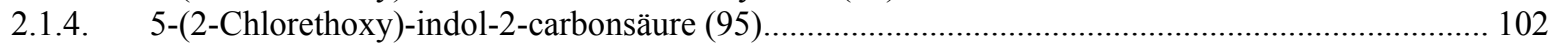

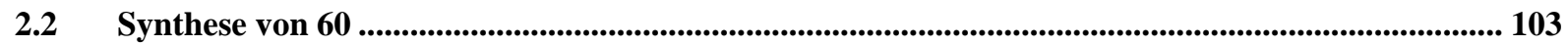

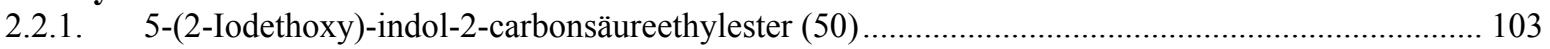

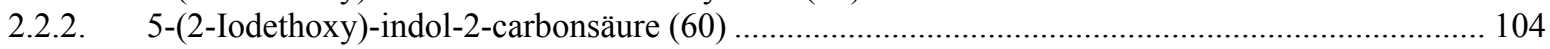

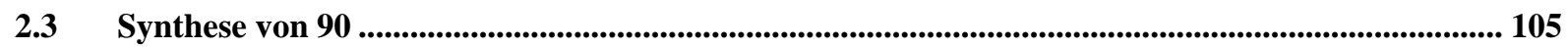

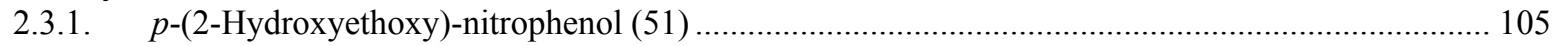

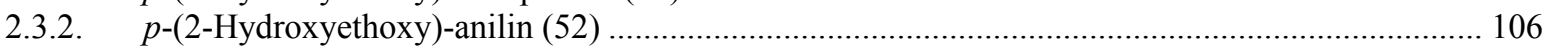

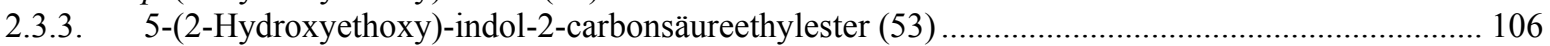

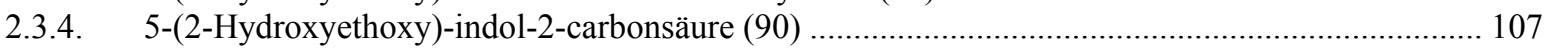

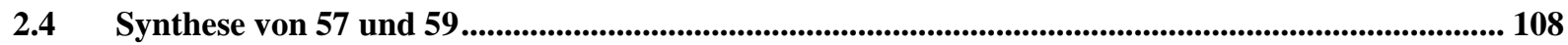

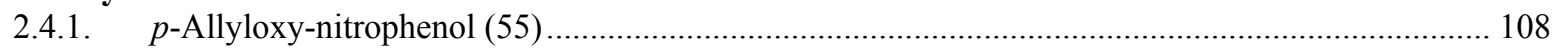

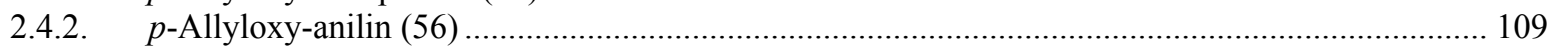

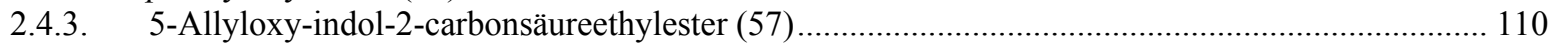

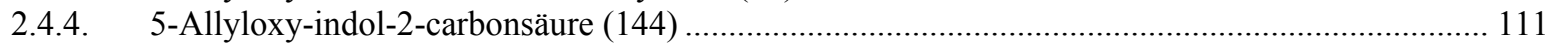

2.4.5. 5-(2-Azidoethoxy)-indol-2-carbonsäureethylester (59) ………………………………............... 112

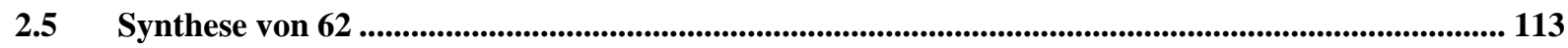

2.5.1. 5-[2-(2-Ethoxycarbonylethyl)-methyl-aminoethoxy]-indol-2-carbonsäure (62)…........................ 113

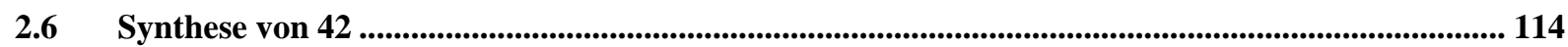

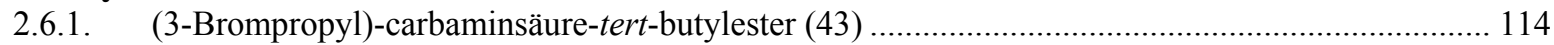

2.6.2. 5-(2-Methylaminoethoxy)-indol-2-carbonsäureethylester (64) …………………………........ 114

2.6.3. 5-\{2-[(3-tert-Butoxycarbonylamino-propyl)-methyl-amino]-ethoxy\}-]-indol-2-carbonsäure (42) 115

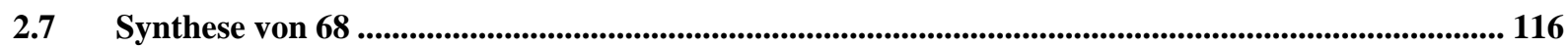

2.7.1. 5-[2-(2-Cyanoethyl)-methyl-aminoethoxy]-indol-2-carbonsäureethylester (67) …….................... 116

2.7.2. 5-[2-(2-Cyanoethyl)-methyl-aminoethoxy]-indol-2-carbonsäure (68) ............................................ 117

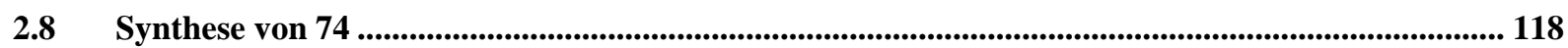

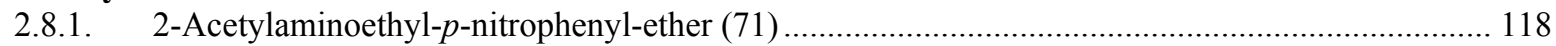

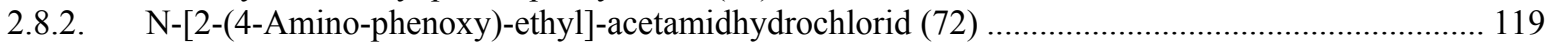

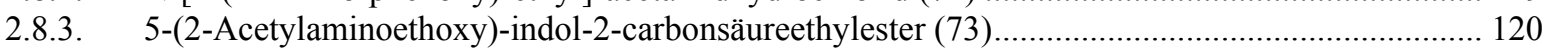

2.8.4. 5-(2-tert-Butoxycarbonylaminoethoxy)-indol-2-carbonsäureethylester (74) .................................... 121

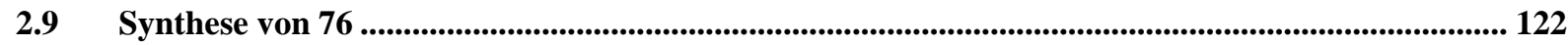

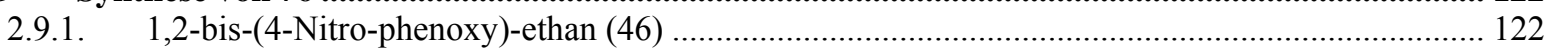

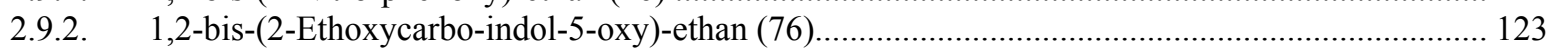


$3.1 \quad 3-A m i n o-1-b e n z y l o x y-N$-(tert-butoxycarbonyl)-naphthalin (78) ........................................................ 125

$3.2 \quad$ 2-Amino-4-benzyloxy-1-iod- $N$-(tert-butoxycarbonyl)-naphthalin (79) ................................................ 126

$3.3 \quad(E / Z)$-2-Amino-4-benzyloxy- $N$-(tert-butyloxycarbonyl)- $N$-(3-chlor-2-butenyl)-1-iod-naphthalin ....... (81).

$3.4 \quad r a c-\{(1,10)$-anti-5-Benzyloxy-3-(tert-butyloxycarbonyl)-1-(10-chlor-ethyl)-1,2-dihydro-3Hbenz[e]indol\} (82) .

3.5 rac-\{(1,10)-syn-5-Benzyloxy-3-(tert-butyloxycarbonyl)-1-(10-chlor-ethyl)-1,2-dihydro-3H-

benz[e]indol\} $(83)$

3.6 rac-(9,9a)-syn-2-(tert-Butyloxycarbonyl)-9-methyl-1,2,9,9a-tetrahydro-cyclopropa[c]benz[e] indol-4on (86).

$3.7 \quad$ rac-\{(1,10)-syn-1-(10-Chlor-ethyl)-5-hydroxy-1,2-dihydro-3H-benz[e]indol-hydrochlorid $\}$ (143). 130

4 SYNTHESE VON ANTI-METHYL-SECO-CBI-DNA-BINDER.

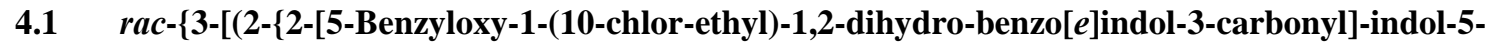

yloxy\}-ethyl)-methylamino]-propionsäure\} (88)

4.2 rac-\{(1,10)-anti-5-Benzyloxy-1-(10-chlor-ethyl)-3-[(5-(2-cyanoethyl-methyl-aminoethoxy)-indol-2-

yl)carbonyl]-1,2-dihydro-3H-benz[e]indol\} (89).

4.3 rac-\{(1,10)-anti-5-Benzyloxy-1-(10-chlor-ethyl)-3-[(5-(2-hydroxylethoxy)-indol-2-yl)carbonyl]-1,2dihydro-3H-benz $[e]$ indol $\}$ (91)

4.4 rac-\{(1,10)-anti-5-Benzyloxy-3-[(5-(2-(tert-butyloxycarbonyl)-aminoethoxy)-indol-2-yl)carbonyl]-1-

(10-chlor-ethyl)-1,2-dihydro-3H-benz[e]indol\} (92). 136

4.5 rac-\{3-[(2-\{2-[5-Benzyloxy-1-(10-chlor-ethyl)-1,2-dihydro-benzo[e]indol-3-carbonyl]-indol-5yloxy\}-ethyl)-amino]-propionsäure\} (94)

4.6 rac-\{(1,10)-syn-5-Benzyloxy-1-(10-chlor-ethyl)-3-[(5-(2-chlorethoxy)-indol-2-yl)carbonyl]-1,2-

dihydro-3H-benz[e]indol\} (96)

$4.7 \quad r a c-\{(1,10)-s y n$-5-Benzyloxy-3-[(5-(2-( $N, N$-dimethylamino)-ethoxy)-indol-2-yl)carbonyl]-1-(10chlor-ethyl)-1,2-dihydro-3H-benz[e]indol\} (98).

5 ÜBERFÜHRUNG ZU DEN DRUG-DNA-BINDERN DURCH DEBENZYLIERUNG.

5.1 rac-\{3-[(2-\{2-[1-(10-Chlor-ethyl)-5-hydroxy-1,2-dihydro-benzo[e]indol-3-carbonyl]-indol-5-yloxy\}ethyl)-methylamino]-propionsäure\} (100) 141

5.2 rac-\{(1,10)-anti-1-(10-Chlor-ethyl)-3-[(5-(2-cyanoethyl-methyl-aminoethoxy)-indol-2-yl)carbonyl]5-hydroxyl-1,2-dihydro-3H-benz[e]indol\} (101)

5.3 rac-\{(1,10)-anti-1-(10-Chlor-ethyl)-5-hydroxyl-3-[(5-(2-hydroxylethoxy)-indol-2-yl)carbonyl]-1,2-

dihydro-3H-benz[e]indol\} (102)

6.1 $\quad N$-(tert-Butyloxycarbonyl)-L-tryptophyl-L-methionin (110) ................................................................. 145

6.2 L-Asparaginsäure- $\beta$-methylester Hydrochlorid (116) 
$6.3 \quad N$-(tert-Butyloxycarbonyl)-L-aspartyl-( $\beta$-O-methyl)-L-phenylalaninamid (122)........................... 146

6.4 L-Asparaginsäure- $\beta$-allylester Hydrochlorid (118) ................................................................... 147

$6.5 \quad N$-(tert-Butyloxycarbonyl)-L-aspartyl-( $\beta$-O-allyl)-L-phenylalaninamid (123) ................................ 148

6.6 $\quad N$-(tert-Butyloxycarbonyl)-L-aspartyl-( $\beta$-O-benzyl)-L-phenylalaninamid (124) ............................. 149

6.7 $\quad N$-(tert-Butyloxycarbonyl)-L-aspartyl-L-phenylalaninamid (129) ............................................ 150

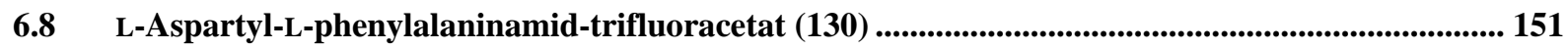

6.9 N-(tert-Butyloxycarbonyl)-L-tryptophyl-L-methionyl-L-aspartyl-( $\beta$-O-methyl)-L-phenylalaninamid

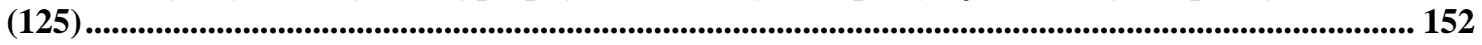

6.10 N-(tert-Butyloxycarbonyl)-L-tryptophyl-L-methionyl-L-aspartyl-L-phenylalaninamid (109) ........ 153

6.11 N-(tert-Butyloxycarbonyl)-L-tryptophyl-L-methionyl-L-aspartyl-( $\beta$-O-allyl)-L-phenylalaninamid

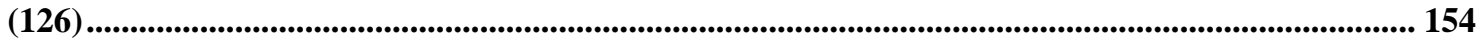

6.12 L-Tryptophyl-L-methionyl-L-aspartyl-L-phenylalaninamid-trifluoracetat (131) ............................. 155

6.13 L-tryptophyl-L-methionyl-L-aspartyl-( $\beta$-O-benzyl)-L-phenylalaninamid-trifluoracetat (128)....... 157

7 SYNTHESE DER ANTI-METHYL-SECO-CBI-DNA-BINDER-TETRAGASTRIN-DERIVATE.... 159

7.1 (1S, 10R/1R, 10S)-3-[(2-\{2-[5-Benzyloxy-1-(10-chlor-ethyl)-1,2-dihydro-benzo[e]indol-3-carbonyl]indol-5-yloxy\}-ethyl)-methylamino]-propionsäure-[L-tryptophyl-L-methionyl-L-aspartyl-( $\beta$-Omethyl)-L-phenylalaninamidyl]-amid (133).

$7.2(1 S, 10 R / 1 R, 10 S)-3-[(2-\{2-[5-B e n z y l o x y-1-(10-c h l o r-e t h y l)-1,2-d i h y d r o-b e n z o[e]$ indol-3-carbonyl]indol-5-yloxy\}-ethyl)-methylamino]-propionsäure-[L-tryptophyl-L-methionyl-L-aspartyl-( $\beta$-Obenzyl)-L-phenylalaninamidyl]-amid (134)

7.3 (1S, 10R/1R, 10S)-3-[(2-\{2-[5-Benzyloxy-1-(10-chlor-ethyl)-1,2-dihydro-benzo[e]indol-3-carbonyl]indol-5-yloxy\}-ethyl)-methylamino]-propionsäure-[L-tryptophyl-L-methionyl-L-aspartyl-Lphenylalaninamidyl]-amid-trifluoracetat (136).

8 SYNTHESE DES ANTI-METHYL-SECO-CBI-DMAI-CARBAMAT-DERIVATS

8.1 rac-\{(1,10)-anti-1-(10-Chlor-ethyl)-3-[(5-(2-( $N, N$-dimethylamino)-ethoxy)-indol-2-yl)carbonyl]-5-

hexylaminocarbonyloxy-1,2-dihydro-3H-benz $[e]$ indol $\}$ (140).

LITERATUR

\section{Danksagung}

\section{Lebenslauf}




\section{Allgemeiner Teil}

\section{$1 \quad$ Einleitung}

Die Krankheit Krebs spielte als Todesursache in früheren Generationen nur eine geringe Rolle. In heutiger Zeit tritt sie allerdings als Alterskrankheit aufgrund der verbesserten Lebensbedingungen und medizinischen Versorgung und dadurch bedingt des höheren Lebensalters des Menschen verstärkt in Erscheinung. So ist im Zuge einer ständig gestiegenen durchschnittlichen Lebenserwartung in den westlichen Industrienationen ist auch die Anzahl von Degenerationserkrankungen, die eine längere Entwicklungsphase benötigen, stetig angestiegen. Hierzu gehören die etwa 200 Krebsarten, die bisher beim Menschen bekannt sind. Diese "Vielfalt" hängt damit zusammen, dass im Prinzip jede Körperzelle mutieren und damit den Prozess des ungehemmten Zellwachstums auslösen kann. Wesentliche Risikofaktoren hat auch die Industrialisierung mit sich gebracht, zu denen cancerogene Chemikalien sowie der Abbau der Ozonschicht und damit verbunden die verstärkte Exposition gegenüber UV-Strahlung gehören. Zu den vermeidbaren Risikofaktoren zählen der Tabakrauch und eine ungesunde Ernährungsweise, die zusammen für über die Hälfte aller Krebserkrankungen verantwortlich gemacht werden. Die genetischen Faktoren spielen im Vergleich dazu nur eine untergeordnete Rolle.

Die Konsequenz ist, dass Krebs heute hinter den Herz-Kreislauferkrankungen die zweithäufigste Todesursache darstellt. In Abb. 1 sind die Todesfälle durch Krebs im Jahr 2000 im Europa dargestellt. ${ }^{1}$

Bei der Behandlung von Krebs gehören regelmäßige Untersuchungen im Rahmen der Frühdiagnostik und die Vermeidung von Risikofaktoren $\mathrm{zu}$ den eigenverantwortlichen Beiträgen, während in der wissenschaftlichen Forschung die Entwicklung angemessener Therapien im Vordergrund steht. Dabei spielt die Chemotherapie - neben der Chirurgie und der Strahlentherapie - eine wichtige Rolle, da sie im fortgeschrittenen Stadium der Erkrankung häufig die einzig erfolgversprechende Therapieform ist und ein hohes Entwicklungspotential beinhaltet. Bei Anwendung der zur Zeit zur Verfügung stehenden Chemotherapeutika müssen allerdings oft gravierende Nebenwirkungen in Kauf genommen werden, die auf die unzureichende Differenzierung des eingesetzten Zytostatika zwischen malignem und gesundem Gewebe zurückzuführen sind, da im Wesentlichen nur die gesteigerte Proliferationsrate von Krebszellen ausgenutzt wird. 
Tod durch Krebs im Jahr 2000

Pro 100000 Personen

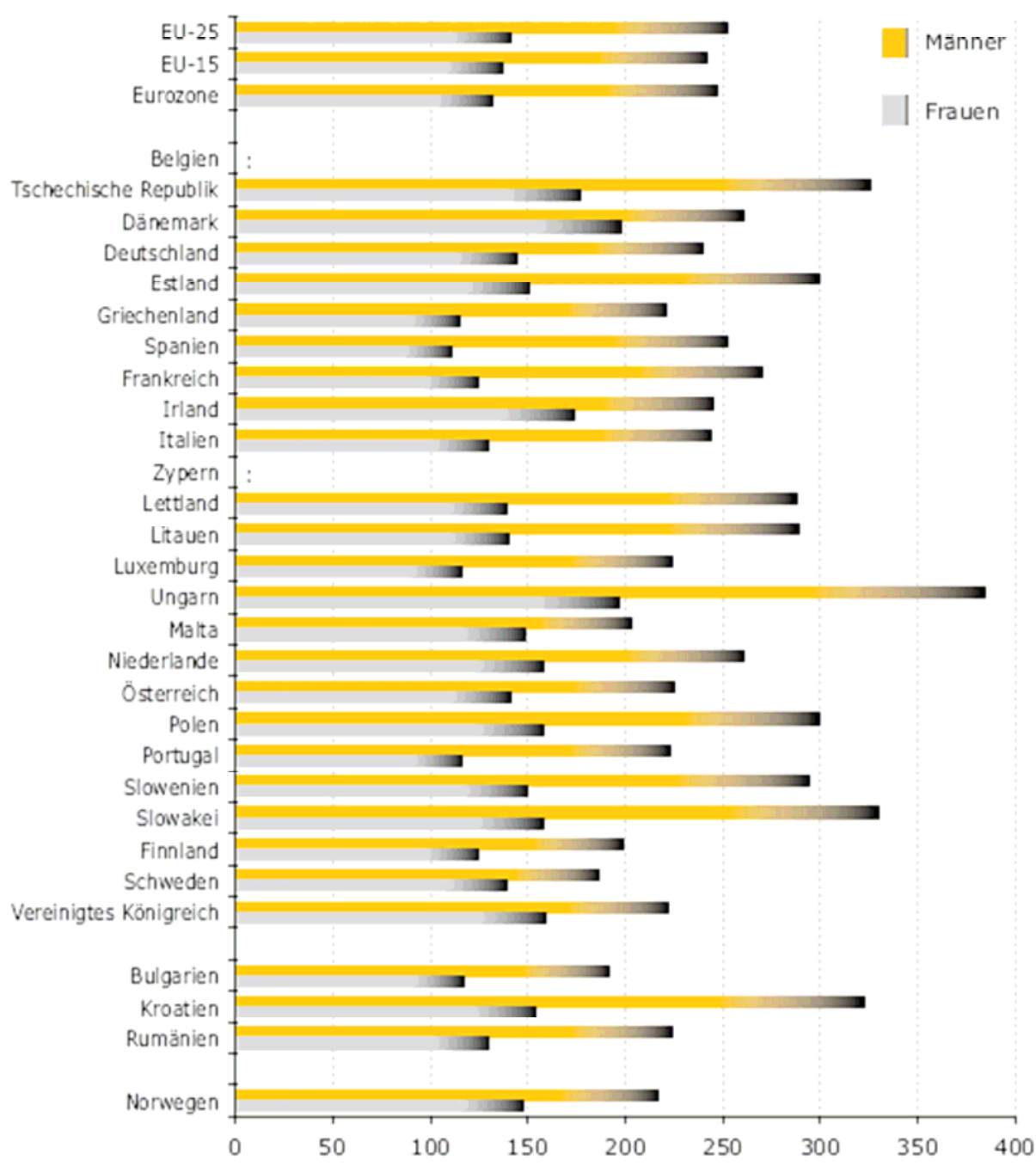

Abb. 1. Tod durch Krebs im Jahr 2000.

Zum Beitrag, den die synthetische organische Chemie zur Krebsbehandlung liefern kann, gehört die chemische Modifikation von antitumorwirksamen Naturstoffen, um ihre Selektivität oder ihre Wirksamkeit zu erhöhen. Hierzu sind im Arbeitskreis von L. F. Tietze bereits vielversprechende Therapieansätze entwickelt worden.

Die vorliegende Arbeit wurde im Rahmen der Forschung für eine selektive Krebstherapie angefertigt und beschäftigt sich mit der Synthese neuer Zytostatika. 


\section{Medizinische Grundlagen der Cancerogenese}

Der exakte molekulare bzw. genetische Mechanismus der Entstehung von Krebs ist bis heute nicht eindeutig geklärt. Sicher ist, dass der Ausgangspunkt durch Veränderungen in einer einzigen Körperzelle markiert wird. Bevor dies aber zur eigentlichen Cancerogenese, also der unkontrollierten Neubildung von Körperzellen (Neoplasie) führt, müssen in der Folge noch weitere Mutationsereignisse auftreten, die hauptsächlich die Kontrollgene für ungehemmtes Zellwachstum betreffen. ${ }^{2}$ Die Ursache solcher Mutationen kann zum einen in der genetischen Prädisposition (endogene Noxen) gesucht werden, die allerdings nur für etwa fünf Prozent der Erkrankungen verantwortlich ist. Den weitaus größeren Teil machen Umwelteinflüsse (exogene Noxen), energiereiche Strahlung, ${ }^{3}$ chemische Stoffe (z.B. Asbest, Benzol, Tabakrauch), aber auch eine falsche Ernährungsweise aus. Daneben gelten Krankheitserreger wie Viren (biologische Noxen) für die Entstehung bestimmter Krebsarten als Hauptrisikofaktoren. Zwischen der Einwirkung von Cancerogenen und dem Auftreten einer Krebserkrankung liegt eine Latenzzeit, die beim Menschen Jahre bis Jahrzehnte betragen kann.

Vermehrung, Wachstum, Differenzierung und Tod von Zellen sind genetisch geregelt. Die Funktion der Gene, die diese Vorgänge steuern, wird im Organismus durch übergeordnete, extrazelluläre Kontrollmechanismen reguliert. Über die interzelluläre Kommunikation ist sichergestellt, dass sich gleichartige Zellen in einem Gewebe gleich verhalten und eine funktionelle Einheit bilden. Während die Zellzahl im Entwicklungsstadium stetig zunimmt, bleibt sie nach der Differenzierung auf ihre jeweilige Funktion beim Erwachsenen weitgehend konstant. Untergang und Neubildung (etwa 50 Millionen Zellen pro Sekunde) von Zellen stehen dann im Gleichgewicht. Im Gegensatz zu normalen Zellen erreichen Krebszellen nicht den Endzustand der Differenzierung. Sie vermehren sich unkontrolliert unter Umgehung von körpereigenen Regelmechanismen.

Prinzipiell ist ein Tumor - neben seinem histologischen Erscheinungsbild - durch die Wachstumsgeschwindigkeit und die Wachstumsautonomie charakterisiert. Benigne Tumoren wachsen am Ort ihrer Entstehung als kompakter Zellverband, verdrängen zwar das umliegende Gewebe, zerstören es aber nicht und bilden keine Tochtergeschwülste (Metastasen). Im Gegensatz dazu wachsen maligne Tumoren unkontrolliert, brechen in Organe und Gefäße ein (Invasivität), zerstören diese (Destruktion) und können an anderen Stellen des Organismus Metastasen bilden. ${ }^{4}$ Zur makroskopischen Einteilung unterscheidet man Tumoren gemäß der TNM-Klassifizierung. ${ }^{5}$ ( $\mathrm{T}=$ Tumor, $\mathrm{N}=$ Nodulus/Knoten, $\mathrm{M}=$ Metastasen) nach ihrer Abstammung vom jeweiligen Muttergewebe, dem Grad ihrer 
Ausdehnung (Staging) und dem histologisch ermittelten Differenzierungsgrad (Grading). Gutartige Zellwucherungen erhalten allgemein die Endung -om und maligne Entartungen entsprechend -karzinom. Die Endung -sarkom gilt für epitheliale Tumoren, wenn sie dem Bindegewebe entstammen.

Im Normalfall dirigieren Gene den Lebenszyklus einer Zelle, wobei die sog. Proto-Onkogene das Zellwachstum fördern und die Tumorsuppressorgene hemmend wirken. ${ }^{6}$

Erbfaktoren (Mutationen)

exogene Faktoren

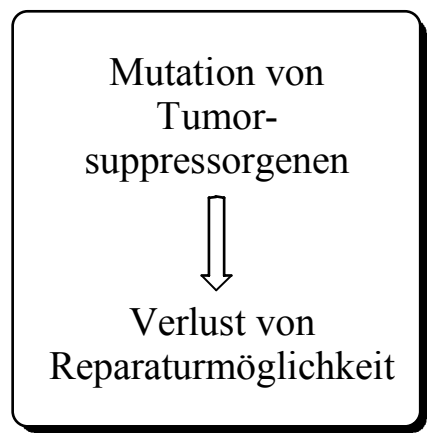

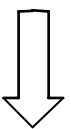

Veränderte Genexpression

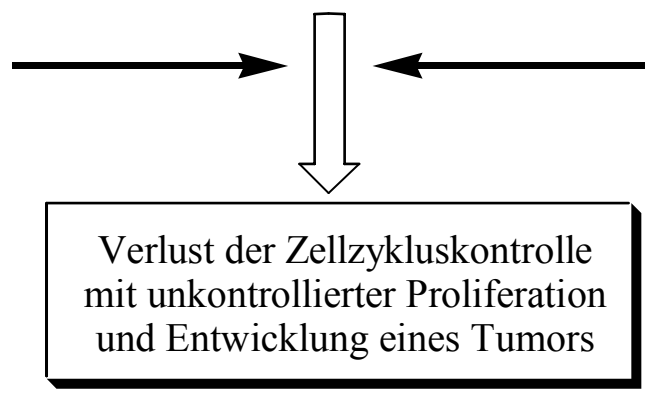

Aktivierung von

Proto-Onkogenen

zu Onkogenen<smiles>[C]=C</smiles>

Veränderte

Zellproliferation

Abb. 2. Genetische Grundlagen der Cancerogenese.

Die Umwandlung von Proto-Onkogenen zu Onkogenen durch Mutationen bzw. deren gesteigerte Expression führt zur verstärkten Aktivität der entsprechenden (Onko)-Proteine. ${ }^{7}$ Die derart veränderten Wachstumsfaktoren können im Gegensatz zu den physiologischen Proteinen ein Dauersignal zur Zellteilung bewirken und damit der Apoptose entgegenwirken. Darüber hinaus nimmt man an, dass durch mutagene Substanzen die Tumorsuppressorgene, zu denen unter anderem das p53-Gen zählt, inaktiviert werden können (Abb. 2). ${ }^{8}$ Die durch p53 kontrollierten Faktoren hemmen den Eintritt von Zellen in die S-Phase des Zellzyklus (Phase der DNA-Synthese) und ermöglichen dadurch eine DNA-Reparatur. Außerdem wird im Fall irreparabler DNA-Schäden durch p53 auch der programmierte Zelltod eingeleitet. Ein durch Mutation verursachter Funktionsverlust derartiger Tumorsuppressorgene fördert also ebenfalls die Zellproliferation. Mutierte p53-Gene wurden inzwischen bei der Hälfte aller menschlichen Tumorarten entdeckt. Die Frage, welche Mutation für die maligne Transformation verantwortlich ist, ist nicht generell $\mathrm{zu}$ beantworten. Angesichts der mehr fachen Kontroll- und Steuerungsmechanismen des Zellstoffwechsels muss in einer Zelle mehr als eine Mutation erfolgen, damit sich ein manifester Tumor entwickelt. 


\section{$3 \quad$ Konzepte der Therapie maligner Entartungen}

Therapeutische Maßnahmen beim manifesten Krebs beschränken sich auf eine Vernichtung oder Wachstumshemmung von Tumorzellen. Die drei Säulen der klassischen Tumortherapie

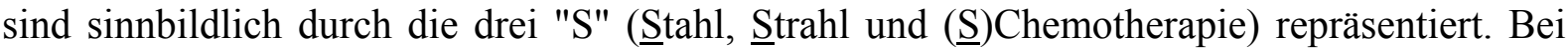
soliden, klar umgrenzten Tumoren stellt eine operative Entfernung des entarteten Gewebes die Methode mit den besten Heilungschancen und geringsten Nebenwirkungen dar. Ist der Tumor schwer zugänglich oder betrifft er lebenswichtige Strukturen wie zum Beispiel Hirnstrukturen, kann eine Strahlenbehandlung angebracht sein, die zudem für den Gesamtorganismus weniger belastend ist als ein operativer Eingriff. In einem fortgeschrittenen Krankheitsstadium, in dem es bereits zu Metastasenbildung gekommen ist, bleibt jedoch meist nur eine Chemotherapie als letzte Möglichkeit, wobei beträchtliche Nebenwirkungen durch mangelnde Differenzierung zwischen benignem und malignem Gewebe in Kauf genommen werden müssen. Da das Ziel von Chemotherapeutika stark proliferierende Zellen sind, zeigen sich Schäden typischerweise an sich ständig regenerierenden Geweben wie zum Beispiel dem Knochenmark (Aplastie), der Schleimhaut (Mukositis) und Haarzellen (Alopezie).

$\mathrm{Zu}$ den neuen vielversprechenden Methoden gehören gen- und immunotherapeutische Ansätze, die unterstützend eingesetzt werden können.

\subsection{Chemotherapie}

Der Begriff Chemotherapie bezeichnet in der Krebsbehandlung die Applikation von toxischen Substanzen (Zytostatika), die in den Stoffwechsel und die Teilung von Zellen eingreifen und dadurch zum Zelltod oder zumindest zu einer Proliferationshemmung führen. Anhand der Wirkmechanismen der in der Tumortherapie eingesetzten Zytostatika erfolgt eine Einteilung dieser in verschiedene Klassen, je nach deren Angriffspunkt in den Zellzyklus. Man unterscheidet dabei Alkylantien, Antimetabolite, Topoisomerase-Hemmstoffe, MitoseHemmstoffe und zytotoxisch wirksame Antibiotika.

Alle eukaryontischen Zellen durchlaufen einen identischen Zellzyklus (Abb. 3.1). ${ }^{4}$ Der Teilungszyklus gliedert sich dabei in die eigentliche Mitosephase $\mathrm{M}$ und die drei Interphasen $\mathrm{G}_{1}$, $\mathrm{S}$ und $\mathrm{G}_{2}$. In der postmitotischen und präsynthetischen $\mathrm{G}_{1}$-Phase $(\mathrm{G}=$ gap: Unterbrechung) werden hauptsächlich für die Zellteilung benötigte RNA und Proteine synthetisiert, während in der relativ kurzen S-Phase (Synthesephase) durch Neubildung der DNA der Chromosomensatz verdoppelt und damit die Zellteilung vorbereitet wird. An die S- 
Phase schließt sich die postsynthetische Wachstumsphase $\left(\mathrm{G}_{2}\right.$-Phase $)$ an. In ihr liegen die Chromosomen bereits in Form von Chromatiden vor. Bei der folgenden Mitosephase (M) werden die Chromatiden mit Hilfe von Mikrotubuli getrennt und auf die Tochterzellen verteilt. Nach Trennung der Tochterzellen ist der Zyklus beendet. Ein Teil der Zellen geht in die stabile Ruhephase $\left(\mathrm{G}_{0}\right)$ über, während der andere Teil wieder in den Zyklus eintritt. Differenziert sich eine Zelle und wird zur Dauergewebszelle, tritt sie in die stabile Ruhephase $\left(\mathrm{G}_{0}\right)$ über und teilt sich nicht mehr. In dieser Phase ist die Zelle für Zytostatika in der Regel nicht zugänglich. Der Zellzyklus wird erst wieder aufgenommen, wenn die Zelle externe Signale empfängt, wie zum Beispiel den Kontaktverlust mit der Nachbarzelle. Da sich maligne Entartungen jedoch durch eine gesteigerte Proliferationsrate auszeichnen, befinden sich teilweise nur $10 \%$ der Tumorzellen in Ruhe. Das macht sie für Chemotherapeutika leichter zugänglich.

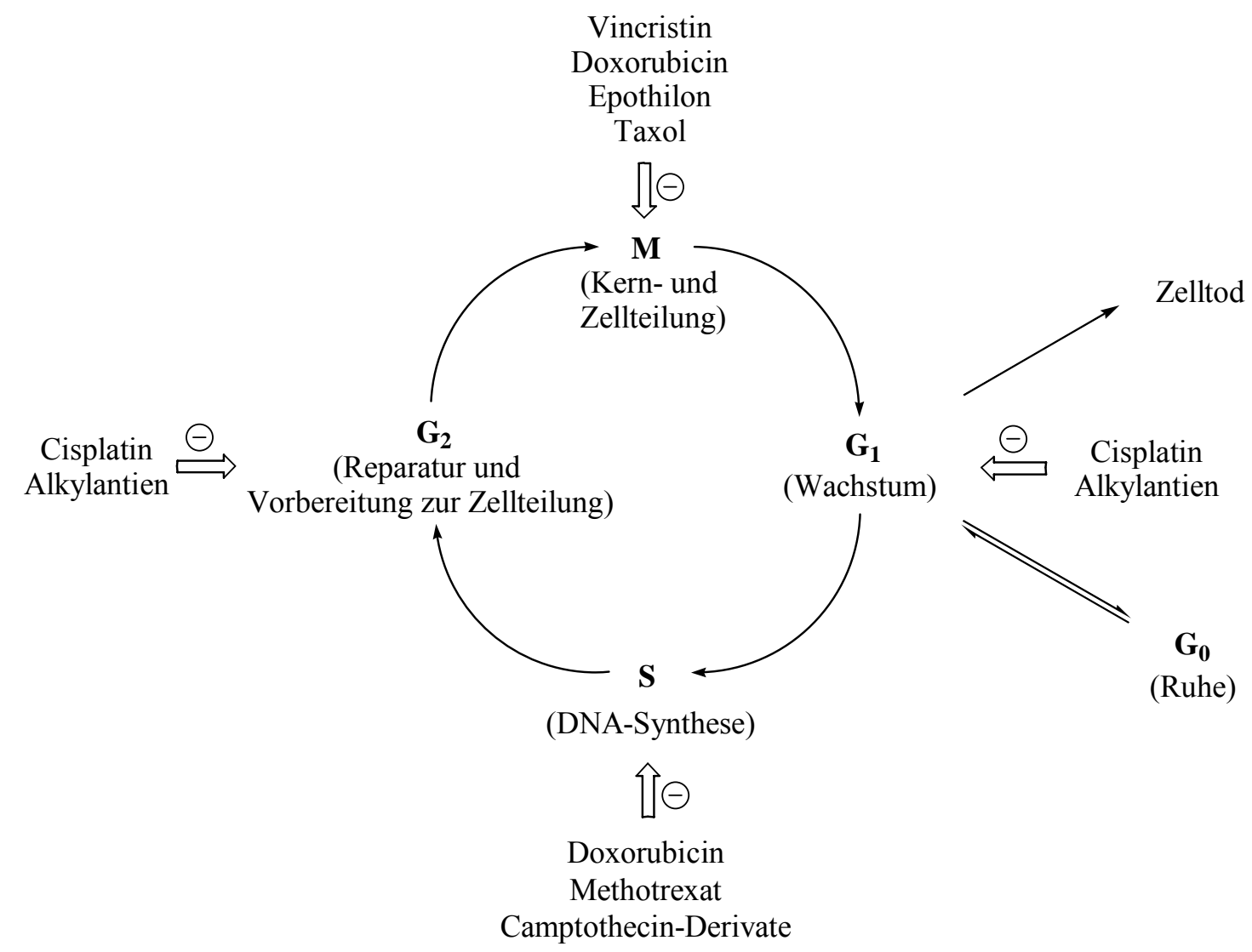

Abb. 3.1. Der Zellzyklus mit Beispielen für Chemotherapeutika und deren Angriffspunkte.

Die bedeutsamste Gruppe der Chemotherapeutika stellen die in der Regel phasenunspezifisch wirkenden DNA-Alkylantien dar. Hierzu gehören Verbindungen unterschiedlicher chemischer Struktur, deren gemeinsames Kennzeichen hochreaktive elektrophile 
Alkylgruppen sind. Diese reagieren mit $\mathrm{N}$-, $\mathrm{O}$ - oder $S$-haltigen Nucleophilen in Proteinen und insbesondere in Nucleinsäuren. Die Folge davon sind Quervernetzungen der DNA, abnorme Basenpaarungen und Strangbrüche, die schließlich zum Tod der Zelle führen. Zu dieser Gruppe gehören die schon früh entwickelten Stickstoff-Lost-Derivate wie das Cyclophosphamid (1), ${ }^{9}$ das als sog. Prodrug erst durch Metabolisierung in den eigentlichen Wirkstoff 2 überführt wird. Ein weiterer wichtiger Vertreter der Alkylantien ist das Cisplatin (3) $\left(\right.$ Abb. 3.2). ${ }^{10}$

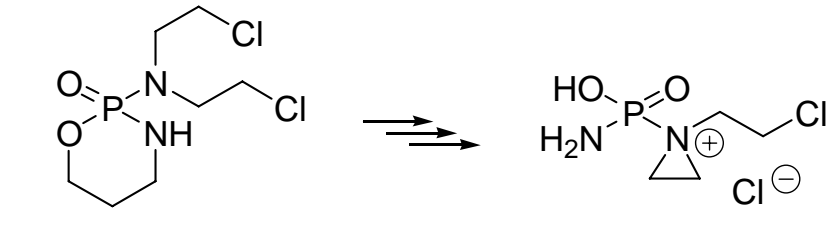

Cyclophosphamid (1)
2

$$
\text { Cisplatin (3) }
$$

Abb. 3.2. Beispiele für DNA-Alkylantien.

$\mathrm{Zu}$ einer Gruppe besonders wirksamer Alkylantien gehören das Antibiotikum CC-1065, die Duocarmycine, das Yatakemycin sowie Derivate und Analoga der genannten Verbindungen (s. Kap. 4).

Die Klasse der Antimetabolite repräsentiert strukturelle Analoga körpereigener Stoffwechselbausteine, die als Antagonisten an die Stelle der eigentlichen Metabolite treten. Hierdurch können wichtige Enzyme gehemmt oder funktionsuntüchtige Makromoleküle synthetisiert werden. Als Beispiel (Abb. 3.3) sei der Folsäureantagonist Methotrexat (4) genannt, der als falsches Substrat die Bildung von Tetrahydrofolsäure verhindert, die als Intermediat der Purinsynthese essentiell für eine Zellproliferation ist. ${ }^{11}$

Mitosehemmstoffe wirken, wie der Name bereits sagt, in der Mitosephase des Zellzyklus. Die entsprechenden Chemotherapeutika binden an die $\beta$-Einheit des Tubulindimers und hemmen dadurch entweder den Aufbau der Kernspindeln (z. B. Colchicin, Vincristin (6), Vinblastin (7), Abb. 3.4) $)^{12}$ oder blockieren ihren Abbau (Taxol, Epothilon). ${ }^{13}$ Eine Kern- und Zellteilung ist dann nicht mehr möglich. 
<smiles>[R]c1nc(N)nc2ncc(CN([R])c3ccc(C(=O)N[C@@H](CCC(=O)O)C(=O)O)cc3)nc12</smiles>

$\mathrm{R}^{1}=\mathrm{NH}_{2}, \mathrm{R}^{2}=\mathrm{Me}$ Methotrexat (4) $\mathrm{R}^{1}=\mathrm{OH}, \mathrm{R}^{2}=\mathrm{H} \quad$ Folsäure (5)

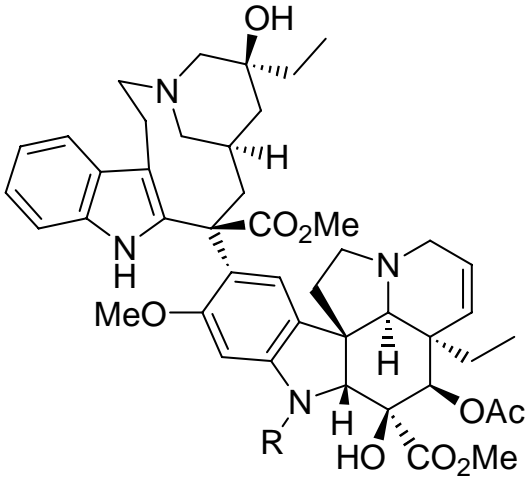

$\mathrm{R}=\mathrm{CHO}$ Vincristin (6)

$\mathrm{R}=\mathrm{Me} \quad$ Vinblastin (7)

Abb. 3.3. Beispiele für Antimetabolite (4) und Mitosehemmstoffe (6), (7).

Eine weitere Gruppe von Chemotherapeutika sind die Hemmstoffe der Topoisomerasen I und II. Die zur Replikation notwendige Entwindung der DNA führt zu einer Verdrillung des DNA-Stückes. Durch die körpereigenen Topoisomerasen wird die Verdrillung aufgehoben, indem einer oder beide DNA-Stränge vorübergehend unterbrochen und nach erfolgter Replikation wieder zusammengefügt werden. Die Hemmung dieser Enzyme und insbesondere die Blockade ihrer Dissoziation von der DNA führt dazu, dass Strangbrüche auftreten, die schließlich den Zelltod bewirken. Typische Vertreter dieser Substanzgruppe sind Derivate des Alkaloids Camptothecin (8) (Abb. 3.4).

Zu den zytostatischen Antibiotika zählen in erster Linie die aus Streptomyces-Arten isolierten Anthracycline Daunorubicin (9) und Doxorubicin (10) (Abb. 3.4). Ihre zytostatische Wirkung ist besonders ausgeprägt in der S-Phase des Zellzyklus. Sie intercalieren in die DNA und hemmen so die Nucleinsäuresynthese oder inhibieren die DNA- und RNA-Synthese, indem sie durch Radikalbildung Doppelstrangbrüche verursachen. ${ }^{14}$<smiles>CC[C@@]1(O)C(=O)OCc2c1cc1n(c2=O)Cc2cc3ccccc3nc2-1</smiles>

Camptothecin (8)<smiles>[R]CC(=O)[C@]1(O)Cc2c(O)c3c(c(O)c2C[C@H]1O)C(=O)c1c(OC)cccc1C3=O</smiles><smiles>[R]=[R]O</smiles>

Daunorubicin (9)

Abb. 3.4. Beispiele für Topoisomerase-Hemmstoffe (8) und zytostatische Antibiotika (9), (10). 
Die Behandlung maligner Tumore mit Chemotherapeutika hat insbesondere in Fällen schwer zugänglicher Tumore oder bei Metastasenbildung zur Verbesserung der Behandlungsmöglichkeiten beigetragen. Neben dem Auftreten zum Teil schwerer akuter Nebenwirkungen, die unter Umständen den Abbruch einer Therapie erfordern, sind die Spätfolgen wie eine Induktion von Sekundärtumoren, eine Schädigung des Knochenmarks, ein Auftreten von Lungenfibrosen oder eine Immundefizienz gravierende Nachteile einer Chemotherapie. Ein weiteres Problem stellen Resistenzentwicklungen von Tumoren gegen einzelne Zytostatika oder Gruppen von Chemotherapeutika dar, die als natürliche Folge der Selektion resistenter Zellen während einer Behandlung auftreten. ${ }^{15}$ Die nicht mehr oder nur noch vermindert auf die Chemotherapeutika ansprechenden Zellen sind z. B. in der Lage, das Zytostatikum innerhalb der Zelle zu entgiften, dieses gar nicht erst aufzunehmen oder es nach der Aufnahme wieder in den extrazellulären Raum abzugeben.

Die Notwendigkeit einer chemotherapeutischen Behandlung in bestimmten Fällen sowie die beschriebenen Nebenwirkungen und Resistenzentwicklungen verlangen eine stete Weiterentwicklung im Bereich der Chemotherapeutika.

\subsection{Immuntherapie}

In einem weiteren neuartigen Ansatz wird versucht, das eigene Immunsystem für die Zerstörung entarteter Zellen zu nutzen. So ist die Oberfläche jeder Zelle durch ein komplexes Muster an Oberflächenantigenen gekennzeichnet. Dabei handelt es sich um Glycosphingolipide, also um Substanzen mit einer Kohlenhydratkette und einem lipophilen Ceramidrest. Dieser lagert sich in die Lipiddoppelschicht der Zellmembran ein, während sich der hydrophile Oligosaccharidteil auf der äußeren Membranseite befindet und für die interzelluläre Kommunikation verantwortlich ist. Im Zuge einer malignen Entartung kommt es zu einer Veränderung dieser Oberflächenantigene, die von der Wirtszelle und dem krebsauslösenden Agens abhängig ist. Neben einer Störung der normalen GlycosphingolipidSynthese, die eine geregelte Zellerkennung verhindert, werden auch neuartige Glycosphingolipide synthetisiert und auf der Oberfläche präsentiert. Diese tumorassoziierten Antigene sind eine wichtige molekulare Eigenheit von Krebszellen und stellen die Voraussetzung für eine Immuntherapie dar. ${ }^{16}$ Obwohl das körpereigene Immunsystem solche Strukturen prinzipiell als fremd ansieht, entziehen sich die Krebszellen dieser Erkennung. Einfache mögliche Gründe hierfür sind u. a. eine zu geringe Zahl an tumorassoziierten Antigenen oder die schwere Zugänglichkeit solider Tumore. Die molekularen und 
strukturellen Ursachen sind noch nicht eindeutig geklärt. Es werden jedoch verschiedene Ansätze diskutiert, nach denen entartete Zellen nicht mehr über spezielle Erkennungsmerkmale verfügen, die für die Bindung an Lymphozyten erforderlich sind. Hierzu gehört zum Beispiel das Glycoprotein CD40, das normalerweise mit einem speziellen Liganden (CD40L) an den Lymphozyten komplexiert, dessen Bildung durch Kontakt der TZelle mit den MHC-Molekülen (Major Histocompatibility Complex) auf der Tumorzelloberfläche angeregt wird. ${ }^{17}$ Neben den fehlenden Erkennungsmerkmalen CD40 und MHC zeichnen sich einige Krebszellen darüber hinaus durch die Präsentation von membrangebundenen, komplementregulierenden Proteinen (mCRP) auf ihrer Oberfläche aus, welche sie ebenfalls vor einem Angriff durch das Komplementsystem schützen. ${ }^{18}$ Ein Ziel der Immuntherapie ist es daher, diese Defizite von Krebszellen auszunutzen und das körpereigene Immunsystem zu aktivieren. Eine wichtige Rolle spielen hierbei monoklonale Antikörper, die selektiv an tumorassoziierte Antigene binden. Mit deren Hilfe gelingt es beispielsweise, die Krebszellen zu markieren und durch eine entsprechende zweite spezifische Bindungsstelle an den Antikörpern die Anknüpfung von T-Lymphozyten oder natürlichen Killerzellen (NK) zu ermöglichen, die schließlich die Zytolyse der Tumorzelle einleiten (Ansatz A in Abb. 3.5). Daneben können die komplementregulierenden Oberflächenproteine durch bifunktionelle Antikörper blockiert und somit inaktiviert werden (Ansatz B). ${ }^{17}$ Weiterhin wurde festgestellt, dass Zytokine, also regulatorisch wirkende Proteine, eine wichtige Rolle bei der Aktivierung der körpereigenen Abwehrmechanismen spielen. Hierzu gehört zum Beispiel das Interleukin-2 (IL-2), das von aktivierten T-Helfer-Zellen produziert wird und das Wachstum von T-Zell-Klonen anregt. Eine Therapie mit Interleukin-2 kann auf verschiedene Weise erfolgen. Es besteht die Möglichkeit einer direkten Gabe oder einer in vitro-Aktivierung von Lymphozyten des Patienten und Reinfusion der als LAK (Lymphokin Aktivierte $\underline{\text { Killerzellen) }}$ bezeichneten Zellen. ${ }^{15}$ Eine dritte Möglichkeit ist die Verknüpfung von Interleukinen mit monoklonalen Antikörpern zu den Immunozytokinen, wodurch ihre Selektivität erhöht und die systemischen Nebenwirkungen eingeschränkt werden sollten (Ansatz C). ${ }^{19}$ Ein vollkommen anderer Ansatz, die körpereigene Abwehr gegen Krebszellen zu mobilisieren, ist deren Verschmelzung mit Antigen-präsentierenden Zellen. Die daraus entstehenden Hybride exprimieren auf ihrer Oberfläche verstärkt tumorassoziierte Antigene und kostimulierende Moleküle wie zum Beispiel das CD40-Protein oder MHC-Moleküle. Sie fungieren als eine Art Impfstoff (Vakzin) und aktivieren zytotoxische Lymphozyten (CTL). ${ }^{20}$ Der gleiche Effekt wird auch durch das Beladen von dendritischen Zellen (DZ) mit Tumorproteinen, -peptiden oder -DNA erzielt (Ansatz D). ${ }^{21}$ 


\section{Antikörper als Carrier von Toxinen}

(F)

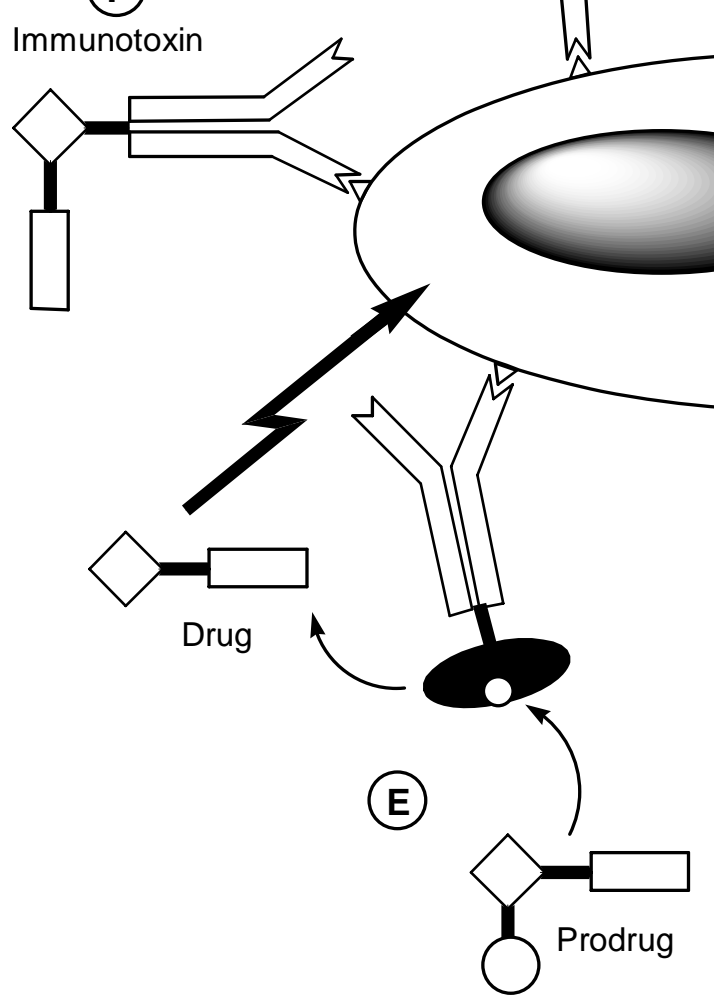

\section{Aktivierung der körpereigenen Abwehr}

(G)
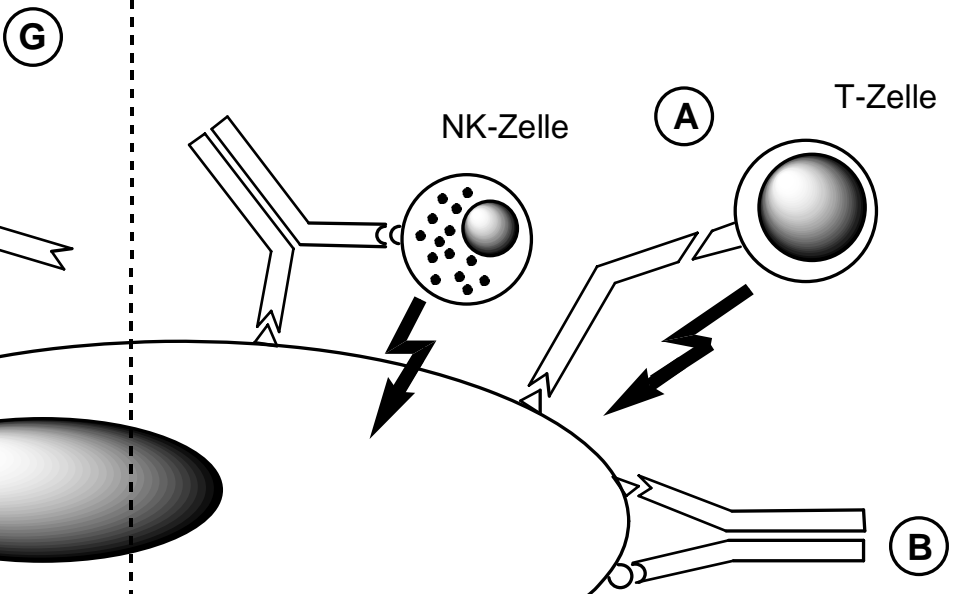

Abb. 3.5. Verschiedene Ansätze für eine Immuntherapie von Tumoren: A Antikörper-vermittelte Tumorzelllyse; B Inaktivierung von komplementregulierenden Antigenen; C Immunozytokine; D Aktivierung von CTL durch beladene dendritische Zellen; E Antikörper-Enzym-Konjugat mit Prodrug (ADEPT); F Immunotoxine; G Antikörper-Isotopen-Konjugat.

Neben diesen das körpereigene Immunsystem stimulierenden Ansätzen ist ein wichtiger Ansatz in der Immuntherapie die Verwendung von Toxin-Immunkonjugaten, in denen der Antikörper als selektiver „,carrier“ für zytotoxische Substanzen eingesetzt wird. ${ }^{22}$ Hierbei wird die Spezifität monoklonaler Antikörper für tumorassoziierte Antigene genutzt, um eine Schädigung gesunder Zellen durch die verwendeten Toxine möglichst gering zu halten. Bei dem sogenannten ADEPT-Konzept (Antibody Directed Enzyme Prodrug Therapy) werden 
Antikörper-Enzym-Konjugate verwendet, die in der Lage sind, ein reversibel detoxifiziertes Zytostatikum (Prodrug) selektiv an der Krebszelle in seine toxische Form (Drug) zu überführen (Ansatz E) ${ }^{23}$ Im Gegensatz zu den direkt an die Antikörper gekoppelten Toxinen (Ansatz F) weist das ADEPT-System den Vorteil auf, dass nur eine relativ niedrige Konzentration von Immunkonjugaten notwendig ist, da die Enzyme in der Regel eine hohe Aktivität besitzen und in der Lage sind, eine große Anzahl von Prodrugmolekülen direkt am Tumor in das entsprechende Toxin zu überführen. Zusätzlich ergibt sich durch die Diffusion des nicht an den Antikörper gebundenen Zytostatikums ein Effekt auf die umliegenden Tumorzellen (sogenannter bystander effect), welche nicht unbedingt über denselben Antikörper verfügen müssen. Möglich ist des Weiteren eine Kupplung radioaktive Isotope $\left({ }^{131} \mathrm{I},{ }^{90} \mathrm{Y}\right)$ mit Antikörpern. Dieser Ansatz wird nicht nur zur Therapie, sondern auch in der Diagnostik verwendet und ermöglicht u. a. die Lokalisation von Metastasen im Körper (selektive Radio-Therapie) (Ansatz G). ${ }^{24}$

Der Großteil der vorgestellten Ansätze zur Immuntherapie nutzt Antikörper als wichtigstes Instrument. Es ist zwar möglich, monoklonale Antikörper in ausreichender Menge herzustellen, doch sind diese in der Regel murinen Ursprungs und lösen daher im Patienten eine Immunantwort aus. Die Verwendung humanisierter oder humaner Antikörper könnte hier Abhilfe schaffen. Problematischer ist hingegen die Tatsache, dass Zellen verschiedener Krebsarten unterschiedliche Antigenmuster präsentieren, die sich darüber hinaus in jedem Individuum unterscheiden. Für optimale Therapieerfolge müssten die Antikörper demzufolge individuell auf die tumorassoziierten Antigene der jeweiligen Patienten abgestimmt werden.

\subsection{Gentherapie}

Gentherapie ist definiert als das Einbringen von Genen in Gewebe oder Zellen mit dem Ziel, durch die Expression und Funktion dieses Gens einen therapeutischen Nutzen zu erzielen. ${ }^{25}$ Durch eine gezielte Anreicherung eines Arzneistoffs am Wirkort können die sonst bei systemischer Gabe induzierten Nebenwirkungen reduziert werden. Der für gentherapeutische Methoden prognostizierte Erfolg konnte im Jahr 2000 erstmals für monogene Erbkrankheiten klinisch bestätigt werden. ${ }^{26}$ Mittlerweile wird versucht, die Methode der Gentherapie auch bei anderen Erkrankungen einzusetzen. In Abb. 3.6 sind die zur Zeit laufenden klinischen Gentherapiestudien bezüglich der zu therapierenden Krankheiten dargestellt. Die meisten Studien erfolgen im Bereich der Krebsforschung (67\%). Einen geringeren Anteil stellen die monogenetischen (8.7\%), kardiovaskulären (8.7\%) und infektiösen Erkrankungen (6.6\%) dar. 


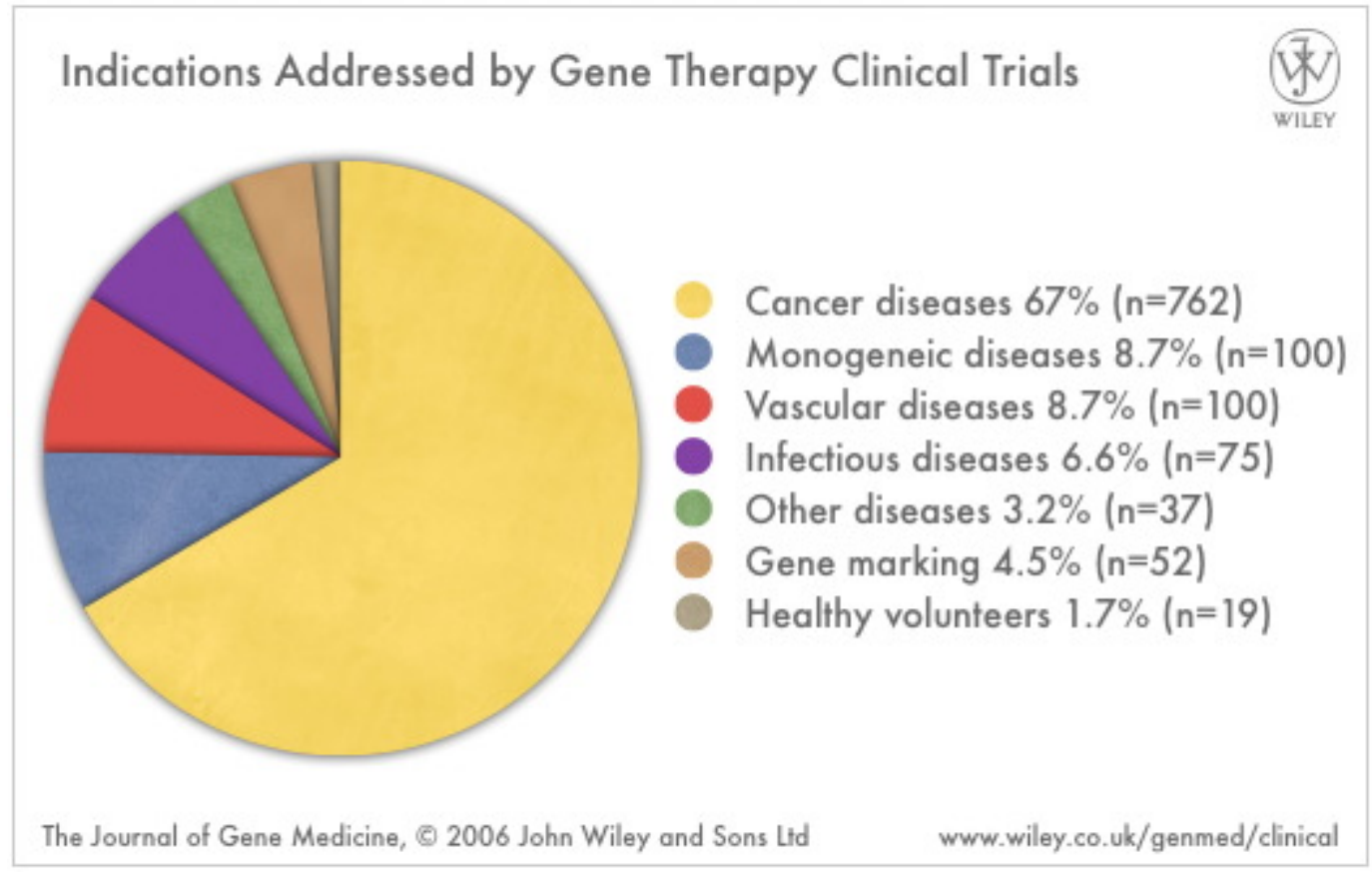

Abb. 3.6. Einsatzbereiche zur Zeit laufender klinisher Gentherapiestudien (Phase I-III).

Es steht außer Zweifel, dass die Gentherapie eine neue Therapieoption in der zukünftigen Medizin darstellen wird.

\subsection{Das Konzept der reversibel detoxifizierten Prodrugs für eine selektive Krebstherapie}

Die bis heute praktizierte Chemotherapie von malignen Tumoren ist mit zahlreichen Nebenwirkungen verbunden, da eine Differenzierung zu gesundem Gewebe allein über die gesteigerte Proliferationsrate von Krebszellen nicht ausreicht. Es wurden daher neue Konzepte entwickelt, die genotypische und phänotypische Eigenheiten von Tumorzellen ausnutzen, um eine gezielte Aktivierung von reversibel detoxifizierten Prodrugs direkt an ihrem Wirkort zu ermöglichen.

Pharmakophor

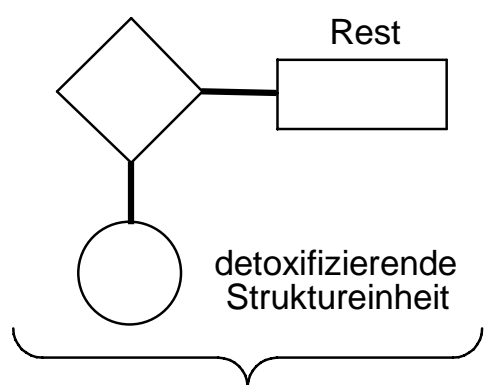

untoxisches Prodrug
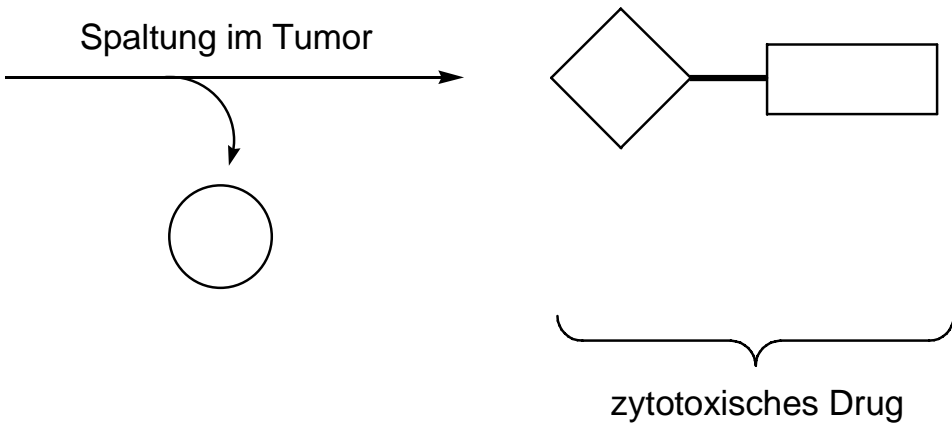

Abb. 3.7. Schematische Darstellung des Konzeptes der reversibel detoxifizierten Prodrugs. 
Ein aussagekräftiges Beispiel für eine selektive Therapie auf der Grundlage phänotypischer Eigenschaften von Krebszellen ist der Einsatz säurelabiler Prodrugs. Bereits 1930 beobachtete O. Warburg durch in vitro-Untersuchungen einen signifikant erniedrigten $\mathrm{pH}-\mathrm{Wert}$ in Tumorzellen. ${ }^{27}$ Ursache hierfür ist die auf eine gesteigerte anabolische und mitotische Aktivität der Krebszellen zurückzuführende erhöhte Lactatproduktion, wobei eine schlechte Versorgung mit Blutgefäßen und ein gestörtes $\mathrm{H}_{3} \mathrm{O}^{+}$-Transportsystem die Übersäuerung des Gewebes zusätzlich begünstigen. ${ }^{28}$ Da bei maligne entarteten Zellen eine über Rezeptoren kontrollierte, geregelte Aufnahme von Glucose außer Kraft gesetzt ist, wird die intrazelluläre Glucosekonzentration direkt durch die Serumkonzentration bestimmt. ${ }^{29}$ Dadurch ist es möglich, unter hyperglykämischen Bedingungen, also unter exogener Glucosezufuhr, eine für therapeutische Zwecke nutzbare Absenkung des pH-Wertes um etwa 1.8 Einheiten (von $\mathrm{pH} \cong 7.4$ auf 5.6) zu erreichen, die über einen Zeitraum von 24 Stunden konstant bleibt. ${ }^{30}$ Hierauf aufbauend entwickelte L. F. Tietze das Konzept der säurelabilen acetalischen Prodrugs, die erst im Tumorgewebe säurekatalysiert zum aktiven Toxin hydrolysiert werden und das gesunde Gewebe im Idealfall nicht schädigen. ${ }^{31}$
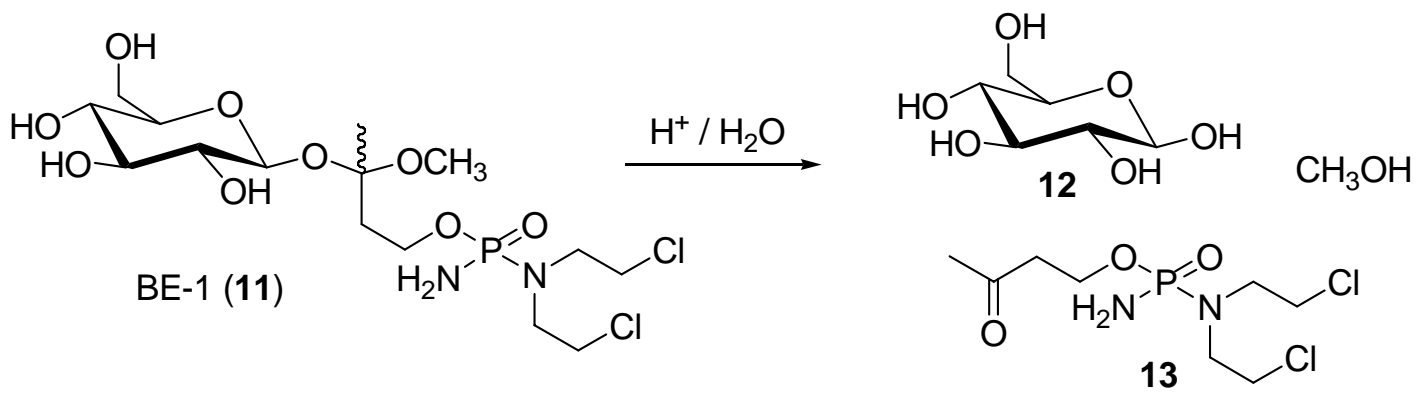

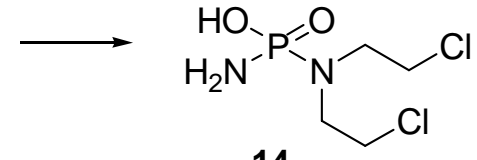

14

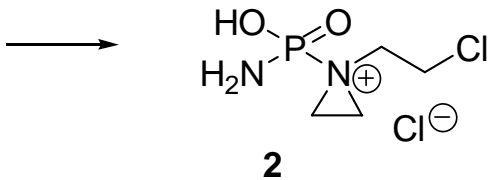

2

Abb. 3.8. Säurekatalysierte Aktivierung des acetalischen Prodrugs BE-1 (11).

Als mögliche Prodrugs wurden zunächst Acetalglycoside von Ketonen untersucht, wie zum Beispiel das Ketophosphamid BE-1 (11). ${ }^{32}$ Unter Säurekatalyse wird dieses nach Abspaltung von Glucose (12) und Methanol zu 13 hydrolysiert, einem instabilen Metaboliten des Chemotherapeutikums Cyclophosphamid (1) (siehe auch Kapitel 3.1). Durch weitere Metabolisierung über die Friedmannsäure (14) entsteht schließlich das Aziridiniumion 2 als 
eigentlich zytotoxische Verbindung (Abb. 3.8). Während BE-1 (11) an Mammakarzinomzellen der Marshall-Ratte (M1R) unter normalen physiologischen Bedingungen $(\mathrm{pH}=7.4)$ und einer Konzentration von $10 \mu \mathrm{g} / \mathrm{mL}$ praktisch untoxisch war, verringerte sich die Überlebensrate der Krebszellen bei $\mathrm{pH}=6.2 \mathrm{um}$ den Faktor $5 \times 10^{4}$. Trotz dieser beeindruckenden Ergebnisse ist es für eine klinische Anwendung jedoch nicht geeignet, da die Zytotoxizität insgesamt zu niedrig ist und daher hohe Dosen notwendig wären.

Ein weiterer vielversprechender Ansatz für eine selektive Krebstherapie unter Verwendung von Prodrugs ist das ADEPT-Konzept (siehe auch Kapitel 3.2). ${ }^{23}$ Hierbei wird eine Differenzierung durch monoklonale Antikörper erreicht, die selektiv an tumorassoziierte Antigene binden und kovalent mit Enzymen verknüpft sind. Im ersten Schritt der Therapie wird zunächst das Antikörper-Enzym-Konjugat verabreicht und die Krebszellen dadurch markiert. In einem zweiten, zeitlich verzögerten Schritt wird der Patient mit untoxischen Prodrugformen von zytotoxisch wirksamen Substanzen behandelt, die dann selektiv an den Tumorzellen enzymatisch in ihre aktive Form überführt werden. Diese greifen dann entsprechend ihrer Wirkmechanismen in den Stoffwechsel der Krebszelle ein und entfalten somit ihre zytostatische bzw. zytotoxische Wirkung lediglich im malignen Tumorgewebe, während das Enzym weiterhin aktiv bleibt und weitere Prodrugmoleküle spalten kann (Abb. 3.9). Auf diese Weise ist eine relativ niedrige Konzentration an Antikörper-Enzym-Konjugat ausreichend und außerdem ein Einsatz unterschiedlicher Zytostatika möglich, die lediglich nach demselben Mechanismus toxifizierbar sein müssen.

Hohe Substratspezifität und eine cofaktorunabhängige hohe katalytische Aktivität sind für die verwendeten Enzyme in solchen ADEPT-Systemen unbedingt notwendig. Sinnvoll ist ebenso der Verzicht auf körpereigene Enzymsysteme, da eine Spaltung der Prodrugs sonst auch außerhalb der Tumorzellen erfolgen würde. Geeignete Enzyme sind beispielsweise Peptidasen, ${ }^{33}$ alkalische Phosphatase, $\beta$-Glucuronidase, ${ }^{34}$ Nitroreduktasen oder auch $\beta$-Lactamase. ${ }^{35}$ Prodrugs mit $\beta$-Lactameinheit haben zudem den Vorteil, dass diese durch körpereigene Enzyme nicht gespalten werden und das Enzym eine hohe Spezifität besitzt. 


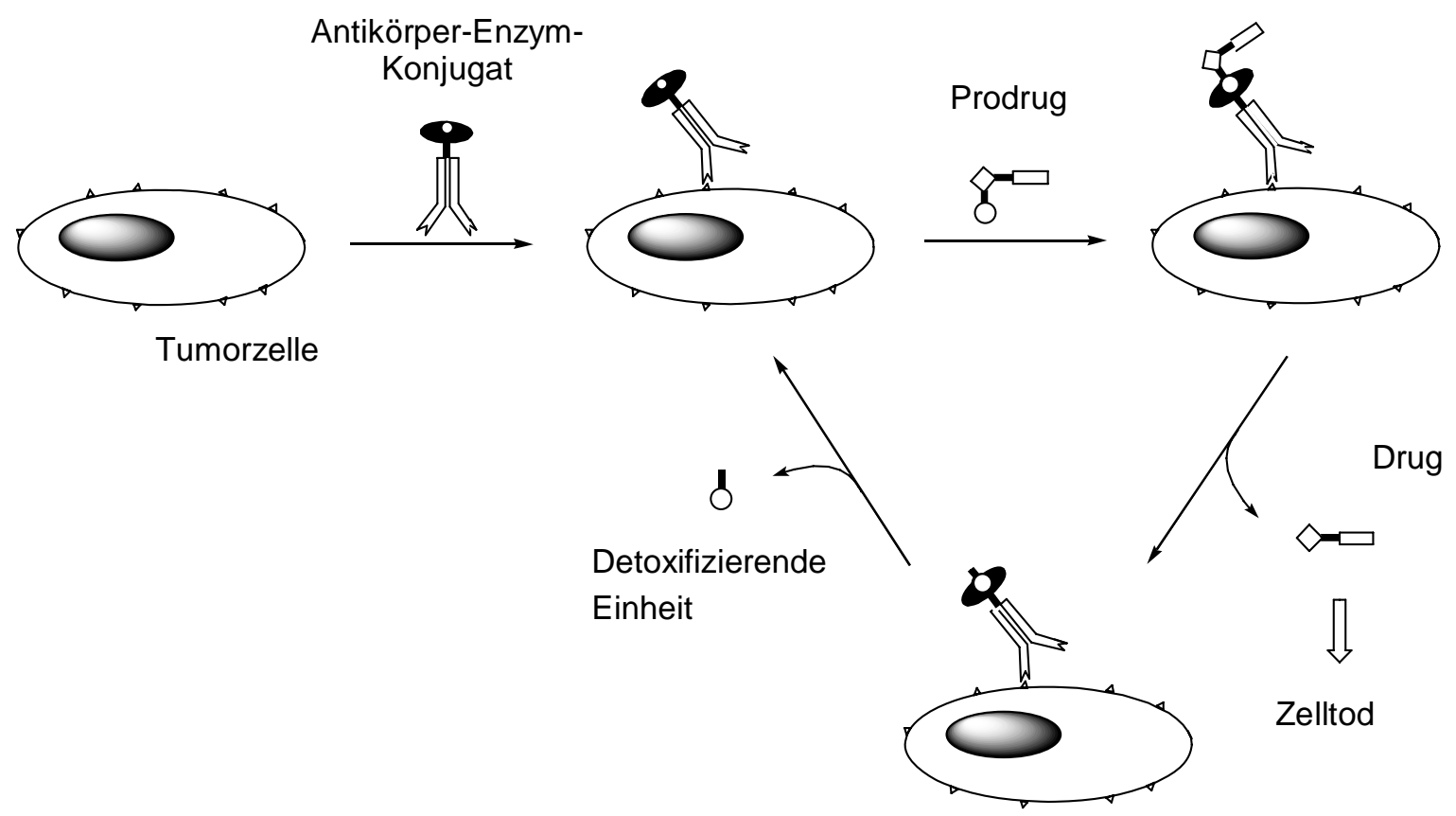

Abb. 3.9. Schematische Darstellung des ADEPT-Konzeptes.

Ideale Substrate für den Einsatz als Prodrugs müssen in freier Form eine möglichst hohe Zytotoxizität besitzen und auf einfache Weise in untoxische Derivate überführbar sein, die unter physiologischen Bedingungen stabil sind und erst an den Krebszellen enzymatisch aktiviert werden können. Eine unter diesen Gesichtspunkten gut geeignete Verbindungsklasse sind seco-Verbindungen von Analoga des Antibiotikums CC-1065(16), von denen insbesondere zahlreiche seco-CI- und seco-CBI-Derivate bereits erfolgreich auf ihre Eignung hin untersucht worden sind (siehe Kapitel 4). ${ }^{36,37,38}$

Die Gene Directed Enzyme Prodrug Therapy (GDEPT) ist ein dem ADEPT-System verwandter Ansatz. ${ }^{39}$ Im Gegensatz zu ADEPT werden dabei nicht die fertigen Enzyme verwendet, sondern ein für das entsprechende Protein codierendes Fremdgen. Dieses Gen wird in die DNA der Tumorzelle implementiert, um dort die Produktion des Enzyms einzuleiten. Das Enzym sollte dabei nicht in den gesunden Körperzellen vorkommen, um das applizierte Prodrug selektiv im Tumorgewebe zu aktivieren. Die Einschleusung des Gens erfolgt oftmals mit Hilfe eines Retrovirus. 


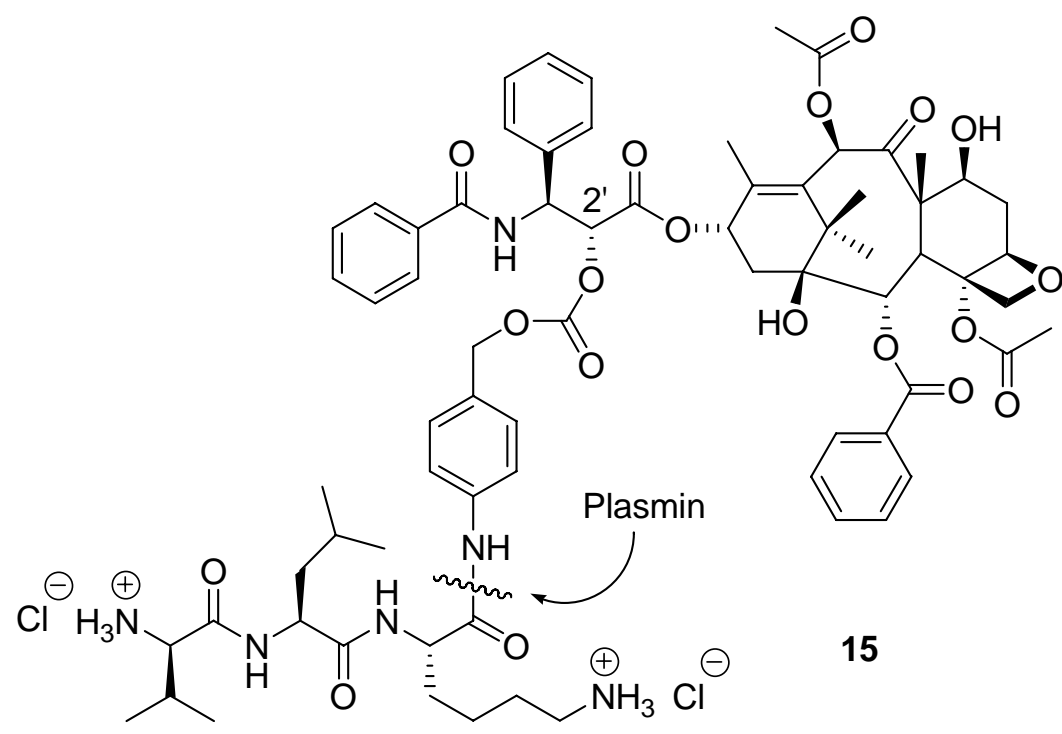

Abb. 3.10. Paclitaxel-Prodrug für die Monotherapie.

Eine weitere Möglichkeit der gezielten Behandlung von Tumoren stellt die Monotherapie dar. Diese basiert auf dem Vorliegen von assoziierten Enzymen im Tumorgewebe, die in der Lage sind, ein detoxifiziertes Prodrug unter Freisetzung des korrespondierenden Drugs zu spalten. Mögliche Enzyme sind zum Beispiel $\beta$-Glucuronidase, die in erhöhten Konzentrationen in nekrotischen Bereichen von Tumorgeweben nachgewiesen werden konnte, oder auch die Protease Plasmin. ${ }^{40}$ Plasmin spielt aufgrund der Beeinflussung der Wachstumsfaktoren und der Angiogenese sowohl beim Tumorwachstum als auch bei der Metastasierung eine wichtige Rolle. So wurden bereits auf Paclitaxel basierende Prodrugs wie 15 erfolgreich in in vitroUntersuchungen eingesetzt. Dabei erfolgt die Detoxifizierung durch die Einführung eines Carbonates an der 2'-Position. Nach der Abspaltung des Tripeptids durch Plasmin kommt es zu einer spontanen Eliminierung des Spacers, was zur Freisetzung des aktiven Drugs führt (Abb. 3.10). ${ }^{41}$ 


\section{CC-1065, Duocarmycine und Yatakemycin}

Das Antibiotikum (+)-CC-1065 (16) wurde 1978 von Mitarbeitern der Upjohn-Company erstmals aus Kulturen von Streptomyces zelensis isoliert. ${ }^{42}$ Bei den durchgeführten Screenings zeigte es sowohl in vitro als auch in vivo eine enorm hohe Zytotoxizität, eine breitgefächerte antibiotische Wirksamkeit und eine starke Antitumoraktivität. ${ }^{43}$ Die außergewöhnliche Struktur des (+)-CC-1065 setzt sich aus drei substituierten Pyrrolo[2,3-e]-indol-Einheiten zusammen, die jeweils über Amidbindungen miteinander verknüpft sind (Abb. 4.1). Die DNA-bindenden Segmente B und C bestehen aus identisch substituierten 1,2-Dihydro-3Hpyrrolo-[3,2-e]-indol-Systemen, die mit PDE-I und PDE-II bezeichnet werden. Das pharmakophore Segment A, auch als CPI (Cyclopropapyrroloindol) bezeichnet, weist eine Spirocyclopropyl-cyclohexadienon-Struktur auf. Aus anderen Streptomycetenstämmen konnten strukturverwandte Verbindungen wie die Duocarmycine ${ }^{44}$ (z.B. Duocarmycin SA (17)) sowie das Yatakemycin ${ }^{45}$ (18), welches mit einem ED $_{50}$-Wert (Toxinkonzentration, bei der das Zellwachstum um $50 \%$ unterbunden wird) von nur $3 \mathrm{pM}$ derzeit das potenteste Zytostatikum darstellt, isoliert werden. Innerhalb der Zytostatika werden die genannten Verbindungen in die Klasse der Alkylantien (s. Kap. 3.1) eingeordnet.

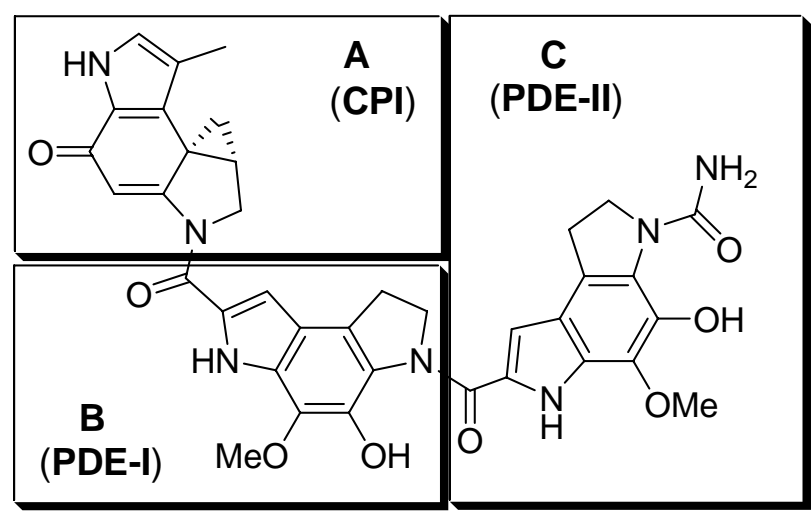

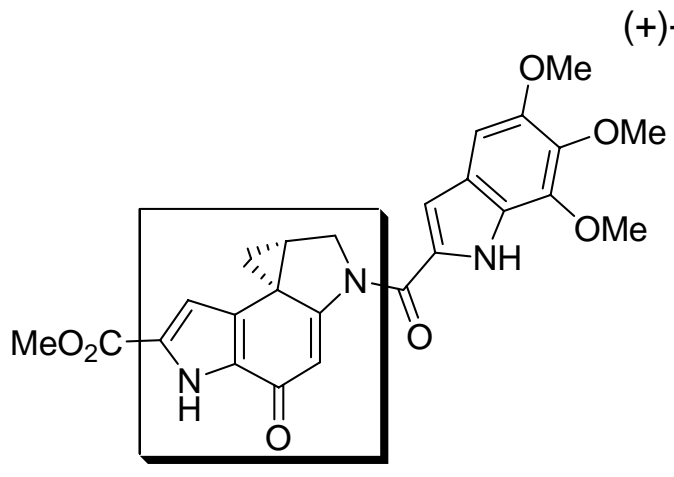

(+)-Duocarmycin SA (17)

$+)-C C-1065(16)$

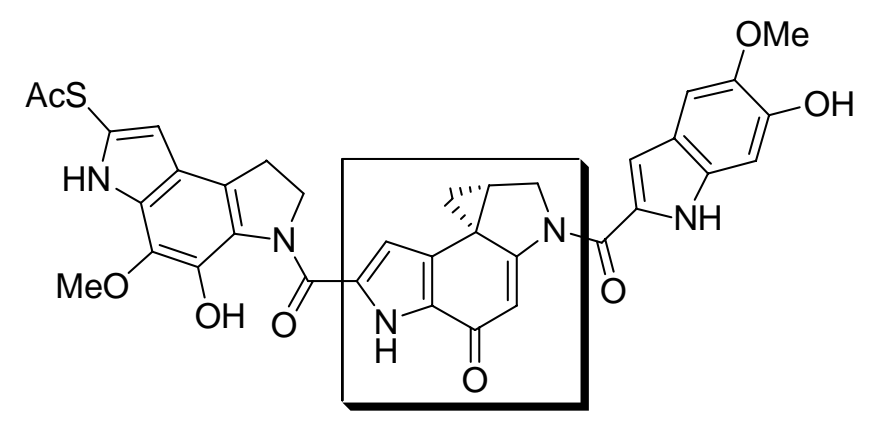

(+)-Yatakemycin (18)

Abb. 4.1. Die Alkylantien (+)-CC-1065 (16), (+)-Duocarmycin SA (17) und (+)-Yatakemycin (18). 
Die zytotoxische Wirkung des CC-1065 (16) und analoger Verbindungen beruht wahrscheinlich auf einer sequenzspezifischen DNA-Alkylierung durch eine Addition des Adenin- $N-3$ an das am niedrigsten substituierte Kohlenstoffatom der Cyclopropaneinheit (Abb. 4.2). Zusätzlich behindern die Wirkstoffe durch ihre bevorzugte Wechselwirkung mit AT-reichen DNARegionen die Bindung TATA-Box-bindender Proteine an die DNA und damit die Gentranskription. $^{46}$

Im Verlauf der Untersuchungen des CC-1065 und der Duocarmycine sind mehrere Hypothesen über den Ursprung der beobachteten Alkylierungsselektivität aufgestellt worden. Das von L. H. Hurley vertretene Alkylierungsmodell postuliert eine Protonierung der Carbonylfunktion an C-4 durch eine günstig angeordnete Phosphatgruppe im flexiblen DNA-Rückgrat, wodurch sich die Konformation der DNA ändert und das nucleophile $N$-3-Atom in einen günstigen Abstand zum elektrophilen Zentrum des Wirkstoffes gelangt. ${ }^{47}$ Gegen dieses Alkylierungsmodell spricht jedoch die Tatsache, dass auch Strukturanaloga, die an C-4 keine Carbonylgruppe tragen, dieselben alkylierenden Eigenschaften und Selektivitäten besitzen.
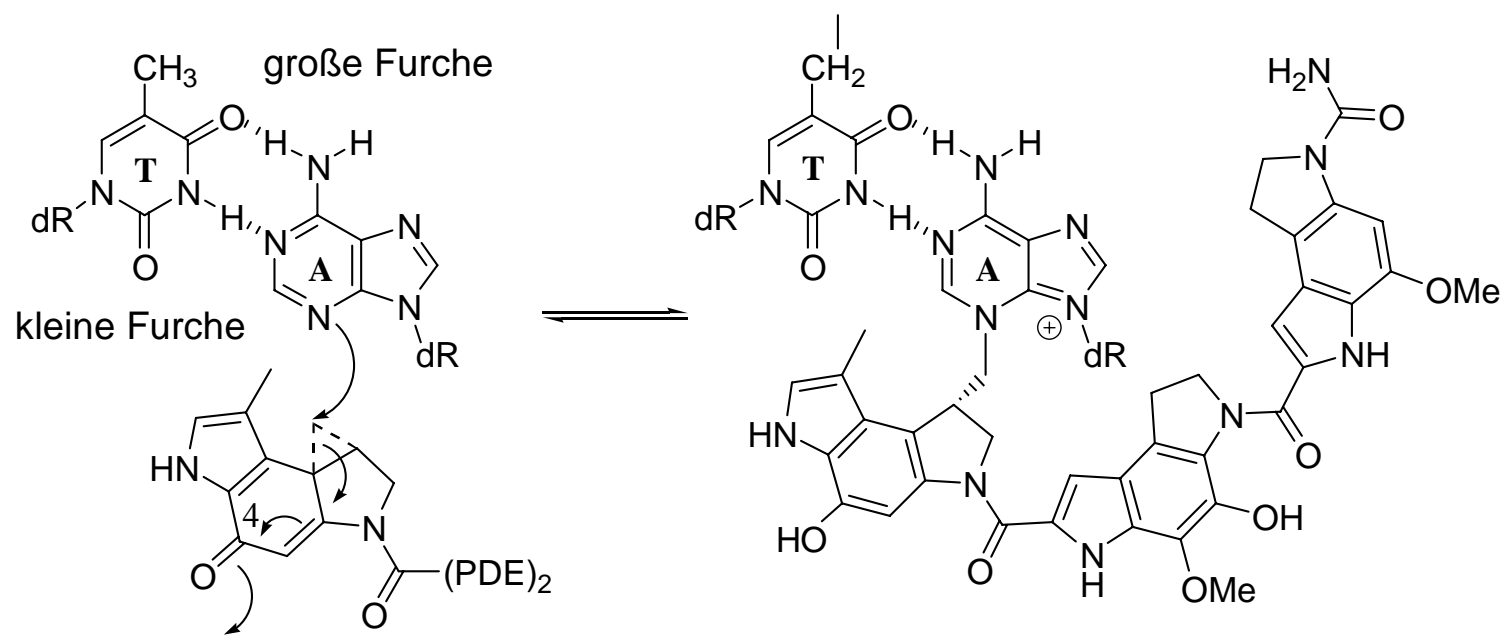

Abb. 4.2. Mechanismus der DNA-Alkylierung durch CC-1065 (16).

D. L. Boger hingegen vertritt das Modell der konformativen Aktivierung, bei dem eine DNAbindende Untereinheit, die in starrer Weise über eine Amidbindung an das Pharmakophor angeknüpft ist, tief in die kleine Furche der DNA eindringt und dort über WasserstoffbrückenBindungen an AT-reiche Sequenzen bindet. ${ }^{48}$ Diese formerkennende nichtkovalente Bindung und Fixierung der Seitenkette führt zu einer Verdrillung der Amidbindung, wodurch die vinyloge Amidstabilisierung des Enons aufgehoben und die Reaktivität bezüglich eines nucleophilen Angriffs erhöht wird.

$(+)$-Duocarmycin SA (17) und (+)-Yatakemycin (18) wurden verwendet, um freie DNA sowie mit Nukleosom Kern Partikel (NCP) gebundene DNA zu alkylieren. Die beide Verbindungen 
zeigten ähnliche Aktivitäten an NCP gebundener DNA verglichen mit freier DNA bezüglich Effizienz der Alkylierung sowie Sequenz Selektivität, trotz der sterischen und konformativen Störungen, die durch die NCP Packung verursacht werden. Die Ergebnisse illustrierten dass die in vitro Studie von diese Klasse von Antikrebs Verbindungen mit Protein-freier DNA wertvolle Einblicke für ihre in vivo Eigenschaft liefern könnte. ${ }^{49}$

\subsection{Analoga von CC-1065 und Struktur-Wirkungsbeziehungen}

Trotz einer enorm hohen Zytotoxizität $\left(\mathrm{ED}_{50}=20 \mathrm{pM}\right)$ ist CC-1065 (16) wegen einer im Tierversuch an Mäusen beobachteten verzögerten letalen Hepatotoxizität nicht für eine klinische Anwendung geeignet. ${ }^{50}$ Die Untersuchungen verschiedener Analoga des CC-1065 ergaben eine ähnlich hohe Zytotoxizität, jedoch keine Hepatotoxizität. Diese scheint daher ein Charakteristikum der Originalstruktur und nicht des Wirkmechanismus zu sein. ${ }^{51}$ Ziel vieler Synthesen war das CI-Grundgerüst, das eine ungefähr 100fach geringere Toxizität verglichen mit dem natürlichen CPI aufweist. In allen natürlich vorkommenden (CPI, DA, DSA) und synthetisierten (CBI, CBQ, CpyI, MCBI, MCCPI) pharmakophoren Gruppen findet sich somit die Spirocyclopropyl-cyclohexadienon-Struktur des CI wieder (Abb. 4.3).

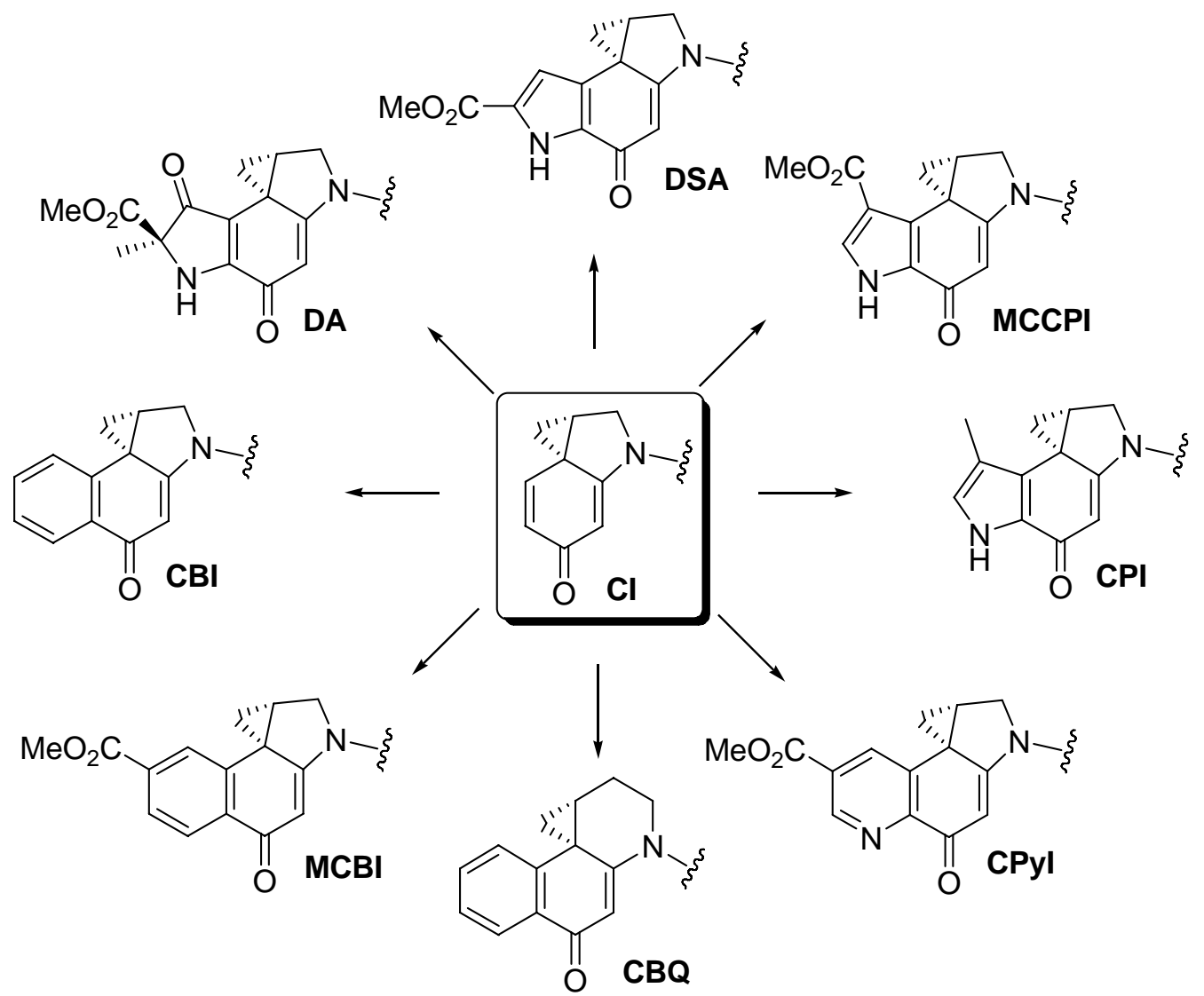

Abb. 4.3. Analoga des CC-1065 mit der pharmakophoren CI-Einheit. 
Neben der Variation der phamakophoren Gruppe wurde auch die DNA-bindende Substruktur des CC-1065 und verwandter Verbindungen systematisch untersucht, indem verschiedene Analoga synthetisiert und biologisch getestet wurden. ${ }^{52}$ Tabelle 4.1 zeigt einige ausgewählte Beispiele dieser Studien mit den pharmakophoren Gruppen DSA, CPI und CBI (Abb. 4.3) und verschiedenen DNA-bindenden Einheiten.

\section{DNA-bindende Einheit}

$\mathrm{ED}_{50}(\mathrm{L1210})[\mathrm{pM}]$

DSA CPI CBI

2

MMI<smiles>COc1ccc2[nH]c(C(C)(C)C)cc2c1</smiles>

3<smiles>CC(C)C(=O)c1cc2ccccc2[nH]1</smiles>

4

5

(Ind) 2<smiles>CC(C)C(=O)c1cc2cc(NC(=O)c3cc4ccccc4[nH]3)ccc2[nH]1</smiles>

6<smiles>[3H]C(=O)OC(C)(C)C</smiles>

65 200 5000 20$$
3
$$
20-40 5-10 $6 \cdot 10^{3}$ $3.3 \cdot 10^{5}$ $8 \cdot 10^{4}$

Tabelle 4.1. Einfluss der DNA-bindenden Struktureinheit auf die Antitumoraktivität von DSA-, CPI- und CBI-Analoga.

Anhand dieser Strukturvariationen und der daraus resultierenden in vitro-Zytotoxizitäten konnten einige charakteristische Struktur-Wirkungsbeziehungen gefunden werden. Während 
die C-6- und C-7-Methoxysubstituenten des TMI z. B. nur geringfügig zur biologischen Aktivität beitragen, ist die C-5-Methoxygruppe essentiell für eine hohe Wirksamkeit (Tabelle 4.1. Einträge 1-3). Die Bisindol-Derivate (Eintrag 5) zeigen eine um den Faktor drei bis sechs höhere Zytotoxizität als die TMI-Derivate und Analoga ohne DNA-bindende Struktureinheit sind etwa 1000 bis 10000 mal weniger wirksam als der Naturstoff (Eintrag 6). Des Weiteren wurde herausgefunden, dass der Pyrrolring im CPI durch einen Benzolring ausgetauscht werden kann (CBI-Analoga), wobei durch Herabsetzung der Ringspannung eine höhere Stabilität und vielfach gesteigerte Toxizität erreicht wird (Eintrag 5). ${ }^{53}$

Insgesamt ergab sich, dass Verbindungen mit der größten chemischen Stabilität die stärkste zytotoxische Aktivität aufwiesen, was möglicherweise auf eine effizientere Hinführung des Wirkstoffes an seinen Wirkort zurüchzuführen ist. Das Vorhandensein einer DNA-bindenden Einheit ist zudem notwendig für die Zytotoxizität der Substanzen.

\section{2 seco-Verbindungen und Prodrugs der CC-1065-Analoga}

Die entsprechenden seco-Verbindungen der oben beschriebenen CC-1065- und DuocarmycinAnaloga zeigen im Allgemeinen ähnliche Toxizitäten und Selektivitäten wie die Spirocyclopropylverbindungen. ${ }^{54}$ Es wird daher angenommen, dass aus den seco-Verbindungen der Cyclopropanring in situ über eine Winstein-Aryl-3'-Spirocyclisierung gebildet wird und erst dann eine Alkylierung der DNA stattfindet (Abb. 4.4). ${ }^{55}$

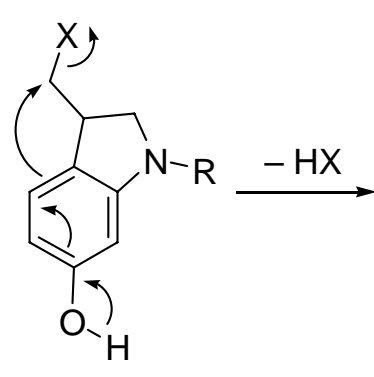

19

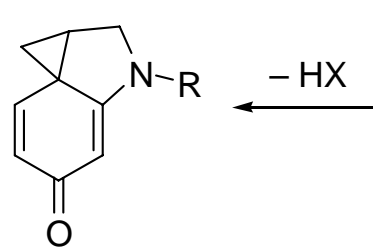

20

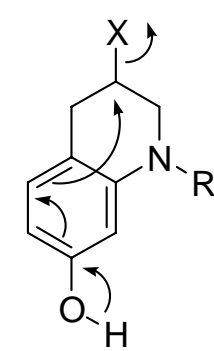

21

Abb. 4.4. Winstein-Aryl-3'-Spirocyclisierung der beiden möglichen seco-CI-Derivate.

Die Blockierung der phenolischen Hydroxyfunktion, die für den gezeigten Spirocyclisierungsmechanismus von essentieller Bedeutung ist, sollte demzufolge untoxische Vorstufen liefern. ${ }^{56}$ In den letzten Jahren gelang im Arbeitskreis Tietze die Synthese von Grundkörpern verschiedener Analoga des CC-1065, deren biologische Wirksamkeit getestet wurde. ${ }^{57,58}$ Hierbei konnten mit den reversibel durch Glykosidierung detoxifizierten anti-Methyl-secoCBI-DMAI-Verbindungen (Abb. 4.5) hervorragende Ergebnisse erzielt werden. ${ }^{59}$ Die Zyto- 
toxizität des enantiomerenreinen Drugs (+)-22 ist mit einem $\mathrm{ED}_{50}$-Wert von $0.75 \mathrm{nM}$ sehr hoch. Von besonderer Bedeutung für eine selektive Krebstherapie ist der außerordentlich hohe Unterschied der Toxizitäten des Prodrugs (+)-24 und des entsprechenden Drugs (+)-22 mit einem $\mathrm{Q} E \mathrm{ED}_{50}$-Wert von $4800\left(\mathrm{Q} \mathrm{ED}_{50}=\mathrm{ED}_{50}\right.$ des Prodrugs $/ \mathrm{ED}_{50}$ des Prodrugs in Anwesenheit des Enzyms).

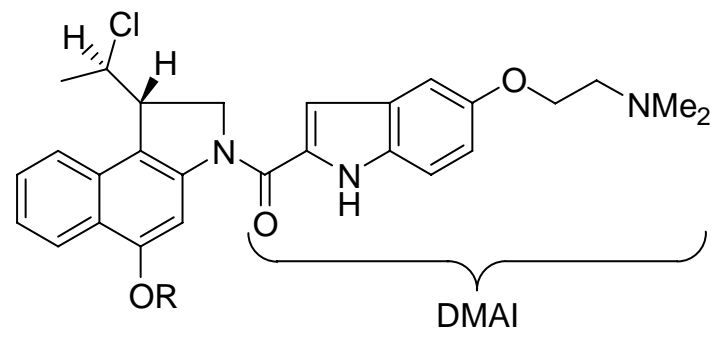

$(+)-22: \mathrm{R}=\mathrm{H}$

$(+)-23: \mathrm{R}=\mathrm{Bn}$

$(+)-24: \mathrm{R}=\beta$-D-Gal

Abb. 4.5. Anti-Methyl-seco-CBI-DMAI-Verbindungen.

Nach ausführlichen Studien zu Struktur-Wirkungsbeziehungen, wurden Adozelesin, Carzelesin (25), Bizelesin (26) und KW2189 auch klinisch getestet. ${ }^{60}$ Aufgrund schwerer Myelotoxizitäten fielen drei Verbindungen aus der Studie und Bizelesin ist bis heute die einzige Verbindung, die im klinischen Test verblieben ist.<smiles>CCNc1ccc2cc(C(=O)Nc3ccc4[nH]c(C(=O)N5C[C@@H](CCl)c6c5cc5oc(=O)[nH]c6=c-c=c-c=c-c6c(C)c[nH]c6-5)cc4c3)oc2c1</smiles>

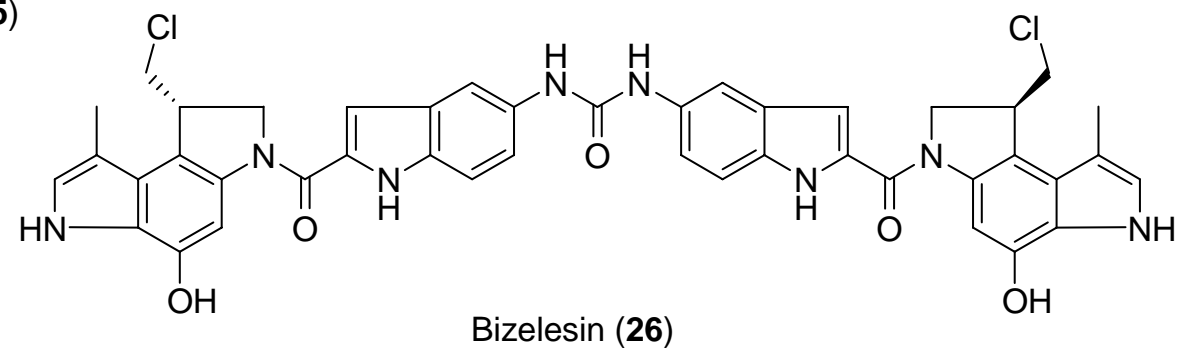

Abb.4.6 Beispiele für seco-Verbindungen in der klinischen Erprobung. 


\section{CCK-B/Gastrinrezeptor-vermittelte Krebstherapie}

Die ADEP-Therapie hat, trotz der schon erzielten Erfolge, einige Nachteile. Zum einen müssen vor einer möglichen Anwendung eines einzelnen Medikamentes drei verschiedene Substanzen getestet werden: Drug, Prodrug und Antikörper-Enzym-Konjugat. Daneben muss der Zytotoxizitätsunterschied $\mathrm{Q}^{\mathrm{E}} \mathrm{D}_{50}\left(=\mathrm{ED}_{50 \text { Prodrug }} / \mathrm{ED}_{50 \mathrm{Drug}}\right)$ zwischen Drug und Prodrug hinreichend groß sein, um eine ausreichende Differenzierung zwischen gesundem Gewebe und Tumorgewebe zu erreichen. Schließlich haben die benötigten monoklonalen Antikörper neben einer möglichen unerwünschten Immunantwort - oft eine schlechte Bioverfügbarkeit und Pharmakokinetik. Eine mögliche Alternative ist die Monotherapie, bei der tumorassoziierte Enzyme das applizierte Prodrug aktivieren (siehe Kapitel 3.2). Auch der Einsatz von niedermolekularen Liganden anstelle der monoklonalen Antikörper für ein selektives Tumor-Targeting stellt eine vielversprechende Form der Monotherapie dar. Der Vorteil solcher niedermolekularen Liganden ist ihre schnellere Clearance bei bleibender, hochspezifischer Rezeptoraffinität. ${ }^{61}$ Attraktive Zielstrukturen für solche Liganden sind zum Beispiel Peptide, da bei einigen Krebsformen bestimmte Peptid-Rezeptoren auf der Oberfläche der Krebszellen überexprimiert werden. Zu solchen schon im Einsatz befindlichen Peptiden gehören Somatostatin, Substanz P, Gastrin, Bombesin, Neurotensin und das vasoaktive intestinale Peptid (VIP). ${ }^{62}$ Entwickelt wurden außerdem Konjugate aus Zytostatika und niedermolekularen Liganden, wie zum Beispiel das Camptothecin-Bombesin-Konjugat 27 (Abb. 5.1). ${ }^{63}$

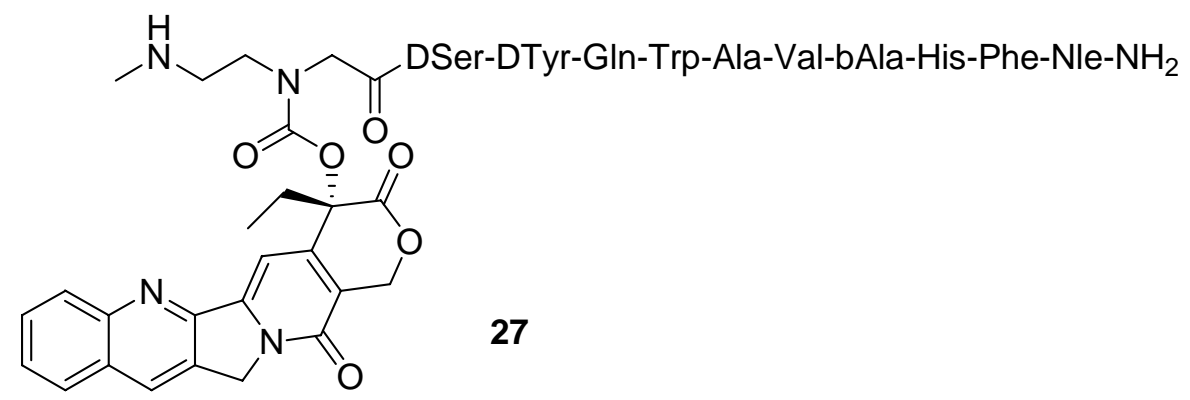

Abb. 5.1 Camptothecin-Konjugat mit tumordirigierendem Bombesin-Analogon.

\subsection{CCK-B/Gastrin}

Cholecystokinin (CCK) und Gastrin sind Regulatorpeptide, die der gleichen Familie angehören. Sie spielen eine wichtige Rolle als Hormone des Gastrointestinaltrakts und als 
Neurotransmitter im Gehirn. ${ }^{64}$ Beide Peptide besitzen an ihrem $C$-Terminus eine identische Primärstruktur aus fünf Aminosäuren (Gly-Trp-Met-Asp-Phe- $\mathbf{N H}_{2}$ ), wobei das TetrapeptidAmid das für die biologische Wirkung essentielle Strukturelement repräsentiert. ${ }^{65}$ Ihre Funktion wird durch zwei unterschiedliche G-Protein-gekoppelte Rezeptoren gesteuert. Der CCK-A-Rezeptor besitzt eine niedrige, der CCK-B-Rezeptor ein hohe Affinität für Gastrin. ${ }^{66}$

Durch Autoradiographie-Studien wurde gezeigt, dass die CCK-B-Rezeptoren - neben ihrem natürlichen Vorkommen im Magen, Blut, Nieren, Gallenblase und Gehirn - auf bestimmten Arten von Tumorzellen in großer Zahl exprimiert werden und auch als Wachstumshormone für diese Zellen fungieren. So konnten sie in einer umfangreichen Studie zum Beispiel in Schilddrüsenkarzinomen (92\%), Lungentumoren (kleinzellig, $57 \%$ ), Astrocytomen (65\%) und stromalen Eierstocktumoren (100\%) in hoher Dichte nachgewiesen werden. ${ }^{66}$ Über diese Rezeptoren könnte ein selektiver Zugang für zytotoxische Verbindungen $\mathrm{zu}$ solchen Krebszellen ermöglicht werden. ${ }^{67}$

Dabei würde die partielle Zerstörung von Zellen der Magenschleimhaut in Kauf genommen, da sich diese regenerieren können. Bei Tests mit menschlichem Serum stellte sich heraus, dass der größte Teil der untersuchten Gastrinderivate nicht an Serumproteine gebunden ist, sondern ungebunden vorliegt. Dies ist eine wichtige Voraussetzung für eine schnelle "Hintergrund-Clearance". ${ }^{68}$ Auch das Vorhandensein von CCK-B-Rezeptoren im Gehirn stellt kein Problem dar, da das hydrophile Peptid nicht die Blut-Hirn-Schranke durchbricht.

Mit Hilfe eines fluoreszenzmarkierten Heptagastrins konnte gezeigt werden, dass die Gastrin/CCK-B-Rezeptoren die Peptide über Endozytose in die Zelle schleusen. Danach kehren sie wieder zur Zelloberfläche zurück, um neue Peptide zu binden. Die Zeit für einen solchen Zyklus beträgt etwa eine Stunde. ${ }^{67}$

Die Gastrin/CCK-B-Rezeptoren werden seit einiger Zeit auf ihr diagnostisches und therapeutisches Potential hin untersucht. Dabei kamen z.B. radiomarkierte Verbindungen wie das ${ }^{111}$ In-DTPA-Minigastrin (28) zum Einsatz (Abb. 5.2). Die stark anionische Pentaglutamat-Sequenz scheint dabei für eine hohe Affinität und Rezeptorselektivität wichtig zu sein. Gleichzeitig verringert sie die renale Akkumulation des Derivates, denn dieses wird hauptsächlich über die Nieren (und zu einem kleineren Teil biliär) ausgeschieden. ${ }^{68}$ 


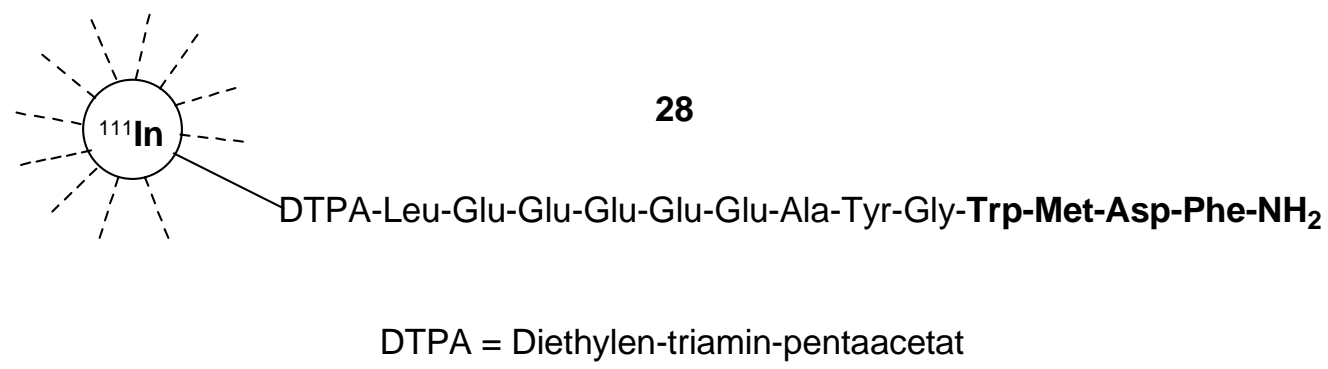

Abb. 5.2. Derivat aus Radiometall, Chelatbildner DTPA und Minigastrin.

Es wurden aber auch Konjugate aus Zytostatika und Gastrinderivaten entwickelt, wie zum Beispiel ein Hybrid aus einem Triazenderivat und Pentagastrin (Abb. 5.3). In den durchgeführten Zelltests wurden zwar gute Selektivitäten, aber eine nur geringe Zytotoxizität festgestellt. ${ }^{69}$

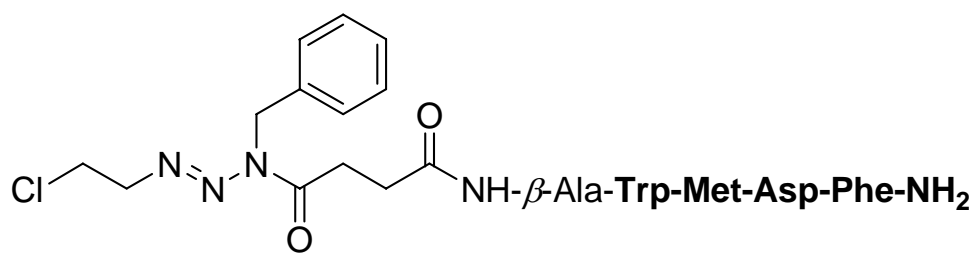

29

Abb. 5.3. Derivat aus einem Dialkyltriazen als Alkylans und Pentagastrin.

Im Arbeitskreis von L. F. Tietze wurden CCBI-TMI-Pentagastrin-Konjugate erfolgreich von O. Panknin synthetisiert. ${ }^{70}$ In in vitro Zytotoxizitätsuntersuchung zeigten Verbindung 30 sowie 31 keine Selektivität zwischen CCKb-Rezeptor positive und negative Zell-Linien.<smiles>COc1cc2cc(C(=O)N3CC(CCl)c4c3cc(O)c3cc(C(=O)NN)ccc43)[nH]c2c(OC)c1OC</smiles>

30

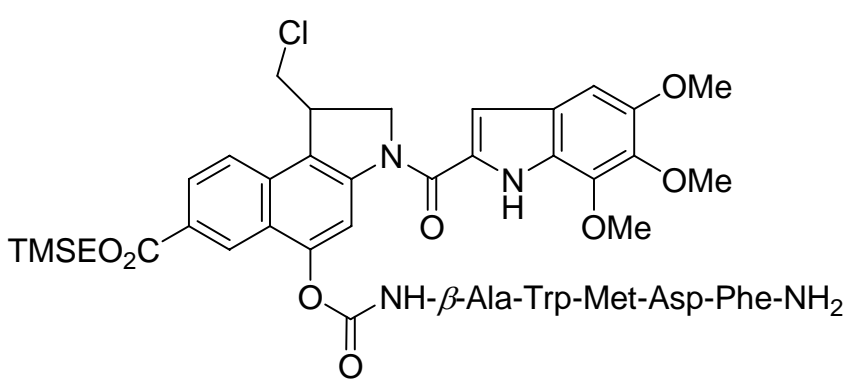

31

Abb. 5.4. CCBI-TMI-Pentagastrin-Konjugate synthetisiert bei O. Panknin. 


\section{$6 \quad$ Zielsetzung und Planung der Arbeit}

Im Arbeitskreis von L. F. Tietze wurden in den letzten Jahren erfolgreich neuartige CC-1065Analoga für eine selektive Krebstherapie im Rahmen des ADEPT-Konzeptes entwickelt. ${ }^{58}$ Insbesondere mit den von $F$. Major synthetisierten anti-Methyl-seco-CBI-DMAIVerbindungen konnten hervorragende Ergebnisse erzielt werden (Abb. 4.5) ${ }^{59}$ Es sollten daher auf der Grundlage dieser Untersuchungen neuartige Zytostatika entwickelt werden, die im Rahmen einer Monotherapie durch Verknüpfung mit einem Tetragastrin als „Targeting Component“" eine selektive Krebsbehandlung ermöglichen. Folgende Aufgaben waren zu erfüllen.

- Synthese von DNA Bindern (32) mit verschiedenen Resten $\mathrm{R}^{1}$, die eine Verknüpfung mit Tetragastrin ermöglicht (Abb. 6.1). Hierzu sollten Struktur-Wirkungsbeziehungen abgeleitet werden.<smiles>[R]CCOc1ccc2[nH]c(C(=O)O)cc2c1</smiles>

32

$$
\begin{aligned}
\mathrm{R}^{1}= & \mathrm{N}\left(\mathrm{CH}_{3}\right)\left(\mathrm{CH}_{2}\right)_{\mathrm{n}} \mathrm{CO}_{2} \mathrm{H}, \\
& \mathrm{NH}\left(\mathrm{CH}_{2}\right)_{\mathrm{n}} \mathrm{CO}_{2} \mathrm{H}, \\
& \mathrm{N}\left(\mathrm{CH}_{3}\right)\left(\mathrm{CH}_{2}\right)_{n} \mathrm{NH}_{2}, \\
& \mathrm{~N}\left(\mathrm{CH}_{3}\right)\left(\mathrm{CH}_{2}\right)_{n} \mathrm{CN}, \\
& \mathrm{OH}, \mathrm{OAc}, \mathrm{Cl}, \text { Alken, } \mathrm{N}_{3}, \\
& \mathrm{n}=1-3
\end{aligned}
$$

Abb. 6.1. Übersicht des zu bearbeitenden DNA-Binder.

\begin{tabular}{ll}
\hline $\mathbf{R}^{\mathbf{1}}$ & Begründungen für die Wahl der Seitenkette \\
\hline $\mathrm{N}\left(\mathrm{CH}_{3}\right)\left(\mathrm{CH}_{2}\right)_{\mathrm{n}} \mathrm{CO}_{2} \mathrm{H}$, & $\begin{array}{l}\text { gut Wasserlöslichkeit, über Amidbindung an Gastrin } \\
\text { kuppelbar }\end{array}$ \\
& $\begin{array}{l}\text { gut Wasserlöslichkeit, über einen Dicarboxyl-Binder } \\
\text { an Gastrin kuppelbar, mit einer Carboxyl-Gruppe } \\
\text { von Fluoreszenzreagenz kuppelbar }\end{array}$ \\
$\mathrm{NH}\left(\mathrm{CH}_{2}\right)_{\mathrm{n}} \mathrm{NH}_{2}$ & $\begin{array}{l}\text { gut Wasserlöslichkeit } \\
\mathrm{NH}\left(\mathrm{CH}_{2}\right)_{n} \mathrm{CN}\end{array}$ \\
$\mathrm{OH}$ & über Carbamatbindung an Gastrin kuppelbar \\
$\mathrm{Cl}$, Alken, $\mathrm{N}_{3}$ & $\begin{array}{l}\text { hohe chemische Reaktivität, Ausgangsubstanz für } \\
\text { die Einführung anderer chemischer Gruppen }\end{array}$ \\
\hline
\end{tabular}

Tabelle 6.1. Begründungen für die Wahl der Seitenkette. 
- Kupplung der anti-Methyl-seco-CBI mit verschiedenen indolartigen DNA-Bindern<smiles>[R1]CCOc1ccc2[nH]c(C(=O)N3C[C@@H]([C@H](C)Cl)c4c3cc([R2])c3ccccc43)cc2c1</smiles>

33

$$
\begin{aligned}
& \mathrm{R}^{1}= \mathrm{N}\left(\mathrm{CH}_{3}\right)\left(\mathrm{CH}_{2}\right)_{\mathrm{n}} \mathrm{CO}_{2} \mathrm{H}, \\
& \mathrm{NH}\left(\mathrm{CH}_{2}\right)_{\mathrm{n}} \mathrm{CO}_{2} \mathrm{H}, \\
& \mathrm{N}\left(\mathrm{CH}_{3}\right)\left(\mathrm{CH}_{2}\right)_{\mathrm{n}} \mathrm{NH}_{2}, \\
& \mathrm{~N}\left(\mathrm{CH}_{3}\right)\left(\mathrm{CH}_{2}\right)_{\mathrm{n}} \mathrm{CN}, \\
& \mathrm{OH}, \mathrm{OAc}, \mathrm{Cl}, \text { Alken, } \mathrm{N}_{3}, \\
& \mathrm{n}=1-3 \\
& \mathrm{R}^{2}= \mathrm{H}, \mathrm{Bn}
\end{aligned}
$$

Abb. 6.2. Allgemeine Struktur des anti-Methyl-seco-CBI mit unterschiedlichen DNA-Bindern.

- Synthese der anti-Methyl-seco-CBI-DNA-Binder-Peptid-Derivate

Ziel war es, die neuen anti-Methyl-seco-CBI-DNA-Binder-Derivate über ihre Carboxylfunktion mit dem $N$-Terminus der Gastrinderivate zu verknüpfen.

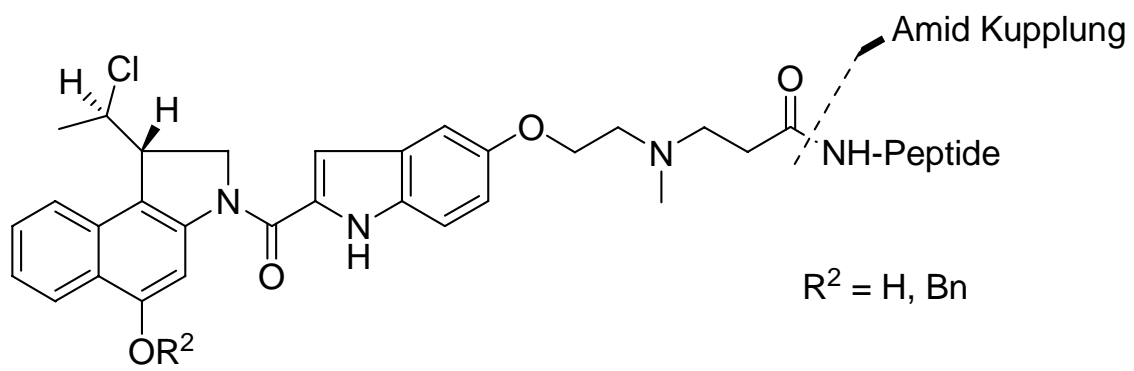

34

Abb. 6.3. Allgemeine Struktur der anti-Methyl-seco-CBI-DNA-Binder-Peptid-Derivate.

- Synthese des bekannten Tetragastrin

Die Etablierung einer geeigneten Schutzgruppe in der Asparaginsäureseitenkette stand dabei im Vordergrund der Untersuchungen.

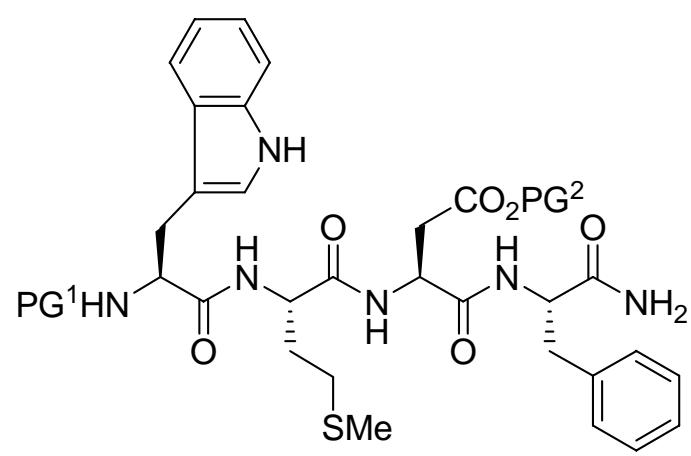

35

Abb. 6.4. Allgemeine Struktur des geschützten Tetragastrins.

- Synthese eines Carbamat-geschützten anti-Methyl-seco-CBI-DMAI-Prodrug 
<smiles>CC(Cl)[C@H]1CN(C(=O)c2cc3cc(OCCN(C)C)ccc3[nH]2)c2cc(OC(=O)N[AlH2])c3ccccc3c21</smiles>

Abb. 6.5. Allgemeine Struktur der anti-Methyl-seco-CBI-DMAI-Carbamate-Derivate. 


\section{Synthese der indolhaltigen DNA-Binder}

\subsection{Retrosynthetische Analyse}

Durch retrosynthetische Analyse lässt sich $\mathbf{3 7}$ konvergent in $\mathbf{3 8}$ und Acrylsäureethylester (39) zerlegen. Über eine Michael-Addition sollten sich diese beide Bausteine miteinander verknüpfen lassen. Die Einführung der Methylamingruppe könnte durch Aminierung mit $\mathrm{Cl}$ oder I als Abgangsgruppe erfolgen. Das Indolsystem sollte dabei über die Japp-KlingemannVariante der Fischer-Indol-Synthese ${ }^{71}$ aufgebaut werden.

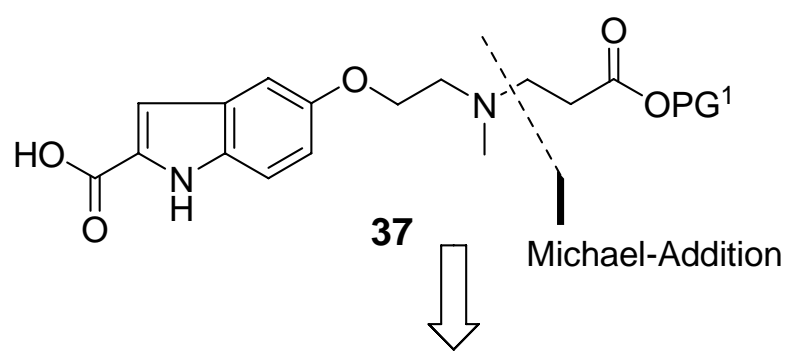<smiles>CNCCOc1ccc2[nH]c(C(=O)O)cc2c1</smiles><smiles>C=CC(=O)OCC</smiles>

39<smiles>O=C(O)c1cc2cc(OCCCl)ccc2[nH]1</smiles>

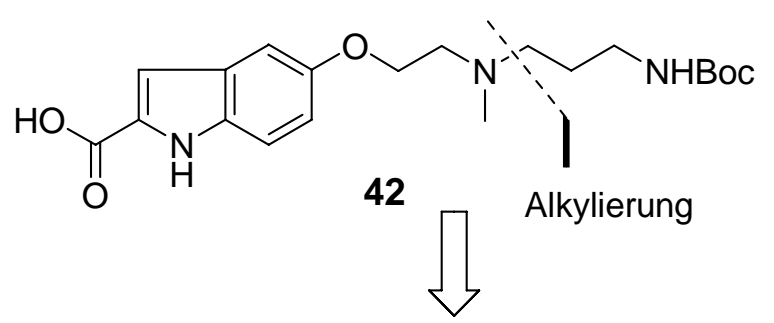<smiles>CNCCOc1ccc2[nH]c(C(=O)O)cc2c1</smiles><smiles>CC(C)(C)OCCNCCCBr</smiles>

43

Schema 7.1. Retrosynthetische Analyse der indolhaltigen DNA-Binder. 
Verbindung 38 könnte auch zur Darstellung von 42 genutzt werden, hierzu sollte 43 als Alkylans synthetisiert werden.

\subsection{Synthese von 5-(2-Chlorethoxy)-indol-2-carbonsäureethylester (49)}

Im ersten Schritt der Synthese wurde kommerziell erhältliches 4-Nitrophenol (41) mit Dichlorethan sowie Kaliumcarbonat zu 44 umgesetzt. Nach Reduktion der Nitrogruppe von 44 unter $\mathrm{H}_{2}$-Atmosphäre mit Palladium auf Aktivkohle als Katalysator erhielt man das Anilinderivat $\mathbf{4 5}$ in eine Ausbeute von 97\% (Schema 7.2).

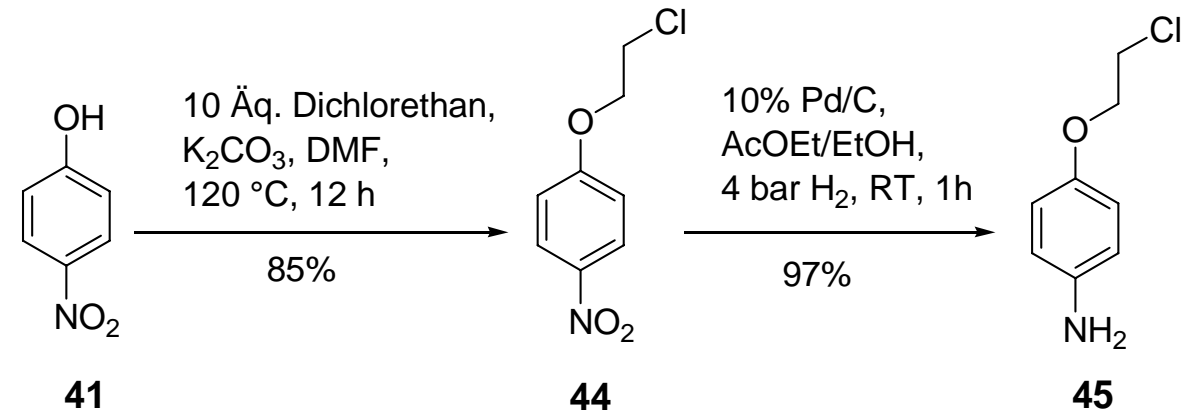

Schema 7.2. Synthese des Anilinderivats 45.

Für die Synthese von $\mathbf{4 4}$ aus $\mathbf{4 1}$ war es erforderlich, Dichlorethan im größeren Überschuss zu verwenden (Tabelle 7.1), da sonst das Bisphenoxyethan 46 in nicht unerheblicher Menge erhalten wurde.

\begin{tabular}{lll}
\hline Nr. & Äq. Dichlorethan & Ergebnis \\
\hline 1 & 4.0 & $79 \%(13 \% 46)$ \\
2 & 10.0 & $85 \%$ \\
\hline
\end{tabular}

Tabelle 7.1. Versuchsergebnisse der Alkylierung des Nitrophenols (41).

Das unerwartete Nebenprodukt 46 findet jedoch eine interessante Anwendungsmöglichkeit im Rahmen dieser vorliegenden Arbeit, über die in Kapitel 7.9 ausführlich berichtet wird.

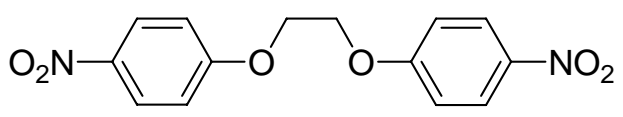

46

Abb. 7.1. Struktur des Bisphenoxyethanderivats 46. 
<smiles>Nc1ccc(OCCCl)cc1</smiles>

45

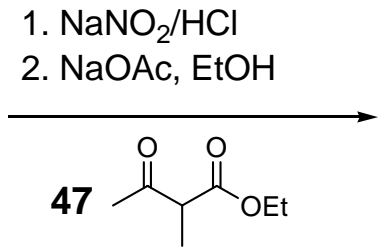

$\underset{\text { 2. } \mathrm{NaNO}_{2} / \mathrm{HCl}}{\text { (2) }}$

$\begin{array}{ll}48 \% \text { über drei Stufen } & \begin{array}{l}\text { ges. essigsaüre HCl-Lsg., } \\ 70^{\circ} \mathrm{C}, 30 \mathrm{~min}\end{array}\end{array}$<smiles>CCOC(=O)c1cc2cc(OCCCl)ccc2[nH]1</smiles>

49<smiles>CCOC(=O)/C(C)=N/Nc1ccc(OCCCl)cc1</smiles>

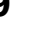

Schema 7.3. Synthese des Indols 49.

Die Diazotierung von 45 mit Natriumnitrit in wässriger $\mathrm{HCl}$ und sofortiger Umsetzung des Diazoniumsalzes mit einer Suspension aus 2-Methylacetessigsäureethylester (47) und Natriumacetat in Ethanol lieferte das Hydrazon 48. In der anschließenden Fischer-Indol-Synthese wurde 48 in einer hergestellten, gesättigten, essigsauren HCl-Lösung für 30 min bei $70{ }^{\circ} \mathrm{C}$ erhitzt. Nach Kristallisation aus EtOH/ $\mathrm{H}_{2} \mathrm{O}$ (1:1) erhielt man das Indol 49 in einer Ausbeute von 73\% über drei Stufen, welches als wichtige Depotverbindung diente (Schema 7.3). 


\subsection{Synthese von 5-(2-Iodethoxy)-indol-2-carbonsäureethylester (50)}

Wegen der schlechten Abgangsgruppenqualität des Chlors in Indol 49 wurde versucht, ein Iodderivat 50 herzustellen.<smiles>CCOC(=O)c1cc2cc(OCCCl)ccc2[nH]1</smiles>

49<smiles>CCOC(=O)c1cc2cc(OCCI)ccc2[nH]1</smiles>

50

Schema 7.4. Versuche zur Synthese des Iodderivats $\mathbf{5 0 .}$

\begin{tabular}{lccc}
\hline Nr. & Iodid-Quelle & Lösungsmittel & Ausbeute an 50 \\
\hline 1 & $\mathrm{NaI}$ & 2 -Butanon & $80 \%(12 \% \mathbf{4 9})$ \\
2 & $\mathrm{NaI}$ & $\mathrm{CH}_{3} \mathrm{CN}$ & $85 \%(1 \% 49)$ \\
3 & $\mathrm{KI}$ & 2 -Butanon & $<5 \%$ \\
4 & $\mathrm{KI}$ & $\mathrm{CH}_{3} \mathrm{CN}$ & $<5 \%$ \\
\hline
\end{tabular}

Tabelle 7.2. Versuche zur Synthese des Iodderivats 50.

Alle Reaktionen im Tabelle 7.2 wurden über 2 d unter Rückfluss erhitzt. Die lange Reaktionszeit war wegen des langsamen Umsatzes erforderlich. Kaliumiodid schien ein ungeeignetes Reagenz zu sein, da das gewünschte Iodderivat 50 nur in geringen Mengen erhalten wurde. Mit Natriumiodid als Iodid-Quelle konnten in Acetonitril als Lösungsmittel die besten Ergebnisse erzielt werden. Die Menge an nicht umgesetztes Edukt wurde aus des ${ }^{1}$ H-NMR-Spektrum des Gemisches bestimmt, da es schwierig war, das Chlorderivat vom Iodderivat abzutrennen. 


\subsection{Synthese von 5-(2-Hydroxyethoxy)-indol-2-carbonsäureethylester} (53)

Für die Synthese des Hydroxyderivats 53 wurde dieselbe synthetische Strategie wie für das Chlorderivat 49 verfolgt.<smiles>O=[N+]([O-])c1ccc(O)cc1</smiles>

41

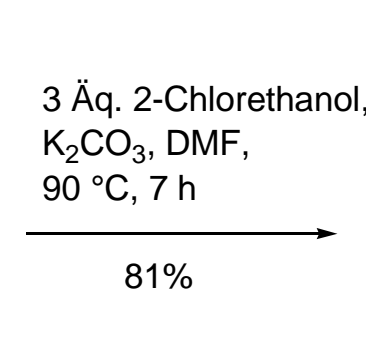
$\mathrm{K}_{2} \mathrm{CO}_{3}$, DMF
3 Äq. 2-Chlorethanol,

1. $\mathrm{NaNO}_{2} / \mathrm{HCl}$

2. $\mathrm{NaOAc}, \mathrm{EtOH}$<smiles>[CH+]C(C)=C(C)C(C)C(=O)OCC</smiles><smiles>O=[N+]([O-])c1ccc(OCCCl)cc1</smiles>

51<smiles>Nc1ccc(OCCO)cc1</smiles>

52

$10 \% \mathrm{Pd} / \mathrm{C}$,

AcOEt/EtOH,

4 bar $\mathrm{H}_{2}, \mathrm{RT}, 1 \mathrm{~h}$

$100 \%$ 


\subsection{Synthese von 5-Allyloxyindol-2-carbonsäureethylester (57) und 5-(2- Azidoethoxy)-indol-2-carbonsäureethylester (59)}

Zur Synthese des Indols 57 wurde das Phenol 41 mit Propen zu 55 allyliert, das nachfolgend mit $\mathrm{SnCl}_{2} \cdot 2 \mathrm{H}_{2} \mathrm{O}$ zum Anilin 56 reduziert wurde. Die nachfolgende Indolsynthese, die analog $\mathrm{zu}$ den bereits beschriebenen Reaktionen durchgeführt wurde, lieferte 57 in $52 \%$ über drei Stufen.<smiles>O=[N+]([O-])c1ccc(O)cc1</smiles>

41

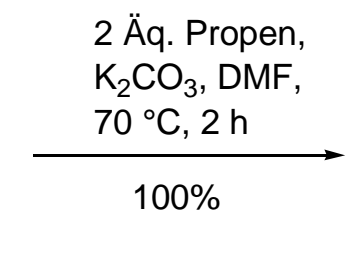<smiles>C=CCOc1ccc([N+](=O)[O-])cc1</smiles>

55
$\mathrm{SnCl}_{2} \cdot 2 \mathrm{H}_{2} \mathrm{O}$, AcOEt, Rückfluss, $14 \mathrm{~h}$

$$
54 \%
$$<smiles>C=CCOc1ccc(N)cc1</smiles>

56

1. $\mathrm{NaNO}_{2} / \mathrm{HCl}$

2. $47 / \mathrm{NaOAc}, \mathrm{EtOH}$

3. $6 \mathrm{M}$ iso-propanolische $\mathrm{HCl}$-Lsg., $70^{\circ} \mathrm{C}, 15 \mathrm{~min}$

52\% über drei Stufen<smiles></smiles><smiles>C=CCOc1ccc2[nH]c(C(=O)OCC)cc2c1</smiles>

57

Schema 7.6. Synthese des Indols 57.

Das Hydroxyderivat 53 wurde zuerst mit Methansulfonsäurechlorid sowie Triethylamin zu 58 umgesetzt, welches dann durch Azidolyse das Azidoderivat 59 in einer Ausbeute von 90\% über zwei Stufen lieferte.<smiles>CCOC(=O)c1cc2cc(OCCO)ccc2[nH]1</smiles>

53

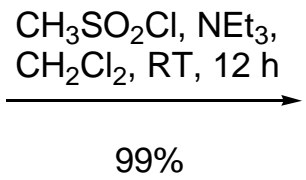

$99 \%$<smiles>CCOC(=O)c1cc2cc(OCCOS(=O)(=O)OCC)ccc2[nH]1</smiles>

58

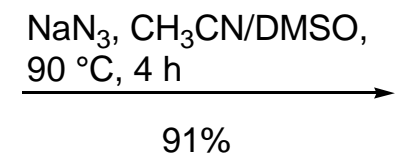

$\mathrm{NaN}_{3}, \mathrm{CH}_{3} \mathrm{CN} / \mathrm{DMSO}$,

$91 \%$<smiles>CCOC(=O)c1cc2cc(OCCN)ccc2[nH]1</smiles>

59

Schema 7.7. Synthese des Azidoindols 59. 
Ähnlich konnte 58 in einer Substition mit 92\% Ausbeute in das Iodderivat 50 überführt werden.<smiles>CCOC(=O)c1cc2cc(OCCOS(C)(=O)=O)ccc2[nH]1</smiles>

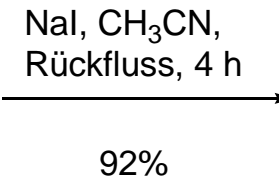<smiles>CCOC(=O)c1cc2cc(OCCI)ccc2[nH]1</smiles>

Schema 7.8. Synthese des Azidoindols 50.

\subsection{Synthese des Indolderivats 62}<smiles>CCOC(=O)c1cc2cc(OCCI)ccc2[nH]1</smiles>

50

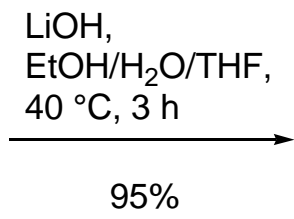

$\mathrm{CO}_{2} \mathrm{Et} 39$

$\mathrm{EtOH}$,

Rückfluss, $4 \mathrm{~h}$

$86 \%$ über zwei Stufen<smiles>O=C(O)c1cc2cc(OCCI)ccc2[nH]1</smiles>

60<smiles>CCOC(=O)CCN(C)CCOc1ccc2[nH]c(C(=O)O)cc2c1</smiles>

62
$\mathrm{CH}_{3} \mathrm{NH}_{2} / \mathrm{EtOH}$, $\mathrm{RT}, 4 \mathrm{~h}$<smiles>CNCCOc1ccc2[nH]c(C(=O)O)cc2c1</smiles>

Schema 7.9. Synthese des Indolderivats 62.

Die Carbonsäuregruppe an Position 2 in 62 sollte über eine Amidbindung mit dem CBIGrundgerüst gekuppelt werden. Um eine Differenzierung der beiden Säurefunktionen in 62 zu gewährleisten, wurde der Ethylester ins Substrat 50 zuerst mit Lithiumhydroxid-Monohydrat unter Bildung von 60 verseift. Die nachfolgende Aminolyse lieferte die Verbindung 61, die direkt mit Acrylsäureethylester (39) durch Michael-Addition in den gewünschten DNABinder 62 überführt wurde.

Der relative hohe Siedepunkt von Ethanol im Vergleich zu Methanol favorisierte die Verwendung des Ethylesters anstatt des Methylesters. 


\subsection{Synthese des Indolderivats 42}

Das kommerziell erhältliche Amin 63 wurde mit Boc-Anhydrid in einer Ausbeute von 91\% in das geschützte Derivat 43 überführt ${ }^{72}$.

Ausgehend von dem Iodderivat 50 konnte 64 mit einer ethanolischen Methylamin-Lösung. in einer Ausbeute von 68\% erhalten werden. Das Reaktionsgemisch sollte nicht längere Zeit gerührt werden, um die Menge des durch Amidierung der Esterfunktion entstandenen Nebenprodukts zu verringern. Das sekundäre Amin 64 konnte anschließend mit 43 zum tertiären Amin 65 umgesetzt werden, welches durch Verseifung das Zielmolekül 42 mit 66\% Ausbeute lieferte.

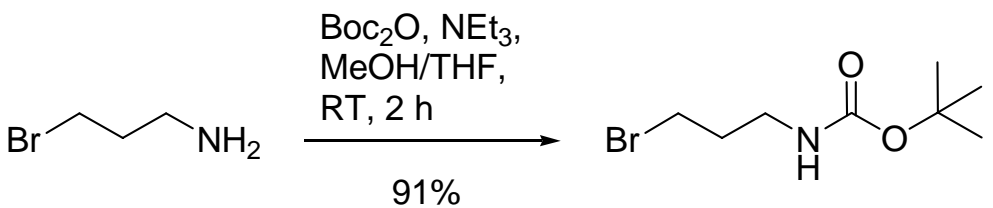

63<smiles>CCOC(=O)c1cc2cc(OCCI)ccc2[nH]1</smiles>

50<smiles>CN(CCCNC(=O)OCc1ccccc1)CCOc1ccc2[nH]c(C(=O)O)cc2c1</smiles>

$\mathrm{LiOH}$,

$$
\mathrm{H}_{2} \mathrm{O} / \mathrm{MeOH} / \mathrm{THF} \text {, }
$$$$
\mathrm{RT}, 2 \mathrm{~h}
$$

$66 \%$
43

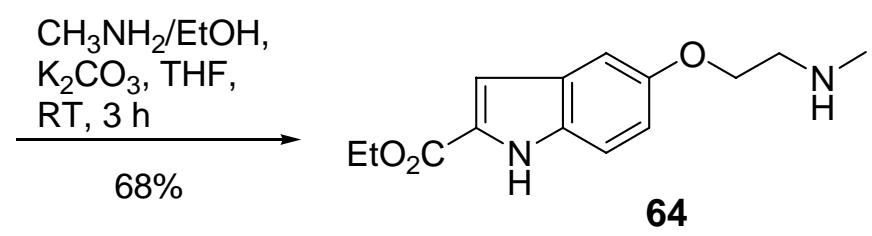

64

Schema 7.10. Synthese des Indolderivats 42.

Die Michael-Addition von 64 mit Acrylsäurenitril (66) wurde bei Raumtemperatur mit DMAP katalysiert ${ }^{73}$ und lieferte in einer Ausbeute von 83\% den Ester 67, der dann zu der endsprechenden Säure 68 mit 93\% Ausbeute überführt werden konnte. 


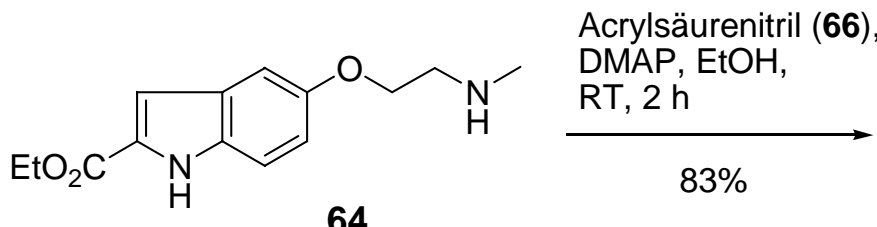<smiles>CCOC(=O)c1cc2cc(OCCN(C)CCC#N)ccc2[nH]1</smiles>

64<smiles>CN(CCC#N)CCOc1ccc2[nH]c(C(=O)O)cc2c1</smiles>

68

Schema 7.11. Synthese des Indolderivats 68.

Es wurde versucht, die Nitril-Funktion in $67 \mathrm{zu}$ reduzieren (Schema 7.10 sowie Tabelle 7.3). Bei Raumtemperatur und unter 1 bar Wasserstoff-Atmosphäre verursachte Raney-Nickel die Zersetzung des Eduktes innerhalb einer Stunde. Palladium auf Aktivkohle als Katalysator führte bei $1 \mathrm{~d}$ Reaktionszeit zu einem Gemisch. Diese Reduktion wurde nicht weiter getestet, da die Darstellung von 65 durch eine direkte Alkylierung gelang (Schema 7.10).<smiles>CCOC(=O)c1cc2cc(OCCN(C)CCC#N)ccc2[nH]1</smiles>

Schema 7.12. Versuche zur Reduktion von 67.

\begin{tabular}{lcccl}
\hline Nr. & Katalysator & H$_{2}$-Druck & Zeit & Ergebnis \\
\hline 1 & Raney-Ni & 1 bar & $2 \mathrm{~h}$ & Zersetzung \\
2 & $10 \% \mathrm{Pd} / \mathrm{C}$ & $1 \mathrm{bar}$ & $1 \mathrm{~d}$ & Gemisch \\
\hline
\end{tabular}

Tabelle 7.3. Versuche zur Reduktion von 67. 


\subsection{Synthese des Indolderivats 74}

Zuerst wurde versucht, das Nitroderivat $\mathbf{7 1}$ mit der schon in Kapitel 7.1 beschriebenen Methode durch Umsetzung von 41 mit 2-Chlorethyl-acetamid zu synthetisieren; nach $24 \mathrm{~h} \mathrm{am}$ Rückfluss in der Gegenwart von Kaliumhydroxid war jedoch keine Reaktion erkennbar.

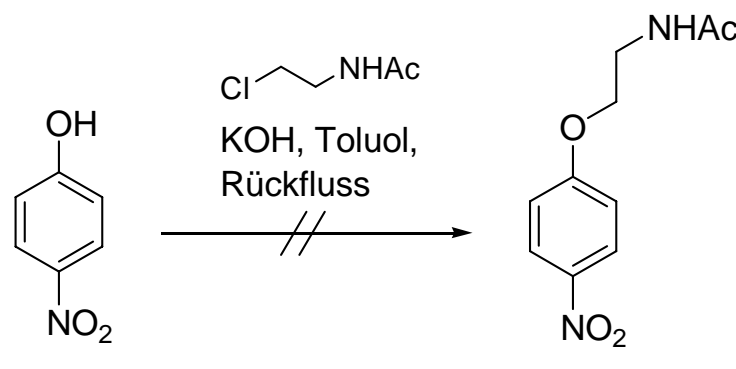

41

71

Schema 7.13. Versuche zur Synthese von 71.

Eine alternative Strategie verlief über eine nucleophile aromatische Substitution ${ }^{74}$, bei welcher der kommerziell erhältliche Alkohol 69 zuerst mit Natriumhydrid deprotoniert und dann mit dem Fluorbenzol 70 am Rückfluss erhitzt wurde. Das gewünschte Nitroderivat $\mathbf{7 1}$ wurde in 57\% Ausbeute erhalten. Die folgenden Schritte wurden in Analogie zum Indolderivat 49 durchgeführt. Nach der Fischer-Indol-Synthese wurde 73 mit 57\% Ausbeute über drei Stufen erhalten. Unter drastischen Bedingungen wurde die Verbindung 73 zugleich verseift sowie deacetyliert, das so entstandene sehr wasserlösliche Zwischenprodukt direkt mit BocAnhydrid geschützt und das Zielmolekül 74 letztlich in 83\% Ausbeute über zwei Stufen erhalten. 


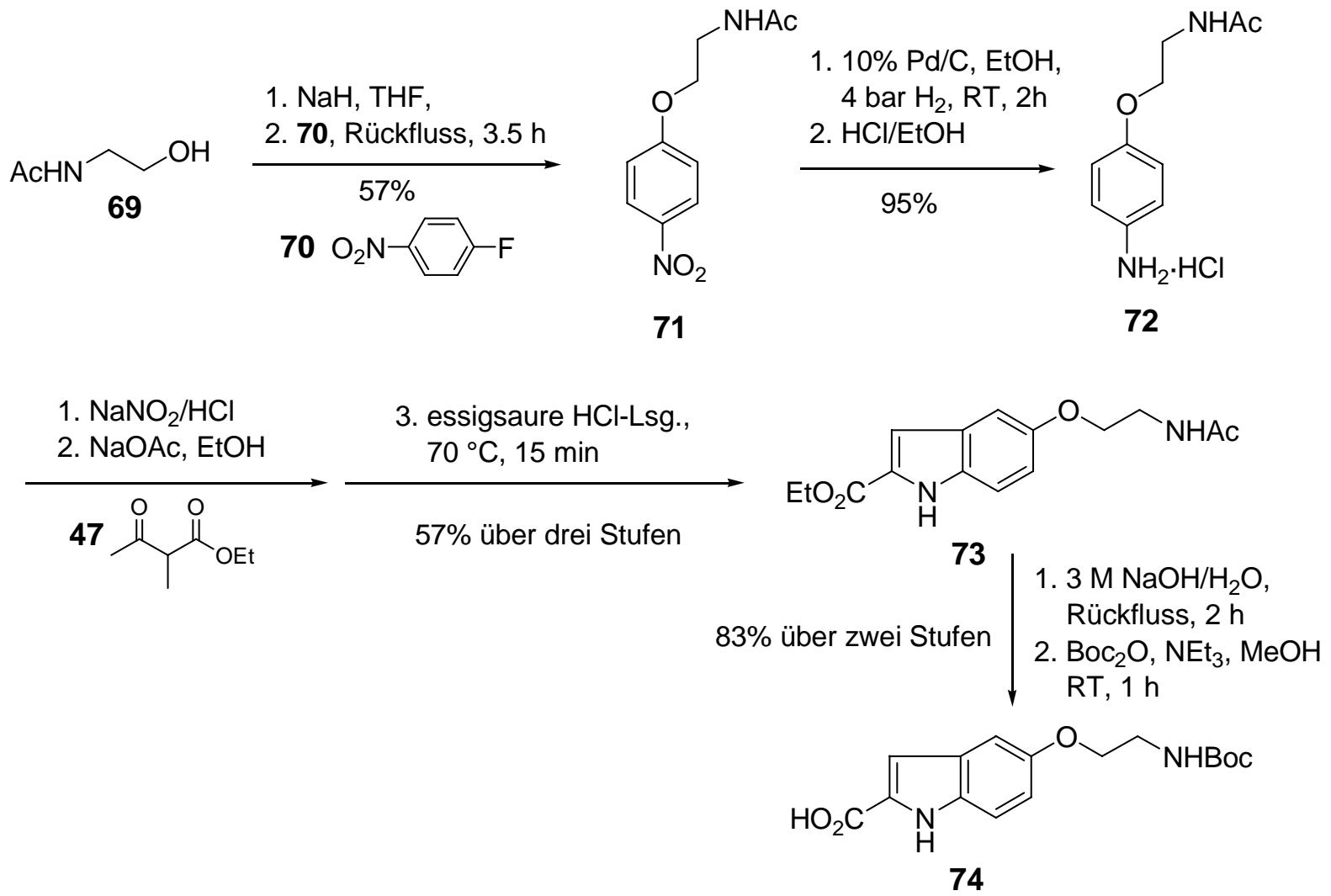

Schema 7.14. Synthese des Indolderivats 74.

\subsection{Synthese des Bisindolderivats 76}

Das in Kapitel 7.1 erhaltene Nebenprodukt zeigte strukturelle Ähnlichkeit zu Bizelesin (26), die einzige heute noch im klinischen Test verbliebende Verbindung der CC-1065 Analoga, und stellte somit ein interessantes Molekül dar.

Es wurde versucht, das Bisindolderivat $\mathbf{7 6}$ herzustellen. Analog $\mathrm{zu}$ der in Kapitel 7.4 beschriebenen Methode konnte die Verbindung 76 mit einer Ausbeute von 56\% über drei Stufen aus 75 erhalten werden.
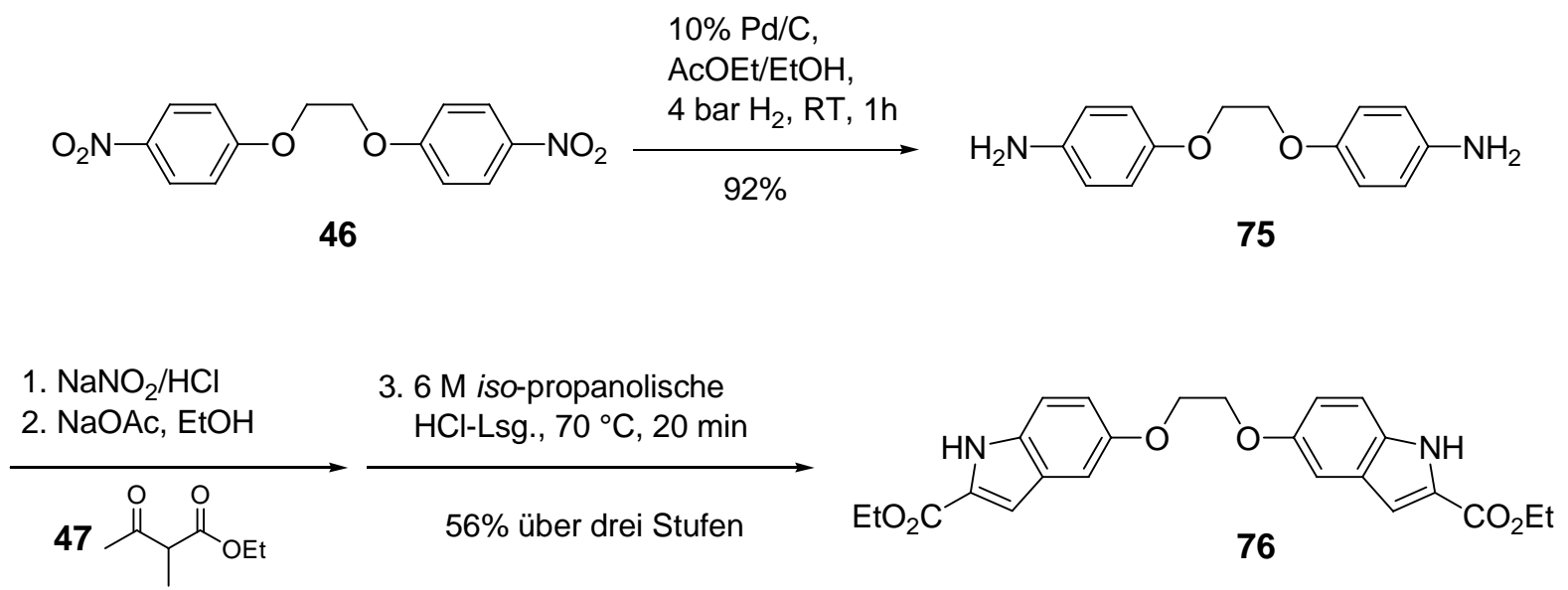

Schema 7.15. Synthese des Bisindolderivats 76. 


\subsection{Diskussion ausgewählter spektroskopischer Daten von 49 und 42}

Es erfolgt hier eine Diskussion der spektroskopischen Daten der indolhaltigen DNA-Bindern, dabei dienen 49 und 42 als Beispiele.

Im ${ }^{1}$ H-NMR-Spektrum (Abb. 7.3) von 49 beobachtet man bei $\delta=1.41$ ein Triplett mit einer Kopplungskonstante von $J=7.2 \mathrm{~Hz}$, welches der Methylgruppe des Ethylesters zugeordnet werden kann. Diese Kopplungskonstante findet sich im Quartett bei $\delta=4.41$ wieder, welches der Methylengruppe des Ethylesters entspricht. Die beiden an C-2' gebundenen Protonen resonieren bei $\delta=3.82$ als Triplett mit einer Kopplungskonstante von $J=6.0 \mathrm{~Hz}$ und die beiden 1'-H resonieren bei $\delta=4.26$ als Triplett mit der gleichen Kopplungskonstante. Von den aromatischen Wasserstoffatomen des Indols 49 resoniert das 6- $\mathrm{H}$ am stärksten hochfeldverschoben als Dublett von Dubletts mit $J_{o}=8.7 \mathrm{~Hz}$ und $J_{m}=2.4 \mathrm{~Hz}$ bei $\delta=7.02$. Das Signal für 4-H findet man als Dublett bei $\delta=7.09$ mit einer Kopplungskonstante von $J_{m}$ $=2.4 \mathrm{~Hz}$. Etwas weiter zum tiefen Feld verschoben resoniert $3-\mathrm{H}$ als Dublett bei $\delta=7.13$ mit einer Kopplungskonstante von $J=1.5 \mathrm{~Hz}$, die für die Kopplung mit dem NH charakteristisch ist. Das verbleibende tieffeldverschobene Signal für die aromatischen Protonen ist ein Dublett mit $J_{o}=9.3 \mathrm{~Hz}$ bei $\delta=7.32$, das dem 7-H zugeordnet werden kann. Das Indol-NH resoniert in den $\mathrm{CDCl}_{3}$-Spektren gewöhnlich weniger tieffeldverschoben als in den DMSO- $\mathrm{d}_{6}-$ Spektren, in diesem Fall bei $\delta=9.00$.

Im ${ }^{13} \mathrm{C}$-NMR-Spektrum resoniert im Hochfeld die Methylgruppe bei $\delta=14.37$. Für C-2' findet man das Signal bei $\delta=42.00$ und C-1' bei $\delta=60.99$. Das Signal für die Methylengruppe des Ethylesters liegt bei $\delta=68.98$. Die aromatischen C-Atome resonieren im Bereich von $\delta=104.7$ bis $\delta=132.7$. Charakteristische Verschiebung weist das Sauerstoffsubstituierte C-Atom C-5 bei $\delta=153.2$ auf. Das Carbonyl-C-Atom des Esters resoniert typischerweise bei $\delta=161.9$.

Im Massenspektrum erkennt man die Signale vom Molpeak $[\mathrm{M}]^{+}$, sowie des Fragmentes nach Verlust des Ethanol $\left[\mathrm{M}-\mathrm{C}_{2} \mathrm{H}_{5} \mathrm{OH}\right]^{+}$. 


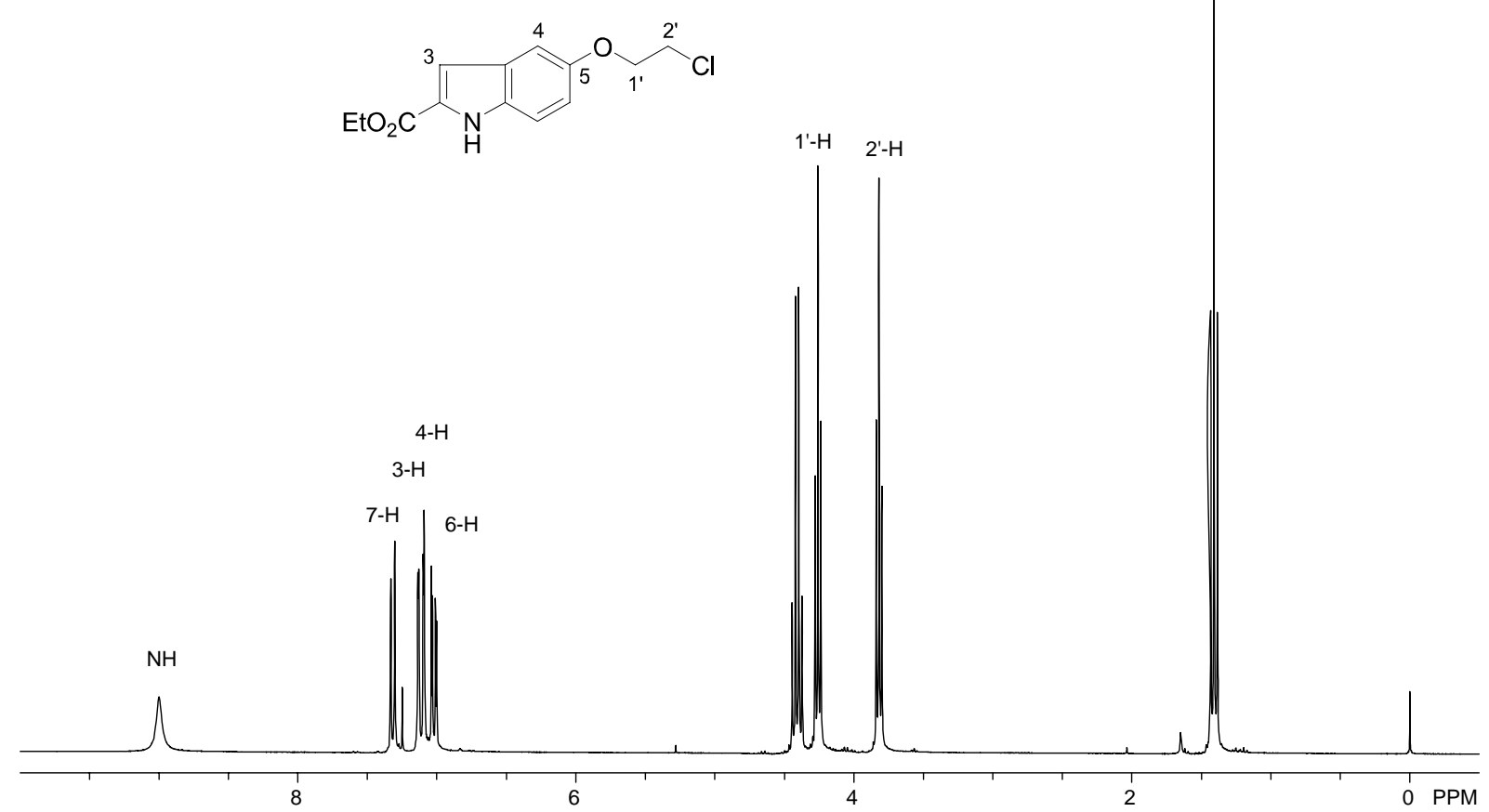

Abb. 7.3. ${ }^{1} \mathrm{H}-\mathrm{NMR}-\mathrm{Spektrum}$ von $49\left(300 \mathrm{MHz}, \mathrm{CDCl}_{3}\right)$.

Im ${ }^{1} \mathrm{H}-\mathrm{NMR}-$ Spektrum (Abb. 7.4) von 42 ist das Signal der tert-Butylgruppe deutlich dem Singulett bei $\delta=1.37$ zuzuordnen. Das zentrierte Multiplett bei $\delta=1.56$ entspricht 2 ' '-H und das Singulett bei $\delta=2.26$ der Methylamingruppe. Man erkennt das Triplett für 1''-H bei $\delta=2.42$ mit einer Kopplungskonstante von $J=6.9 \mathrm{~Hz}$ und das Quartett für 3'"-H bei $\delta=2.97$ mit $J=6.3 \mathrm{~Hz}$. Als Triplett resoniert 2'-H bei $\delta=2.72$ mit einer Kopplungskonstante von $J=6.0 \mathrm{~Hz}$. Diese Kopplungskonstante findet sich im Triplett bei $\delta=4.02$ wieder, welches dem Signal des 2'-H entspricht. Die Signale für das 3-H und das 6-H werden von dem Signal des NH-Protons der Boc-Schutzgruppe im Bereich von $\delta=6.75-6.77$ überlagert. Für das 4-H findet man ein Dublett bei $\delta=7.02\left(J_{m}=2.4 \mathrm{~Hz}\right)$ und für das $7-\mathrm{H}$ ein Dublett bei $\delta=7.38$ $\left(J_{0}=8.7 \mathrm{~Hz}\right)$. Das Indol-NH resoniert bei $\delta=11.40$.

Mit Hilfe des ${ }^{1} \mathrm{H}-{ }^{13} \mathrm{C}$-Korrelationsexperimentes konnten die für das ${ }^{1} \mathrm{H}-\mathrm{NMR}-$ Spektrum getroffenen Zuordnungen auf das Kohlenstoffspektrum übertragen werden. Das Signal für die tert-Butylgruppe liegt bei $\delta=28.21$. Man erkennt das Signal für C-2"' bei $\delta=27.05$, für C-3"' bei $\delta=38.28$ und für C-1" ' bei $\delta=54.92$. Die Methylamingruppe zeigt eine Verschiebung bei $\delta=42.31$. Weiter zum tiefen Feld verschoben resonieren C-2' und C-1' bei $\delta=55.91$ beziehungsweise $\delta=66.19$. Charakteristisch resoniert das quartäre C-Atom der tert- 
Butylgruppe bei $\delta=77.27$. Die aromatischen C-Atome resonieren im Bereich von $\delta=103.0$ bis $\delta=136.0$. Charakteristische Verschiebung weist das Sauerstoff-substituierte C-Atom C-5 bei $\delta=152.4$ auf. Die Carbonyl-C-Atome der Boc-Gruppe und der Carbonsäure resonieren typischerweise bei $\delta=155.5$ beziehungsweise $\delta=165.6$.

Daneben bestätigt ein hochaufgelöstes ESI-Massenspektrum die angenommene Struktur.<smiles>CN([CH]CCNC(=O)OC(C)(C)C)CC(F)Oc1ccc2[nH]c(C(=O)O)cc2c1</smiles>

$\mathrm{NCH}_{3} \quad \mathrm{C}\left(\mathrm{CH}_{3}\right)_{3}$

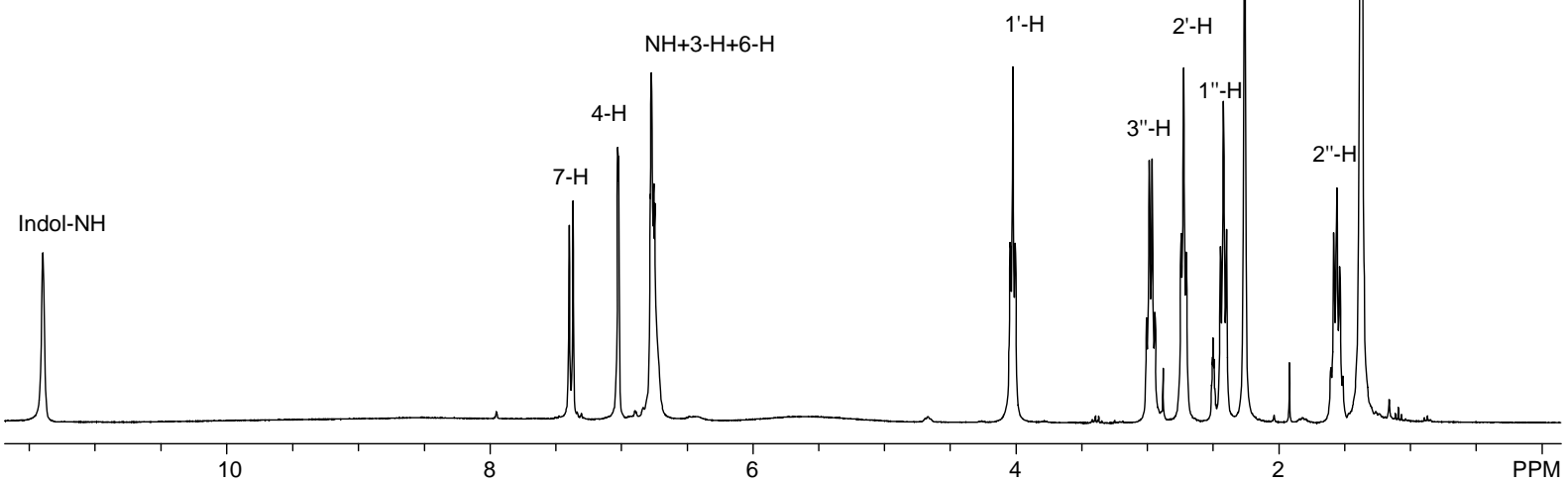

Abb. 7.4. ${ }^{1} \mathrm{H}-\mathrm{NMR}-$ Spektrum von $42\left(300 \mathrm{MHz}, \mathrm{DMSO}-\mathrm{d}_{6}\right)$. 


\section{Synthese von anti-Methyl-seco-CBI-DNA-Bindern}

In diesem Kapitel wurde versucht, das anti-Methyl-seco-CBI-Grundgerüst mit unterschiedlichen indolhaltigen DNA-Bindern, die in Kapitel 7 dargestellt wurden, zu kuppeln. Außerdem wurden hier die Modifikation der gekuppelten Verbindungen, die Entschützung des Prodrug sowie alternative Strategien zum Zielmolekül behandelt.

\subsection{Synthese des anti-Methyl-seco-CBI-Grundgerüstes 82}

Das vorliegende Kapitel beschreibt die Synthese des anti-Methyl-seco-CBI-Grundgerüstes nach bekannten Methoden aus dem Arbeitskreis Tietze. ${ }^{75,76,77}$

Als Ausgangspunkt der Synthese des Grundgerüstes 82 diente die Naphtholcarbonsäure 77, welche unter Verwendung klassischer Synthesemethoden ausgehend von Benzaldehyd in sechs Stufen hergestellt werden kann. ${ }^{78,79}$ Die im Molekül enthaltene Carbonsäurefunktionalität konnte direkt durch eine Curtius-Umlagerung in eine geschützte Aminofunktion umgewandelt werden. Man verwendete hierzu Diphenylphosphorylazid (DPPA), das sog. Hamado-Shiori-Reagenz, und rührte 3 Stunden unter Rückfluss in Gegenwart von tert-Butylalkohol und Triethylamin. Auf die übliche Verwendung von Molsieb (4 Å) konnte verzichtet werden, da diese die Ausbeute kaum verbesserte $(83 \%$ im Vergleich zu 84\% mit Molsieb). 78 wurde nach der Methode von Königstein ${ }^{80}$ regioselektiv an C-4 iodiert und lieferte das Aryliodid 79 in $87 \%$ Ausbeute.

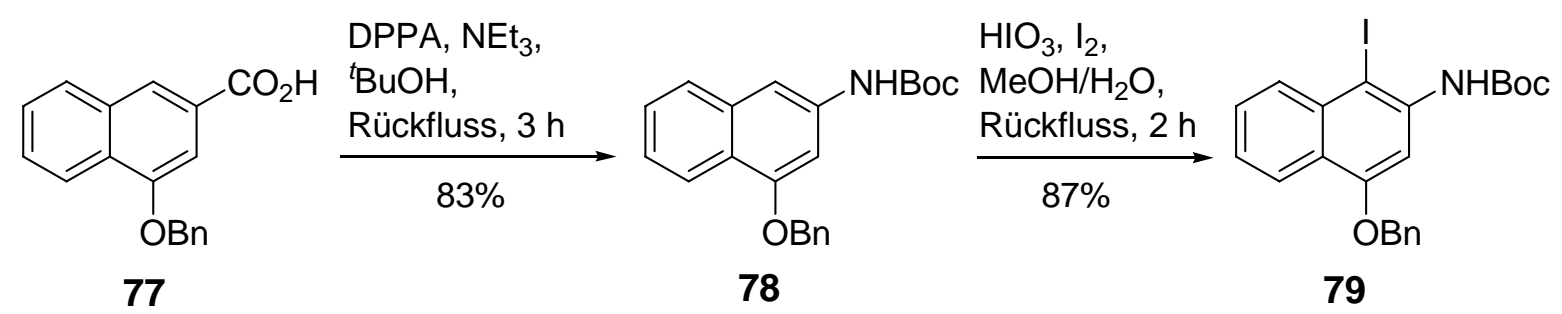

Schema 8.1. Synthese des Aryliodids 79.

Die Synthese der Benzoindoline 82 und 83 erfolgte über eine Alkylierung von $\mathbf{7 9}$ mit dem Allylchlorid 80 und nachfolgende radikalische Cyclisierung. Hierzu wurde das Bocgeschützte Naphthylaminderivat $\mathbf{7 9}$ mit $\mathrm{NaH}$ deprotoniert und mit einem kommerziell erhältlichen E/Z-Gemisch von 1,3-Dichlor-2-buten (80) in $91 \%$ Ausbeute zu dem E/ZGemisch 81 umgesetzt (Schema 8.2.). 


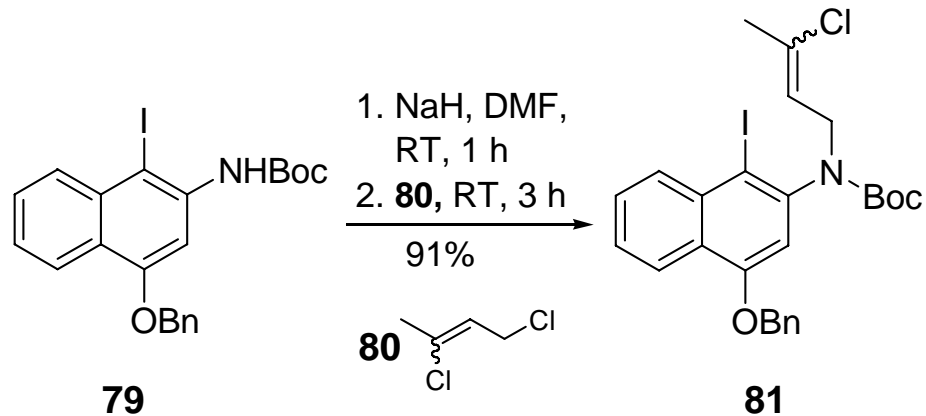

Schema 8.2. Alkylierung des Naphthylaminderivates 79.

In der anschließenden radikalischen Cyclisierungsreaktion wurde das E/Z-Gemisch $\mathbf{8 1}$ mit Tris-(trimethylsilyl)-silan (TTMSS) und AIBN in Toluol bei $80^{\circ} \mathrm{C}$ zu 82 bzw. 83 transformiert. Der Aufbau der zwei stereogenen Zentren erfolgte unselektiv und es entstanden etwa gleiche Mengen der racemischen anti- und syn-Diastereomere 82 bzw. 83 (Schema 8.3.) in einer Gesamtausbeute von $82 \%$.<smiles>CC(Cl)=CCN(C(=O)OCc1ccccc1)c1cc(OCc2ccccc2)c2ccccc2c1I</smiles>

81

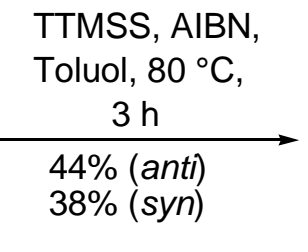

TTMSS, AIBN<smiles>CC(C)(C)OC(=O)Nc1cc(OCc2ccccc2)c2ccccc2c1</smiles>

anti: 82

syn: 83

Schema 8.3. Radikalische Cyclisierungsreaktion.

\subsubsection{Nomenklatur der Cyclisierungsprodukte}

Die Diastereomere waren aufgrund deutlich unterschiedlicher $\mathrm{R}_{\mathrm{f}}$-Werte problemlos chromatographisch voneinander trennbar.

Die relative Konfiguration der Diastereomere wurde durch eine Kristallstrukturanalyse ermittelt. ${ }^{59}$ Gemäß der relativen Konfiguration der Wasserstoffatome an C-1 und C-10 werden die Diastereomere gemäß Abbildung 8.1 mit syn und anti bezeichnet. 


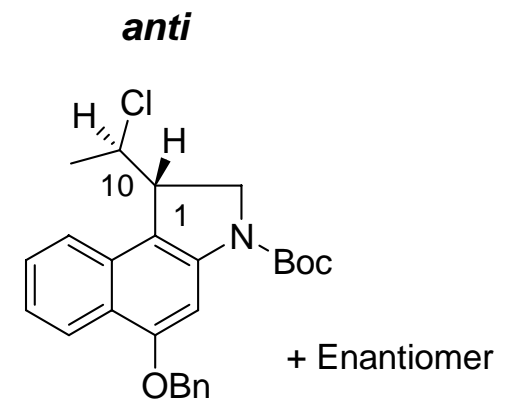

82 syn

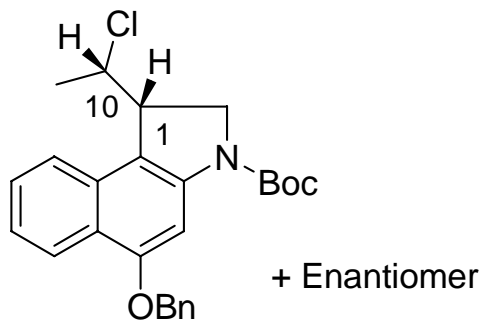

83

Abb. 8.1. Nomenklatur der diastereomeren Enantiomerenpaare 82 und 83.

\subsection{Synthese von anti-Methyl-seco-CBI-DNA-Binder}

\subsubsection{Abspaltung der Boc-Schutzgruppe in 82}

Um die Boc-Schutzgruppe in $\mathbf{8 2}$ abzuspalten, wurden unterschiedliche Bedingungen getestet. Aufgrund von Löslichkeitsproblemen schien die in der Literatur beschriebene Methode ${ }^{81}$ nicht praktikabel zu sein. Nach 1 d Rühren bei Raumtemperatur war die Reaktion nicht vollständig (Tabelle 8.1, Eintrag 1). Die Temperatur wurde auf $60{ }^{\circ} \mathrm{C}$ erhöht; die Reaktion war allerdings nach $2 \mathrm{~h}$ immer noch nicht komplett (Tabelle 8.1, Eintrag 2). Der Wechsel zu einem Lösungsmittelgemisch von Ethanol und THF brachte keine Verbesserung (Tabelle 8.1, Eintrag 3).<smiles>CC(Cl)C1CN(C(=O)OC(C)(C)C)c2cc(OCc3ccccc3)c3ccccc3c21</smiles>

82 (rac.)<smiles>CC(Cl)C1CNc2cc(OCc3ccccc3)c3ccccc3c21</smiles>

84 (rac.)

Schema 8.4. Abspaltung der Boc-Schutzgruppe in 82.

Da die Anwesenheit von Wasser im Reaktionsgemisch $\mathrm{zu}$ der schlechten Löslichkeit beitragen könnte, wurde eine käufliche $6 \mathrm{M}$ iso-propanolische HCl-Lösung verwendet (Tabelle 8.1, Eintrag 4). Unter diesen Bedingungen war die Reaktion nach $1 \mathrm{~h}$ bei $60{ }^{\circ} \mathrm{C}$ vollständig und das Rohprodukt 84 wurde quantitativ erhalten. Wegen der Instabilität von 84 wurde keine weitere Reinigung durchgeführt. 


\begin{tabular}{|c|c|c|c|}
\hline Nr. & Reagenz & T / Zeit & Ergebnis \\
\hline 1 & $12 \mathrm{M} \mathrm{HCl}\left(\mathrm{H}_{2} \mathrm{O}\right) / \mathrm{AcOEt}=1: 2$ & $\mathrm{RT} / 1 \mathrm{~d}$ & $\begin{array}{l}\text { sehr schlechte } \\
\text { Löslichkeit }\end{array}$ \\
\hline 2 & $12 \mathrm{M} \mathrm{HCl}\left(\mathrm{H}_{2} \mathrm{O}\right) / \mathrm{AcOEt}=1: 2$ & $60^{\circ} \mathrm{C} / 2 \mathrm{~h}$ & nicht komplett \\
\hline 3 & $\begin{array}{c}12 \mathrm{M} \mathrm{HCl}\left(\mathrm{H}_{2} \mathrm{O}\right) / \mathrm{EtOH} / \mathrm{THF} \\
=1: 1: 1\end{array}$ & $60{ }^{\circ} \mathrm{C} / 2 \mathrm{~h}$ & nicht komplett \\
\hline 4 & $6 \mathrm{M} \mathrm{HCl}(i-\mathrm{PrOH}) / \mathrm{AcOEt}=1: 1$ & $60^{\circ} \mathrm{C} / 1 \mathrm{~h}$ & komplett \\
\hline
\end{tabular}

Tabelle 8.1. Versuche zur Entschützung von 82.

Die vorgestellte Bedingung ließ sich ebenfalls auf die Entschützung von 83 anwenden, welches eine noch schlechtere Wasserlöslichkeit als 82 zeigte (Schema 8.4).<smiles>CC(C)(C)OC(=O)N1C[C@H](C(C)(Cl)Cl)c2c1cc(OCc1ccccc1)c1ccccc21</smiles>

83 (rac.)
$6 \mathrm{M}$ isopropanolische $\mathrm{HCl}-\mathrm{Lsg}$., $60^{\circ} \mathrm{C}, 1 \mathrm{~h}$

quantitative Isolierung des Rohprodukts<smiles>CC(Cl)C1CNc2cc(OCc3ccccc3)c3ccccc3c21</smiles>

85 (rac.)

Schema 8.4. Abspaltung der Boc-Schutzgruppe in 83.

Die käufliche $6 \mathrm{M}$ iso-propanolische HCl-Lösung wurde auch erfolgreich bei der FischerIndol-Synthese verwendet, wie schon in Kapitel 7 beschrieben.

Eine weitere Verwendung der iso-propanolischen HCl-Lösung ist in Schema 8.5 gezeigt. Verbindung 86, die nach T. Herzig aus 83 dargestellt konnte ${ }^{58}$, wurde mit der isopropanolischen HCl-Lösung versetzt, wobei sich das Molekül 143 quantitativ bildete. Neben der Abspaltung der Boc-Schutzgruppe wurde der Cyclopropanring in $\mathbf{8 6}$ mit Chlorid selektiv geöffnet. Das ${ }^{1}$ H-NMR-Spektrum zeigte nur die Anwesenheit des Enantiomerenpaars 143, was eine gute Bestätigung der Wirkungsweise vom Methyl-seco-CBI-Grundgerüst ergab ${ }^{82}$.<smiles></smiles>

86 (rac.)
$6 \mathrm{M}$ isopropanolische $\mathrm{HCl}$-Lsg., $60^{\circ} \mathrm{C}, 1 \mathrm{~h}$

quantitative Isolierung des Rohprodukts<smiles></smiles>

143 (rac.)

Schema 8.5. Selektive Ringöffnung von 86. 


\subsubsection{Kupplung von 84 mit unterschiedlichen DNA-Bindern}

Nach erfolgreicher Synthese des anti-Methyl-seco-CBI-Grundgerüstes 84 konnte nun die Kupplung mit den in Kapitel 7 erhaltenen DNA-Bindern nach literaturbekannter Methode ${ }^{81}$ durchgeführt werden. Hierzu wurde EDC $\cdot \mathrm{HCl}$, ein aus der Peptidchemie bekanntes, wasserlösliches Carbodiimid-Derivat, als Kupplungsreagenz verwendet.

Das Indolderivat 62 wurde mit $\mathbf{8 4}$ gekuppelt und anschließend mit Lithiumhydroxid verseift. Die Verbindung 88 wurde in einer Ausbeute von $88 \%$ über zwei Stufen erhalten (Schema 8.6).<smiles>CCOC(=O)OCCN(C)CCOc1ccc2[nH]c(C(=O)OCC)cc2c1</smiles>

62<smiles>CCOC(=O)CCN(C)CCOc1ccc2[nH]c(C(=O)N3C[C@H](C(C)Cl)c4c3cc(OCc3ccccc3)c3ccccc43)cc2c1</smiles>

87<smiles>CC(Cl)C1CN(C(=O)c2cc3cc(OCCN(C)CCC(=O)O)ccc3[nH]2)c2cc(OCc3ccccc3)c3ccccc3c21</smiles>

Schema 8.6. Synthese von 88 .

Ausgehend von 68 wurde die nitrilhaltige Verbindung 89 mit 53\% Ausbeute gebildet (Schema 8.7). 
<smiles>CN(CCC#N)CCOc1ccc2[nH]c(C(=O)O)cc2c1</smiles>

68<smiles>CC(Cl)[C@H]1CN(C(=O)c2cc3cc(OCCN(C)CCC#N)ccc3[nH]2)c2cc(Cc3ccccc3)c3ccccc3c21</smiles>

Schema 8.7. Synthese von 89.

Für die Darstellung von 91 wurde der Ester 53 mit Lithiumhydroxid zu der Säure 90 verseift, welche nach Kupplung mit 84 das gewünschte Zielmolekül 91 mit 54\% Ausbeute lieferte (Schema 8.8).<smiles>CCOC(=O)c1cc2cc(OCCO)ccc2[nH]1</smiles>

53

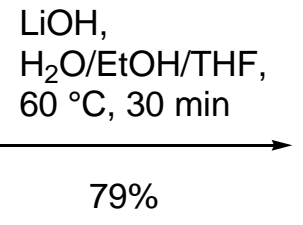

$\mathrm{H}$<smiles>O=C(O)c1cc2cc(OCCO)ccc2[nH]1</smiles>

90<smiles>CC(Cl)[C@H]1CN(C(=O)c2cc3cc(OCCO)ccc3[nH]2)c2cc(OCc3ccccc3)c3ccccc3c21</smiles>

Schema 8.8. Synthese von 91.

Die Kupplung von 74 mit 84 zum Derivat 92 verlief in einer Ausbeute von 47\% (Schema 8.9).<smiles>[Z4]c1ccc2[nH]c(C(=O)O)cc2c1</smiles>

84, EDC. $\mathrm{HCl}$, DMF, RT, $12 \mathrm{~h}$ $47 \%$<smiles></smiles>

Schema 8.9. Synthese von 92. 
Die vorgestellten Ergebnisse zeigen, dass die Ausbeuten der Kupplungsreaktion von der Art des DNA-Binders abhängig ist.

\subsubsection{Modifikation der gekuppelten Verbindungen}

Die in Kapitel 8.2.2 beschriebene Methode für die Darstellung der Prodrug-DNA-Binder war zwar erfolgreich, jedoch nicht effizient, da die dort gekuppelten DNA-Binder keinerlei weitere Modifikationen zuließen und demnoch jeweils nur ein neues Prodrug lieferten. Zur besseren Analyse der Struktur-Wirkungsbeziehungen sind jedoch mehrere strukturell ähnliche Prodrugs wünschenswert. Daher wurden in diesem Kapitel DNA-Binder gekuppelt, die dann nachträglich weiter modifiziert werden könnten, um einen Zugang zu viele unterschiedlichen analogen Prodrugs zu haben.

Zuerst wurde versucht, die im Molekül 88 enthaltene Carbonsäurefunktionalität direkt in einer Curtius-Umlagerung $^{83}$ in eine geschützte Aminofunktion umzuwandeln. Unter Standardbedingungen wurde $\mathbf{8 8}$ mit Diphenylphosphorylazid (DPPA) versetzt und 2 Stunden unter Rückfluss in Gegenwart von tert-Butylalkohol und Triethylamin gerührt. Nach Aufarbeitung erhielt man ein untrennbares Gemisch, das jedoch im Massenspektrum den gewünschten Molekülpeak zeigte.

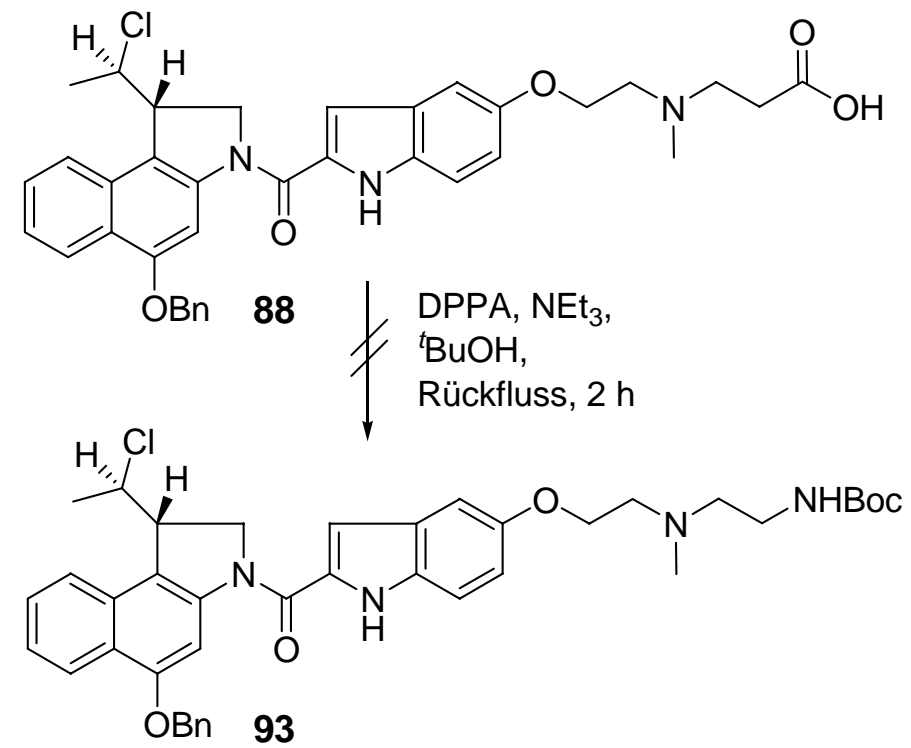

Schema 8.10. Versuche zur Curtius-Umlagerung von 88.

Es wurde ebenfalls versucht, eine Carboxylgruppe in dem gekuppelten Prodrug-DNA-Binder 92 durch Michael-Addition einzuführen (Schema 8.11). Hierzu wurde 92 mit einer 
essigsauren HCl-Lsg. entschützt, um anschließend den Acrylsäureethylester nucleophil anzugreifen. Nach Verseifung mit Lithiumhydroxid konnte die gewünschte Zielverbindung in $60 \%$ über drei Stufen erhalten werden.

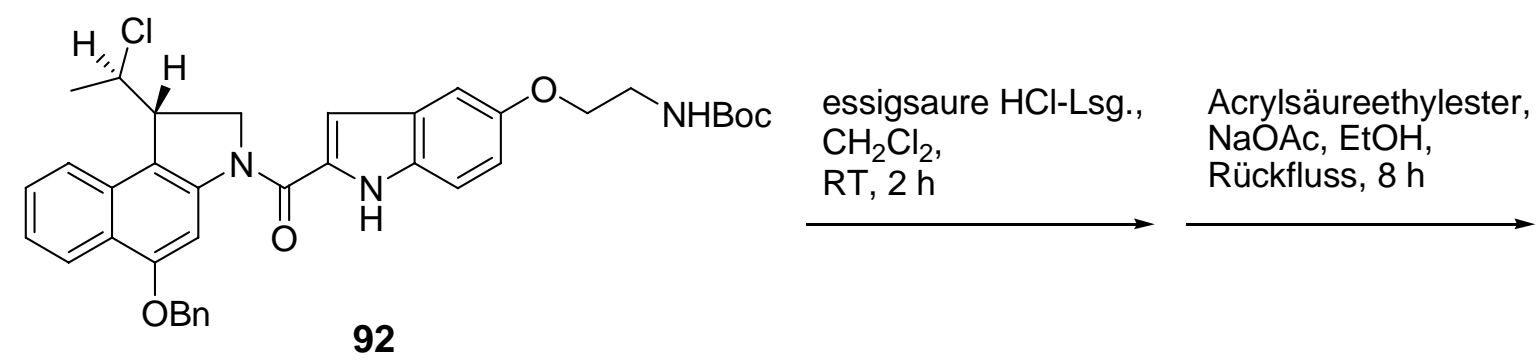

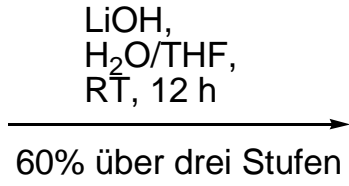<smiles>CC(Cl)C1CN(C(=O)c2cc3cc(OCCNCCC(=O)O)ccc3[nH]2)c2cc(OCc3ccccc3)c3ccccc3c21</smiles>

Schema 8.11. Synthese von 94 durch Michael-Addition.

Aufgrund der hervorragenden Ergebnisse von anti-Methyl-seco-CBI-DMAI-Verbindungen im Zelltest stellte das dialkylamin-substituierte Indol eine interessante Gruppe dar ${ }^{59}$. Es wurde versucht, die Dialkylamingruppe in der letzten Stufe einzuführen. Als Testsystem wurde die syn-Verbindung 85 verwendet (Schema 8.12). Zuerst wurde die Säure 95, die man durch Verseifung von 49 erhielt, mit 85 gekuppelt. Das entstande Chlorderivat 96 wurde durch Finkelstein-Reaktion in das Iodderivat 97 überführt, welches nach Aminierung das gewünschte Zielmolekül 98 in 66\% Ausbeute über zwei Stufen lieferte. 
<smiles>[R6]OC(=O)c1cc2cc(OCCCl)ccc2[nH]1</smiles>

Schema 8.12. Alternative Strategie zu Methyl-seco-CBI-DNA-Bindern.

Der Vorteil der in Schema 8.12 gezeigten Strategie liegt darin, mit unterschiedlichen Dialkylaminogruppen das entsprechende Zielmolekül über nur eine Stufe aufzubauen.

\subsection{4. Überführung zu den Drug-DNA-Bindern durch Debenzylierung}

In diesem Kapitel wurde versucht, die Benzyl-Schutzgruppe der Prodrugs zu entschützen, damit das entsprechende toxische Drug freigesetzt wurde und für biologische Testungen zugänglich war.

Das literaturbekannte Verfahren behandelt die katalytische Transferhydrierung mit Ammoniumformiat als Wasserstoffquelle ${ }^{84}$. Allerdings gibt es einige Nachteile an dieser Methode; z. B. hängt die Ausbeute stark von Parametern wie Temperatur und Zeit ab. Des weiteren gelang dieses Verfahren in einigen Fällen nicht, wie $O$. Panknin ${ }^{70}$ zeigte, dass das Molekül 99 nicht erfolgreich debenzyliert werden konnte.<smiles>CNCCOc1ccc2[nH]c(C(=O)N3CC(CCl)c4c3cc(OCc3ccccc3)c3cc(C(=O)O)ccc43)cc2c1</smiles>

Abb. 8.2. Struktur von 99 . 
Das Problem, das mit der direkten Hydrierung mit Wasserstoff verbunden ist, ist die in situ ablaufende Winstein Spirocyclisierung des debenzylierten Moleküls.

Deshalb wurde im Rahmen dieser Dissertation versucht, durch Zusatz von Säure in das Reaktionsgemisch den Anteil an Nebenprodukt zu verringern.
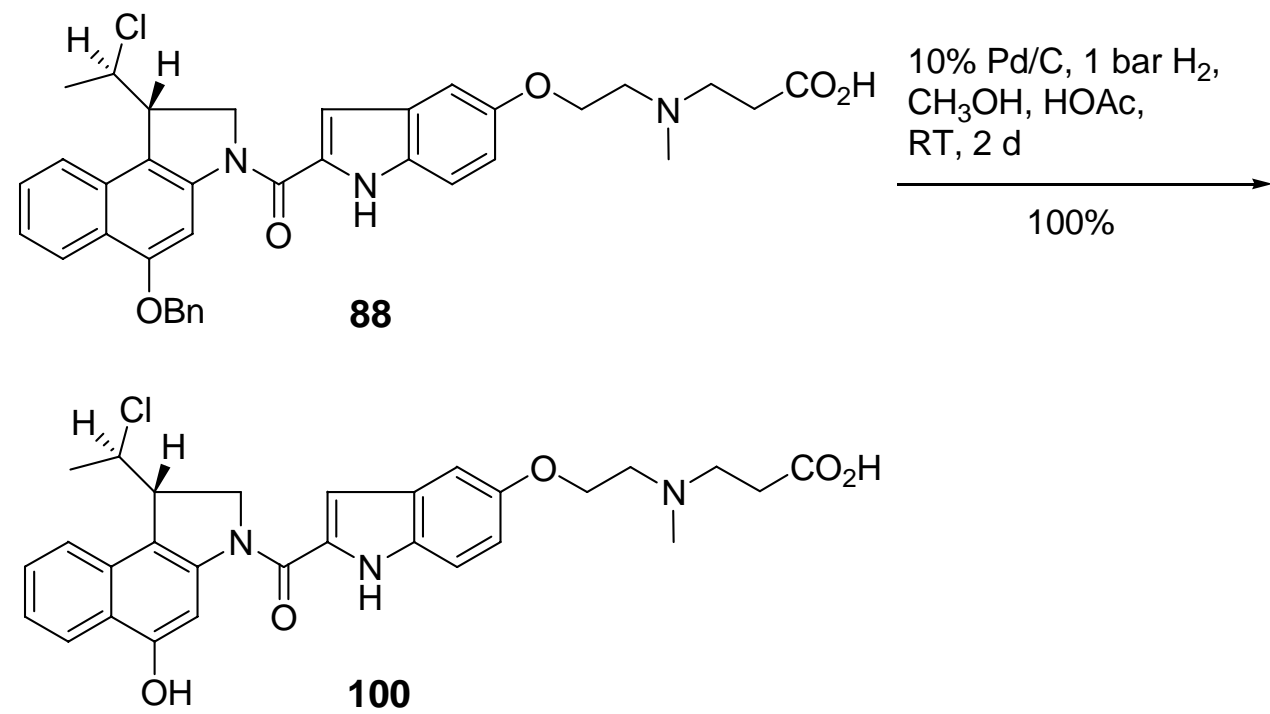

Schema 8.13. Synthese von 100.

Nach einigen Versuchen verlief die Reaktion wie gewünscht (Schema 8.13). Mit Zusatz von Essigsäure (30\% basierend auf dem Gewicht vom Edukt) konnte das benzylgeschützte Derivat 88 langsam zur Zielverbindung 100 mit quantitativer Ausbeute reagieren.

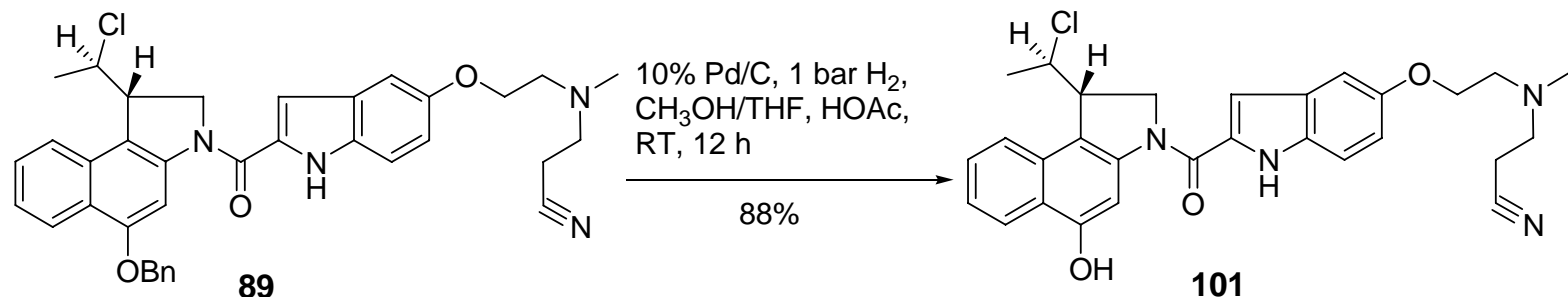

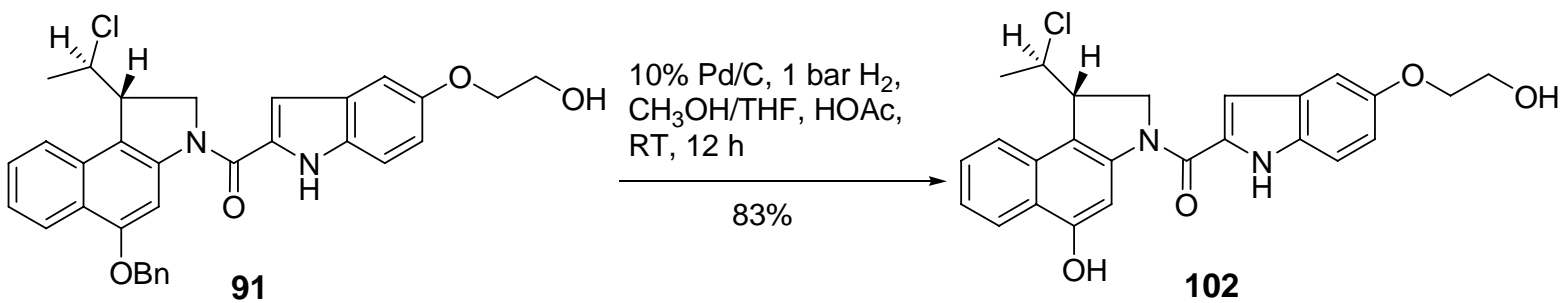

Schema 8.14. Synthese von 101 und 102. 
Analog dazu wurden die Zielmoleküle 101 und 102 in 88\% bzw. 83\% Ausbeute nach säulenchromatographischer Reinigung gebildet, welche nach Umkristallisation aus Ethanol mit 58\% bzw. 48\% Ausbeute weiter aufgereinigt werden konnten.

\subsection{Diskussion ausgewählter spektroskopischer Daten von 91 und 101}

Als Beispiel für die spektroskopischen Daten der anti-Methyl-seco-CBI-DNA-BinderDerivate sollen hier die Daten für den Benzylester 91 näher diskutiert werden. Im ${ }^{1} \mathrm{H}-\mathrm{NMR}$ Spektrum von 91 findet man das Signal der 11- $\mathrm{CH}_{3}$-Gruppe bei $\delta=1.65$ als Dublett mit einer Kopplungskonstante von $J=6.9 \mathrm{~Hz}$. Das 2'"-H resoniert bei $\delta=3.78$ als Quartett mit einer Kopplungskonstante von $J=5.4 \mathrm{~Hz}$ und das 1 ''-H resoniert bei $\delta=4.03$ als Triplet mit einer identischen Kopplungskonstante. Das Signal für das 1-H ist als Multiplett bei $\delta=4.19-4.22$ zu erkennen. Die Signale für 2-H und 10-H überlagern sich im Bereich vom $\delta=4.61-4.87$. Die Signale der beiden benzylischen Protonen des Benzylethers spalten als Multiplett im Bereich von $\delta=5.25-5.35$ auf. Die Zuordnung der Protonen des Indolring erfolgt wie schon in Kapitel 7.8 diskutiert. Die Protonen an dem Phenylring der Benzylgruppe erzeugen ein Multiplett im Bereich von $\delta=7.33-7.60$, in dem auch die Signale für 7-H, 8-H und 7'-H liegen. Die verbleibenden tieffeldverschobenen Signale der aromatischen Protonen sind die Dubletts bei $\delta=7.95(J=8.7 \mathrm{~Hz})$ und $8.23(J=7.8 \mathrm{~Hz})$, die dem 9-H bzw. 6-H entsprechen, sowie das breite Singulett bei $\delta=8.14$, welches dem $4-\mathrm{H}$ entspricht. Charakteristisch ist darüber hinaus das zum tiefen Feld verschobene breite Singulett bei $\delta=11.62$ für das Indol-NH.

Mit Hilfe des ${ }^{1} \mathrm{H}^{13}{ }^{13}$-Korrelationsexperimentes konnten die für das ${ }^{1} \mathrm{H}-\mathrm{NMR}-$ Spektrum getroffenen Zuordnungen auf das Kohlenstoffspektrum übertragen werden. Man beobachtet das Signal für C-11 erwartungsgemäß im Hochfeld bei $\delta=23.33$. Darüber hinaus sind die für Indoline charakteristischen Signale für C-1, C-2 und C-10 bei $\delta=45.92,52.00$ und $61.33 \mathrm{zu}$ finden. C-2" resoniert bei $\delta=59.73$ und C-1"' resoniert bei $\delta=69.93$. Das Signal für die benzylische $\mathrm{CH}_{2}$-Gruppe liegt bei $\delta=69.63$. Die Zuordnung der tertiären $\mathrm{C}$-Atome des Indolring erfolgt wie schon in Kapitel 7.8 diskutiert. Die Aromatischen C-Atome resonieren im Bereich von $\delta=98.40$ bis $\delta=142.2$. Charakteristischen Verschiebungen weisen die Sauerstoff-substituierte C-Atome C-5 und C-5' bei $\delta=153.2$ bzw. 154.2 auf. Das CarbonylC-Atom resoniert typischerweise bei $\delta=160.1$.

Daneben bestätigt ein hochaufgelöstes ESI-Massenspektrum die angenommene Struktur. 


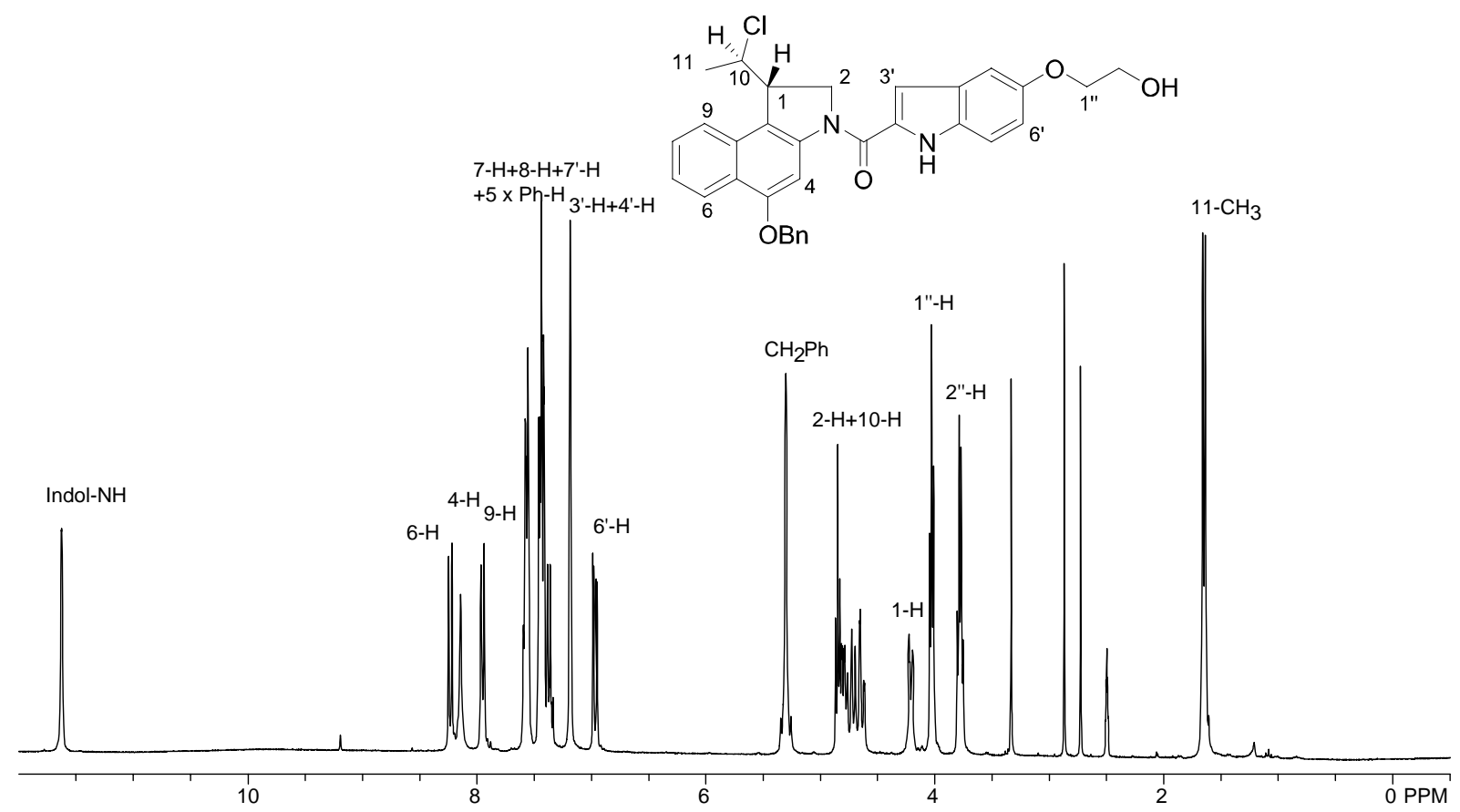

Abb. 8.3. ${ }^{1} \mathrm{H}-\mathrm{NMR}-\mathrm{Spektrum}$ von 91 (300 MHz, DMSO-d $\left.\mathrm{d}_{6}\right)$.

Stellvertretend für die debenzylierten anti-Methyl-seco-CBI-DNA-Binder-Derivate 100, 101, 102 sollen hier die spektroskopischen Daten von Verbindung 101 besprochen werden. Basierend auf der Diskussion der NMR-Daten von 91 wurden hier nur die Unterschiede aufgezeigt. So resonieren 1'"'-H und 2'"'-H im Bereich von $\delta=2.63-2.78$ je als ein Multiplett. Das Signal für 2"'-H findet man bei $\delta=2.83$ als Triplett mit einer Kopplungskonstante von $J=5.7 \mathrm{~Hz}$. Diese Kopplungskonstante findet sich im Triplett bei $\delta=4.08$ wieder, welches dem 1' '-H entspricht. Im Bereich von $\delta=5.0-5.5$ findet man das Signal für die benzylischen Protonen des Benzylethers nicht mehr. Unter den Signalen des Naphthalinsystems findet man für 7-H bei $\delta=7.36$ ein Triplett mit einer Kopplungskonstante von $J=6.9 \mathrm{~Hz}$ und $8-\mathrm{H}$ bei $\delta=7.51$ ein Triplett mit einer Kopplungskonstante von $J=7.2$ Hz. Beide Signale werden im Fall des benzylgeschützten Prodrugs von den Signalen der Protonen am Phenylring der Benzylgruppe überlagert. Zum tiefen Feld verschoben liegen Singuletts bei $\delta=10.35$ für $\mathrm{OH}$ und $\delta=10.56$ für Indol-NH.

Im ${ }^{13}$ C-NMR-Spektrum erkennt man das Signal von C-2, ', bei $\delta=15.26$, welches typisch für eine mit einer Nitrilfunktionälität verbundene Methylengruppe ist. Das C-Atom des Methylamin resoniert bei $\delta=41.73$ und das Signal bei $\delta=52.44$ entspricht C-1",' Die Aromatischen C-Atome resonieren im Bereich von $\delta=100.3$ bis $\delta=142.2$. Charakteristischen Verschiebungen weisen die Sauerstoff-substituierte C-Atome C-5 und 
C-5' bei $\delta=152.9$ bzw. 153.8 auf. Das Carbonyl-C-Atom resoniert typischerweise bei $\delta=159.9$

Daneben bestätigt ein hochaufgelöstes ESI-Massenspektrum die angenommene Struktur.

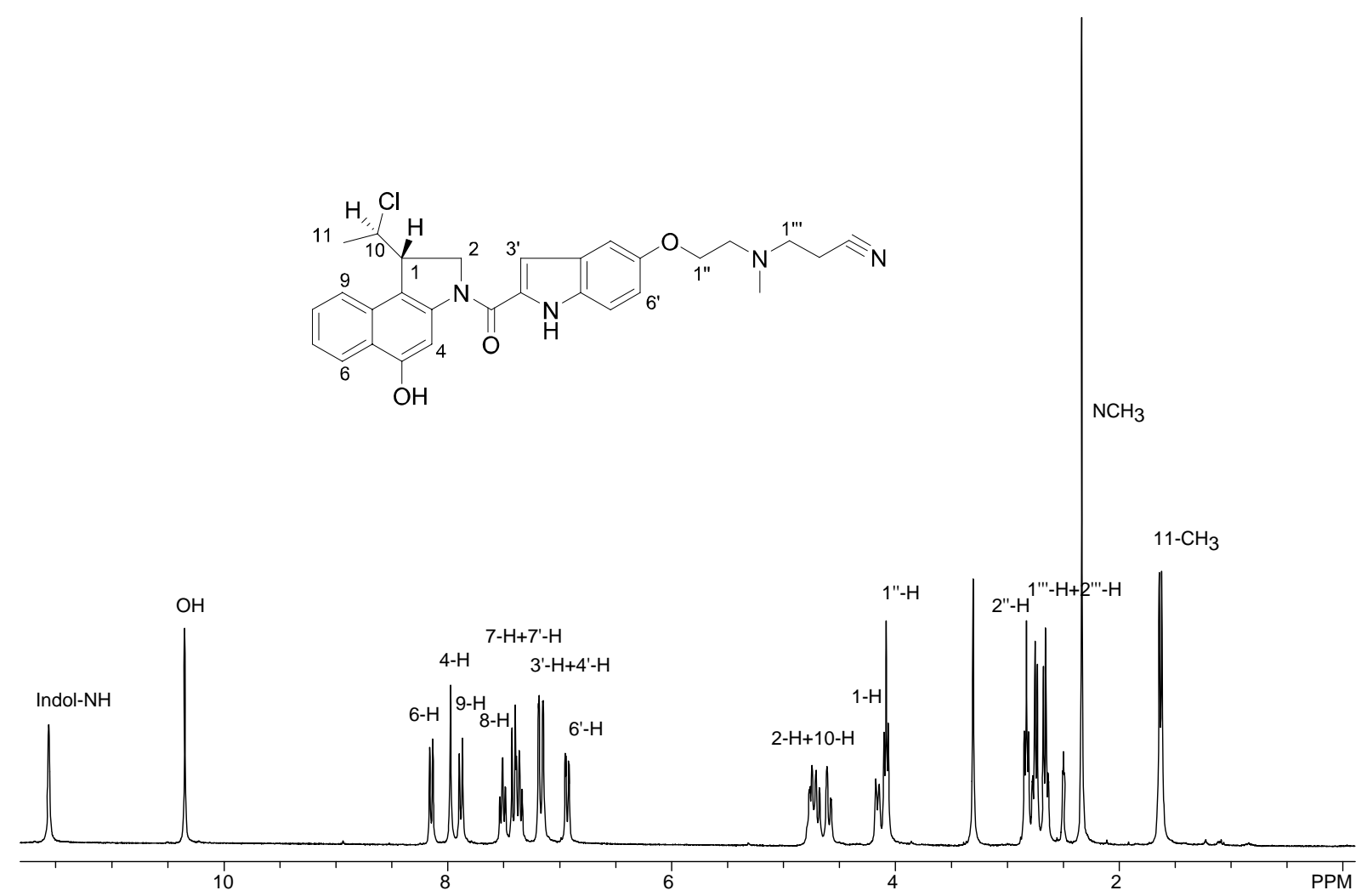

Abb. 8.4. ${ }^{1} \mathrm{H}-\mathrm{NMR}-$ Spektrum von $101\left(300 \mathrm{MHz}\right.$, DMSO-d $\left.{ }_{6}\right)$. 


\section{Synthese der anti-Methyl-seco-CBI-DNA-Binder- Tetragastrin-Derivate}

In diesem Kapitel wurde versucht, das Tetragastrin mit unterschiedlichen Schutzgruppen in der Asparaginsäureseitenkette zu synthetisieren sowie die Kupplung der erhaltenen Peptide mit anti-Methyl-seco-CBI-DNA-Binder-Derivat, die in Kapitel 8 dargestellt wurden, durchzuführen.

\subsection{Synthese von Tetragastrin}

Die Struktur des 1964 erstmals isolierten Heptadecapeptids Gastrin wurde von H. Gregory et al. kurze Zeit später aufgeklärt und unter anderem durch die erste Totalsynthese von J.C. Anderson et al. bestätigt. ${ }^{85}$ Nachfolgende Untersuchungen $\mathrm{zu}$ StrukturWirkungsbeziehungen ergaben, dass nur das $C$-terminale Tetrapeptid-Amid Trp-Met-Asp-Phe- $\mathrm{NH}_{2}$ für die biologische Wirkung essentiell ist. ${ }^{65}$

\subsubsection{Literaturbekannte Tetragastrinsynthesen}

Auf der Suche nach einem möglichst effizienten Zugang zum Tetragastrin wurden zunächst die schon literaturbekannten Synthesen dieses Systems näher betrachtet. Es gibt zwei Möglichkeiten, je nachdem mit geschützter oder ungeschützter Asparaginsäureseitenkette gearbeitet wird. Das im Schema 9.1 gezeigte Beispiel verwendet eine Synthese mit ungeschützter Asparaginsäureseitenkette. ${ }^{86}$ Der Aktivester der zweifach benzylgeschützten LAsparaginsäure 103 wurde mit dem Salz des L-Phenylalaninamids 104 zum geschützten Dipeptid 105 gekuppelt, welches anschließend hydrogenolytisch zu 106 entschützt wurde. Nach Kupplung des Dipeptides 106 mit dem Boc-geschützten Aktivester von L-Methionin zum Tripeptid 107 konnte die Boc-Schutzgruppe unter sauren Bedingungen entfernt werden. Das Hydrochlorid 108 des Tripeptides wurde schließlich mit dem Boc-geschützten Aktivester von L-Tryptophan zum Boc-geschützten Tetragastrin 109 umgesetzt. Der Nachteil der vorgestellten Sequenz, die auch im größeren Maßstab durchgeführt werden kann, ist die noch relativ hohe Anzahl an Synthesestufen, wobei zusätzlich die eingesetzten Aktivester synthetisiert werden müssen. 


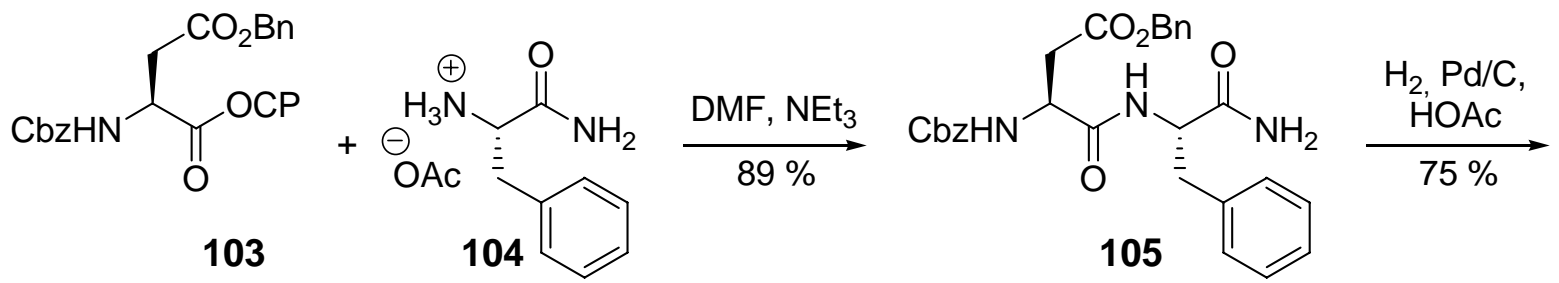

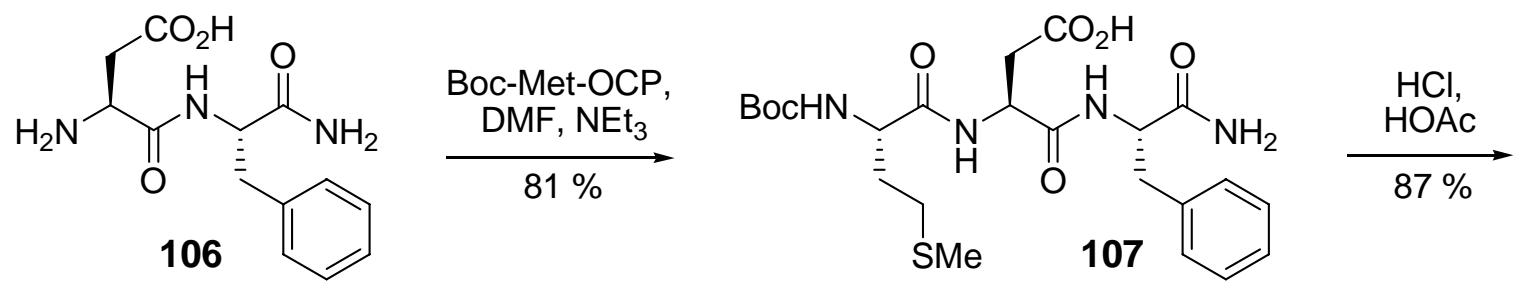

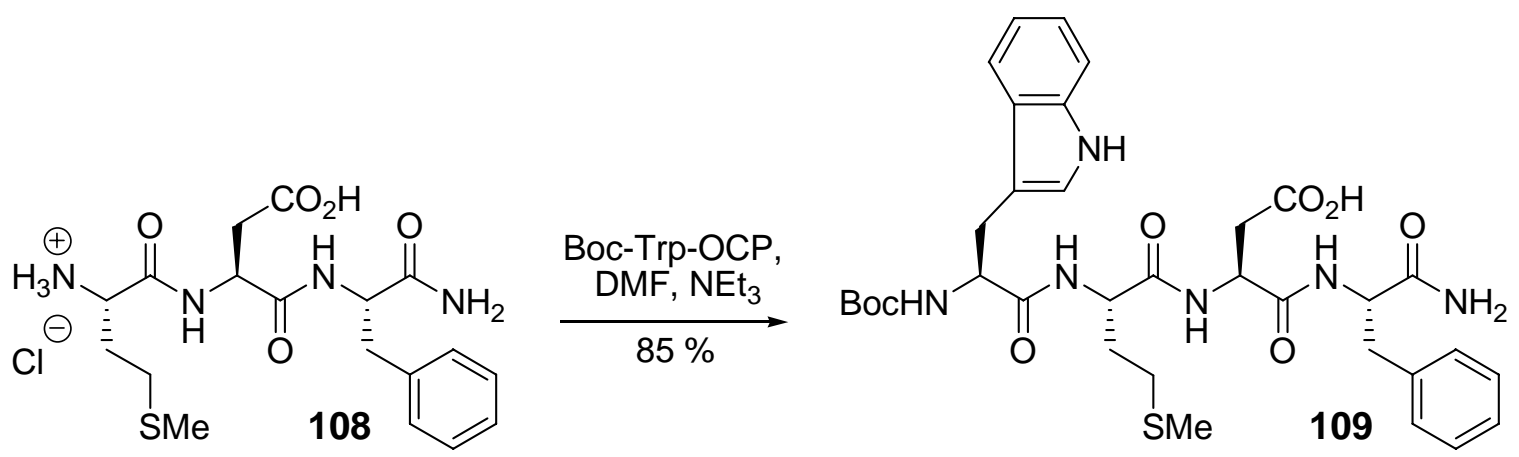

Schema 9.1. Lineare Synthese von Tetragastrin (109) nach J. M. Davey et al.

P. Henklein et al. synthetisierten Tetragastrin mit einer $t$-Butyl-Schutzgruppe in der Asparaginsäureseitenkette. ${ }^{87}$ Der Schlüsselschritt dieser Strategie ist im Schema 9.2 gezeigt, in der eine "2+2"-Synthesestrategie angewandt wurde, die die Kupplung von zwei Dipeptiden zum Tetrapeptid beinhaltet.

Nach Bereitstellung der beiden Dipeptide erfolgte die Kupplung zum zweifach geschützten Tetragastrin (112) unter Aktivierung mit DCC/HONB. Im Vergleich zum stufenweisen Aufbau des Peptides konnten bei der "2+2"-Synthesestrategie drei Reaktionsschritte eingespart werden. 
<smiles>CSCC[C@H](NC(=O)[C@H](Cc1c[nH]c2ccccc12)NC(=O)OCc1ccccc1)C(=O)O</smiles>

110<smiles>CC(C)(C)ONC(=O)CCC(=O)N[C@@H](Cc1ccccc1)C(N)=O</smiles>

111

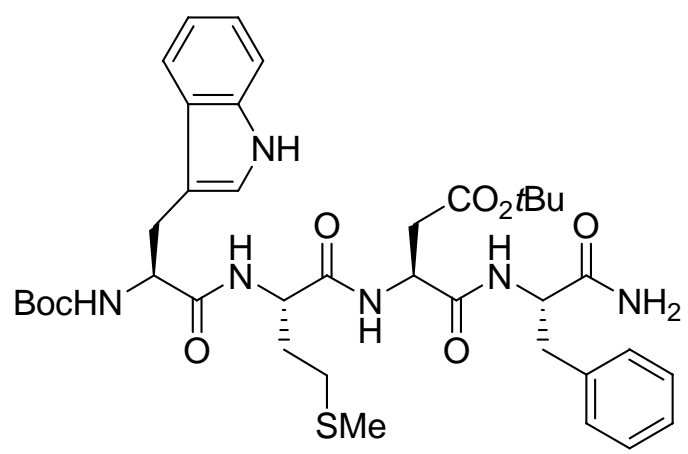

112

Schema 9.2. Schlüsselschritt der "2 + 2"-Synthese von geschütztem Tetragastrin (112) nach P. Henklein.

Bei der Synthese von Tetragastrin wurde in der Literatur von einigen Nebenprodukte berichtet, ${ }^{87}$ wie z.B. Aminosuccinimidbildung an der Asparaginsäure, Substitution am Indolring des Tryptophan sowie Oxidation des Methionins.

Im Arbeitskreis wurden einige Tetragastrinderivate von U. Griesbach ${ }^{88}$ und O. Panknin ${ }^{70}$ dargestellt, jedoch gab es einige ungelöste Probleme, wie z.B. das Dublettsignal im ${ }^{13} \mathrm{C}$ NMR-Spektrum des erhaltenen Tetragastrin. Hierfür wurden in dieser Dissertation noch einige an der Seitenkette geschützte Tetragastrin-Derivate sowie ungeschützes Tetragastrin synthetisiert.

\subsubsection{Synthese an der Seitenkette geschützten Tetragastrins}

In der vorliegenden Arbeit wurden drei Tetragastrinderivate, die an der Asparaginsäureseitenkette mit jeweils Methyl-, Allyl- sowie Benzyl-Schutzgruppen geschützt waren, synthetisiert. Dabei sollte eine "2 + 2"-Synthesestrategie verwendet werden.

Für die Darstellung des $N$-terminalen Dipeptids wurde das käufliche Boc-Trp-OH (113) nach Aktivierung mit HOSu/EDC mit L-Methionin (114) unter Zusatz von Hünig-Base zu 
Boc-Trp-Met-OH (110) in 72\% Ausbeute gekuppelt (Schema 9.3). Anhand von ${ }^{13} \mathrm{C}-\mathrm{NMR}$ Untersuchungen konnte gezeigt werden, dass das Peptid 110 diastereomerenrein erhalten werden konnte, was auch durch den Drehwert $\left([\alpha]_{\mathrm{D}}^{20}=-16.6^{\circ}\right)$ bestätigt wurde. $^{70}$

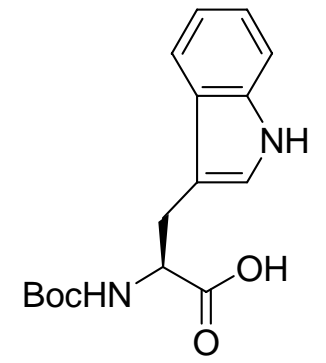

113
1. HOSu, EDC. $\mathrm{HCl}$, $\mathrm{CH}_{2} \mathrm{Cl}_{2}, \mathrm{RT}, 4 \mathrm{~h}$

2. Methion (114), NEtiPr 2 , $\mathrm{THF} / \mathrm{H}_{2} \mathrm{O}, \mathrm{RT}, 12 \mathrm{~h}$

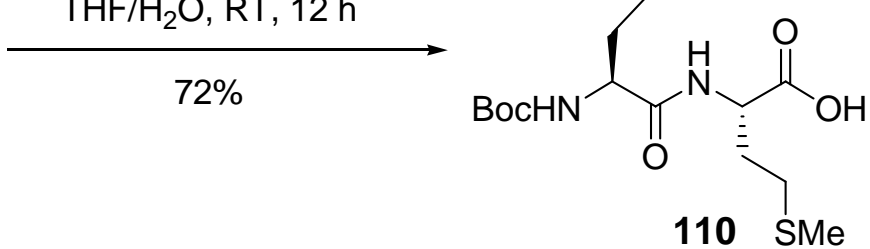

Schema 9.3. Synthese des $N$-terminalen Dipeptides Boc-Trp-Met-OH (110).

Für die Einführung der Schutzgruppe an der Seitenkette wurde L-Asparaginsäure (115) nach der Methode von G. A. Lajoie et al. mit TMSCl in Methanol oder Allylalkohol selektiv an der $\beta$-Carboxylgruppe verestert. ${ }^{89}$ Die so erhaltenen Ester wurden mit Boc-Anhydrid in Boc-Asp( $\beta$-OMe)-OH (117) bzw. Boc-Asp( $\beta$-O-allyl)-OH (118) überführt (Schema 9.4).<smiles>N[C@@H](CC(=O)O)C(=O)O</smiles>

115<smiles>N[C@@H](CC(=O)O)C(=O)O</smiles>

115<smiles>COC(=O)C[C@H]([NH3+])C(=O)O</smiles>

116

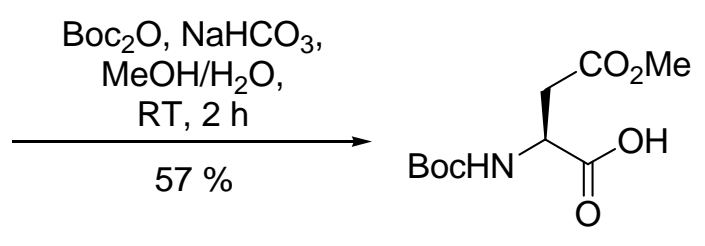

117

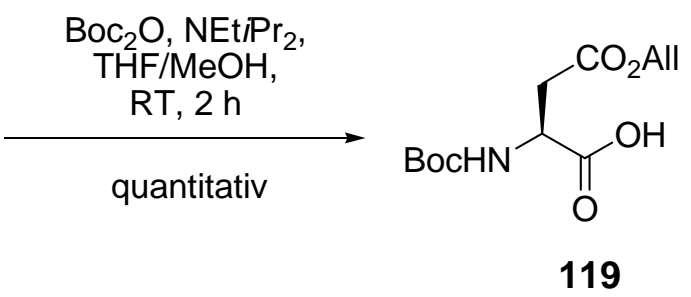

Schema 9.4. Synthese von Boc-Asp(OMe)-OH (117) und Boc-Asp(OAll)-OH (119) .

Zur Darstellung der $C$-terminalen Dipeptide 122 wurde die Carbonsäure der geschützten LAsparaginsäure 117 als gemischtes Anhydrid aktivert, welches in situ hergestellt und mit LPhenylalaninamid (121) in einer Ausbeute von 60 \% zu 110 umgesetzt wurde (Schema 9.5). Ausgehend von 119 oder von kommerziell erhältlicher 120 konnten die Dipeptide 123 bzw. 124 auf dem gleichen Weg mit 94\% bzw. 82\% Ausbeute erhalten werden. 
<smiles>[R]OC(=O)C[C@@H](NC(=O)O)C(=O)O</smiles>

$\mathrm{R}=\mathrm{Me}, \mathbf{1 1 7}$

$\mathrm{R}=\mathrm{All}, 119$

$\mathrm{R}=\mathrm{Bn}, \mathbf{1 2 0}$
1. $\mathrm{ClCO}_{2} \mathrm{Et}, \mathrm{NEt} / \mathrm{Pr}_{2}$, THF, $-18^{\circ} \mathrm{C}$ auf $0{ }^{\circ} \mathrm{C}$, $1 \mathrm{~h}$

2. Phenylalaninamid (121), $\mathrm{H}_{2} \mathrm{O}, 0^{\circ} \mathrm{C}$ auf RT, $2 \mathrm{~h}$

$\mathrm{R}=\mathrm{Me}, 60 \%, 122$

$\mathrm{R}=\mathrm{All}, 94 \%, \mathbf{1 2 3}$

$\mathrm{R}=\mathrm{Bn}, 82 \%, 124$

Schema 9.5. Synthese der geschützten $C$-terminalen Dipeptide.

Im nächsten Schritt wurde das $N$-terminale Dipeptid 110 zuerst mit HOSu/EDC aktiviert, dann mit dem durch Boc-Entschützung von 122 entstandenen C-terminalen Dipeptid gekuppelt. Nach Säulenchromatographie erhielt man in 66\% Ausbeute das Tetrapeptid 125 (Schema 9.6), dessen Reinheit etwa 85\% betrug.

Analog dazu wurde das allylgeschützte Tetrapeptid 126 in einer Ausbeute von 85\% dargestellt, jedoch konnte durch Säulenchromatographie nur eine Reinheit von etwa 70\% erzielt werden.<smiles>[R]OC(=O)CC(NC(=O)[O-])C(=O)N[C@@H](Cc1ccccc1)C(N)=O</smiles>

1. TFA, $\mathrm{CH}_{2} \mathrm{Cl}_{2}, \mathrm{H}_{2} \mathrm{O}$, $\mathrm{RT}, 2 \mathrm{~h}$

2. $110, \mathrm{HOSu}, \mathrm{EDC} \cdot \mathrm{HCl}$ (Nach $2 \mathrm{~h}$ für Aktivierung), NEtiPr 2 , THF/H $\mathrm{H}_{2} \mathrm{O}, \mathrm{RT}, 2 \mathrm{~h}$

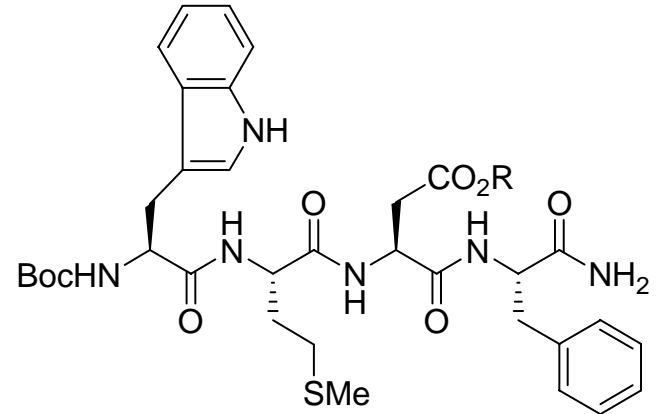

$\mathrm{R}=\mathrm{Me}, 66 \%, 125$ $\mathrm{R}=\mathrm{All}, 85 \%, 126$

Schema 9.6. Synthese der Tetrapeptide 125 und 126.

Das benzylgeschützte Tetrapeptid 127 wurde unter Verwendung von HOBt anstelle von HOSu synthetisiert. Nach Boc-Entschützung unter üblichen Bedingungen sowie präparativer HPLC-Reinigung konnte 128 in einer Ausbeute von $44 \%$ über drei Stufen erhalten werden (Schema 9.7). 
<smiles>CC(C)(C)OC(=O)NC(CC(=O)OCc1ccccc1)C(=O)N[C@@H](Cc1ccccc1)C(N)=O</smiles>

124
1. TFA, $\mathrm{CH}_{2} \mathrm{Cl}_{2}, \mathrm{H}_{2} \mathrm{O}$, $\mathrm{RT}, 2 \mathrm{~h}$

2. $110, \mathrm{HOBt}, \mathrm{EDC} \cdot \mathrm{HCl}$, $\mathrm{NEtiPr}, \mathrm{CH}_{2} \mathrm{Cl}_{2}$ $\mathrm{RT}, 12 \mathrm{~h}$

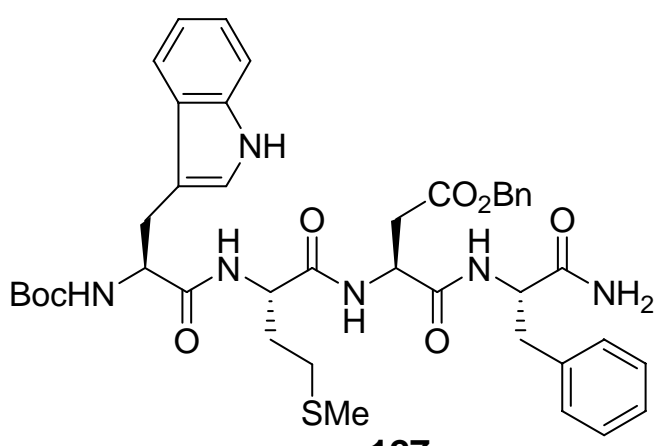

127

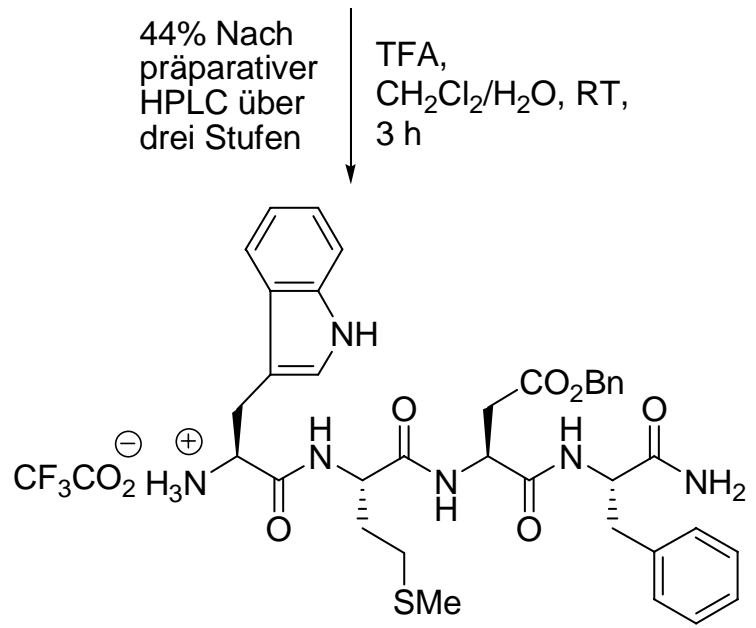

128

Schema 9.7. Synthese des Tetrapeptides 128.

\subsubsection{Synthese von an der Seitenkette ungeschütztem Tetragastrin}

Für die Synthese von an der Seitenkette ungeschütztem Tetragastrin wurden zwei Strategien verwendet.

Ausgehend vom Dipeptid 124 wurde 129 durch Hydrierung in einer Ausbeute von 84\% erhalten, welches nach Boc-Entschützung das entsprechende ungeschützte Dipeptid 130 mit 99\% Ausbeute lieferte (Schema 9.8). 


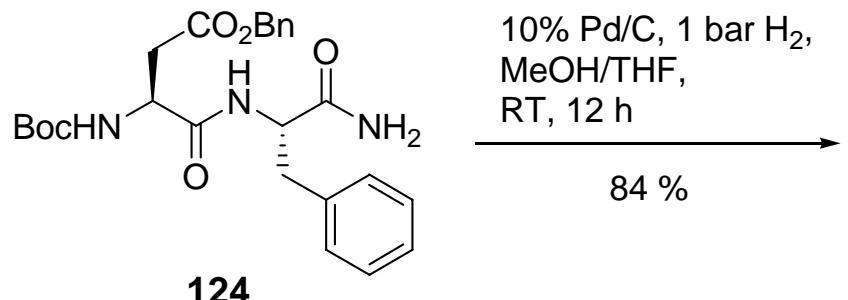<smiles>NC(=O)[C@H](Cc1ccccc1)NC(=O)[C@H](CC(=O)O)NC(=O)O</smiles>

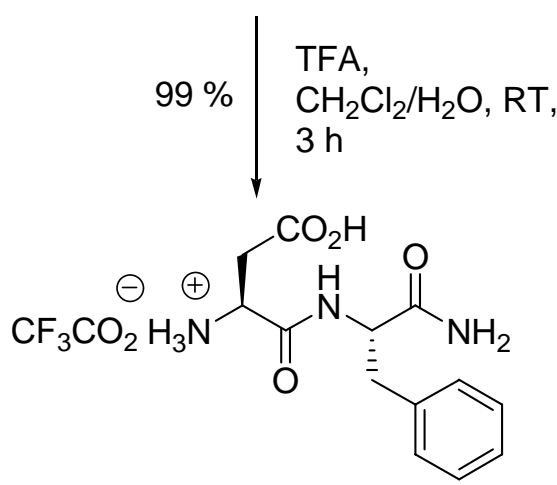

130

Schema 9.8. Synthese des ungeschützten $C$-terminalen Dipeptides (130).

Im nächstem Schritt wurde das $N$-terminale Dipeptid 110 zuerst mit HOBt/EDC aktiviert und dann mit 130 gekuppelt. Nach Boc-Entschützung unter üblichen Bedingungen sowie präparativer HPLC-Reinigung konnte das Tetragastrin 131 als TFA-Salz in einer Ausbeute von $42 \%$ erhalten werden (Schema 9.9). Durch HPLC und NMR-Vergleichsanalyse mit einer kommerziellen Tetragastrinprobe ${ }^{90}$ konnte gezeigt werden, dass diese identisch waren. 

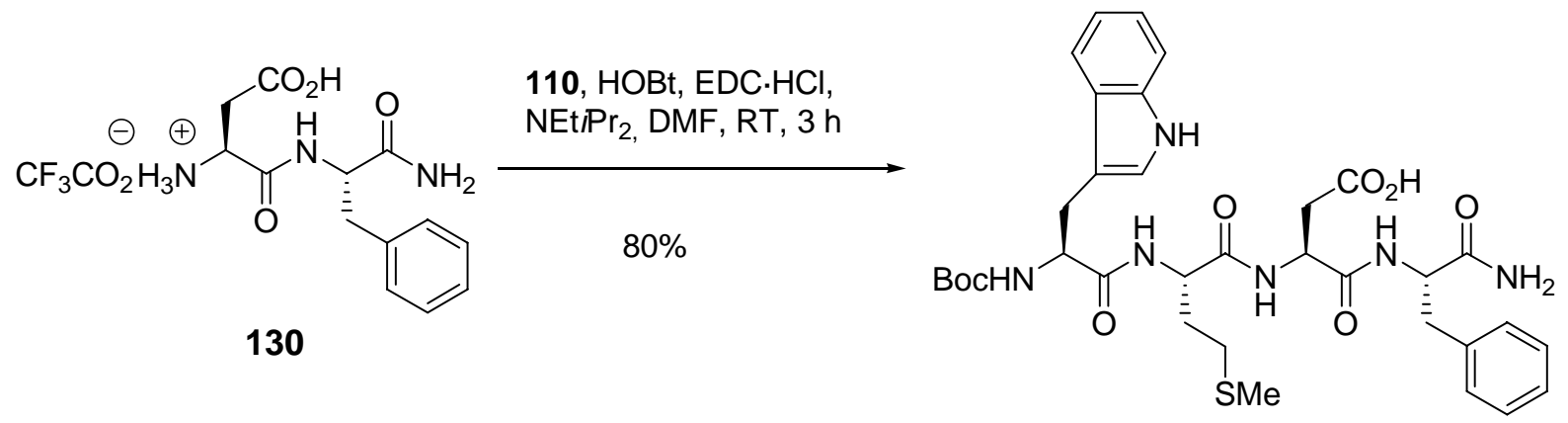

109

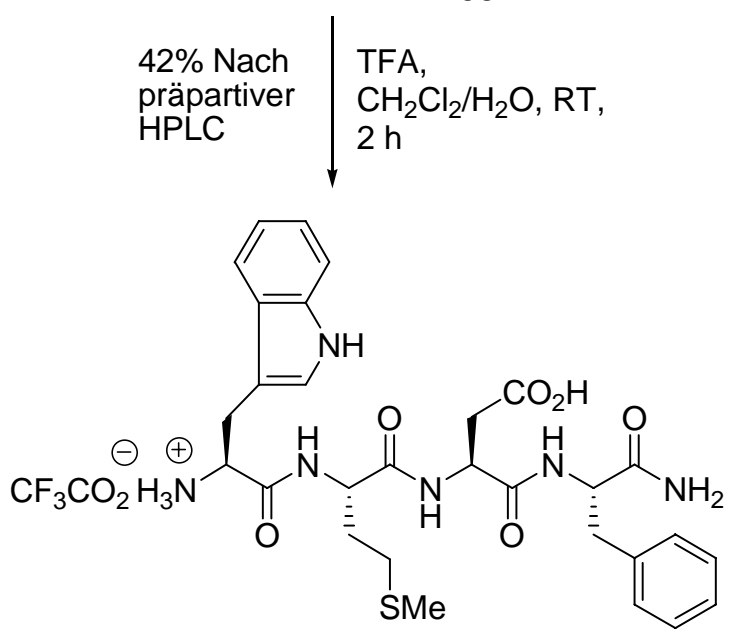

131

Schema 9.9. Synthese des Tetrapeptids 131.

Eine alternative Strategie zur Darstellung von 109 war die direkte Verseifung des Methylesters 125. Es gibt einige literaturbekannte Vorschriften ${ }^{91}$, welche die Verseifung von Asparaginsäure- $\beta$-methylester in Polypeptiden behandeln. In diesem Fall wurde das Edukt 125 mit 2 Äq. Lithiumhydroxid versetzt und die Reaktion nach 5 min Rühren bei Raumtemperatur beendet. Nach Aufarbeitung wurde die Zielverbindung 109 mit 90\% Ausbeute und einer Reinheit von etwa $85 \%$ erhalten. Verlängerung der Reaktionszeit führte zu einer Verdoppelung und Verdreifachung mehrerer Signalen des ${ }^{13} \mathrm{C}-\mathrm{NMR}$-Spektrum, dies ist vermutliche auf eine Isomerisierung der stereogenen Zentren zurückzuführen.<smiles>CCCC[C@H](NC(=O)[C@H](Cc1c[nH]c2ccccc12)NC(C)(C)C)C(=O)N[C@@H](CCSC)C(=O)N[C@H](Cc1ccccc1)C(N)=O</smiles>

125

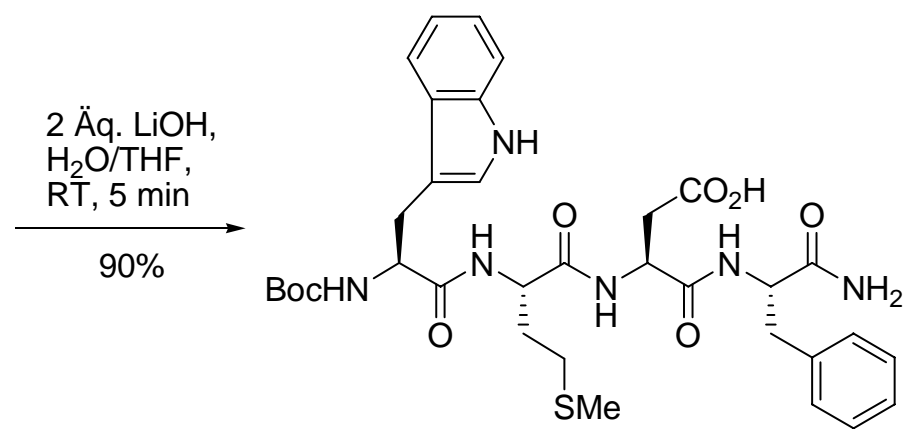

109

Schema 9.10. Verseifung von 125. 


\subsubsection{Diskussion ausgewählter spektroskopischer Daten von 131 und 128}

Die genaue Zuordnung der Signale erfolgte unter Zuhilfenahme von ${ }^{1} \mathrm{H}-{ }^{1} \mathrm{H}$ - und ${ }^{1} \mathrm{H}-{ }^{13} \mathrm{C}$ Korrelationsexperimenten. Im ${ }^{1} \mathrm{H}-\mathrm{NMR}$-Spektrum des erhaltenen Tetragastrins 131 findet man das Signal für $2 \mathrm{c}-\mathrm{H}_{\mathrm{a}}$ als Multiplett im Bereich von $\delta=1.81-1.87$ und für $2 \mathrm{c}-\mathrm{H}_{\mathrm{b}}$ als Multiplett im Bereich von $\delta=1.94-2.00$. Für die Methylgruppe am Schwefel des Methionins beobachtet man ein Singulett bei $\delta=2.05$. Die Signale der beiden diastereotopen Protonen an C-2c fallen in einem Multiplett im Bereich von $\delta=2.42-2.52$ zusammen. Die anderen Protonen der Methlenguppen resonieren je als ein Dublett von Dubletts, wie z.B. $2 b-\mathrm{H}_{\mathrm{b}}$ bei $\delta=2.71(J=16.2,6.6 \mathrm{~Hz}), 2 \mathrm{a}-\mathrm{H}_{\mathrm{b}}$ bei $\delta=3.06(J=13.8,5.4 \mathrm{~Hz})$ und $2 \mathrm{~d}-\mathrm{H}_{\mathrm{b}}$ bei $\delta=3.29(J=$ 15.0, $5.4 \mathrm{~Hz})$.

Charakteristische Signale des Tetrapeptids sind die Multipletts für die $\alpha$-Protonen an den Stereozentren der Aminosäuren, so findet man für das 1d-H, 1c-H, 1a-H und 1b-H Multipletts zwischen $\delta=4.11$ und 4.60 .

Im Bereich der aromatischen Protonen findet man für das $5 \mathrm{~d}^{\prime}-\mathrm{H}$ bei $\delta=7.02$ ein Triplett mit einer Kopplungskonstante von $J=7.2 \mathrm{~Hz}$ und für das $6 \mathrm{~d}$ '-H bei $\delta=7.10$ ein Triplett mit einer identischen Kopplungskonstante. Der Phenylring des Phenylalaninamids kann dem Multiplett im Bereich von $\delta=7.17-7.27$ zugeordnet werden. Im tieferen Feld liegen zwei weitere Signale des Indols. Das 7d'-H resoniert als Dublett bei $\delta=7.38$ mit einer ortho-Kopplung von $J=7.2 \mathrm{~Hz}$ und das 4d'-H ebenfalls als Dublett bei $\delta=7.68$ mit einer ortho-Kopplung von $J=7.8 \mathrm{~Hz}$ zum $5 \mathrm{~d}^{\prime}-\mathrm{H}$. Im Anschluss an die aromatischen Protonen findet man weitere NHProtonen im Bereich von $\delta=7.67-8.58$. Das Indol-NH des Tryptophans resoniert typischerweise am weitesten tieffeldverschoben als Singulett bei $\delta=10.80$.

Im ${ }^{13} \mathrm{C}-\mathrm{NMR}-$ Spektrum erkennt man das Signal der Methionin-Methylgruppe bei $\delta=14.28$ Die fünf Signale der alkylischen $\mathrm{CH}_{2}$-Gruppen zwischen $\delta=26.96$ und 37.18. Von $\delta=49.52$ bis $\delta=53.62$ resonieren die $\alpha$-C-Atome der Aminosäuren. Die aromatischen C-Atome können den Signalen im Bereich von $\delta=106.7$ bis $\delta=137.4$ zugeordnet werden. Die carbonylischen C-Atome zeigen charakteristische Verschiebungen im Bereich von $\delta=168.1$ bis $\delta=172.1$. Daneben bestätigt ein hochaufgelöstes ESI-Massenspektrum die angenommene Struktur. 


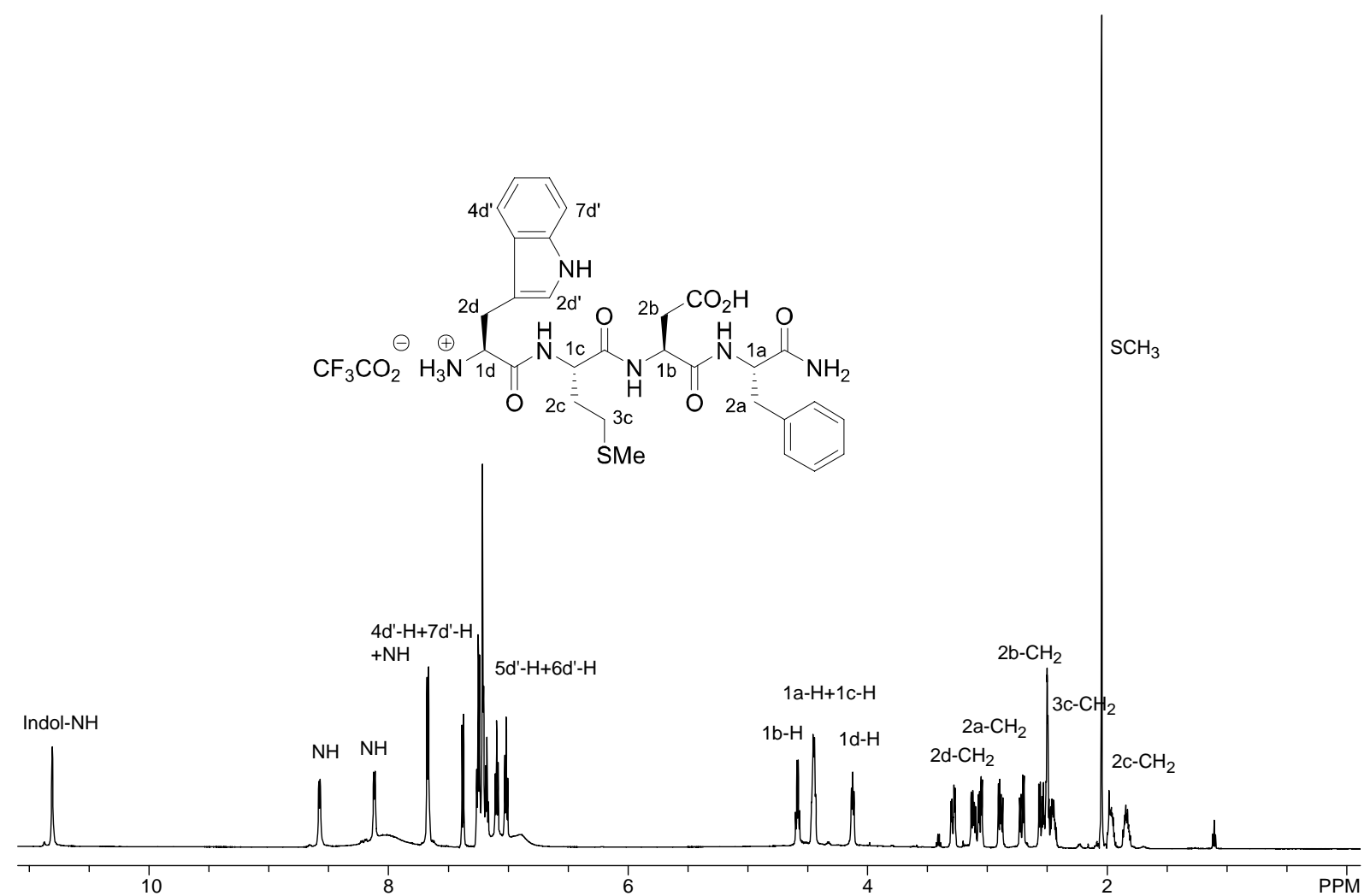

Abb. 9.1. ${ }^{1} \mathrm{H}-\mathrm{NMR}-\mathrm{Spektrum}$ von $131\left(600 \mathrm{MHz}, \mathrm{DMSO}-\mathrm{d}_{6}, 80^{\circ} \mathrm{C}\right)$.

Für die erhaltenen Tetragastrin-Derivate, die an der Asparaginsäureseitenkette geschützt sind, ist in der Abb. 9.2 das ${ }^{1}$ H-NMR-Spektrum des Benzylesters 128 als Beispiel gezeigt. Im Vergleich zu dem ungeschützten Tetragastrin 131 resultieren aus der Einführung der Benzylschutzgruppe nur wenig Unterschiede. Bemerkungswert ist die Verschiebung beider diastereotopen Protonen an C-2c zum tiefen Feld von 0.12 ppm.

Die zwei benzylische Protonen des Benzylesters resonieren als Singulett bei $\delta=5.09$. Auch im ${ }^{13} \mathrm{C}$-NMR-Spektrum findet man das Signal für das benzylishe C-Atom bei $\delta=65.33$.

Daneben bestätigt ein hochaufgelöstes ESI-Massenspektrum die angenommene Struktur. 


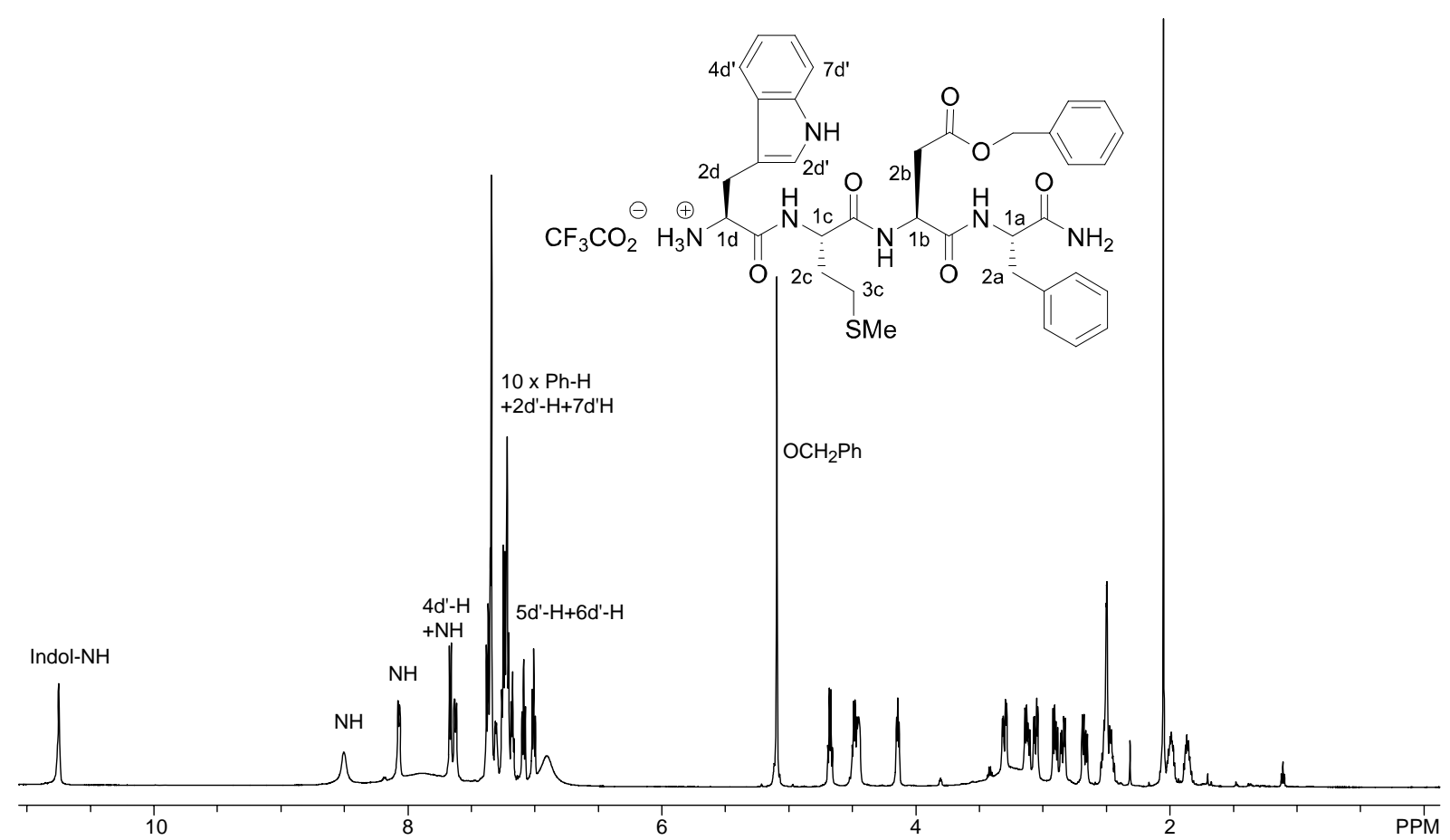

Abb. 9.2. ${ }^{1} \mathrm{H}-\mathrm{NMR}-S p e k t r u m$ von $128\left(600 \mathrm{MHz}, \mathrm{DMSO}-\mathrm{d}_{6}, 100{ }^{\circ} \mathrm{C}\right)$.

\subsection{Synthese der anti-Methyl-seco-CBI-DNA-Binder-Tetragastrin- Derivate}

In diesem Kapitel wurde die Kupplung zwischen dem seco-Drug mit einem DNA-Binder und dem Peptid durchgeführt. Für den Drug-Teil wurde zunächst die Carbonsäure 88 verwendet, während die an der Seitenkette geschützen Tetragastrin-Derivate 132 und 128 als Peptid-Teil dienten.

Zuerst wurde 125 durch Boc-Entschützung mit nachfolgender präparativen HPLC-Reinigung in 132 mit 88\% Ausbeute überführt (Schema 9.11).<smiles>CCCC[C@H](NC(=O)C(Cc1c[nH]c2ccccc12)NC(C)(C)C)C(=O)N[C@@H](CC(C)=O)C(=O)N[C@@H](Cc1ccccc1)C(N)=O</smiles>

125
TFA, $\mathrm{CH}_{2} \mathrm{Cl}_{2}, \mathrm{H}_{2} \mathrm{O}$, $\mathrm{RT}, 3 \mathrm{~h}$

$88 \%$ nach präparativer HPLC

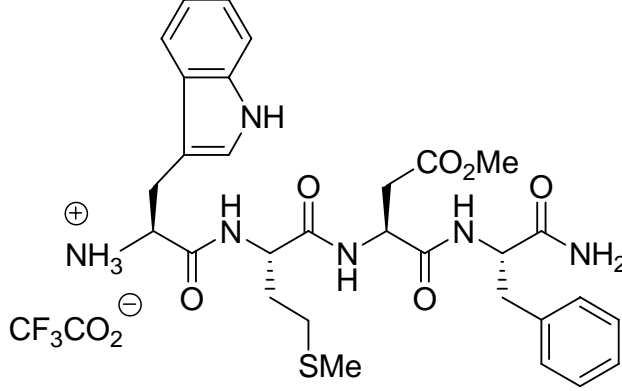

132

Schema 9.11. Synthese von 132. 
Die Carbonsäure 88 wurde mit HOBt sowie EDC aktiviert und anschließend mit dem Peptid 132 in Gegenwart von Hünig-Base umgesetzt. Das Zielmolekül 133 wurde nach Chromatographie an Kieselgel in eine Ausbeute von 49\% erhalten (Schema 9.12). In den ${ }^{13} \mathrm{C}$ NMR-Spektren wurde nur ein Signalsatz gefunden, obwohl die Verbindungen 133 und 134 als Gemisch zweier Diastereomere vorliegen, da $\mathbf{8 8}$ als racemisches Gemisch eingesetzt wurde.

Analog dazu wurde die Verbindung 134, die an der Asparaginsäureseitenkette eine Benzylschutzgrupe besitzt, in einer Ausbeute von $71 \%$ synthetisiert.<smiles>CC(Cl)C1CN(C(=O)c2cc3cc(OCCN(C)CCC(=O)O)ccc3[nH]2)c2cc(Cc3ccccc3)c3ccccc3c21</smiles>

1. $\mathrm{HOBt}, \mathrm{EDC} \cdot \mathrm{HCl}$, DMF

2. 132 oder $\mathbf{1 2 8}$, NEtiPr ${ }_{2}$, RT, $12 \mathrm{~h}$

88<smiles></smiles>

$\mathrm{R}=\mathrm{Me}, 49 \%, 133$

$\mathrm{R}=\mathrm{Bn}, 71 \%, 134$

Schema 9.12. Synthese von 133 und 134.

Auf dem gleichen Weg wurde das Molekül 135 synthetisiert, welches anschließend durch die Spaltung des Allylesters in 136 überführt werden konnte. Die Ausbeute betrug 21\% über drei Stufen (Schema 9.13).

Die Spaltung des Allylesters in 135 gelang mit Tetrakis(triphenylphosphan)palladium $(0)^{92}$ als Katalysator und Pyrrolidin als Nucleophi1 ${ }^{93}$ in einer Tsuji-Trost-artigen allylischen Substitution. ${ }^{94}$ 
<smiles>CS(=O)(=O)CC[C@H](NC(=O)C(Cc1c[nH]c2ccccc12)NS(C)(=O)=O)C(=O)N[C@@H](CC(=O)OCc1ccccc1)C(=O)N[C@@H](Cc1ccccc1)C(N)=O</smiles>

126
1. TFA, $\mathrm{CH}_{2} \mathrm{Cl}_{2}, \mathrm{H}_{2} \mathrm{O}$, $\mathrm{RT}, 2 \mathrm{~h}$

2. 88, $\mathrm{HOBt}, \mathrm{EDC} \cdot \mathrm{HCl}$, NEtiPr, DMF, $\mathrm{RT}, 12 \mathrm{~h}$<smiles>CSCC[C@H](NC(=O)[C@H](Cc1c[nH]c2ccccc12)NC(=O)CCN(C)CCOc1ccc2[nH]c(C(=O)N3C[C@@H](C(C)Cl)c4c3cc(C)c3ccccc43)cc2c1)C(=O)N[C@@H](CC(=O)O)C(=O)N[C@@H](Cc1ccccc1)C(N)=O</smiles>

135 \begin{tabular}{l|l}
$\begin{array}{l}\text { 21\% über drei Stufen } \\
\text { nach präparativer } \\
\text { HPLC }\end{array}$ & $\begin{array}{l}\mathrm{Pd}\left(\mathrm{PPh}_{3}\right)_{4}, \mathrm{PPh}_{3} \\
\text { Pyrrolidin, } \mathrm{CH}_{3} \mathrm{CN}, \mathrm{DMF} \\
\mathrm{RT}, 2 \mathrm{~h}\end{array}$
\end{tabular}<smiles>CSCC[C@H](NC(=O)[C@H](Cc1c[nH]c2ccccc12)NC(=O)CC[NH+](C)CCOc1ccc2[nH]c(C(=O)N3C[C@H](C(C)Cl)C4=C3C=C3OCC(=CC=CC=C4)c4ccccc43)cc2c1)C(=O)N[C@@H](CC(=O)O)C(=O)N[C@@H](Cc1ccccc1)C(N)=O</smiles>

Schema 9.13. Synthese von 136.

Ausgehend vom 136 sollte das freie Toxin durch Spaltung des Benzylethers erhalten werden (Schema 9.14). Dazu wurden die für die Entschützung des Benzylesters 88 etablierten Bedingungen mit Palladium auf Aktivkohle und Wasserstoff getestet, jedoch gelang die Umsetzung nicht (Tabelle 9.1, Eintrag 1). Unter Transferhydrierung-Bedingungen ${ }^{95}$ bei $40{ }^{\circ} \mathrm{C}$ in Ameisensäure und Methanol zersetzte sich 136. Im Massenspektrum war lediglich das Oxidationsprodukt von 136 nachzuweisen, welches durch Oxidation des Thioethers in der Methioninseitenkette entstand. 
<smiles>CSCC[C@H](NC(=O)[C@H](Cc1c[nH]c2ccccc12)NC(=O)CC[NH+](C)CCOc1ccc2[nH]c(C(=O)N3C[C@H](C(C)Cl)c4c3cc(I)c3ccccc43)cc2c1)C(=O)N[C@@H](CCC(=O)O)C(=O)N[C@@H](Cc1ccccc1)C(N)=O</smiles>

\section{6}<smiles>CSCC[C@H](NC(=O)[C@H](Cc1c[nH]c2ccccc12)NC(=O)CCN(C)CCOc1ccc2[nH]c(C(=O)N3C[C@H](C(C)Cl)c4c3cc(O)c3ccccc43)cc2c1)C(=O)N[C@@H](CC(=O)O)C(=O)N[C@@H](Cc1ccccc1)C(N)=O</smiles>

137

Schema 9.14. Versuche zur Debenzylierung von 136.

\begin{tabular}{lccll}
\hline Nr. & Katalysator & Bedingungen & T & Ergebnis \\
\hline 1 & $10 \% \mathrm{Pd} / \mathrm{C}$ & 1 bar $\mathrm{H}_{2}, \mathrm{THF} / \mathrm{MeOH}$ & $\mathrm{RT}$ & keine Reaktion \\
2 & $10 \% \mathrm{Pd} / \mathrm{C}$ & $\mathrm{HCO}_{2} \mathrm{H} / \mathrm{MeOH}$ & $40{ }^{\circ} \mathrm{C}$ & Zersetzung \\
\hline
\end{tabular}

Tabelle 9.1. Versuche zur 137 durch Debenzylierung.

Die Entschützung des Benzylethers in 133 sowie 134 unter den in Tabelle 9.1 angegebenen Bedingungen gelang ebenfalls nicht. Ein möglicher Grund könnte in einer Inhibierung des Katalysators durch den Thioester des Methionins liegen.

Aus diesem Grund wurde nach einer Möglichkeit gesucht, die phenolische Hydroxyfunktion während der Synthese ungeschützt zu lassen. Hierzu wurden unterschiedliche Bedingungen (Tabelle 9.2) für die Kupplung zwischen dem Drug-Teil 100 und dem Peptid-Teil 131 getestet, jedoch versagten alle verwendeten Bedingungen. O.Panknin hat gezeigt ${ }^{70}$, dass das Drug-Peptid-Derivat 30 durch Ausbildung vom Aktivester mittels HOSu/EDC synthetisiert 
werden konnte. Im Fall der Carbonsäure 100 war jedoch die Bildung des Aktivesters nicht erfolgreich (Eintrag 1). Beim Einsatz des sehr reaktiven HATU erhielt man ein untrennbares Gemisch, das jedoch im Massenspektrum den gewünschten Molekülpeak zeigte (Eintrag 2). Wurden jedoch drei Äquivalente HATU und HOAt eingesetzt um einen vollständigen Umsatz $\mathrm{zu}$ erzielen, trat die bereits beschriebene Nebenreaktion der Aminosuccinimidbildung auf, was sowohl im Massenspektrum sowie im ${ }^{1}$ H-NMR-Spektrum zu erkennen war (Eintrag 3). Der Einsatz von EDC und HOBt als Aktivatoren lieferte ebenfalls ein untrennbares Produktgemisch, in dem wiederum die Bildung des Aminosuccinimids nachgewiesen werden konnte (Eintrag 4).<smiles>CC#CC</smiles><smiles>CSCC[C@H](NC(=O)[C@H](Cc1c[nH]c2ccccc12)NC(=O)CCN(C)CCOc1ccc2[nH]c(C(=O)N3C[C@H](C(C)Cl)c4c3cc(O)c3ccccc43)cc2c1)C(=O)N[C@@H](CC(=O)O)C(=O)N[C@@H](Cc1ccccc1)C(N)=O</smiles>

Schema 9.15. Versuche zur Synthese von 137 durch Kupplung.

\begin{tabular}{lccl}
\hline Nr. & Kupplungsreagenz & $\begin{array}{c}\text { Äq. des } \\
\text { Kupplungsreagenzes }\end{array}$ & Ergebnis \\
\hline 1 & HOSu/EDC & 2 & kein Aktivester gebildet \\
2 & HATU/HOAt & 1 & Gemisch \\
3 & HATU/HOAt & 3 & Gemisch \\
4 & HOBt/EDC & 1 & Gemisch \\
\hline
\end{tabular}

Tabelle 9.2. Versuche zur Synthese von 137 durch Kupplung. 


\subsubsection{Diskussion ausgewählter spektroskopischer Daten von 133 und 136}

Die genaue Zuordnung der Signale erfolgte unter Zuhilfenahme von ${ }^{1} \mathrm{H}-{ }^{1} \mathrm{H}$ - und ${ }^{1} \mathrm{H}-{ }^{13} \mathrm{C}$ Korrelationsexperimenten. Das ${ }^{1} \mathrm{H}-\mathrm{NMR}-$ Spektrum von 133 setzt sich im Wesentlichen aus den Einzelspektren für das Drug und das Tetrapeptid zusammen. So findet man das Signal der 11- $\mathrm{CH}_{3}$-Gruppe bei $\delta=1.65$ als Dublett mit einer Kopplungskonstante von $J=6.0 \mathrm{~Hz}$. Die beide Multipletts im Bereich von $\delta=1.77-1.83$ und $\delta=1.88-2.04$ entsprechen den diastereotypen Protonen am C-2 Atom. Man beobachtet für die Methylgruppe am Schwefel des Methionins ein Singulett bei $\delta=2.01$ und für Methylamingruppe ein Singulett bei $\delta=2.21$. Die Signale der alkylischen $\mathrm{CH}_{2}$-Gruppen von Tetragastrin findet man im Bereich von $\delta=2.25-3.17$, meistens als Multiplett. Im diesem Bereich resonieren auch 2, ', $-\mathrm{H}, 1$ ', '-H und 2"-H. Man erkennt das Signal für den Methylester bei $\delta=3.57$ als Singulett. Die $\alpha$ Protonen an den Stereozentren der Aminosäuren resonieren als Multipletts im Bereich von $\delta=4.32-4.64$. Die Signale der beiden benzylischen Protonen des Benzylethers spalten als Multiplett im Bereich von $\delta=5.30-5.33$ auf. Die Protonen des aromatischen Systems resonieren im Bereich von $\delta=6.92-8.24$, darunter findet man für 6'-H ein Dublett bei $\delta=6.92(J=8.4 \mathrm{~Hz})$, für $5 \mathrm{~d}$ '-H ein Triplett bei $\delta=6.97(J=7.2 \mathrm{~Hz})$, für $6 \mathrm{~d}$ '-H ein Triplett bei $\delta=7.06(J=7.2 \mathrm{~Hz})$, für $9-\mathrm{H}$ ein Dublett bei $\delta=7.97(J=8.4 \mathrm{~Hz})$ sowie für $6-\mathrm{H}$ ein Dublett bei $\delta=8.24(J=8.4 \mathrm{~Hz})$. Zum tiefen Feld verschoben resonieren die zwei Indol-NH bei $\delta=10.78$ und $\delta=11.61$ je als breites Singulett.

Mit Hilfe des ${ }^{1} \mathrm{H}^{13} \mathrm{C}$-Korrelationsexperimentes konnten die für das ${ }^{1} \mathrm{H}-\mathrm{NMR}-$ Spektrum getroffenen Zuordnungen direkt auf das Kohlenstoffspektrum übertragen werden. So findet man die charakteristischen Verschiebungen für $\mathrm{SCH}_{3}$-Gruppe bei $\delta=14.54$, für $\mathrm{C}-11$ bei $\delta=23.32$ sowie für die $\mathrm{NCH}_{3}$-Gruppe bei $\delta=41.78$. Die fünf Signale der alkylischen $\mathrm{CH}_{2}$ Gruppen von Tetragastrin findet man bei $\delta=27.20-37.29$, während die $\alpha$-C-Atome der Aminosäuren bei $\delta=49.51-53.89$ resonieren. Die Aromatischen C-Atome resonieren im Bereich von $\delta=98.41$ bis $\delta=142.1$. Charakteristischen Verschiebungen weisen die Sauerstoff-substituierte C-Atome C-5 / C-5' bei $\delta=152.9$ / 154.2 auf. Die sieben Carbonyl-CAtome resonieren typischerweise bei $\delta=160.1-172.3$.

Das ${ }^{1} \mathrm{H}-\mathrm{NMR}-$ Spektrum von 136 (Abb. 9.4) zeigt eine wesentliche Ähnlichkeit zum Spektrum von 133. Nennenswert ist das Fehlen eines Signals für den Allylester von seinem Vorläufer 135. Außerdem findet man ein typisches breites Singulett bei $\delta=12.39$ für die Carbonsäure. 
Daneben bestätigen hochaufgelöste ESI-Massenspektren die angenommene Struktur von 133 und 136.

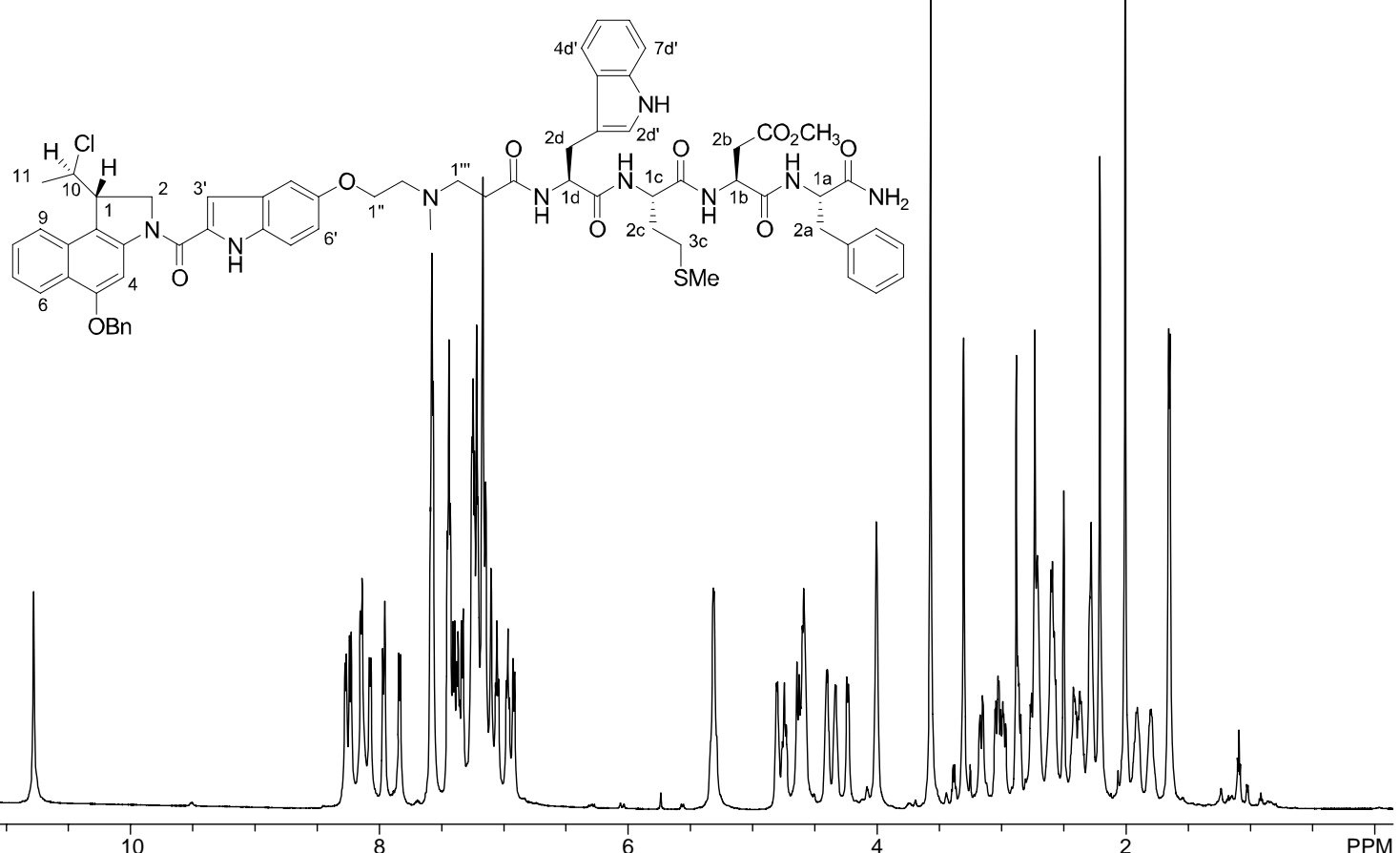

Abb. 9.3. ${ }^{1} \mathrm{H}-\mathrm{NMR}-$ Spektrum von 133 (600 MHz, DMSO-d $\left.{ }_{6}\right)$.
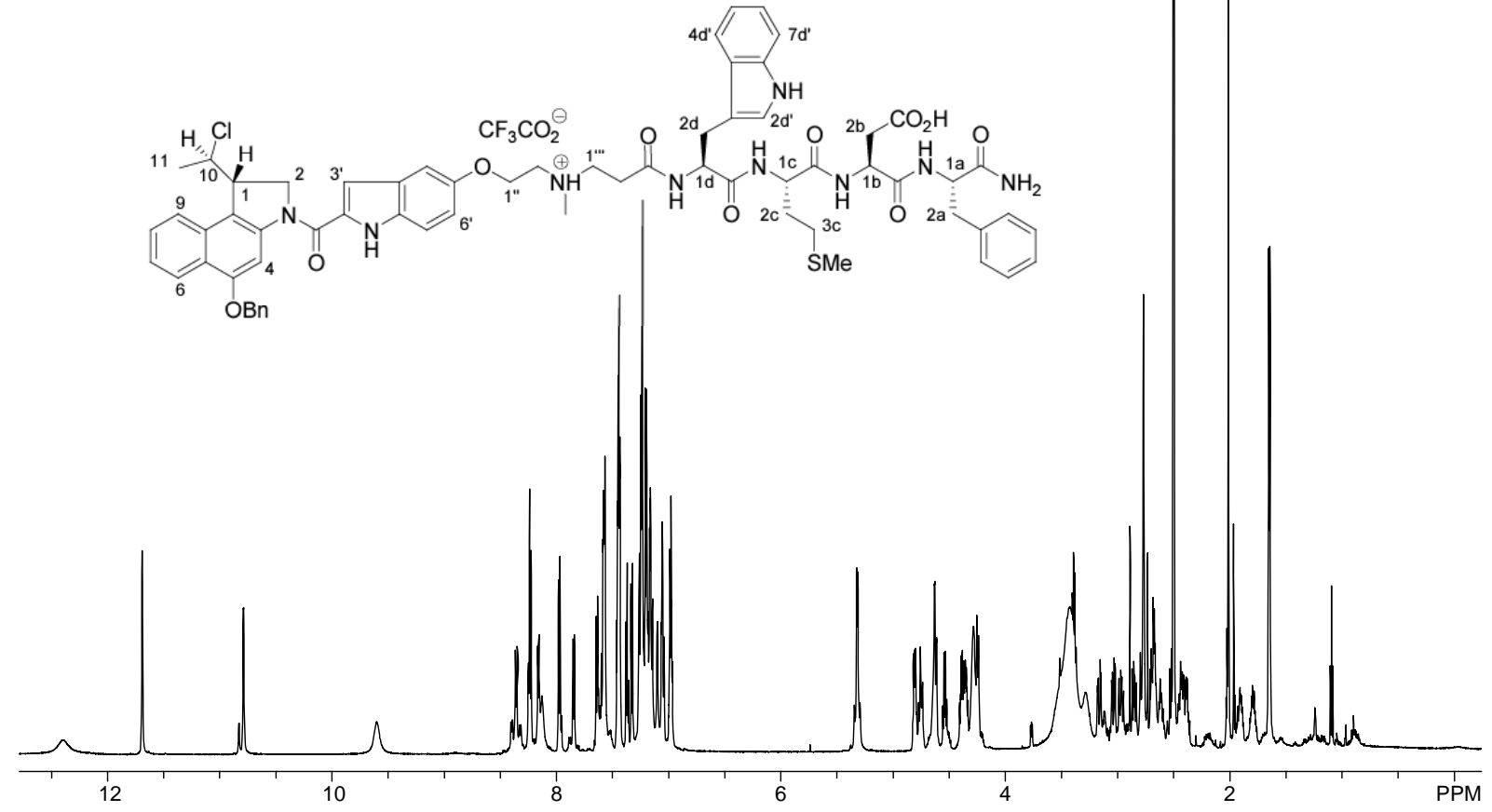

Abb. 9.4. ${ }^{1} \mathrm{H}-\mathrm{NMR}-\mathrm{Spektrum}$ von 136 (600 MHz, DMSO-d 6 ). 


\section{Synthese des anti-Methyl-seco-CBI-DMAI-Carbamat- Derivats}

Organische Carbamate finden in der Medizin eine breite Anwendung als Antikrebs- und Antimalariamittel sowie als antimikrobielle Wirkstoffe ${ }^{96}$. Sie können einerseits direkt als Drug oder auch - wie beispielweise in der Krebstherapie üblich - als Prodrug eingesetzt werden. Für die Entwicklung eines Antikrebs-Prodrugs ist es wichtig, die freie phenolische Hydroxylgruppe, die im Allgemeinen für die Zytotoxizität notwendig ist, in Form eines Carbamats zu maskieren. Die Einführung eines Carbamat-Prodrugs kann hinsichtlich einer verbesserten Pharmakokinetik, der Synthese-Sicherheit in großem Maßstab sowie einer selektiven Überführung in das entsprechende toxische Drug in der Tumorzelle vorteilhaft sein.

Carzelesin (25) und KW2189 sind zwei CC-1065-Analoga mit einer Carbamatgruppe und wurden klinisch getestet (Kapitel 4.2). D. L. Boger et al. hatten auch verschiedene carbamathaltige Analoga von CC-1065 synthetisert und die in vitro Zytotoxizität getestet ${ }^{97}$.

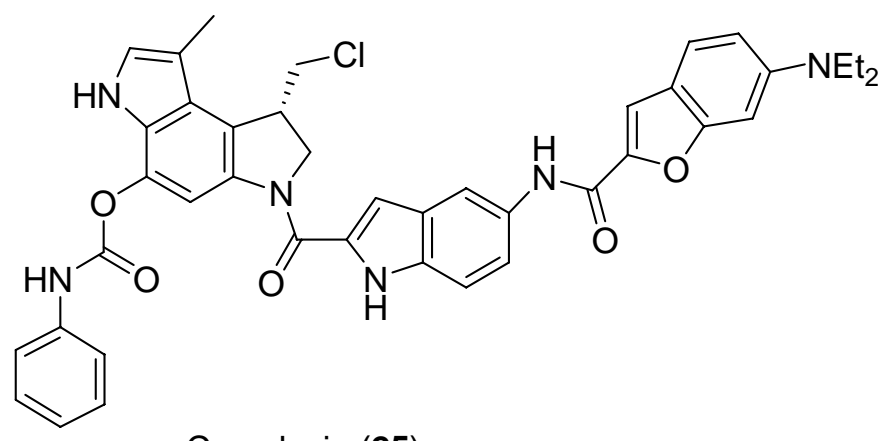

Carzelesin (25)

Abb. 10.1. Struktur von 25.

Aufgrund der hervorragenden in vitro Ergebnisse der von F. Major synthetisierten antiMethyl-seco-CBI-DMAI-Verbindungen (Abb. 4.5), ${ }^{59}$ wurde in diesem Teil der Arbeit versucht, ein Prodrug daraus zu entwickeln, das eine Carbamat-Einheit beinhalten sollte.

Hierzu wurde zuerst das Drug 22 nach F. Major synthetisiert ${ }^{59}$ und anschließend mit dem Chlorameisensäure-4-nitrophenylester (138) unter Zusatz von Hünig-Base aktiviert. Da das so entstandene Zwischenprodukt 139 nicht hinreichend stabil war, wurde es direkt mit das Hexylamin versetzt und das Carbamat-Derivat 140 in einer Ausbeute von 47\% über zwei Stufen erhalten. 
<smiles>CC(Cl)[C@H]1CN(C(=O)c2cc3cc(OCCN(C)C)ccc3[nH]2)c2cc(O)c3ccccc3c21</smiles>

22

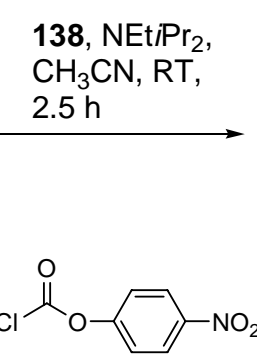

138<smiles>CC(Cl)[C@H]1CCN(C(=O)c2cc3cc(OCCN(C)C)ccc3[nH]2)c2cc(OC(=O)Oc3ccc([N+](=O)[O-])cc3)c3ccccc3c21</smiles>

10 Äq. Hexylamin, $\mathrm{CH}_{3} \mathrm{CN}, \mathrm{RT}, 1 \mathrm{~h}$ zwei Stufe<smiles>CCCCCCNC(=O)Oc1cc2c(c3ccccc13)[C@@H](C(C)Cl)CN2C(=O)c1cc2cc(OCCN(C)C)ccc2[nH]1</smiles>

140

Schema 10.1. Synthese des Carbamat-Prodrugs 140. 


\section{In vitro-Zytotoxizitätsuntersuchungen}

Im Rahmen dieser Arbeit wurden mit den synthetisierten anti-Methyl-seco-CBI-Derivaten 100, 101, 102, den entsprechenden benzylgeschützten Verbindungen 88, 89, 91 und dem Carbamat 140 in vitro-Zellversuche durchgeführt.

\subsection{Der HTCFA-Test zur Bestimmung der Zytotoxizitäten}

Die Bestimmung der Zytotoxizitäten erfolgte durch einen Klonogenitätstest, der sich an den

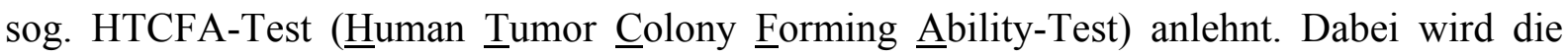
Proliferationsfähigkeit einzelner Zellen untersucht. Als Zelllinie diente das adhärent wachsende humane Bronchialkarzinom der Linie A549.

Die Aussaat der Tumorzellen erfolgte aus einer Stammkultur, in der sie in einem Kulturmedium (DMEM mit Zusatz von $10 \%$ fötalem Kälberserum, $44 \mathrm{mM} \mathrm{NaHCO}_{3}$ und $4 \mathrm{mM}$ Glutamin) bei $37{ }^{\circ} \mathrm{C}$ und $7.5 \% \mathrm{CO}_{2}$-Begasung in Luft permanent gehalten wurden, in Konzentrationen von $10^{2}$ bis $10^{5}$ Zellen in 6-well Multischalen (Schema 11.1). Nach 24 Stunden entfernte man das Kulturmedium, wusch die Zellen einmal mit dem serumfreien Inkubationsmedium UltraCulture und inkubierte anschließend in diesem Medium 24 Stunden mit 10 bis 12 verschiedenen Konzentrationen (3 Log-Stufen) der zu testenden Substanz. Diese wurde vorher frisch in einer DMSO-Stocklösung angesetzt und mit dem Inkubationsmedium verdünnt, so dass in den Näpfen letztlich eine Konzentration von 1 \% DMSO vorlag.

Nach Entfernen der Testsubstanz und einem weiteren Waschgang wurden die verbliebenen Zellen 12 Tage kultiviert. Anschließend wurde das Kulturmedium entfernt, die entstandenen Klone getrocknet, mit Löfflers Methylenblau angefärbt und ab einer Klongröße von ca. $500 \mu \mathrm{m}$ makroskopisch ausgezählt. Die Bestimmung der relativen Klonbildungsraten erfolgte anhand der in (Schema 11.1) angegebenen Formel, wobei sich die Klonzahl des Kontrollversuches aus unbehandelten Zellen ergab und gleich $100 \%$ gesetzt wurde. Soweit nicht anders angegeben, wurde jede Versuchsreihe in der Regel dreimal durchgeführt, um reproduzierbare Testergebnisse zu erzielen. 


\section{Stammkultur}

(z. B. humane Bronchialkarzinomzellen der Linie A549)

ת

Ablösen der adhärent wachsenden Zellen mit Trypsin / EDTA-Lösung

凤

Aussaat der Zellen in 6-well-Multischalen

(Verdünnungsreihe $10^{2}$ bis $10^{5}$ )

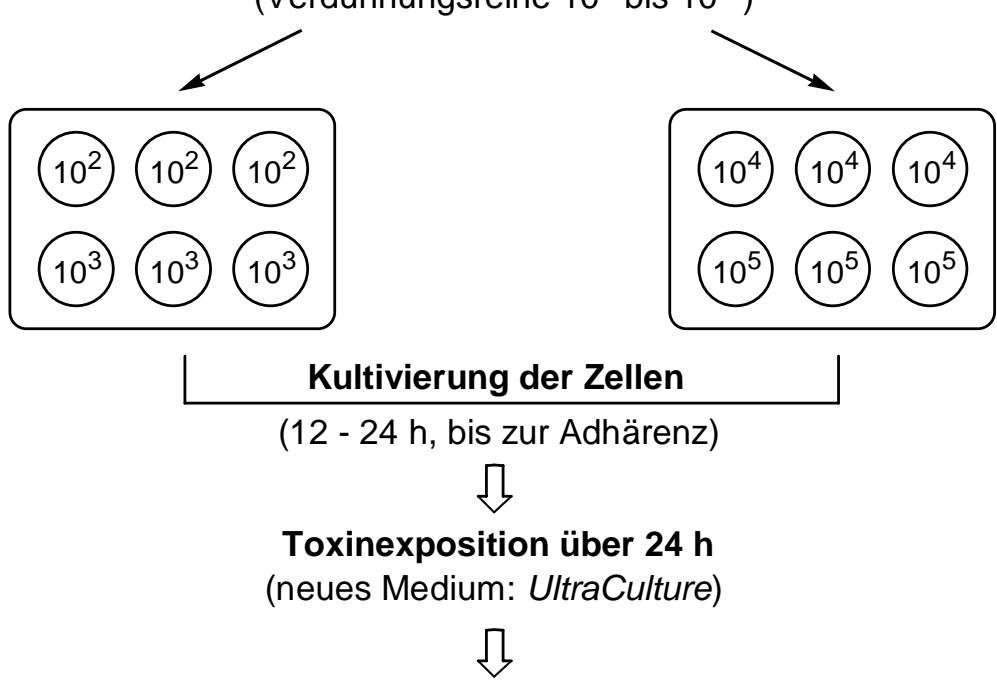

Proliferation der Zellen über 12 Tage

(Medium: DMEM / FCS)

ת

Entfernen des Mediums, Trocknen und Anfärben der Klone, Makroskopische Auszählung der Klone ab einer Größe von 500-1000 um

$\Omega$

rel. Klonbildungsrate [\%] $=\frac{\text { Anzahl der Klone nach Inkubation mit dem Toxin }}{\text { Anzahl der Klone aus dem Kontrollansatz }} \times 100$

Schema 11.1. Schematische Darstellung des HTCFA-Tests (Human Tumor Colony Forming Ability Test), modifiziert nach I. Schuberth. 


\subsection{In vitro-Zytotoxizitäten der anti-Methyl-seco-CBI-DNA-Binder- Derivate}

Die getesteten Verbindungen weisen bezüglich der DNA-Binder-Komponente erhebliche strukturelle Unterschied auf. Dieses spiegelt sich auch bei den gemessenen Zytotoxizitäten wider. So findet man bei den $\mathrm{ED}_{50}$-Werte für die benzylgeschützten Derivate einen Faktor von 20 und für die ungeschützten Derivate einen Faktor von 110. Der Bereich der Q ED ${ }_{50^{-}}$ Werte variiert zwischen 20 und 1900.

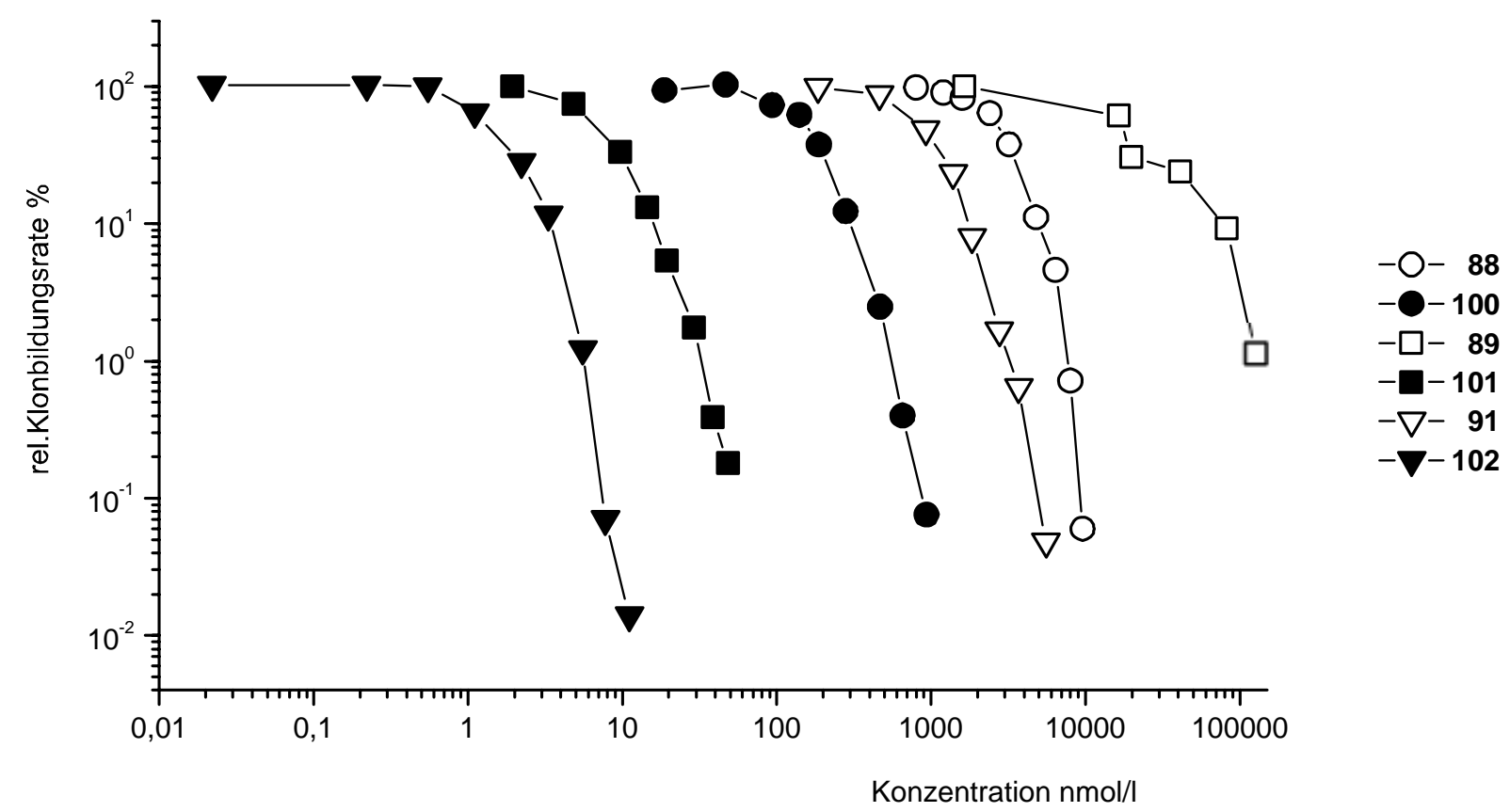

Schema 11.2. Vergleich der in vitro-Zytotoxizitäten von anti-Methyl-seco-CBI-DNA-Binder-Derivate auf humanen Bronchialkarzinomzellen der Linie A549. 


\begin{tabular}{ccc}
\hline Substanz & Selektivität & ED $_{\mathbf{5 0}}$ in $\mathbf{~ n m o l} / \mathbf{l}$ \\
\hline $\mathbf{8 8}$ & 20 & 2750 \\
$\mathbf{1 0 0}$ & & 160 \\
\hline
\end{tabular}

89

101
17500

1900

9

$\begin{array}{lrr}91 & 640 & 890 \\ 102 & & 1.4\end{array}$

Tabelle 11.1. Übersicht der $\mathrm{ED}_{50}$ Werte der (+/-)-anti-Methyl-seco-CBI-DNA-Binder-Derivate.

Besonders interessant ist die Verbindung 101 mit einer Nitrilgruppe in der DNABindungskomponente mit einen $\mathrm{ED}_{50}$-Wert von $9 \mathrm{nM}$ und $17500 \mathrm{nM}$ für das entsprechende benzylgeschützte Derivat 89. Mit einem Q ED E0 Werte von 1900 stellt 101 einen geeigneten Kandidat für weitere Entwicklungen dar.

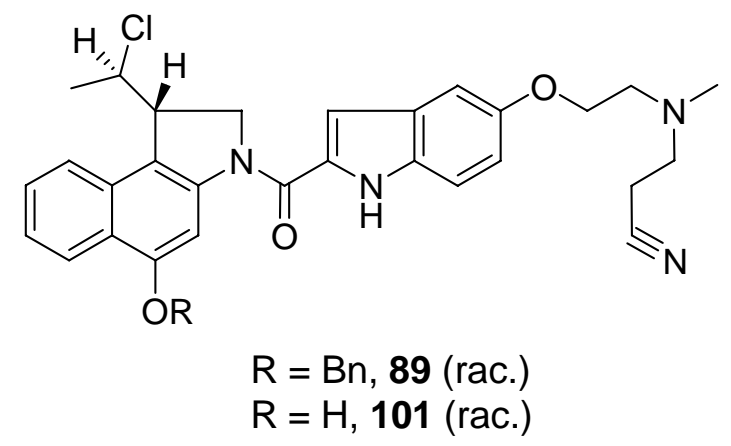

Abb. 11.1. Strukturen von 89 und 101.

\subsection{In vitro-Zytotoxizitäten des anti-Methyl-seco-CBI-DMAI-Carbamats}

Das Carbamat-Derivat 140 zeigt den gleichen $\mathrm{ED}_{50}$-Wert von $1.5 \mathrm{nM}$ wie das entsprechende Drug 22, was 140 zu einem interessanten Kandidat für weitere Entwicklungen macht. 


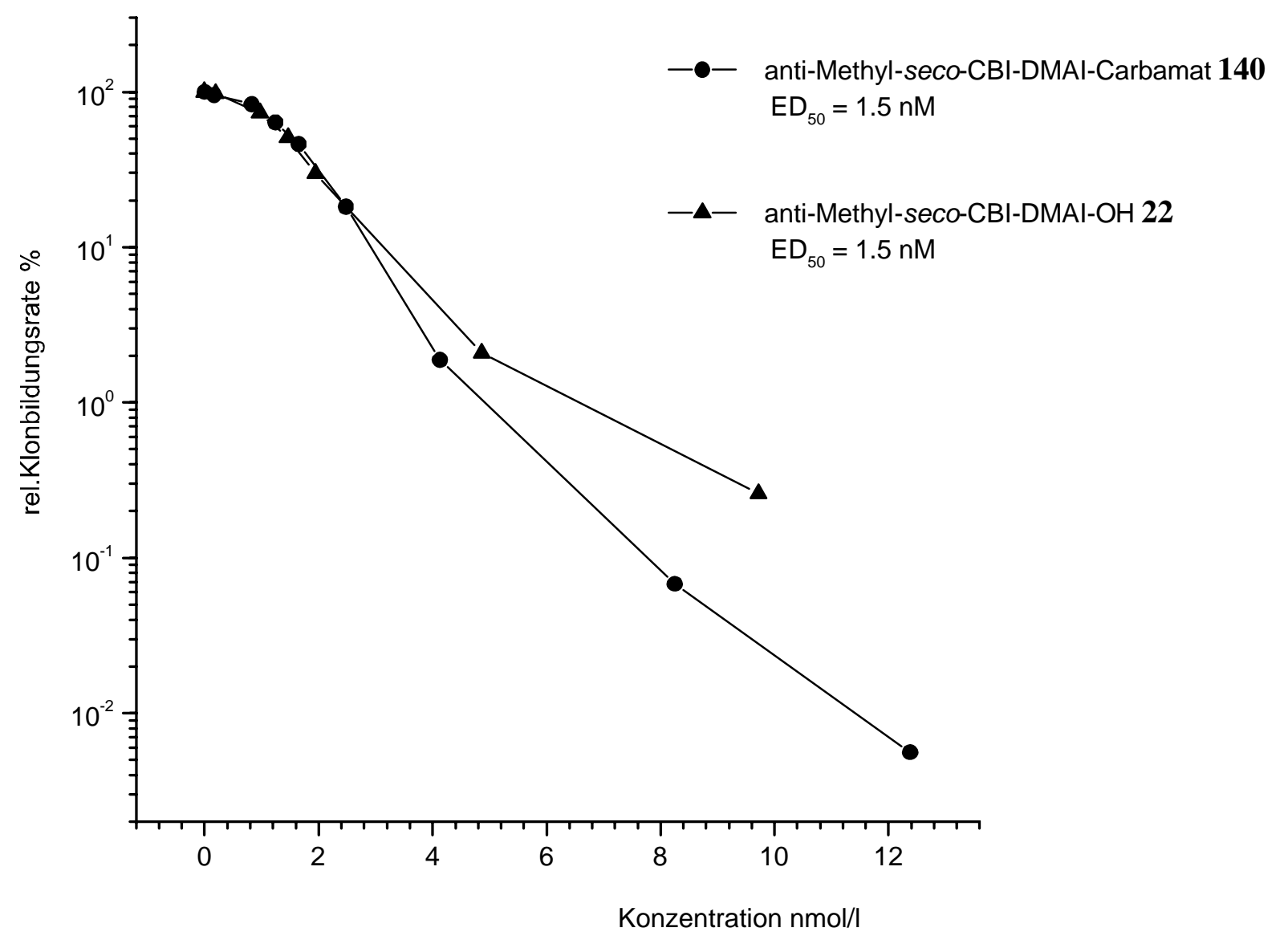

Schema 11.3. Vergleich der in vitro-Zytotoxizitäten von $\mathbf{1 4 0}$ und 22 auf humanen Bronchialkarzinomzellen der Linie A549. 


\section{Zusammenfassung}

Krebserkrankungen stellen heute mit einem Viertel aller Todesfälle nach den HerzKreislauferkrankungen die zweithäufigste Todesursache in den Industrienationen dar. Dieses Verhältnis wird sich in Zukunft vermutlich noch mehr in Richtung der Tumorerkrankungen verschieben. Neben den entscheidenden Faktoren der Prävention und der Vermeidung von Risikofaktoren steht die Entwicklung angemessener Therapien im Vordergrund der wissenschaftlichen Forschung. Dabei spielt die Chemotherapie eine wichtige Rolle, da sie im fortgeschrittenen Stadium der Erkrankung, in dem es häufig zur Bildung von Metastasen kommt, die einzig erfolgversprechende Therapieform darstellt. Bei Anwendung der zur Zeit zur Verfügung stehenden Chemotherapeutika müssen allerdings gravierende Nebenwirkungen in Kauf genommen werden, die häufig zu einem Abbruch der Therapie führen oder zumindest eine Reduktion der Dosis erforderlich macht, so dass eine Heilung nicht mehr gewährleistet ist. Diese Nebenwirkungen sind auf eine nicht ausreichende Differenzierung zwischen malignem und gesundem Gewebe zurückzuführen, da im Wesentlichen nur die gesteigerte Proliferationsrate von Krebszellen ausgenutzt wird.

Auf der Suche nach neuen Therapiemöglichkeiten wurden im Arbeitskreis von L. F. Tietze vielversprechende Ansätze unter anderen für das ADEPT-Konzept entwickelt, das die Nutzung einer gezielten Aktivierung von reversibel detoxifizierten Prodrugs direkt am erwünschten Wirkort beinhaltet. Dabei kommen Analoga des Antibiotikums (+)-CC-1065 (16) zum Einsatz, das eine sehr hohe Zytotoxizität besitzt. Neben dem Pharmakophor (Segment A), spielen auch die DNA-Bindungskomponenten (Segment B und C) eine wichtige Rolle für die Wirksamkeit.

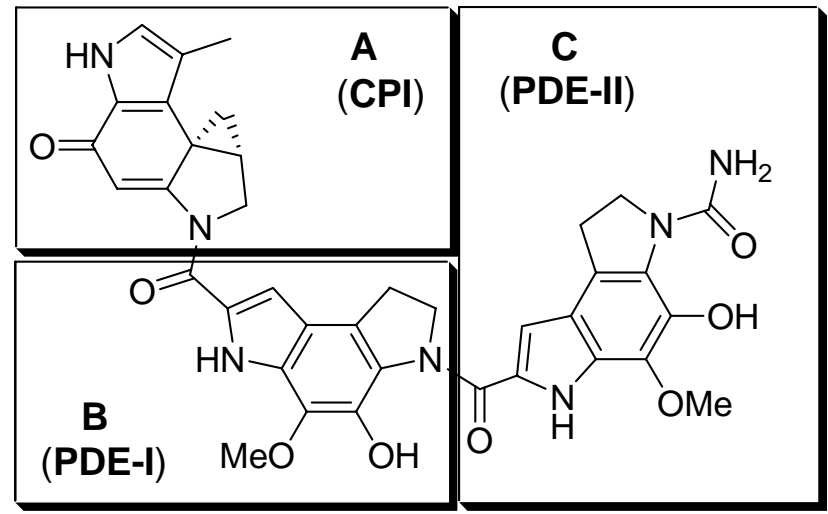

(+)-CC-1065 (16)

Abb. 12.1. Das Antitumor-Antibiotikum (+)-CC-1065 (16). 
Bei dem ADEPT-Konzept handelt es sich um einen binären Therapieansatz, der den Nachteil höherer Kosten mit sich bringt. Deswegen ist zusätzlich die Entwicklung niedermolekularer Liganden für das selektive Targeting von Tumorzellen von Interesse. $\mathrm{Zu}$ solchen niedermolekularen Liganden gehören Peptide wie das Tetragastrin. Diese Peptide können einen selektiven Zugang $\mathrm{zu}$ Krebszellen ermöglichen, auf deren Oberfläche der CCK-B/Gastrinrezeptor überexprimiert wird.

In dieser Arbeit wird die Entwicklung neuartiger CC-1065-Analoga mit DNA-Bindern und einem Tetragastrin-Derivat beschrieben. Zusätzlich wurden auch die Verknüpfungen zwischen einem Prodrug (88), das eine freie Carboxylgruppe besitzt und den synthetisierten Tetragastrin-Derivaten durchgeführt. Des weiteren wurde ein Carbamat-Prodrug 140 des antiMethyl-seco-CBI-DMAI synthetisiert. Mit den erhaltenen Carbamat-Prodrug 140 und den anderen anti-Methyl-seco-CBI-Derivate wurden in vitro Zytotoxizitätsuntersuchungen durchgeführt.

Das Indolsystem, das als DNA-Binder eingesetzt wurde, konnte über die Japp-KlingemannVariante der Fischer-Indol-Synthese aufgebaut werden. Ausgehend von 4-Nitrophenol (41) wurde das Indolderivat 49 in einer Ausbeute von 60\% über fünf Stufen synthetisiert.
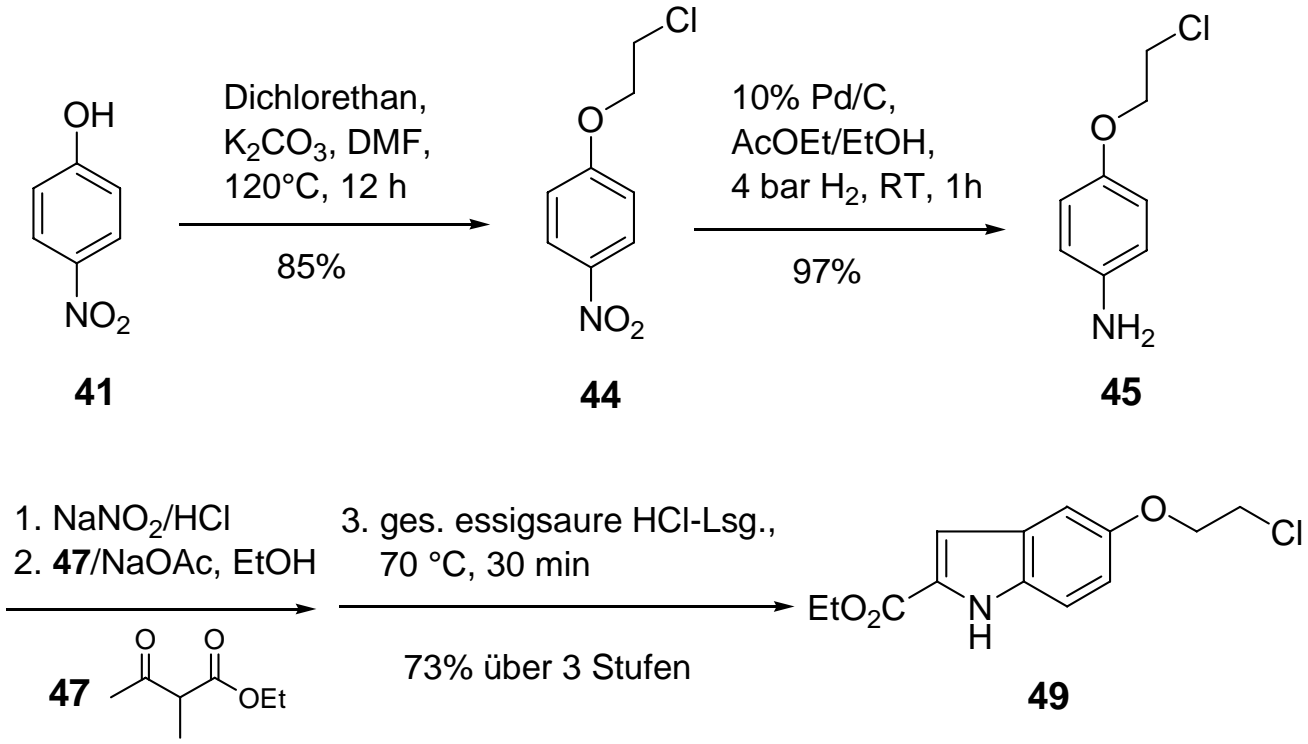

Schema 12.1. Synthese von 49.

Auf ähnlichem Weg wurden die Indolderivate 53 und 57 in Ausbeuten von 44\% bzw. 28\% jeweils über fünf Stufen hergestellt. 


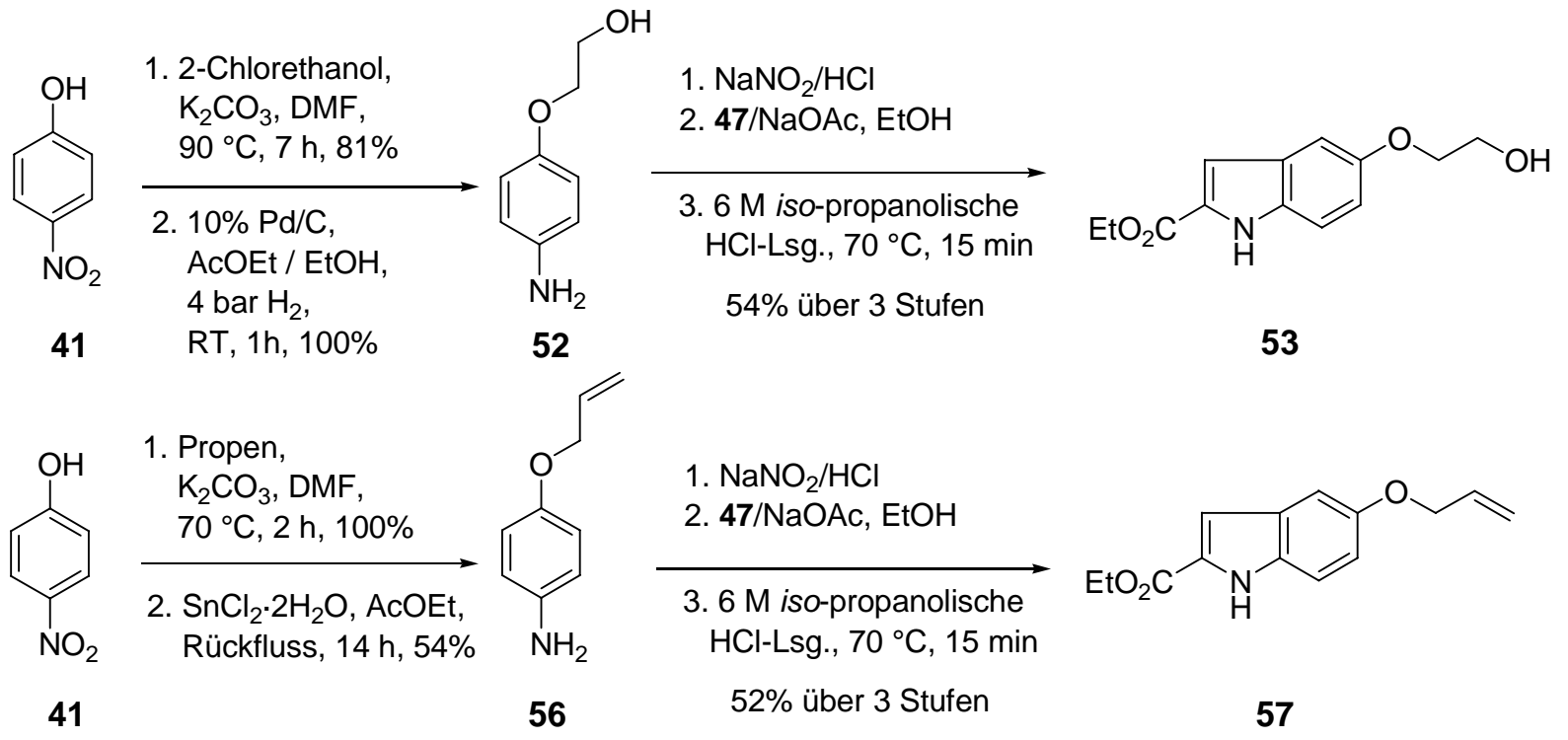

Schema 12.2. Synthese von 53 und 57.

Durch eine Finkelstein-Reaktion wurde das Chlorderivat 49 in das Iodderivat 50 in $85 \%$

Ausbeute überführt. Das Azidoderivat 59 wurde in einer Gesamtausbeute von 90\% über zwei

Stufen durch die Bildung eines Sulfonsäureesters und anschließende Azidolyse dargestellt.<smiles>CCOC(=O)c1cc2cc(OCCCl)ccc2[nH]1</smiles>

49

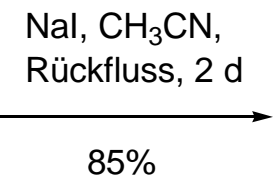<smiles>CCOC(=O)c1cc2cc(OCCI)ccc2[nH]1</smiles>

50

1. $\mathrm{CH}_{3} \mathrm{SO}_{2} \mathrm{Cl}, \mathrm{NEt}_{3}, \mathrm{CH}_{2} \mathrm{Cl}_{2}$,

$\mathrm{RT}, 12 \mathrm{~h}, 99 \%$<smiles>CCOC(=O)c1cc2cc(OCCO)ccc2[nH]1</smiles>

53
2. $\mathrm{NaN}_{3}, \mathrm{CH}_{3} \mathrm{CN} / \mathrm{DMSO}$, $90{ }^{\circ} \mathrm{C}, 4 \mathrm{~h}, 91 \%$<smiles>CCOC(=O)c1cc2cc(OCCN)ccc2[nH]1</smiles>

59

Schema 12.3. Synthese von 50 und 59.

Für die Synthese des Indolderivats 62 wurde die Carbonsäure 60, die durch Verseifung des Ester 50 dargestellt wurde, mit einer ethanolischen Methylamin-Lösung umgesetzt und anschließend an Acrylsäureethylester (39) addiert. Die Ausbeute dieser zwei-stufigen Synthese betrug $86 \%$. 


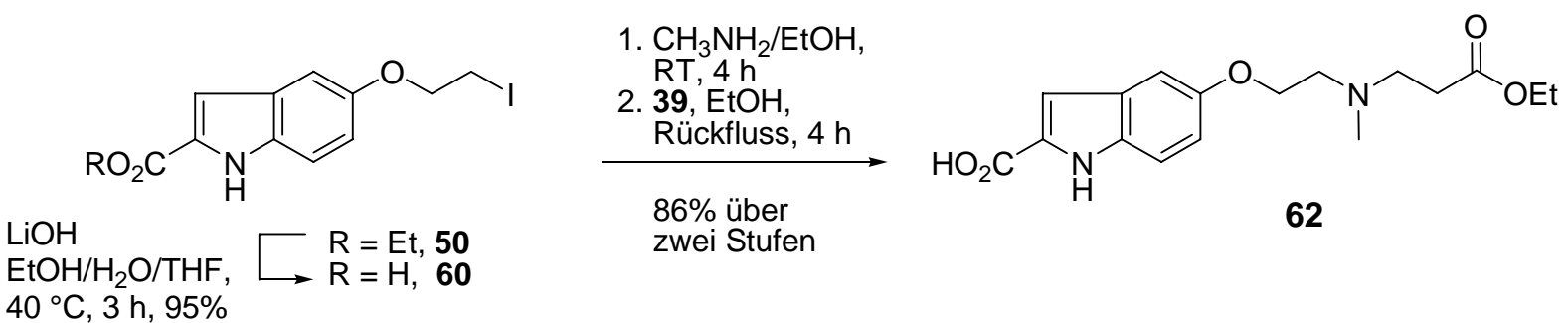

Schema 12.4. Synthese von 62.

Die Synthese von $\mathbf{4 2}$ verlief über eine direkte Substitution. Hierzu wurde das aus $\mathbf{5 0}$ gebildete Amin 64 mit 43 zum Ester 65 umgesetzt, aus dem durch Verseifung die Carbonsäure 42 in einer Ausbeute von 41\% über zwei Stufen erhalten wurde.<smiles>CCOC(=O)c1cc2cc(OCCI)ccc2[nH]1</smiles>

50<smiles>CN(CCCNC(=O)OCc1ccccc1)CCOc1ccc2[nH]c(C(=O)O)cc2c1</smiles>

$\mathrm{LiOH}$,

$\mathrm{H}_{2} \mathrm{O} / \mathrm{MeOH} / \mathrm{THF}$, $\mathrm{RT}, 2 \mathrm{~h}$<smiles>[R14][R16]([H])(C)NC(=O)OCCOc1ccc2[nH]c(C(=O)OCC)cc2c1</smiles>

64

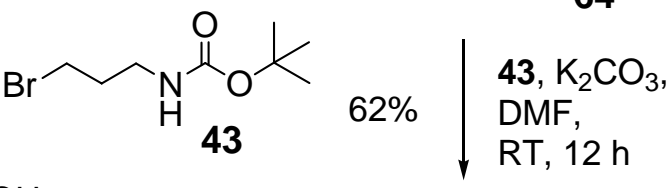

Die DNA-Bindungskomponente mit einer Nitrilgruppe 68, wurde durch eine MichaelAddition von Acrylsäurenitril (66) an das Amin 64 unter DMAP-Katalyse hergestellt. Ausgehend von 64, konnte die Carbonsäure 68 in einer Ausbeute 77\% über zwei Stufen synthetisiert werden.<smiles>CCOC(=O)c1cc2cc(OCCNC)ccc2[nH]1</smiles>

64
1. Acrylsäurenitril (66), DMAP, EtOH, RT, 2 h, 83\%

2. $\mathrm{LiOH}$, $\mathrm{H}_{2} \mathrm{O} / \mathrm{MeOH} / \mathrm{THF}$, RT, 2 h, 93\%<smiles>CN(CCC#N)CCOc1ccc2[nH]c(C(=O)O)cc2c1</smiles>

68

Schema 12.6. Synthese von 68 . 
Zur Synthese der Indolcarbonsäure 74 wurde die Nitroverbindung 71, die durch eine nucleophile aromatische Substitution aus 69 und 70 erhalten wurde, unter den beschriebenen Bedingungen in einer Ausbeute von 45\% über sechs Stufen synthetisiert.

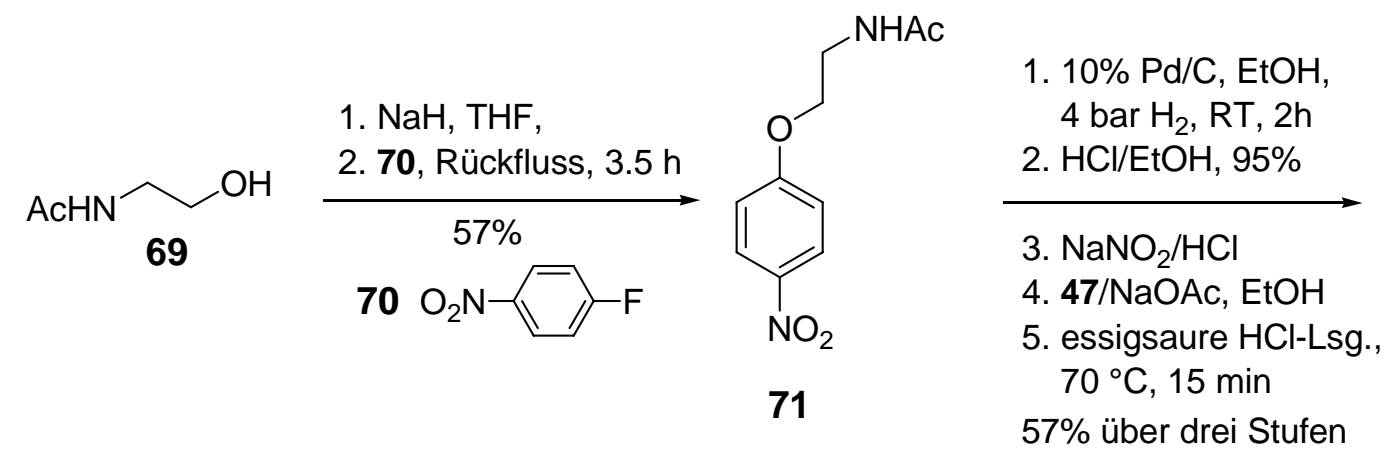<smiles>[Z6]CCNC(=O)OCCOc1ccc2[nH]c(C(=O)O)cc2c1</smiles>

Schema 12.7. Synthese von 74 .

Schließlich wurde auch aus 46 das Bisindol 76 hergestellt. Diese DNA-Bindungskomponente hat eine gewisse strukturelle Ähnlichkeit mit der entsprechenden Komponente im Bizelesin (26), das die einzige heute noch im klinischen Test verbliebende Verbindung der CC-1065 Analoga darstellt. Unter den entwickelten Bedingungen wurde das Bisindolderivat $\mathbf{7 6}$ in einer Ausbeute von 52\% über vier Stufen gebildet.<smiles></smiles>

Abb. 12.2. Struktur von Bizelesin (26). 


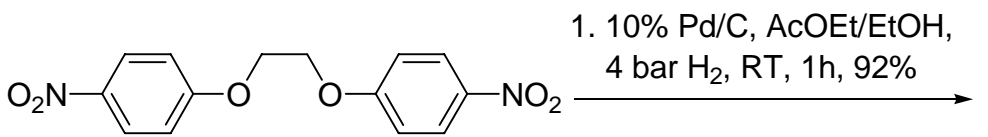

46

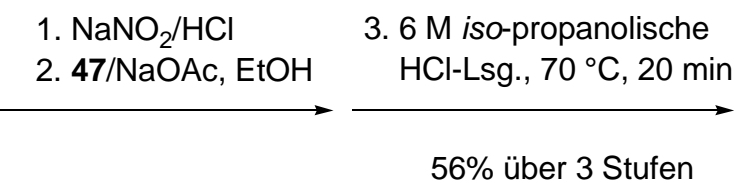<smiles>Nc1ccc(OCCOc2ccc(N)cc2)cc1</smiles>

75

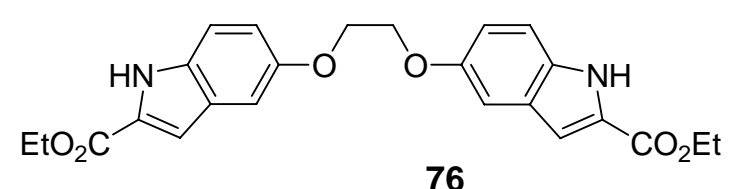

Schema 12.8. Synthese von 76 .

Die Synthese des anti-Methyl-seco-CBI-Grundgerüstes 82 wurde nach bekannten Methoden aus dem Arbeitskreis Tietze durchgeführt und die anschließende Boc-Entschützung gelang mit einer käuflichen, $i$-propanolischen Salzsäure-Lösung.

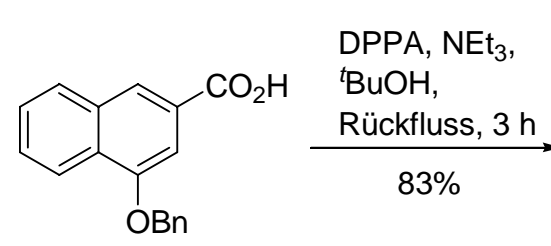

77<smiles>CC(C)(C)OCc1cc(Cc2ccccc2)cc2ccccc12</smiles>

78
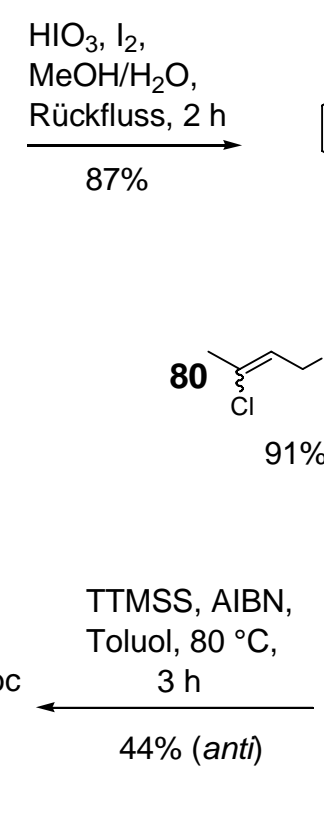

82 (rac.)<smiles>C[C@H](Cl)[C@H]1CN(C(=O)OCc2ccccc2)c2cc(Cc3ccccc3)c3ccccc3c21</smiles><smiles>CC(C)(C)Nc1cc(OCc2ccccc2)c2ccccc2c1I</smiles>

79

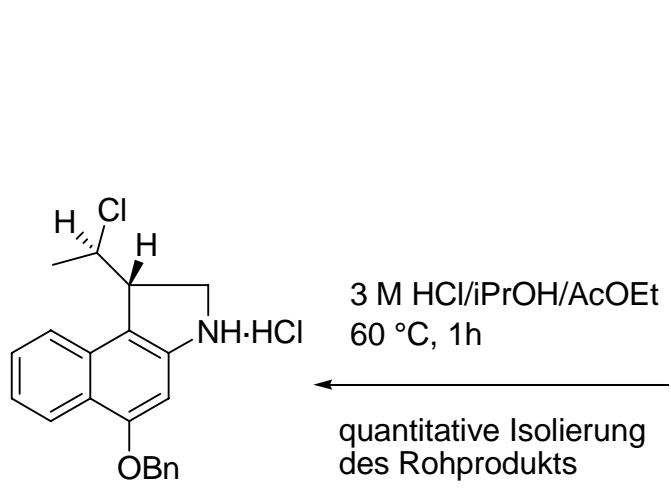

84 (rac.)
1. NaH, DMF, $\mathrm{RT}, 1 \mathrm{~h}$ 2. $80, \mathrm{RT}, 3 \mathrm{~h}$ $91 \%$

81

\section{Schema 12.9. Synthese von 84 .}

Die Kupplungen zwischen dem anti-Methyl-seco-CBI-Grundgerüst 84 und den indolhaltigen DNA-Bindern erfolgte erfolgreich nach literaturbekannter Methode. 
<smiles>CCOCCCN(C)CCOc1ccc2[nH]c(C(=O)O)cc2c1</smiles>

62<smiles>CN(CCC#N)CCOc1ccc2[nH]c(C(=O)O)cc2c1</smiles>

68<smiles>O=C(O)c1cc2cc(OCCO)ccc2[nH]1</smiles>

90
1. 84, EDC. $\mathrm{HCl}$, DMF, RT, $1 \mathrm{~d}$

2. $\mathrm{LiOH}$,

$\mathrm{EtOH} / \mathrm{H}_{2} \mathrm{O} / \mathrm{THF}$, $\mathrm{RT}, 2 \mathrm{~h}$

88\% über zwei Stufen<smiles>CC(Cl)C1CN(C(=O)c2cc3cc(OCCN(C)CCC(=O)O)ccc3[nH]2)c2cc(OCc3ccccc3)c3ccccc3c21</smiles>

88

84, $\mathrm{EDC} \cdot \mathrm{HCl}$, DMF, RT, $12 \mathrm{~h}$

$53 \%$<smiles>CC(Cl)C1CN(C(=O)c2cc3cc(OCCN(C)CCC=N)ccc3[nH]2)c2cc(C(=O)O)c3ccccc3c21</smiles>

89

84, EDC. $\mathrm{HCl}$, DMF, RT, $12 \mathrm{~h}$ $54 \%$<smiles>CC(Cl)C1CN(C(=O)c2cc3cc(OCCO)ccc3[nH]2)c2cc(OCc3ccccc3)c3ccccc3c21</smiles>

91

Schema 12.10. Synthese von 88, 89 und 91.

Um einen Zugang zu vielen unterschiedlichen analogen Prodrugs zu ermöglichen, wurde der DNA-Binder 74 mit 84 zu 92 gekuppelt, das nachfolgend weiter modifiziert werden konnte. So wurde aus 92 durch eine dreistufige Umwandlung in einer Ausbeute von $60 \%$ die Verbindung 94 erhalten.<smiles>CC(C)(C)NCCOc1ccc2[nH]c(C(=O)O)cc2c1</smiles>

74

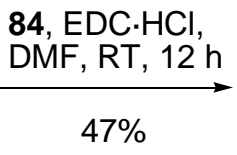

$47 \%$<smiles></smiles>

92

1. essigsaure $\mathrm{HCl}$-Lsg., $\mathrm{CH}_{2} \mathrm{Cl}_{2}$, RT, 2 h

2. Acrylsäureethylester, NaOAc, EtOH, Rückfluss, $8 \mathrm{~h}$

3. $\mathrm{LiOH}, \mathrm{H}_{2} \mathrm{O} / \mathrm{THF}, \mathrm{RT}, 12 \mathrm{~h}$ $60 \%$ über drei Stufen

Schema 12.11. Synthese von 94 .<smiles>CC(Cl)[C@H]1CN(C(=O)c2cc3cc(OCCNCCC(=O)O)ccc3[nH]2)c2cc(Cc3ccccc3)c3ccccc3c21</smiles> 
Aufgrund der hervorragenden Ergebnisse von anti-Methyl-seco-CBI-DMAI-Verbindungen im Zelltest stellte das dialkylamin-substituierte Indol eine interessante Gruppe dar. Es ist in dieser Arbeit gelungen, die Dialkylamingruppe in der letzten Stufe einzuführen. Das aus 95 und 85 erhaltenene Chlorderivat 96 konnte durch Finkelstein-Reaktion in das Iodderivat 97 überführt werden, welches nach Aminierung das gewünschte Zielmolekül 98 in 66\% Ausbeute über zwei Stufen lieferte.<smiles>[R]OC(=O)c1cc2cc(OCCC)ccc2[nH]1</smiles>

$\mathrm{LiOH}$,

$$
\begin{array}{lr}
\mathrm{LiOH}, \\
\mathrm{EtOH} / \mathrm{H}_{2} \mathrm{O} / \mathrm{THF}, & \mathrm{R}=\mathrm{Et}, 49 \\
40^{\circ} \mathrm{C}, 1 \mathrm{~h}=\mathrm{H}, 95 & 96 \%
\end{array}
$$<smiles></smiles>

85, EDC. $\mathrm{HCl}$, DMF, RT, $1 \mathrm{~h}$ $48 \%$<smiles>CC(Cl)C1CN(C(=O)c2cc3cc(OCCCl)ccc3[nH]2)c2cc(OCC(=O)OCc3ccccc3)c(C(C)(C)Cl)cc21</smiles>

Dimethylamin, $\mathrm{EtOH} / \mathrm{THF}$, $\mathrm{K}_{2} \mathrm{CO}_{3}$, $\mathrm{RT}, 12 \mathrm{~h}$

$66 \%$ über zwei Stufen
$\mathrm{Nal}, \mathrm{CH}_{3} \mathrm{CN}$, Rückfluss, $2 \mathrm{~d}$<smiles>CC(Cl)C1CN(C(=O)c2cc3cc(OCCI)ccc3[nH]2)c2cc(OCCI)c3ccccc3c21</smiles>

Schema 12.12. Synthese von 97 .

Die Abspaltung der Benzyl-Schutzgruppe der Prodrugs ließ sich durch katalytische Hydrierung unter Zusatz von Essigsäure erfolgreich durchführen. Somit konnten die drei neuen seco-Drugs 100-102 in Ausbeuten zwischen 83-100\% hergestellt und für in vitro Zytotoxizitätsuntersuchungen zur Verfügung gestellt werden. 
<smiles>CC(Cl)[C@H]1CN(C(=O)c2cc3cc(OCCN(C)CCC(=O)O)ccc3[nH]2)c2cc(OCc3ccccc3)c3ccccc3c21</smiles>

88<smiles>CC(Cl)C1CN(C(=O)c2cc3cc(OCCN(C)CCC#N)ccc3[nH]2)c2cc(OCc3ccccc3)c3ccccc3c21</smiles>

89<smiles>CC(Cl)[C@H]1CN(C(=O)c2cc3cc(OCCO)ccc3[nH]2)c2cc(OCCO)c3ccccc3c21</smiles>

91

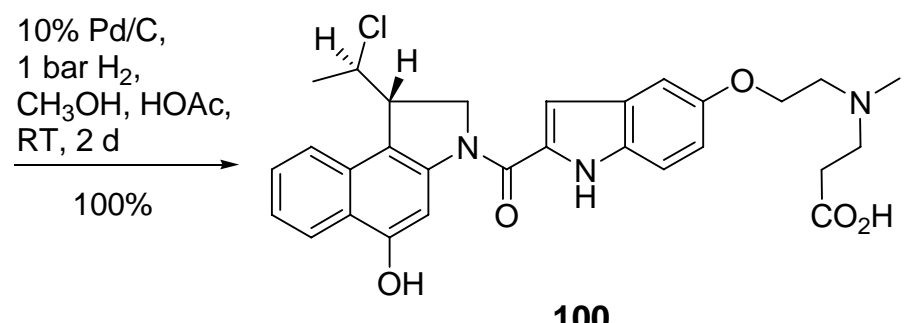

$10 \% \mathrm{Pd} / \mathrm{C}$,

1 bar $\mathrm{H}_{2}, \mathrm{HOAc}$, $\mathrm{CH}_{3} \mathrm{OH} / \mathrm{THF}$, $\stackrel{\mathrm{RT}, 12 \mathrm{~h}}{\mathrm{~B}}$ $88 \%$<smiles>CC(Cl)[C@H]1CN(C(=O)c2cc3cc(OCCN(C)CCC#N)ccc3[nH]2)c2cc(O)c3ccccc3c21</smiles>

$10 \% \mathrm{Pd} / \mathrm{C}$, 1 bar $\mathrm{H}_{2}$, HOAc, $\mathrm{CH}_{3} \mathrm{OH} / \mathrm{THF}$ $\mathrm{RT}, 12 \mathrm{~h}$ $83 \%$<smiles>CC(Cl)C1CN(C(=O)c2cc3cc(OCCO)ccc3[nH]2)c2cc(O)c3ccccc3c21</smiles>

Schema 12.13. Synthese von 100, 101 und 102.

Die Synthese der Tetragastrin-Derivate, welche an der Asparaginsäureseitenkette geschützt sowie ungeschützt waren, wurde nach einer "2+2"-Synthesestrategie unter Standardbedingungen durchgeführt. Zuerst wurden die Dipepetid synthetisiert. So erhielt man das $N$-terminale Dipeptid 110 unter Verwendungen von HOSu und EDC in einer Ausbeute von $72 \%$.

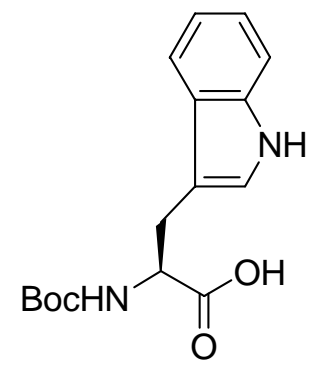

113
1. $\mathrm{HOSu}, \mathrm{EDC} \cdot \mathrm{HCl}$, $\mathrm{CH}_{2} \mathrm{Cl}_{2}, \mathrm{RT}, 4 \mathrm{~h}$

2. Methion (114), NEtiPr $\mathrm{THF} / \mathrm{H}_{2} \mathrm{O}, \mathrm{RT}, 12 \mathrm{~h}$

$72 \%$<smiles>CCCCC(NC(=O)[C@H](CCSCC)NC(=O)COC(C)(C)C)C(=O)O</smiles>

Schema 12.14. Synthese von 110.

Zur Darstellungen der $C$-terminalen Dipeptide wurden die Carbonsäure der geschützten L-Asparaginsäuren 117, 119 und 120 als gemischtes Anhydrid aktivert, dann mit Phenylalaninamid (121) in die entsprechenden Dipeptide 122, 123 und 124 überführt. 
<smiles>[R]OC(=O)CC(NC(=O)OCc1ccccc1)C(=O)O</smiles>

$\mathrm{R}=\mathrm{Me}, \mathbf{1 1 7}$

$\mathrm{R}=$ All, 119

$\mathrm{R}=\mathrm{Bn}, \mathbf{1 2 0}$
1. $\mathrm{ClCO}_{2} \mathrm{Et}, \mathrm{NEt} i \mathrm{Pr}_{2}$, THF, $-18^{\circ} \mathrm{C}$ auf $0{ }^{\circ} \mathrm{C}, 1 \mathrm{~h}$

2. Phenylalaninamid (121), $\mathrm{H}_{2} \mathrm{O}, 0^{\circ} \mathrm{C}$ auf $\mathrm{RT}$, $2 \mathrm{~h}$<smiles>[R]OC(=O)C[C@H](NC(=O)OCc1ccccc1)C(=O)N[C@@H](Cc1ccccc1)C(N)=O</smiles>

$\mathrm{R}=\mathrm{Me}, 60 \%, 122$

$\mathrm{R}=$ All, $94 \%, 123$

$\mathrm{R}=\mathrm{Bn}, 82 \%, 124$

Schema 12.15. Synthese von 122, 123 und 124.

Nach Bereitstellung des N-terminalen sowie der C-terminalen Dipeptide erfolgten die Kupplungen zu den entsprechenden Tetragastrin-Derivaten. So erhielt man 125, 126 und 128, die an der Asparaginsäureseitenkette als Methyl-, Allyl- sowie Benzylester geschützt sind.<smiles>[R]OC(=O)CC(NC(=O)[O-])C(=O)N[C@@H](Cc1ccccc1)C(N)=O</smiles>

$\mathrm{R}=\mathrm{Me}, 122$

$\mathrm{R}=$ All, 123
1. TFA, $\mathrm{CH}_{2} \mathrm{Cl}_{2}, \mathrm{H}_{2} \mathrm{O}$, RT, $2 \mathrm{~h}$

2. 110, HOSu, EDC. $\mathrm{HCl}$ (Nach 2 h für Aktivierung), NEtiPr 2 THF/ $\mathrm{H}_{2} \mathrm{O}, \mathrm{RT}, 2 \mathrm{~h}$<smiles>[R]C(=O)C[C@H](NC(=O)[C@H](CCSC)NC(=O)[C@H](Cc1c[nH]c2ccccc12)NC(=O)[C@H](Cc1ccccc1)NC(=O)OCc1ccccc1)C(N)=O</smiles>

$\mathrm{R}=\mathrm{Me}, 66 \%, 125$

$\mathrm{R}=\mathrm{All}, 85 \%, 126$

1. TFA, $\mathrm{CH}_{2} \mathrm{Cl}_{2}, \mathrm{H}_{2} \mathrm{O}, \mathrm{RT}, 2 \mathrm{~h}$<smiles>NC(=O)[C@H](Cc1ccccc1)NC(=O)[C@H](CC(=O)OCc1ccccc1)NC(=O)c1ccccc1</smiles>

124
2. 110, $\mathrm{HOBt}, \mathrm{EDC} \cdot \mathrm{HCl}$, NEtiPr ${ }_{2} \mathrm{CH}_{2} \mathrm{Cl}_{2}, \mathrm{RT}, 12 \mathrm{~h}$

3. TFA, $\mathrm{CH}_{2} \mathrm{Cl}_{2} / \mathrm{H}_{2} \mathrm{O}, \mathrm{RT}, 3 \mathrm{~h}$

$44 \%$ nach präparativer HPLC über drei Stufen<smiles>CSCC[C@H](NC(=O)[C@H](N)Cc1c[nH]c2ccccc12)C(=O)N[C@@H](CC(=O)OCc1ccccc1)C(=O)N[C@@H](Cc1ccccc1)C(N)=O</smiles>

128

Schema 12.16. Synthese von 125, 126 und 128.

Für die Synthese des an der Seitenkette ungeschützten Tetragastrins 131 wurde zuerst aus 124 das Dipeptid 130 durch die Abspaltung der Benzyl- und der Boc-Gruppe synthetisiert und anschließend mit 110 unter Verwendungen von HOBt sowie EDC gekuppelt. Nach erneuter Entschützung der Boc-Gruppe sowie präparativer HPLC-Reinigung erhielt man das Tetragastrin 131. Durch HPLC und NMR-Vergleichsanalyse mit einer kommerziellen Tetragastrinprobe konnte gezeigt werden, dass diese identisch waren. 
<smiles>CC(C)(C)OC(=O)NC(CC(=O)OCc1ccccc1)C(=O)N[C@@H](Cc1ccccc1)C(N)=O</smiles>

124
1. $10 \% \mathrm{Pd} / \mathrm{C}, 1$ bar $\mathrm{H}_{2}$, $\mathrm{MeOH} / \mathrm{THF}, \mathrm{RT}, 12 \mathrm{~h}, 84 \%$

2. TFA, $\mathrm{CH}_{2} \mathrm{Cl}_{2} / \mathrm{H}_{2} \mathrm{O}$, $\mathrm{RT}, 3 \mathrm{~h}, 99 \%$

1. 110, $\mathrm{HOBt}$, EDC. $\mathrm{HCl}$, NEtiPr 2 , DMF, RT, 3 h, 80\%

2. TFA, $\mathrm{CH}_{2} \mathrm{Cl}_{2} / \mathrm{H}_{2} \mathrm{O}$, $\mathrm{RT}, 2 \mathrm{~h}$, 42\% Nach präparativer HPLC<smiles>NC(=O)[C@H](Cc1ccccc1)NC(=O)[C@H](CC(=O)O)Cc1ccccc1</smiles>

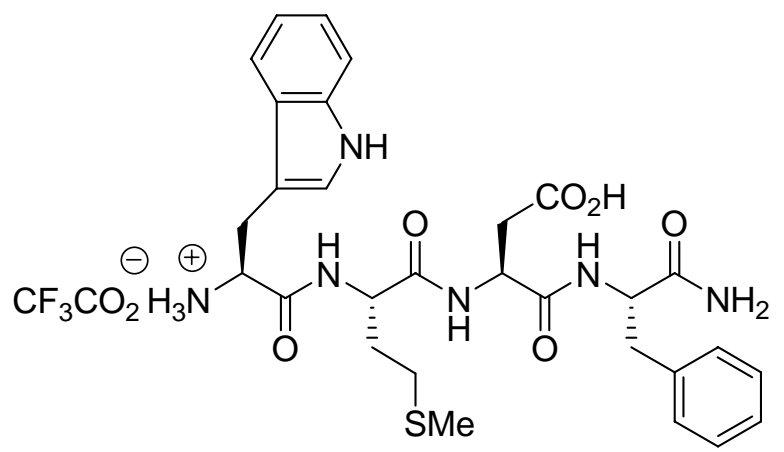

131

Schema 12.17. Synthese von 131.

Für die Kupplung zwischen Drug und Peptid wurde die Carbonsäure 88 als der Drug-Teil verwendet, während die an der Seitenkette geschützten Tetragastrin-Derivate 132 und 128 als Peptid-Teil dienten.

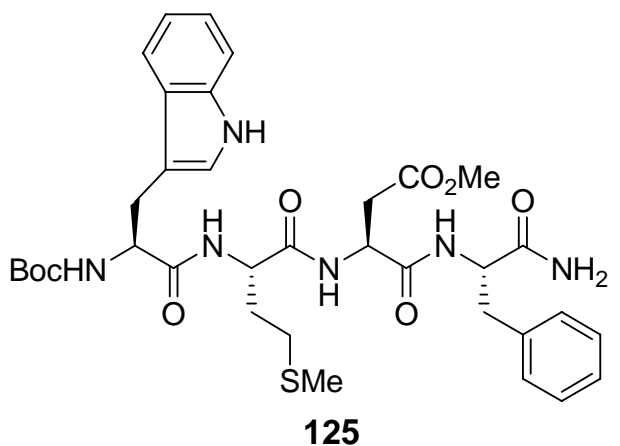

125
TFA, $\mathrm{CH}_{2} \mathrm{Cl}_{2}, \mathrm{H}_{2} \mathrm{O}$, $\mathrm{RT}, 3 \mathrm{~h}$

88\% Ausbeute nach präparativer HPLC

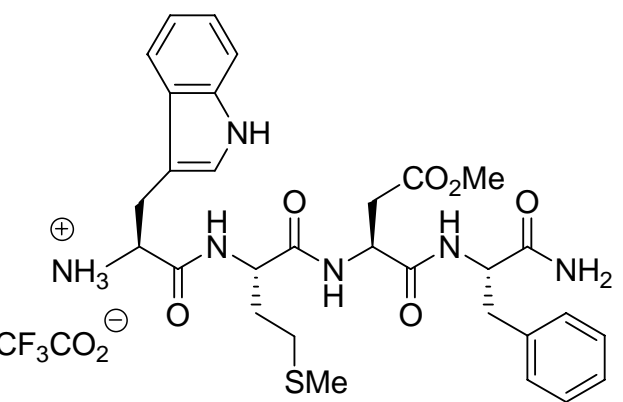

132

Schema 12.18. Synthese von 132.

Die Verbindungen 133 und 134 wurden unter Standardbedingungen mit HOBt und EDC als Aktivatoren synthetisiert und in Ausbeuten von 49\% bzw. $71 \%$ erhalten. 
<smiles>CC(Cl)C1CN(C(=O)c2cc3cc(OCCN(C)CCC(=O)O)ccc3[nH]2)c2cc(OCc3ccccc3)c3ccccc3c21</smiles>

1. $\mathrm{HOBt}, \mathrm{EDC} \cdot \mathrm{HCl}$,

DMF

2. 132 oder $128, \mathrm{NEtiPr}_{2}$, $\mathrm{RT}, 12 \mathrm{~h}$<smiles></smiles>

$\mathrm{R}=\mathrm{Me}, 49 \%, 133$

$\mathrm{R}=\mathrm{Bn}, 71 \%, 134$

Schema 12.19. Synthese von 133 und 134.

Die Herstellung des an der Seitenkette ungeschützten peptidischen Prodrugs 136 wurde über einen Allylester 135 erreicht. Die Spaltung des Allylesters in 135 gelang mit Tetrakis(triphenylphosphan)palladium(0) als Katalysator und Pyrrolidin als Nucleophil. 
<smiles>CSCC[C@H](NC(=O)[C@H](Cc1c[nH]c2ccccc12)NC(=O)OCc1ccccc1)C(=O)N[C@@H](CC(=O)O)C(=O)N[C@@H](Cc1ccccc1)C(N)=O</smiles>

126<smiles></smiles>

135 \begin{tabular}{l|l}
$\begin{array}{l}\text { 21\% über drei Stufen } \\
\text { nach präparativer } \\
\text { HPLC }\end{array}$ & $\begin{array}{l}\mathrm{Pd}\left(\mathrm{PPh}_{3}\right)_{4}, \mathrm{PPh}_{3} \\
\mathrm{Pyrrolidin}, \mathrm{CH}_{3} \mathrm{CN}, \mathrm{DMF} \\
\mathrm{RT}, 2 \mathrm{~h}\end{array}$
\end{tabular}<smiles>CSCC[C@H](NC(=O)[C@H](Cc1c[nH]c2ccccc12)NC(=O)CCN(C)CCOc1ccc2[nH]c(C(=O)N3C[C@H](C(C)Cl)C4=C3C=C3OCC(=CC=CC=C4)c4ccccc43)cc2c1)C(=O)N[C@@H](CCOC(=O)OC(C)(C)C)C(=O)N[C@@H](Cc1ccccc1)C(N)=O</smiles>

Schema 12.20. Synthese von 136.

Die Synthese des Drugs durch Entschützung des Benzylethers in 133, 134 und 136 war leider nicht erfolgreich. Weder durch direkte Hydrierung mit Palladium auf Aktivkohle und Wasserstoff noch durch Transferhydrierung mit Palladium auf Aktivkohle und Ameisensäure konnte das freie Phenol erhalten werden. Es wurde auch ohne Erfolg getestet, das DrugPeptid-Konjugat durch eine direkte Kupplung zwischen 100 und 131 zu erreichen. 
Für die Synthese des carbamathaltigen Prodrugs 140 wurde die Phenol-Gruppe von 22 mit Chlorameisensäure-4-nitrophenylester (138) aktiviert und anschließend mit Hexylamin in das Carbamat überführt.<smiles>C[C@H](Cl)[C@H]1CN(C(=O)c2cc3cc(OCCN(C)C)ccc3[nH]2)c2cc(O)c3ccccc3c21</smiles>

22

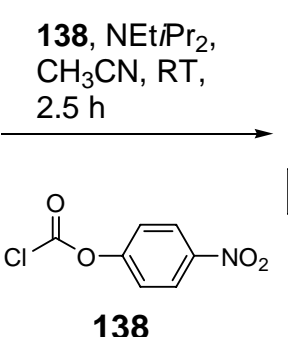<smiles>CC(Cl)[C@@H]1CN(C(=O)c2cc3cc(OCCN(C)C)ccc3[nH]2)c2cc(OC(=O)Oc3ccc([N+](=O)[O-])cc3)c3ccccc3c21</smiles>

139

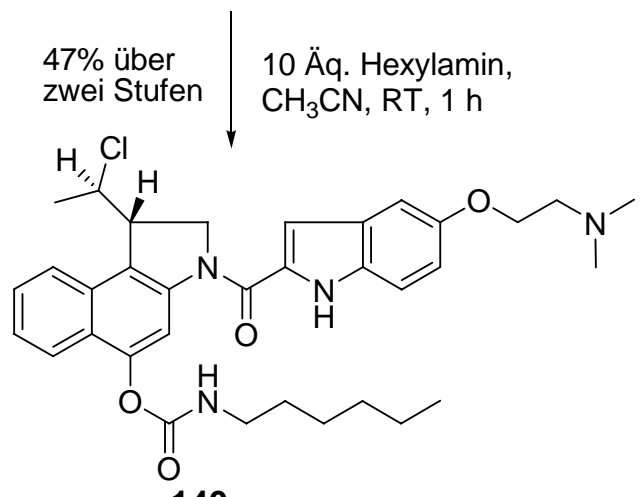

Schema 12.21. Synthese von 140 .

Im Rahmen dieser Dissertation konnten insgesamt acht benzylgeschützte seco-Drugs und drei der korrespondierenden freien seco-Drugs synthetisiert und analysiert werden. Als bestes Ergebnis der in vitro-Zytotoxizitätsuntersuchungen konnte für 101 ein $\mathrm{ED}_{50}$-Werte von $9 \mathrm{nM}$ und für das benzylgeschützte Derivat 89 ein $\mathrm{ED}_{50}$-Werte von $17.5 \mu \mathrm{M}$ ermittelt werden. Dies entspricht einen Q ED 50 Werte von 1900.

Das Carbamat-Derivat 140 zeigte den gleichen $\mathrm{ED}_{50}$ Wert von $1.5 \mathrm{nM}$ wie das entsprechende Drug 22.

Somit können die Verbindungen 101 sowie 140 als geeignete Kandidaten für weitere Entwicklungen dienen. 


\section{Experimenteller Teil}

\section{Allgemeine Methoden}

\subsection{Präparative Methoden}

Umsetzungen wurden - soweit nötig - in ausgeheizten Glasapparaturen unter einer ArgonSchutzgasatmosphäre durchgeführt. Lösungsmittel wurden vor ihrer Verwendung entsprechend der üblichen Laboratoriumsmethoden gereinigt und getrocknet. Käufliche Substanzen wurden ohne weitere Reinigung eingesetzt.

\subsection{Instrumentelle Analytik und verwendete Geräte}

Schmelzpunkte: Die Bestimmung der Schmelzpunkte erfolgte mit dem Schmelzpunktbestimmungsgerät FP 61 der Firma Mettler. Die angegebenen Werte sind nicht korrigiert.

UV-Spektren: UV-Spektren wurden mit dem Modell Lambda 2 der Firma Perkin-Elmer aufgenommen.

IR-Spektren: Infrarot-Spektren wurden mit dem Modell Vector 22 der Firma Bruker gemessen. Feststoffe wurden als KBr-Presslinge, flüssige Substanzen als Film zwischen $\mathrm{NaCl}-\mathrm{Platten}$ gemessen.

Drehwerte: Drehwerte wurden in einem Polarimeter Modell 241 der Firma Perkin-Elmer gemessen.

${ }^{1}$ H-NMR-Spektren: ${ }^{1}$ H-NMR-Spektren wurden mit den Modellen Mercury-200, VXR-200 (200 MHz), Unity-300 (300 MHz), Inova-500 (500 MHz) und Unity Inova-600 (600 MHz) der Firma Varian und dem Modell AMX-300 (300 MHz) der Firma Bruker aufgenommen. Die chemischen Verschiebungen sind in Einheiten der $\delta$-Skala angegeben, als interner Standard diente Tetramethylsilan $\left(\delta_{\mathrm{TMS}}=0.00 \mathrm{ppm}\right)$. Zur Kennzeichnung der Signalmultiplizitäten wurden folgende Abkürzungen verwendet: s (Singulett), sbr (breites Singulett), $d$ (Dublett), $t$ (Triplett), $m$ (Multiplett) und $m_{c}$ (zentriertes Multiplett). Die 
Kopplungskonstanten $J$ sind in Hertz $(\mathrm{Hz})$ angegeben. Im Fall diastereotoper Protonen kennzeichnet ein tiefgestelltes "b" das tieffeldverschobene Signal und ein tiefgestelltes "a" das hochfeldverschobene Signal.

${ }^{13}$ C-NMR-Spektren: ${ }^{13}$ C-NMR-Spektren wurden mit den Modellen Mercury-200, VXR-200 (50 MHz), Unity-300 (75 MHz), Inova-500 (125 MHz) und Inova-600 (150 MHz) der Firma Varian und dem Modell AMX-300 (75 MHz) der Firma Bruker aufgenommen. Als interner Standard diente $\mathrm{CDCl}_{3}\left(\delta \mathrm{CDCl}_{3}=77.00 \mathrm{ppm}\right)$, wobei die chemischen Verschiebungen ( $\delta$-Skala) den ${ }^{1} \mathrm{H}$-breitbandentkoppelten Spektren entnommen und die Multiplizitäten der Signale in Multiplett-Selection-Experimenten (APT-Pulsfolge) oder über eine inverse ${ }^{1} \mathrm{H}_{-}{ }^{13} \mathrm{C}$ Korrelation bestimmt wurden.

Massenspektren: Massenspektren wurden mit den Modellen MAT 311A (niederaufgelöste Spektren) und MAT 731 (hochaufgelöste Spektren) der Firma Varian gemessen. In Klammern sind die relativen Intensitäten bezogen auf den Basispeak $(I=100 \%)$ angegeben.

Elementaranalysen: Elementaranalysen wurden im mikroanalytischen Labor des Instituts für Organische Chemie der Universität Göttingen bestimmt. 


\subsection{Chromatographische Methoden}

Dünnschichtchromatographie (DC): Es wurden DC-Fertigfolien SIL G/UV ${ }_{254}$ (Schichtdicke $0.25 \mathrm{~mm}$ ) der Firma Macherey-Nagel \& Co. verwendet. Angegeben sind $\mathrm{R}_{\mathrm{f}}$-Werte. Neben der UV-Detektion dienten eine Vanillin- $\mathrm{H}_{2} \mathrm{SO}_{4}$-Lösung $\left(0.5 \mathrm{~g}\right.$ Vanillin, $3 \mathrm{~mL} \mathrm{H}_{2} \mathrm{SO}_{4}$, $85 \mathrm{~mL} \mathrm{MeOH}, 10 \mathrm{~mL}$ HOAc) und eine Molybdatophosphorsäure-Lösung (10 \% in EtOH) als Anfärbereagenzien.

Säulenchromatographie: Säulenchromatographische Trennungen wurden mit Kieselgel 60 (Korngröße: 0.040-0.063 mm) der Firma Merck durchgeführt.

Präparative Dünnschichtchromatographie (PDC): Die Platten für die PDC wurden selbst hergestellt. Dazu wurden $65 \mathrm{~mL}$ einer Mischung von $1200 \mathrm{~g}$ Kieselgel 60 PF $_{254}$ der Firma Merck und $2800 \mathrm{~mL}$ Wasser auf eine Glasplatte $(20 \times 20 \mathrm{~cm})$ aufgetragen und gleichmäßig verteilt, um eine Schichtdicke von ca. $2 \mathrm{~mm}$ zu erhalten. Die Platten wurden $24 \mathrm{~h}$ bei Zimmertemperatur und $4 \mathrm{~h}$ bei $120^{\circ} \mathrm{C}$ getrocknet.

Hochleistungsflüssigkeitschromatographie (HPLC): Die analytischen Trennungen erfolgten mit einer HPLC-Anlage der Firma Jasco, bestehend aus einem AS-2055 Plus Sampler, einem DG-1580-54 Degasser, einer LG-1580-04 Mischkammer, einer PU-2080 Plus Pumpe und einem MD-2010 Plus Multiwavelength Detector. Verwendet wurde eine Säule des Typs Kromasil $100 \mathrm{C} 18(5 \mu \mathrm{m}, 250 \times 4 \mathrm{~mm})$ der Firma Jasco. Die präparativen Trennungen erfolgten mit einer HPLC-Anlage der Firma Jasco bestehend aus zwei PU-2087 Plus Pumpen, einem UV-2075 Plus UV/VIS-Detector und einer Mischkammer Mika 1000 der Firma Portmann Instruments. Verwendet wurde eine Säule des Typs Kromasil $100 \mathrm{C} 18$ (7 $\mu \mathrm{m}$, $250 \times 20 \mathrm{~mm}$ ) der Firma Jasco in Verbindung mit einer Vorsäule des Typs Kromasil 100 C18 $(5 \mu \mathrm{m}, 50 \times 20 \mathrm{~mm})$ der Firma Jasco.

\subsection{Materialien für die in vitro-Zytotoxizitätsessays}

Zelllinie: A549, ATCC-CCL 185 (American Type Culture Collection Certified Cell Lines), eine 1972 aus einem cancerogenen Tumorexplanat der Lunge eines 58-jährigen männlichen Patienten etablierte, epithelähnliche, adhärent in Monolayern wachsende Zelllinie. Herkunft: Institut für Zellbiologie der Universität Essen. 
Zellzählkammer: Nach Neubauer mit Zählkammer der Firma Bürker.

Multiwellplatten: 6-Multiwellplatten der Firma Biochrom.

Zellablösungsreagenz: Trypsin-EDTA-Lösung für die Passagierung von Monolayer-kulturen der Firma Biochrom. 0.05-0.02\% in PBS (Phosphat-Buffered-Saline) ohne $\mathrm{Ca}^{2+}, \mathrm{Mg}^{2+}$.

Medium: DMEM (Dulbecco's Modified Eagles Medium) der Firma Biochrom in Form von Trockenmedium (enthält $4.5 \mathrm{~g} / \mathrm{L}$ Glucose). Ansatz: $13.43 \mathrm{~g} / \mathrm{L}$ in bidestilliertem Wasser mit $3.7 \mathrm{~g} / \mathrm{L}$ Natriumhydrogencarbonat als Puffer. Das Medium wurde mit verdünnter Salzsäure auf $\mathrm{pH}=7.3$ titriert. Als serumfreies Medium wurde UltraCulture (Zusatz: $2 \mathrm{mM}$ LGlutamin) der Firma Cambrex eingesetzt.

Medium-Zusätze: 10 \% FKS (Fötales Kälberserum) der Firma Biochrom, inaktiviert durch Hitze, 30 min bei $56{ }^{\circ} \mathrm{C}$; $4 \mathrm{mM}$ L-Glutamin der Firma Biochrom. 


\section{Synthese der indolhaltigen DNA-Binder}

\section{$2.1 \quad$ Synthese von 95}

\subsection{1. $p$-(2-Chlorethoxy)-nitrophenol (44)}<smiles>O=[N+]([O-])c1ccc(OCCCl)cc1</smiles>

Zu einer Mischung von $p$-Nitrophenol (20.0 g, 144 mmol, 1 Äq.) und Kaliumcarbonat (39.8 g, 288 mmol, 2 Äq.) wurde DMF (200 mL) zugegeben. Dann wurde Dichlorethan (142.5 g, 1.44 mol, 10 Äq.) zugegeben und $12 \mathrm{~h}$ bei $120{ }^{\circ} \mathrm{C}$ gerührt. Danach wurde Dichlorethan im Vakuum entfernt und Wasser $(200 \mathrm{~mL})$ hinzugegeben. Die wässrige Phase wurde mit AcOEt $(2 \times 200 \mathrm{~mL})$ extrahiert. Die vereinigten organischen Phasen wurden mit ges. NaCl-Lösung $(100 \mathrm{~mL})$ gewaschen, über $\mathrm{Na}_{2} \mathrm{SO}_{4}$ getrocknet und das Lösungsmittel im Vakuum entfernt. Die Titelverbindung wurde als brauner Feststoff (24.8 g, 122.8 mmol, 85 \%) erhalten.

$\mathbf{R}_{\mathbf{f}}=0.7(\mathrm{PE} / \mathrm{AcOEt}=3: 1)$.

${ }^{1}$ H-NMR (300 MHz, $\left.\mathrm{CDCl}_{3}\right): \delta=3.88\left(\mathrm{t}, J=5.7 \mathrm{~Hz}, 2 \mathrm{H}, 2^{\prime}-\mathrm{H}_{2}\right), 4.34(\mathrm{t}, J=5.7 \mathrm{~Hz}, 2 \mathrm{H}$, $\left.1^{\prime}-\mathrm{H}_{2}\right), 6.97-7.03\left(\mathrm{~m}_{\mathrm{c}}, 2 \mathrm{H}, 2-\mathrm{H}, 6-\mathrm{H}\right), 8.18-8.24\left(\mathrm{~m}_{\mathrm{c}}, 2 \mathrm{H}, 3-\mathrm{H}, 5-\mathrm{H}\right)$.

${ }^{13} \mathrm{C}-\mathrm{NMR}\left(50 \mathrm{MHz}, \mathrm{CDCl}_{3}\right): \delta=41.42$ (C-2'), 68.46 (C-1'), 114.5 (C-2, C-6), 125.9 (C-3, C-5), 141.8 (C-4), 163.1 (C-1).

MS (EI, $70 \mathrm{eV}): m / z(\%)=201.3(48)[\mathrm{M}]^{+}$.

$\mathrm{C}_{8} \mathrm{H}_{8} \mathrm{CINO}_{3}$ (201.61). 


\subsection{2. p-(2-Chlorethoxy)-anilin (45)}<smiles>Nc1ccc(OCCCl)cc1</smiles>

Eine Lösung von 44 (24.8 g, 123 mmol, 1 Äq.) in AcOEt/EtOH (100 mL/40 mL) wurde mit Palladium auf Aktivkohle (10\%ig, $0.74 \mathrm{~g})$ versetzt, $1 \mathrm{~h}$ bei Raumtemperatur unter $\mathrm{H}_{2}$ Atmosphäre (4 bar) geschüttelt. Der Feststoff wurde durch Filtration über Celite abgetrennt, gründlich mit $\mathrm{CH}_{2} \mathrm{Cl}_{2} / \mathrm{MeOH}$ (2:1) nachgespült. Nach Entfernen des Lösungsmittels wurde die Titelverbindung (20.4 g, 119 mmol, 97\%) als weißer Feststoff erhalten.

$\mathbf{R}_{\mathbf{f}}=0.7(\mathrm{PE} / \mathrm{AcOEt}=1: 1)$.

${ }^{1}$ H-NMR (300 MHz, DMSO-d 6 ): $\delta=3.85\left(\mathrm{t}, J=5.4 \mathrm{~Hz}, 2 \mathrm{H}, 2{ }^{\prime}-\mathrm{H}_{2}\right), 4.34(\mathrm{t}, J=5.4 \mathrm{~Hz}, 2 \mathrm{H}$, 1'- $\left.\mathrm{H}_{2}\right), 4.60$ ( $\left.\mathrm{s}_{\mathrm{br}}, 2 \mathrm{H}, \mathrm{NH}_{2}\right), 6.49-6.55\left(\mathrm{~m}_{\mathrm{c}}, 2 \mathrm{H}, 2-\mathrm{H}, 6-\mathrm{H}\right), 6.66-6.71\left(\mathrm{~m}_{\mathrm{c}}, 2 \mathrm{H}, 3-\mathrm{H}, 5-\mathrm{H}\right)$.

${ }^{13}$ C-NMR (50 MHz, DMSO-d 6 ): $\delta=43.15$ (C-2'), 68.68 (C-1'), 114.8 (C-3, C-5), 115.8 (C-2, C-6), 142.8 (C-1), 149.1 (C-4).

MS (EI, $70 \mathrm{eV}): m / z(\%)=171.1(34)[\mathrm{M}]^{+}$.

$\mathrm{C}_{8} \mathrm{H}_{10} \mathrm{CINO}$ (171.62). 


\subsubsection{5-(2-Chlorethoxy)-indol-2-carbonsäureethylester (49)}

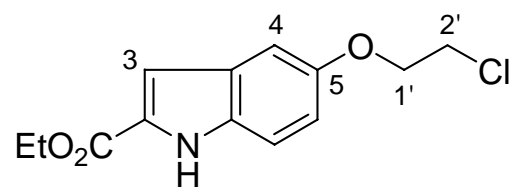

Zu einer Lösung des Anilinderivates 45 (20.4 g, 119 mmol, 1.0 Äq.) in Wasser (280 mL) und konzentrierter Salzsäure $(18.8 \mathrm{~mL})$ wurde bei $0{ }^{\circ} \mathrm{C}$ eine Lösung von $\mathrm{NaNO}_{2}(8.66 \mathrm{~g}$, $102 \mathrm{mmol}, 1.0$ Äq.) in Wasser $(76 \mathrm{~mL})$ getropft und die Reaktionsmischung $15 \mathrm{~min}$ bei $0{ }^{\circ} \mathrm{C}$ gerührt (Lösung A).

Eine Suspension aus NaOAc (39.0 g, $476 \mathrm{mmol}, 4.0$ Äq.) in Ethanol (252 mL) wurde bei $0{ }^{\circ} \mathrm{C}$ tropfenweise mit 2-Methylacetessigsäureethylester (17.2 g, 119 mmol, 1.0 Äq.) versetzt. Nach Rühren bei $0{ }^{\circ} \mathrm{C}$ für 10 min wurde Wasser $(36 \mathrm{~mL})$ zugegeben (Lösung $\mathrm{B}$ ).

Anschließend gab man Lösung A zügig zu Lösung B, erwärmte auf Raumtemperatur und rührte $2 \mathrm{~h}$ bei Raumtemperatur. Nach Entfernen des Ethanols im Vakuum wurde die wässrige Phase mit Ether extrahiert, die vereinigten organischen Phasen über $\mathrm{Na}_{2} \mathrm{SO}_{4}$ getrocknet und das Lösungsmittel im Vakuum entfernt. Zu dem erhaltenen braunen Öl gab man eine Lösung von ges. $\mathrm{HCl} / \mathrm{HOAc}(180 \mathrm{~mL})$. Die Reaktionsmischung wurde $30 \mathrm{~min}$ bei $70{ }^{\circ} \mathrm{C}$ gerührt. Anschließend ließ man auf Raumtemperatur abkühlen, das Lösungsmittel im Vakuum entfernen. Wasser wurde zugegeben, die wässrige Phase mit Ether extrahiert, die vereinigten organischen Phasen über $\mathrm{Na}_{2} \mathrm{SO}_{4}$ getrocknet und das Lösungsmittel im Vakuum entfernt. Das Rohprodukt wurde aus EtOH/ $\mathrm{H}_{2} \mathrm{O}$ (1:1) umkristallisiert, und die Titelverbindung als gelber Feststoff (32.3 g, 87.4 mmol, $73 \%$ ) erhalten.

$\mathbf{R}_{\mathbf{f}}=0.2(\mathrm{PE} / \mathrm{AcOEt}=10: 1)$.

Smp.: $146-147^{\circ} \mathrm{C}$.

UV $\left(\mathrm{CH}_{3} \mathrm{CN}\right): \lambda_{\max }(\lg \varepsilon)=216.0 \mathrm{~nm}$ (4.427), 293.0 (4.297).

IR $(\mathrm{KBr}): \widetilde{v}\left(\mathrm{~cm}^{-1}\right)=3321,1666,1536,1345,1232$.

${ }^{1} \mathbf{H}-\mathbf{N M R}\left(300 \mathrm{MHz} \mathrm{CDCl}_{3}\right): \delta=1.41\left(\mathrm{t}, J=7.2 \mathrm{~Hz}, 3 \mathrm{H}, \mathrm{CH}_{3}\right), 3.82(\mathrm{t}, J=6.0 \mathrm{~Hz}, 2 \mathrm{H}$, 2'- $\left.\mathrm{H}_{2}\right), 4.26$ (t, $\left.J=6.0 \mathrm{~Hz}, 2 \mathrm{H}, 1^{\prime}-\mathrm{H}_{2}\right), 4.41$ (q, $\left.J=7.2 \mathrm{~Hz}, 2 \mathrm{H}, \mathrm{C}_{2}{ }_{2} \mathrm{CH}_{3}\right), 7.02$ (dd, $J=8.7$, $2.4 \mathrm{~Hz}, 1 \mathrm{H}, 6-\mathrm{H}), 7.09$ (d, $J=2.4 \mathrm{~Hz}, 1 \mathrm{H}, 4-\mathrm{H}), 7.13$ (d, J=1.5 Hz, $1 \mathrm{H}, 3-\mathrm{H}), 7.32$ (d, $J=9.3 \mathrm{~Hz}, 1 \mathrm{H}, 7-\mathrm{H}), 9.00$ (s, $1 \mathrm{H}$, Indol-NH). 
${ }^{13}$ C-NMR (75 MHz, $\left.\mathrm{CDCl}_{3}\right): \delta=14.37\left(\mathrm{CH}_{3}\right), 42.00\left(\mathrm{C}-2^{\prime}\right), 60.99\left(\mathrm{C}-1^{\prime}\right), 68.98\left(\underline{\mathrm{CH}}_{2} \mathrm{CH}_{3}\right)$, 104.7 (C-4), 108.2 (C-3), 112.9 (C-7), 117.3 (C-6), 127.8, 128.2 (C-2, C-3a), 132.7 (C-7a), $153.2(\mathrm{C}-5), 161.9(\mathrm{C}=\mathrm{O})$.

MS (EI, $70 \mathrm{eV}): m / z(\%)=267.1(88)[\mathrm{M}]^{+}$.

$\mathbf{C}_{13} \mathbf{H}_{14} \mathrm{ClNO}_{3}$ (267.71). $\quad$ Ber.: 290.05544 für $[\mathrm{M}+\mathrm{Na}]^{+}$

Gef.: 290.05540 (ESI-HRMS).

Ber.: C: $58.32 \quad$ H: $5.27 \quad \mathrm{~N}: 5.23$

Gef:: $\quad$ C: $58.56 \quad$ H: $5.29 \quad$ N: 5.06

\subsubsection{5-(2-Chlorethoxy)-indol-2-carbonsäure (95)}<smiles>O=C(O)c1cc2cc(OCCCl)ccc2[nH]1</smiles>

$\mathrm{Zu}$ einer Lösung von 49 (2.68 g, $10.0 \mathrm{mmol}, 1.0$ Äq.) in EtOH/ $\mathrm{H}_{2} \mathrm{O} / \mathrm{THF}(1: 1: 1,120 \mathrm{~mL})$, versetzte man $\mathrm{LiOH} \cdot \mathrm{H}_{2} \mathrm{O}$ (1.26 g, $30.0 \mathrm{mmol}, 3.0$ Äq.). Das Reaktionsgemisch wurde $3 \mathrm{~h}$ bei $40{ }^{\circ} \mathrm{C}$ gerührt. Man ließ auf $0{ }^{\circ} \mathrm{C}$ abkühlen, gab $\mathrm{H}_{2} \mathrm{O}(50 \mathrm{~mL})$ hinzu und mit $1 \mathrm{M} \mathrm{HCl}$ auf $\mathrm{pH}=2$ einstellte. Die wässrige Phase wurde mit AcOEt $(2 \times 100 \mathrm{~mL})$ extrahiert. Die vereinigten organischen Phasen wurden über $\mathrm{Na}_{2} \mathrm{SO}_{4}$ getrocknet und das Lösungsmittel im Vakuum entfernt. Die Titelverbindung (2.30 g, 9.6 mmol, $96 \%$ ) wurde als brauner Feststoff erhalten.

$\mathbf{R}_{\mathbf{f}}=0.4\left(\mathrm{CH}_{2} \mathrm{Cl}_{2} / \mathrm{MeOH}=20: 1+1 \% \mathrm{HOAc}\right)$.

Smp.: $206-207^{\circ} \mathrm{C}$ (zers.).

${ }^{1}$ H-NMR (300 MHz, DMSO-d $\left.{ }_{6}\right): \delta=3.93\left(\mathrm{t}, J=5.1 \mathrm{~Hz}, 2 \mathrm{H}, 2^{\prime}-\mathrm{H}_{2}\right), 4.23(\mathrm{t}, J=5.1 \mathrm{~Hz}, 2 \mathrm{H}$, 1'- $\left.\mathrm{H}_{2}\right), 6.94$ (dd, $\left.J=9.0,2.4 \mathrm{~Hz}, 1 \mathrm{H}, 6-\mathrm{H}\right), 7.00$ (d, $\left.J=1.5 \mathrm{~Hz}, 1 \mathrm{H}, 3-\mathrm{H}\right), 7.14$ (d, $J=2.7 \mathrm{~Hz}$, $1 \mathrm{H}, 4-\mathrm{H}), 7.36$ (d, J=8.7 Hz, $1 \mathrm{H}, 7-\mathrm{H}), 11.61$ (s, $1 \mathrm{H}$, Indol-NH), 12.80 (s $\left.\mathrm{s}_{\mathrm{b}}, 1 \mathrm{H}, \mathrm{COOH}\right)$.

MS (EI, $70 \mathrm{eV}): m / z(\%)=239.1(65)[\mathrm{M}]^{+}$.

$\mathrm{C}_{11} \mathrm{H}_{10} \mathrm{CINO}_{3}$ (239.65). 


\subsection{Synthese von 60}

\subsubsection{5-(2-Iodethoxy)-indol-2-carbonsäureethylester (50)}<smiles>CCOC(=O)c1cc2cc(OCCI)ccc2[nH]1</smiles>

Zu einer Lösung von 49 (3.28 g, 12.3 mmol, 1.0 Äq.) in trocknem $\mathrm{CH}_{3} \mathrm{CN}$ (140 mL), gab man NaI (36.7 g, 245 mmol, 20 Äq.), rührte 2 d am Rückfluss. Nach Abkühlen auf Raumtemperatur wurde Wasser $(150 \mathrm{~mL})$ versetzt, mit AcOEt $(2 \times 150 \mathrm{~mL})$ extrahiert. Die vereinigten organischen Phasen wurden über $\mathrm{Na}_{2} \mathrm{SO}_{4}$ getrocknet und das Lösungsmittel im Vakuum entfernt. Die Titelverbindung (4.12g, $11.5 \mathrm{mmol}, 94 \%)$ wurde als gelben Feststoff erhalten.

$\mathbf{R}_{\mathbf{f}}=0.3(\mathrm{PE} / \mathrm{AcOEt}=10: 1)$.

Smp.: $144{ }^{\circ} \mathrm{C}$.

UV $\left(\mathrm{CH}_{3} \mathrm{CN}\right): \lambda_{\max }(\lg \varepsilon)=216.0 \mathrm{~nm}$ (4.459), 293.5 (4.328).

IR $(\mathrm{KBr}): \widetilde{v}\left(\mathrm{~cm}^{-1}\right)=3320,1666,1535,1341,1214$.

${ }^{1}$ H-NMR $\left(300 \mathrm{MHz}, \mathrm{CDCl}_{3}\right): \delta=1.42\left(\mathrm{t}, J=7.2 \mathrm{~Hz}, 3 \mathrm{H}, \mathrm{CH}_{3}\right), 3.45(\mathrm{t}, J=7.2 \mathrm{~Hz}, 2 \mathrm{H}$, 2'- $\left.\mathrm{H}_{2}\right), 4.28$ (t, $\left.J=7.2 \mathrm{~Hz}, 2 \mathrm{H}, 1^{\prime}-\mathrm{H}_{2}\right), 4.41$ (q, $\left.J=7.2 \mathrm{~Hz}, 2 \mathrm{H}, \underline{\mathrm{C}}_{2} \mathrm{CH}_{3}\right), 7.02$ (dd, $J=9.0$, $2.7 \mathrm{~Hz}, 1 \mathrm{H}, 6-\mathrm{H}), 7.09$ (d, $J=2.7 \mathrm{~Hz}, 1 \mathrm{H}, 4-\mathrm{H}), 7.14$ (d, J=1.2 Hz, 1 H, 3-H), 7.33 (d, $J=9.0 \mathrm{~Hz}, 1 \mathrm{H}, 7-\mathrm{H}), 9.01$ (s, $1 \mathrm{H}$, Indol-NH).

${ }^{13}$ C-NMR (75 MHz, $\left.\mathrm{CDCl}_{3}\right): \delta=1.58\left(\mathrm{C}-2^{\prime}\right), 14.38\left(\mathrm{CH}_{3}\right), 61.00\left(\mathrm{C}-1\right.$ ') $69.47\left(\underline{\mathrm{CH}}_{2} \mathrm{CH}_{3}\right)$, 104.7 (C-4), 108.1 (C-3), 112.9 (C-7), 117.3 (C-6), 127.7, 128.1 (C-2, C-3a), 132.5 (C-7a), $152.9(\mathrm{C}-5), 161.9(\mathrm{C}=\mathrm{O})$.

MS (EI, $70 \mathrm{eV}): m / z(\%)=358.9(36)[\mathrm{M}]^{+}$.

$\mathbf{C}_{13} \mathrm{H}_{14} \mathrm{INO}_{3}$ (359.16).

Ber.: 360.00911 für $[\mathrm{M}+\mathrm{H}]^{+}$

Gef.: 360.00927 (ESI-HRMS).

Ber.: $\quad$ C: $43.47 \quad$ H: $3.93 \quad$ N: 3.90

Gef.: $\quad$ C: $43.56 \quad$ H: $3.90 \quad$ N: 3.78 


\subsubsection{5-(2-Iodethoxy)-indol-2-carbonsäure (60)}<smiles>O=C(O)c1cc2cc(OCCI)ccc2[nH]1</smiles>

$\mathrm{Zu}$ einer Lösung von 50 (1.08 g, $3.0 \mathrm{mmol}, 1.0$ Äq.) in EtOH/ $\mathrm{H}_{2} \mathrm{O} / \mathrm{THF}(1: 1: 1,60 \mathrm{~mL})$, versetzte man $\mathrm{LiOH} \cdot \mathrm{H}_{2} \mathrm{O}$ (378 mg, $9.0 \mathrm{mmol}, 3.0$ Äq.). Das Reaktionsgemisch wurde $3 \mathrm{~h}$ bei $40{ }^{\circ} \mathrm{C}$ gerührt. Man ließ auf $0{ }^{\circ} \mathrm{C}$ abkühlen, gab $\mathrm{H}_{2} \mathrm{O}(40 \mathrm{~mL})$ hinzu und mit $1 \mathrm{M} \mathrm{HCl}$ auf $\mathrm{pH}=2$ einstellte. Die wässrige Phase wurde mit AcOEt $(2 \times 100 \mathrm{~mL})$ extrahiert. Die vereinigten organischen Phasen wurden über $\mathrm{Na}_{2} \mathrm{SO}_{4}$ getrocknet und das Lösungsmittel im Vakuum entfernt. Die Titelverbindung (0.94 g, $2.8 \mathrm{mmol}, 95 \%)$ wurde als brauner Feststoff erhalten.

$\mathbf{R}_{\mathbf{f}}=0.4\left(\mathrm{CH}_{2} \mathrm{Cl}_{2} / \mathrm{MeOH}=20: 1+1 \% \mathrm{HOAc}\right)$.

Smp.: 202-203 ${ }^{\circ} \mathrm{C}$ (zers.).

IR $(\mathrm{KBr}): \widetilde{v}\left(\mathrm{~cm}^{-1}\right)=3449,2571,1666,1538,1229$.

${ }^{1}$ H-NMR (300 MHz, DMSO-d $\left.)_{6}\right): \delta=3.52\left(\mathrm{t}, J=6.0 \mathrm{~Hz}, 2 \mathrm{H}, 2^{\prime}-\mathrm{H}_{2}\right), 4.24(\mathrm{t}, J=6.0 \mathrm{~Hz}, 2 \mathrm{H}$, 1'- $\left.-\mathrm{H}_{2}\right), 6.94$ (dd, $\left.J=9.0,2.7 \mathrm{~Hz}, 1 \mathrm{H}, 6-\mathrm{H}\right), 7.00$ (d, $\left.J=1.5 \mathrm{~Hz}, 1 \mathrm{H}, 3-\mathrm{H}\right), 7.13$ (d, $J=2.1 \mathrm{~Hz}$, $1 \mathrm{H}, 4-\mathrm{H}), 7.36$ (d, $J=8.7 \mathrm{~Hz}, 1 \mathrm{H}, 7-\mathrm{H}), 11.58$ (s, $1 \mathrm{H}$, Indol-NH), 12.8 (s $\mathrm{br}, 1 \mathrm{H}, \mathrm{COOH})$.

${ }^{13}$ C-NMR (75 MHz, DMSO-d 6 ): $\delta=4.16$ (C-2'), 68.84 (C-1'), 104.1 (C-4), 106.9 (C-3), 113.4 (C-7), 116.1 (C-6), 127.1, 128.8 (C-2 ,C-3a), 132.9 (C-7a), 152.2 (C-5), 162.6(C=O).

MS (EI, $70 \mathrm{eV}): m / z(\%)=331.2(17)[\mathrm{M}]^{+}$.

$\mathrm{C}_{11} \mathrm{H}_{10} \mathrm{INO}_{3}(331.11)$. 


\subsection{Synthese von 90}

\subsection{1. p-(2-Hydroxyethoxy)-nitrophenol (51)}<smiles>O=[N+]([O-])c1ccc(OCCO)cc1</smiles>

$\mathrm{Zu}$ einer Mischung von $p$-Nitrophenol (20.0 g, $144 \mathrm{mmol}, 1.0$ Äq.) und Kaliumcarbonat (39.8 g, 288 mmol, 2.0 Äq.) wurde DMF (200 mL) zugegeben. Dann wurde 2-Chlorethanol (34.8 g, 432 mmol, 3.0 Äq.) zugegeben und $7 \mathrm{~h}$ bei $90{ }^{\circ} \mathrm{C}$ gerührt. Danach wurde das Lösungsmittel im Vakuum entfernt und Wasser $(200 \mathrm{~mL})$ hinzugegeben. Die wässrige Phase wurde mit AcOEt $(2 \times 200 \mathrm{~mL})$ extrahiert. Die vereinigten organischen Phasen wurden mit ges. $\mathrm{NaHCO}_{3}$-Lösung $(100 \mathrm{~mL})$ gewaschen, über $\mathrm{Na}_{2} \mathrm{SO}_{4}$ getrocknet und das Lösungsmittel im Vakuum entfernt. Das Nitroderivat 51 wurde als blass-gelbliche Nadel (21.5 g, 117 mmol, $81 \%$ ) erhalten.

$\mathbf{R}_{\mathbf{f}}=0.5(\mathrm{PE} / \mathrm{AcOEt}=1: 1)$.

${ }^{1}$ H-NMR (300 MHz, DMSO-d $\left.{ }_{6}\right): \delta=3.75\left(\mathrm{t}, J=4.9 \mathrm{~Hz}, 2 \mathrm{H}, 2^{\prime}-\mathrm{H}_{2}\right), 4.14(\mathrm{t}, J=4.8 \mathrm{~Hz}, 2 \mathrm{H}$, $\left.1^{\prime}-\mathrm{H}_{2}\right), 4.48$ (s, $\left.1 \mathrm{H}, \mathrm{OH}\right), 7.11-7.17$ (m $\left.\mathrm{m}_{\mathrm{c}}, 2 \mathrm{H}, 2-\mathrm{H}, 6-\mathrm{H}\right), 8.16-8.21\left(\mathrm{~m}_{\mathrm{c}}, 2 \mathrm{H}, 3-\mathrm{H}, 5-\mathrm{H}\right)$.

${ }^{13}$ C-NMR (75 MHz, DMSO-d 6 ): $\delta=59.25$ (C-2') 70.55 (C-1'), 115.0 (C-2, C-6), 125.7 (C-3, C-5), 140.7 (C-4), 164.0 (C-1).

MS (EI, $70 \mathrm{eV}): m / z(\%)=183.1(53)[\mathrm{M}]^{+}$.

$\mathrm{C}_{8} \mathrm{H}_{9} \mathrm{NO}_{4}(183.16)$. 


\subsection{2. p-(2-Hydroxyethoxy)-anilin (52)}

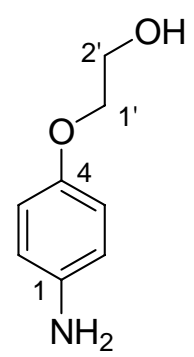

Eine Lösung des Nitroderivats 51 (4.9 g, 26.8 mmol, 1.0 Äq.) in AcOEt/MeOH $(40 \mathrm{~mL} / 20 \mathrm{~mL})$ wurde mit Palladium auf Aktivkohle (10\%ig, $0.24 \mathrm{~g})$ versetzt, $1 \mathrm{~h}$ bei Raumtemperatur unter $\mathrm{H}_{2}$-Atmosphäre (4 bar) geschüttelt. Der Feststoff wurde durch Filtration über Celite abgetrennt, gründlich mit $\mathrm{CH}_{2} \mathrm{Cl}_{2} / \mathrm{MeOH}$ (2:1) nachgespült. Nach Entfernen des Lösungsmittels wurde die Zielverbindung 52 (4.3 g, $26.8 \mathrm{mmol}, 100 \%)$ als gelbes Öl erhalten.

$\mathbf{R}_{\mathbf{f}}=0.3(\mathrm{PE} / \mathrm{AcOEt}=1: 1)$.

$\mathrm{C}_{8} \mathrm{H}_{11} \mathrm{NO}_{2}(153.18)$.

\subsubsection{5-(2-Hydroxyethoxy)-indol-2-carbonsäureethylester (53)}<smiles>CCOC(=O)c1cc2cc(OC=CO)ccc2[nH]1</smiles>

Zu einer Lösung des Aminoderivats 52 (4.94 g, 32.2 mmol, 1.0 Äq.) in Wasser (50 mL) und konzentrierter Salzsäure $(6.0 \mathrm{~mL})$ wurde bei $0{ }^{\circ} \mathrm{C}$ eine Lösung von $\mathrm{NaNO}_{2}(2.22 \mathrm{~g}$, $32.2 \mathrm{mmol}, 1.0$ Äq.) in Wasser $(15 \mathrm{~mL})$ getropft und die Reaktionsmischung 15 min bei $0{ }^{\circ} \mathrm{C}$ gerührt (Lösung A).

Eine Suspension aus NaOAc (10.57 g, $129 \mathrm{mmol}, 4.0$ Äq.) in Ethanol $(40 \mathrm{~mL})$ wurde bei $0{ }^{\circ} \mathrm{C}$ tropfenweise mit 2-Methylacetessigsäureethylester (4.64 g, $32.2 \mathrm{mmol}, 1.0$ Äq.) versetzt. Nach Rühren bei $0{ }^{\circ} \mathrm{C}$ für 10 min wurde Wasser $(10 \mathrm{~mL})$ zugegeben (Lösung B).

Anschließend gab man Lösung A zügig zu Lösung B, erwärmte auf Raumtemperatur und rührte $2 \mathrm{~h}$ bei Raumtemperatur. Nach Entfernen des Ethanols im Vakuum wurde die wässrige Phase mit AcOEt $(2 \times 100 \mathrm{~mL})$ extrahiert, die vereinigten organischen Phasen über $\mathrm{Na}_{2} \mathrm{SO}_{4}$ 
getrocknet und das Lösungsmittel im Vakuum entfernt. Zu dem erhaltenen braunen Öl gab man eine Lösung von $6 \mathrm{M} \mathrm{HCl} / i$-PrOH $(27 \mathrm{~mL})$. Die Reaktionsmischung wurde $15 \mathrm{~min}$ bei $70{ }^{\circ} \mathrm{C}$ gerührt. Anschließend ließ man auf Raumtemperatur abkühlen, das Lösungsmittel im Vakuum entfernen. Wasser $(100 \mathrm{~mL})$ wurde zugegeben, die wässrige Phase mit AcOEt $(2 \times 100 \mathrm{~mL})$ extrahiert, die vereinigten organischen Phasen über $\mathrm{Na}_{2} \mathrm{SO}_{4}$ getrocknet und das Lösungsmittel im Vakuum entfernt. Nach Säulenchromatographie an Kieselgel $\left(\mathrm{CH}_{2} \mathrm{Cl}_{2} / \mathrm{MeOH}=100: 1\right)$ erhielt man die Titelverbindung als gelben Feststoff $(4.3 \mathrm{~g}$, $17.3 \mathrm{mmol}, 54 \%)$.

$\mathbf{R}_{\mathbf{f}}=0.4(\mathrm{PE} / \mathrm{EE}=1: 1)$.

UV $\left(\mathrm{CH}_{3} \mathrm{CN}\right): \lambda_{\max }(\lg \varepsilon)=216.0 \mathrm{~nm}$ (4.422), 293.5 (4.288), 322.5 (3.722).

IR $(\mathrm{KBr}): \widetilde{v}\left(\mathrm{~cm}^{-1}\right)=3327,1687,1528,1449,1341,1214$.

${ }^{1}$ H-NMR (300 MHz, DMSO-d $\left.\mathrm{d}_{6}\right): \delta=1.34\left(\mathrm{t}, J=7.2 \mathrm{~Hz}, 3 \mathrm{H}, \mathrm{CH}_{3}\right), 3.73$ (q, $J=5.1 \mathrm{~Hz}, 2 \mathrm{H}$, 2'- $\left.\mathrm{H}_{2}\right), 3.98$ (t, $\left.J=5.1 \mathrm{~Hz}, 2 \mathrm{H}, 1^{\prime}-\mathrm{H}_{2}\right), 4.33$ (q, $\left.J=7.2 \mathrm{~Hz}, 2 \mathrm{H}, \mathrm{C}_{2} \mathrm{CH}_{3}\right), 4.78$ (t, $J=5.7 \mathrm{~Hz}$, $1 \mathrm{H}, \mathrm{OH}), 6.94(\mathrm{dd}, J=9.0,2.4 \mathrm{~Hz}, 1 \mathrm{H}, 6-\mathrm{H}), 7.04(\mathrm{~s}, 1 \mathrm{H}, 3-\mathrm{H}), 7.11(\mathrm{~d}, J=2.4 \mathrm{~Hz}, 1 \mathrm{H}$, 4-H), 7.36 (d, $J=9.0 \mathrm{~Hz}, 1 \mathrm{H}, 7-\mathrm{H}), 11.66$ (s, $1 \mathrm{H}$, Indol-NH).

${ }^{13}$ C-NMR (75 MHz, DMSO-d 6$): \delta=14.18\left(\mathrm{CH}_{3}\right), 59.64,60.15(\mathrm{C}-1$ ', $\mathrm{C}-2$ ') $), 69.83\left(\underline{\mathrm{CH}}_{2} \mathrm{CH}_{3}\right)$, 103.1 (C-4), 107.2 (C-3), 113.3 (C-7), 116.5 (C-6), 127.0, 127.5 (C-2, C-3a), 132.7 (C-7a), $153.2(\mathrm{C}-5), 161.1(\mathrm{C}=\mathrm{O})$.

MS (EI, $70 \mathrm{eV}): m / z(\%)=249.1(77)[\mathrm{M}]^{+}$.

$\mathrm{C}_{13} \mathrm{H}_{15} \mathrm{NO}_{4}$ (249.26).

\subsubsection{5-(2-Hydroxyethoxy)-indol-2-carbonsäure (90)}<smiles>O=C(O)c1cc2cc(OCCO)ccc2[nH]1</smiles>

$\mathrm{Zu}$ einer Lösung von 53 (1.25 g, $5.0 \mathrm{mmol}, 1.0$ Äq) in $\mathrm{H}_{2} \mathrm{O} / \mathrm{EtOH} / \mathrm{THF}(1: 1: 1,75 \mathrm{~mL}) \mathrm{gab}$ man $\mathrm{LiOH} \cdot \mathrm{H}_{2} \mathrm{O}\left(0.60 \mathrm{~g}, 15 \mathrm{mmol}, 3.0 \mathrm{Äq}\right.$.) und ließ $30 \mathrm{~min}$ bei $60^{\circ} \mathrm{C}$ rühren. Danach wurde Wasser $(50 \mathrm{~mL})$ zugegeben, mit $2 \mathrm{M} \mathrm{HCl}$ den $\mathrm{pH}$-Wert der Lösung auf 2 eingestellt. Die Organische Lösung wurde im Vakuum entfernt und die wässrige Phase wurde mit AcOEt $(2 \times 100 \mathrm{~mL})$ extrahiert. Die vereinigten organischen Phasen wurden über $\mathrm{Na}_{2} \mathrm{SO}_{4}$ getrocknet 
und das Lösungsmittel im Vakuum entfernt. Die Zielverbindung (0.88 g, 4.0 mmol, 79 \%) wurde als brauner Feststoff erhalten.

$\mathbf{R}_{\mathbf{f}}=0.5(\mathrm{PE} / \mathrm{EE}=1: 1)$.

UV $\left(\mathrm{CH}_{3} \mathrm{CN}\right): \lambda_{\max }(\lg \varepsilon)=216.0 \mathrm{~nm}$ (4.348), 293.0 (4.195), 322.5 (3.624).

IR $(\mathrm{KBr}): \tilde{v}\left(\mathrm{~cm}^{-1}\right)=2949,1666,1536,1437,1230$.

${ }^{1} \mathbf{H}-N M R\left(300 \mathrm{MHz}, \mathrm{DMSO}-\mathrm{d}_{6}\right): \delta=3.74\left(\mathrm{t}, J=5.1 \mathrm{~Hz}, 2 \mathrm{H}, 2^{\prime}-\mathrm{H}_{2}\right), 3.98(\mathrm{t}, J=5.4 \mathrm{~Hz}, 2 \mathrm{H}$, 1'- $\left.\mathrm{H}_{2}\right), 6.92(\mathrm{dd}, J=8.7,2.4 \mathrm{~Hz}, 1 \mathrm{H}, 6-\mathrm{H}), 7.00$ (d, $\left.J=1.8 \mathrm{~Hz}, 1 \mathrm{H}, 3-\mathrm{H}\right), 7.10$ (d, $J=2.7 \mathrm{~Hz}$, $1 \mathrm{H}, 4-\mathrm{H}), 7.35$ (d, $J=8.7 \mathrm{~Hz}, 1 \mathrm{H}, 7-\mathrm{H}), 11.54$ (s, $1 \mathrm{H}$, Indol-NH).

${ }^{13}$ C-NMR (75 MHz, DMSO-d 6 ): $\delta=59.78$ (C-1'), 69.93 (C-2'), 103.2 (C-4), 106.9 (C-3), 113.3 (C-7), 116.2 (C-6), 127.2, 128.9 (C-2, C-3a), 132.6 (C-7a), 153.2 (C-5), 162.8 (C=O). MS (ESI): $m / z(\%)=220.1(84)\left[\mathrm{M}-\mathrm{H}^{-}\right]^{-}, 441.0(100)[2 \mathrm{M}-\mathrm{H}]^{-}$.
$\mathrm{C}_{11} \mathrm{H}_{11} \mathrm{NO}_{4}(221.21)$.
Ber.: C: 59.73
H: 5.01
$\mathrm{N}: 6.33$
Gef:: C: 59.60
H: 4.79
$\mathrm{N}: 6.06$

\section{$2.4 \quad$ Synthese von 57 und 59}

\subsection{1. p-Allyloxy-nitrophenol (55)}<smiles>C=CCOc1ccc([N+](=O)[O-])cc1</smiles>

Zu einer Mischung von $p$-Nitrophenol (13.9 g, 0.1 mol, 1.0 Äq.) und Kaliumcarbonat (27.6 g, 0.2 mol, 2.0 Äq.) wurde DMF (150 mL) gegeben. Dann wurde Allylalkohol (24.2 g, 0.2 mol, 2.0 Äq.) zugegeben und $2 \mathrm{~h}$ bei $70{ }^{\circ} \mathrm{C}$ gerührt. Danach wurde das Lösungsmittel im Vakuum entfernt und Wasser $(200 \mathrm{~mL})$ hinzugegeben. Die wässrige Phase wurde mit AcOEt $(2 \times 200$ $\mathrm{mL}$ ) extrahiert. Die vereinigten organischen Phasen wurden mit ges. $\mathrm{NaHCO}_{3}$-Lösung gewaschen, über $\mathrm{Na}_{2} \mathrm{SO}_{4}$ getrocknet und das Lösungsmittel im Vakuum entfernt. Das Nitroderivat wurde als gelbes Öl (19.3 g, $0.1 \mathrm{mmol}, 100 \%)$ erhalten.

$\mathbf{R}_{\mathbf{f}}=0.7(\mathrm{PE} / \mathrm{EE}=3: 1)$. 
${ }^{1}$ H-NMR (300 MHz, DMSO-d $\left.{ }_{6}\right): \delta=4.71\left(\mathrm{dt}, J=5.4,1.2 \mathrm{~Hz}, 2 \mathrm{H}, 1\right.$ ' $\left.-\mathrm{H}_{2}\right), 5.30(\mathrm{dq}, J=10.8$, $\left.1.5 \mathrm{~Hz}, 1 \mathrm{H}, 3^{\prime}-\mathrm{H}_{\mathrm{a}}\right), 5.42$ (dq, $\left.J=17.4,1.5 \mathrm{~Hz}, 1 \mathrm{H}, 3^{\prime}-\mathrm{H}_{\mathrm{b}}\right), 5.98-6.11\left(\mathrm{~m}_{\mathrm{c}}, 1 \mathrm{H}, 2^{\prime}-\mathrm{H}\right), 7.11-$ $7.16\left(\mathrm{~m}_{\mathrm{c}}, 2 \mathrm{H}, 2-\mathrm{H}, 6-\mathrm{H}\right), 8.15-8.20\left(\mathrm{~m}_{\mathrm{c}}, 2 \mathrm{H}, 3-\mathrm{H}, 5-\mathrm{H}\right)$.

${ }^{13}$ C-NMR (75 MHz, DMSO-d 6 ): $\delta=68.96$ (C-1'), 115.1 (C-2, C-6), 118.1 (C-3'), 125.7 (C-3, C-5), 132.5 (C-2'), 140.8 (C-4), 163.4 (C-1).

MS (EI, $70 \mathrm{eV}): m / z(\%)=179.1(65)[\mathrm{M}]^{+}$.

$\mathrm{C}_{9} \mathrm{H}_{9} \mathrm{NO}_{3}(179.17)$.

\subsection{2. $\quad p$-Allyloxy-anilin (56)}

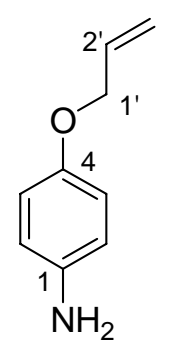

$\mathrm{Zu}$ einer Mischung des Nitroderivats 55 (4.5 g, $25 \mathrm{mmol}, 1.0$ Äq.) und $\mathrm{SnCl}_{2} \cdot 2 \mathrm{H}_{2} \mathrm{O}$ (22.6 g, 0.1 mol, 4.0 Äq.) wurde AcOEt (100 mL) gegeben. Das Reaktionsgemisch wurde $14 \mathrm{~h}$ am Rückfluss erhitzt. Nach Abkühlen auf Raumtemperatur wurde Wasser zugegeben $(100 \mathrm{~mL})$ und der $\mathrm{pH}-\mathrm{Wert}$ der Lösung wurde mit $2 \mathrm{M} \mathrm{NaOH}$ auf 11 eingestellt. Die wässrige Phase wurde mit $\mathrm{CH}_{2} \mathrm{Cl}_{2}(2 \times 200 \mathrm{~mL}, 3 \times 150 \mathrm{~mL})$ extrahiert. Die vereinigten organischen Phasen wurde über $\mathrm{Na}_{2} \mathrm{SO}_{4}$ getrocknet und das Lösungsmittel im Vakuum entfernt. Nach Säulenchromatographie an Kieselgel $\left(\mathrm{CH}_{2} \mathrm{Cl}_{2} \rightarrow \mathrm{CH}_{2} \mathrm{Cl}_{2} / \mathrm{MeOH}=10: 1\right)$ erhielt man das Aminoderivat als gelbes Öl (2.0 g, $13.4 \mathrm{mmol}, 54 \%)$.

$\mathbf{R}_{\mathbf{f}}=0.2(\mathrm{PE} / \mathrm{AcOEt}=3: 1)$.

${ }^{1}$ H-NMR (300 MHz, DMSO-d $\left.{ }_{6}\right): \delta=4.40\left(\mathrm{~d}, J=5.7 \mathrm{~Hz}, 2 \mathrm{H}, 1^{\prime}-\mathrm{H}_{2}\right), 4.56\left(\mathrm{~s}_{\mathrm{br}}, 2 \mathrm{H}, \mathrm{NH}_{2}\right)$, $5.20\left(\mathrm{dd}, J=10.5,1.5 \mathrm{~Hz}, 1 \mathrm{H}, 3^{\prime}-\mathrm{H}_{\mathrm{a}}\right), 5.34\left(\mathrm{dd}, J=16.8,1.8 \mathrm{~Hz}, 1 \mathrm{H}, 3\right.$ ' $\left.-\mathrm{H}_{\mathrm{b}}\right), 5.94-6.07\left(\mathrm{~m}_{\mathrm{c}}\right.$, 1 H, 2'-H), 6.50-6.55 (m $\left.\mathrm{m}_{\mathrm{c}}, 2 \mathrm{H}, 2-\mathrm{H}, 6-\mathrm{H}\right), 6.65-6.70$ (m, 2 H, 3-H, 5-H).

${ }^{13}$ C-NMR (75 MHz, DMSO-d $\left.{ }_{6}\right): \delta=68.80\left(\mathrm{C}-1^{\prime}\right), 114.9$ (C-3, C-5), 115.6 (C-2, C-6), 116.6 (C-3’), 134.4 (C-2'), 142.4 (C-1), 149.5 (C-4).

MS (EI, $70 \mathrm{eV}): m / z(\%)=149.1(24)[\mathrm{M}]^{+}$.

$\mathrm{C}_{9} \mathrm{H}_{11} \mathrm{NO}$ (149.19). 


\subsubsection{5-Allyloxy-indol-2-carbonsäureethylester (57)}

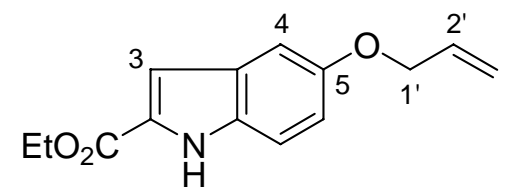

$\mathrm{Zu}$ einer Lösung des Aminoderivats 56 (2.0 g, 13.4 mmol, 1.0 Äq.) in Wasser (30 mL) und konzentrierter Salzsäure $(2.7 \mathrm{~mL})$ wurde bei $0{ }^{\circ} \mathrm{C}$ eine Lösung von $\mathrm{NaNO}_{2}(0.92 \mathrm{~g}$, $13.3 \mathrm{mmol}, 1.0$ Äq.) in Wasser $(10 \mathrm{~mL})$ getropft und die Reaktionsmischung $15 \mathrm{~min}$ bei $0{ }^{\circ} \mathrm{C}$ gerührt (Lösung A).

Eine Suspension aus NaOAc (4.2 g, $51.2 \mathrm{mmol}, 4.0$ Äq.) in Ethanol $(20 \mathrm{~mL})$ wurde bei $0{ }^{\circ} \mathrm{C}$ tropfenweise mit 2-Methylacetessigsäureethylester (1.90 g, $13.2 \mathrm{mmol}, 1.0$ Äq.) versetzt. Nach Rühren bei $0{ }^{\circ} \mathrm{C}$ für 10 min wurde Wasser $(5 \mathrm{~mL})$ zugegeben (Lösung B).

Anschließend gab man Lösung A zügig zu Lösung B, erwärmte auf Raumtemperatur und rührte $2 \mathrm{~h}$ bei Raumtemperatur. Nach Entfernen des Ethanols im Vakuum wurde die wässrige Phase mit AcOEt $(2 \times 100 \mathrm{~mL})$ extrahiert, die vereinigten organischen Phasen über $\mathrm{Na}_{2} \mathrm{SO}_{4}$ getrocknet und das Lösungsmittel im Vakuum entfernt. $\mathrm{Zu}$ dem erhaltenen braunen Öl gab man eine Lösung von $6 \mathrm{M} \mathrm{HCl} / i$-PrOH $(13 \mathrm{~mL})$. Die Reaktionsmischung wurde $15 \mathrm{~min}$ bei $70{ }^{\circ} \mathrm{C}$ gerührt. Anschließend ließ man auf Raumtemperatur abkühlen, das Lösungsmittel im Vakuum entfernen. Wasser $(100 \mathrm{~mL})$ wurde zugegeben, die wässrige Phase mit AcOEt $(2 \times 100 \mathrm{~mL})$ extrahiert, die vereinigten organischen Phasen über $\mathrm{Na}_{2} \mathrm{SO}_{4}$ getrocknet und das Lösungsmittel im Vakuum entfernt. Nach Säulenchromatographie an Kieselgel (PE/AcOEt = $6: 1 \rightarrow 3: 1)$ erhielt man die Titelverbindung als gelben Feststoff (1.7 g, 6.9 mmol, 52 \%).

$\mathbf{R}_{\mathbf{f}}=0.8(\mathrm{PE} / \mathrm{AcOEt}=3: 1)$.

UV $\left(\mathrm{CH}_{3} \mathrm{CN}\right): \lambda_{\max }(\lg \varepsilon)=216.0 \mathrm{~nm}$ (4.421), 293.5 (4.296), 321.5 (3.712).

IR $(\mathrm{KBr}): \widetilde{v}\left(\mathrm{~cm}^{-1}\right)=3320,1686,1530,1450,1342,1258$.

${ }^{1}$ H-NMR (300 MHz, DMSO-d ${ }_{6}$ ): $\delta=1.33\left(\mathrm{t}, J=7.2 \mathrm{~Hz}, 3 \mathrm{H}, \mathrm{CH}_{3}\right.$ ), 4.33 (q, $J=7.2 \mathrm{~Hz}, 2 \mathrm{H}$, $\left.\mathrm{C}_{2} \mathrm{CH}_{3}\right), 4.54\left(\mathrm{dt}, J=5.1,1.5 \mathrm{~Hz}, 2 \mathrm{H}, 1^{\prime}-\mathrm{H}_{2}\right), 5.25$ (dq, $\left.J=10.8,1.5 \mathrm{~Hz}, 1 \mathrm{H}, 3^{\prime}-\mathrm{H}_{\mathrm{a}}\right), 5.41$ (dq, $J=18.6,1.8 \mathrm{~Hz}, 1 \mathrm{H}, 3$ '- $\left.-\mathrm{H}_{\mathrm{b}}\right), 6.00-6.13\left(\mathrm{~m}_{\mathrm{c}}, 1 \mathrm{H}, 2\right.$ '-H), 6.96 (dd, $J=9.0,2.4 \mathrm{~Hz}, 1 \mathrm{H}$, 6-H), 7.05 (s, $1 \mathrm{H}, 3-\mathrm{H}), 7.12$ (d, $J=2.4 \mathrm{~Hz}, 1 \mathrm{H}, 4-\mathrm{H}), 7.37$ (d, $J=9.0 \mathrm{~Hz}, 1 \mathrm{H}, 7-\mathrm{H}), 11.70$ (s, $1 \mathrm{H}$, Indol-NH). 
${ }^{13}$ C-NMR (75 MHz, DMSO-d $\left.\mathrm{d}_{6}\right): \delta=14.19\left(\mathrm{CH}_{3}\right), 60.18\left(\mathrm{C}-1^{\prime}\right), 68.57\left(\mathrm{CH}_{2} \mathrm{CH}_{3}\right), 103.5$ (C-4), 107.2 (C-3), 113.4 (C-7), $116.5(\mathrm{C}-6), 116.9$ (C-3'), 127.0, 127.6 (C-2, C-3a), 132.8 (C-7a), 134.0 (C-2'), $152.8(\mathrm{C}-5), 161.2(\mathrm{C}=\mathrm{O})$.

MS (EI, $70 \mathrm{eV}): m / z(\%)=245.1(48)[\mathrm{M}]^{+}$.
$\mathrm{C}_{14} \mathrm{H}_{15} \mathrm{NO}_{3}$ (245.27).
Ber.: C: 68.56
H: 6.16
$\mathrm{N}: 5.71$
Gef.: C: 68.43
H: 6.18
N: 5.64

\subsubsection{5-Allyloxy-indol-2-carbonsäure (144)}<smiles>C=CCOc1ccc2[nH]c(C(=O)O)cc2c1</smiles>

$\mathrm{Zu}$ einer Lösung von 57 (380 mg, $1.55 \mathrm{mmol}, 1.0$ Äq) in $\mathrm{H}_{2} \mathrm{O} / \mathrm{MeOH} / \mathrm{THF}(4.5 \mathrm{~mL} / 1.5 \mathrm{~mL} /$ $4.5 \mathrm{~mL}$ ) gab man $\mathrm{LiOH} \cdot \mathrm{H}_{2} \mathrm{O}$ (180 mg, $4.29 \mathrm{mmol}, 2.8$ Äq.), und ließ $2 \mathrm{~h}$ bei Raumtemperatur rühren. Danach wurde Wasser $(20 \mathrm{~mL})$ zugegeben, mit $2 \mathrm{M} \mathrm{HCl}$ der $\mathrm{pH}-$ Wert der Lösung auf 3 eingestellt. Die wässrige Phase wurde mit AcOEt $(3 \times 30 \mathrm{~mL})$ extrahiert. Die vereinigten organischen Phasen wurden über $\mathrm{Na}_{2} \mathrm{SO}_{4}$ getrocknet und das Lösungsmittel im Vakuum entfernt. Die Zielverbindung (260 mg, $1.2 \mathrm{mmol}, 77 \%$ ) wurde als blass-gelblicher Feststoff erhalten.

UV $\left(\mathrm{CH}_{3} \mathrm{CN}\right): \lambda_{\max }(\lg \varepsilon)=216.0 \mathrm{~nm}$ (4.432), 293.0 (4.288), 322.5 (3.691).

IR $(\mathrm{KBr}): \widetilde{v}\left(\mathrm{~cm}^{-1}\right)=3344,3077,1691,1439,1197$.

${ }^{1}$ H-NMR (300 MHz, DMSO-d $\left.{ }_{6}\right): \delta=4.53\left(\mathrm{dt}, J=5.4,1.2 \mathrm{~Hz}, 2 \mathrm{H}, 1\right.$ '- $\left.\mathrm{H}_{2}\right), 5.24(\mathrm{dq}, J=10.5$, $1.5 \mathrm{~Hz}, 1 \mathrm{H}, 3$ '- $\mathrm{H}_{\mathrm{a}}$ ), 5.40 (dq, $\left.J=16.8,1.5 \mathrm{~Hz}, 1 \mathrm{H}, 3^{\prime}-\mathrm{H}_{\mathrm{b}}\right), 6.00-6.13\left(\mathrm{~m}_{\mathrm{c}}, 1 \mathrm{H}, 2^{\prime}-\mathrm{H}\right), 6.93$ (dd, $J=9.0,2.7 \mathrm{~Hz}, 1 \mathrm{H}, 6-\mathrm{H}), 7.01$ (d, $J=1.8 \mathrm{~Hz}, 1 \mathrm{H}, 3-\mathrm{H}), 7.11(\mathrm{~d}, J=1.8 \mathrm{~Hz}, 1 \mathrm{H}, 4-\mathrm{H})$, 7.35 (d, $J=9.0 \mathrm{~Hz}, 1 \mathrm{H}, 7-\mathrm{H}), 11.58$ (s, $1 \mathrm{H}$, Indol-NH), 12.79 ( $\left.\mathrm{s}_{\mathrm{br}}, 1 \mathrm{H}, \mathrm{COOH}\right)$.

${ }^{13}$ C-NMR (75 MHz, DMSO-d ${ }_{6}$ ): $\delta=68.63$ (C-1'), 103.5 (C-4), 106.9 (C-3), 113.3 (C-7), 116.1 (C-6), 117.0 (C-3'), 127.2, 128.7 (C-2, C-3a), 132.7 (C-7a), 134.1 (C-2'), 152.7 (C-5), $162.7(\mathrm{C}=\mathrm{O})$.

MS (ESI): $m / z(\%)=216.0(84)\left[\mathrm{M}-\mathrm{H}^{-}, 432.9(100)[2 \mathrm{M}-\mathrm{H}]^{-}\right.$.
$\mathbf{C}_{\mathbf{1 2}} \mathbf{H}_{11} \mathbf{N O}_{3}$ (217.22).
Ber.: C: 66.35
H: 5.10
$\mathrm{N}: 6.45$
Gef.: C: 66.52
H: 5.05
N: 6.41 


\subsubsection{5-(2-Azidoethoxy)-indol-2-carbonsäureethylester (59)}<smiles>CCOC(=O)c1cc2cc(OCCN)ccc2[nH]1</smiles>

$\mathrm{Zu}$ einer Lösung von 53 (500 mg, $2.0 \mathrm{mmol}, 1.0$ Äq.) in $\mathrm{CH}_{2} \mathrm{Cl}_{2}(10 \mathrm{~mL})$ gab man $\mathrm{CH}_{3} \mathrm{SO}_{2} \mathrm{Cl}$ (250 mg, $2.2 \mathrm{mmol}, 1.1$ Äq.) in $\mathrm{CH}_{2} \mathrm{Cl}_{2}(5 \mathrm{~mL})$ und $\mathrm{NEt}_{3}(220 \mathrm{mg}, 2.2 \mathrm{mmol}, 1.1$ Äq.) in $\mathrm{CH}_{2} \mathrm{Cl}_{2}(5 \mathrm{~mL})$, ließ $12 \mathrm{~h}$ auf Raumtemperatur rühren. Nach Entfernen des Lösungsmittels wurde Wasser $(30 \mathrm{~mL})$ zugegeben, mit AcOEt $(2 \times 50 \mathrm{~mL})$ extrahiert. Die vereinigten organischen Phasen wurde über $\mathrm{Na}_{2} \mathrm{SO}_{4}$ getrocknet und das Lösungsmittel im Vakuum entfernt. Nach Säulenchromatographie an Kieselgel $\left(\mathrm{CH}_{2} \mathrm{Cl}_{2} / \mathrm{MeOH}=100: 1 \rightarrow 100: 5\right)$ erhielt man die Zwischenverbindung 58 als blass-gelblichen Feststoff (650 mg, 1,99 mmol, 99 \%).

Ein Lösungsgemisch aus $\mathrm{CH}_{3} \mathrm{CN} / \mathrm{DMSO}(10 \mathrm{~mL} / 2 \mathrm{~mL})$ wurde mit der Zwischenverbindung (164 mg, 0.50 mmol, 1.0 Äq.) sowie Natriumazid (130 mg, 2 mmol, 4.0 Äq.) versetzt, und 3 h bei $90{ }^{\circ} \mathrm{C}$ gerührt. Es wurde Wasser $(30 \mathrm{~mL})$ zugegeben, mit AcOEt $(2 \times 50 \mathrm{~mL})$ extrahiert. Die vereinigten organischen Phasen wurden über $\mathrm{Na}_{2} \mathrm{SO}_{4}$ getrocknet und das Lösungsmittel im Vakuum entfernt. Nach Säulenchromatographie an Kieselgel $\left(\mathrm{CH}_{2} \mathrm{Cl}_{2} / \mathrm{MeOH}=50: 1\right)$ erhielt man die Titelverbindung als blass-gelblichen Feststoff (125 mg, $0.46 \mathrm{mmol}, 91 \%$ ).

UV $\left(\mathrm{CH}_{3} \mathrm{CN}\right): \lambda_{\max }(\lg \varepsilon)=216.0 \mathrm{~nm}$ (4.425), 293.0 (4.285).

IR $(\mathrm{KBr}): \widetilde{v}\left(\mathrm{~cm}^{-1}\right)=3316,2113,1668,1536,1216$.

${ }^{1}$ H-NMR (300 MHz, DMSO-d $\left.{ }_{6}\right): \delta=1.34\left(\mathrm{t}, J=7.2 \mathrm{~Hz}, 3 \mathrm{H}, \mathrm{CH}_{3}\right), 3.64(\mathrm{t}, J=4.8 \mathrm{~Hz}, 2 \mathrm{H}$, 2'- $\mathrm{H}_{2}$ ), 4.17 (t, $\left.J=4.8 \mathrm{~Hz}, 2 \mathrm{H}, 1^{\prime}-\mathrm{H}_{2}\right), 4.33$ (q, $J=7.2 \mathrm{~Hz}, 2 \mathrm{H}, \underline{\mathrm{C}}_{2} \mathrm{CH}_{3}$ ), 6.95 (dd, $J=9.0$, $2.4 \mathrm{~Hz}, 1 \mathrm{H}, 6-\mathrm{H}), 7.05$ (d, $J=1.5 \mathrm{~Hz}, 1 \mathrm{H}, 3-\mathrm{H}), 7.15$ (d, $J=2.1 \mathrm{~Hz}, 1 \mathrm{H}, 4-\mathrm{H}), 7.38$ (d, $J=9.0 \mathrm{~Hz}, 1 \mathrm{H}, 7-\mathrm{H}), 11.72$ (s, $1 \mathrm{H}$, Indol-NH).

${ }^{13}$ C-NMR $(75 \mathrm{MHz}$, DMSO-d 6$): \delta=14.17\left(\mathrm{CH}_{3}\right), 49.62(\mathrm{C}-2$ ') $) 60.19(\mathrm{C}-1$ ') 67.15 $\left(\mathrm{CH}_{2} \mathrm{CH}_{3}\right), 103.5(\mathrm{C}-4), 107.2(\mathrm{C}-3), 113.5$ (C-7), 116.2 (C-6), 126.9, 127.7 (C-2, C-3a), 132.9 (C-7a), $152.5(\mathrm{C}-5), 161.1(\mathrm{C}=\mathrm{O})$.

MS (EI, $70 \mathrm{eV}): m / z(\%)=274.1(100)[\mathrm{M}]^{+}$.

$\begin{array}{lllll}\mathbf{C}_{13} \mathbf{H}_{14} \mathbf{N}_{\mathbf{4}} \mathbf{O}_{3} \text { (274.28). } & \text { Ber.: } & \text { C: } 56.93 & \text { H: } 5.14 & \text { N: } 20.43 \\ & \text { Gef.: } & \text { C: } 56.72 & \text { H: } 4.88 & \text { N: } 20.25\end{array}$




\subsection{Synthese von 62}

\subsubsection{5-[2-(2-Ethoxycarbonylethyl)-methyl-aminoethoxy]-indol-2- carbonsäure (62)}

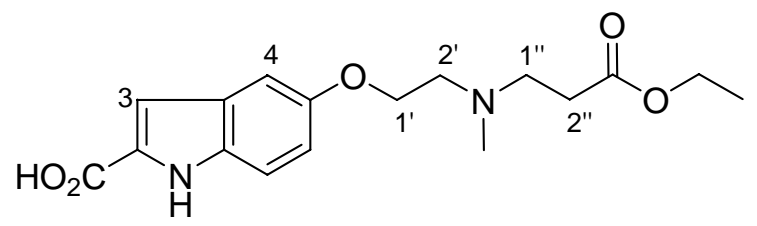

Eine Lösung von Methylamin in Ethanol $(8 \mathrm{M}, 80 \mathrm{~mL})$ wurde mit 60 (3.31 g, 10.0 mmol, 1.0Äq.) versetzt, 4h bei Raumtemperatur gerührt. Nach Entfernen des Lösungsmittels im Vakuum gab man Acrylsäureethylester $(40 \mathrm{~mL})$ und EtOH $(40 \mathrm{~mL})$. Das Reaktionsgemisch wurde 4 h zum Rückfluss erhitzt. Danach wurde das Lösungsmittel im Vakuum entfernt, ges. $\mathrm{NaHCO}_{3}$-Lösung $(100 \mathrm{~mL})$ zugegeben, und mit $n$-Butanol $(2 \times 100 \mathrm{~mL})$ extrahiert. Das nach Entfernen des $n$-Butanols erhaltene Rohprodukt wurde an Kieselgel adsorbiert und durch Säulenchromatographie $\left(\mathrm{CH}_{2} \mathrm{Cl}_{2} / \mathrm{MeOH}=10: 2 \rightarrow 10: 3+0.1 \%\right.$ konz. Salzsäure $)$ gereinigt. Man erhielt die Titelverbindung als braunen Feststoff $(2.88 \mathrm{~g}, 8.6 \mathrm{mmol}, 86 \%$ über zwei Stufen).

$\mathbf{R}_{\mathbf{f}}=0.4\left(\mathrm{CH}_{2} \mathrm{Cl}_{2} / \mathrm{MeOH}=10: 2+1 \% \mathrm{HOAc}\right)$.

IR $(\mathrm{KBr}): \widetilde{v}\left(\mathrm{~cm}^{-1}\right)=3246,1731,1534,1401,1283$.

${ }^{1}$ H-NMR $\left(300 \mathrm{MHz}, \mathrm{DMSO}-\mathrm{d}_{6}\right): \delta=1.19\left(\mathrm{t}, J=6.6 \mathrm{~Hz}, 3 \mathrm{H}, \mathrm{OCH}_{2} \mathrm{CH}_{3}\right), 2.84(\mathrm{~s}, 3 \mathrm{H}$,

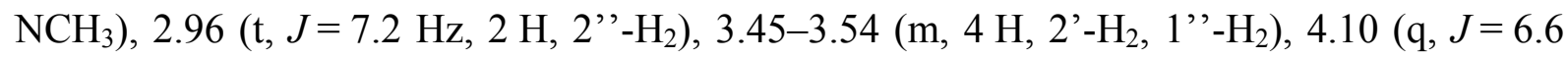
$\left.\mathrm{Hz}, 2 \mathrm{H}, \mathrm{OC}_{2} \mathrm{CH}_{3}\right), 4.40\left(\mathrm{~s}_{\mathrm{br}}, 2 \mathrm{H}, 1\right.$ ' $\left.-\mathrm{H}_{2}\right), 6.96(\mathrm{~d}, J=8.4 \mathrm{~Hz}, 1 \mathrm{H}, 6-\mathrm{H}), 7.01(\mathrm{~s}, 1 \mathrm{H}, 3-\mathrm{H})$, 7.18 (d, $1 \mathrm{H}, 4-\mathrm{H}), 7.38$ (d, $J=8.7 \mathrm{~Hz}, 1 \mathrm{H}, 7-\mathrm{H}), 11.64$ (s, $1 \mathrm{H}$, Indol-NH).

${ }^{13}$ C-NMR (75 MHz, DMSO-d 6 ): $\delta=13.89\left(\mathrm{OCH}_{2} \mathrm{CH}_{3}\right), 28.42\left(\mathrm{C}-2\right.$ '’), $40.04\left(\mathrm{NCH}_{3}\right), 50.75$ (C-1'’), 53.80 (C-2'), 60.49 (C-1'), $62.75\left(\mathrm{OCH}_{2} \underline{\mathrm{CH}}_{3}\right), 103.8$ (C-4), 106.8 (C-3), 113.4 (C-7), 115.8 (C-6), 126.9, 128.9 (C-2, C-3a), 132.9 (C-7a), 151.9 (C-5), $162.5(\mathrm{C}=\mathrm{O}), 169.8(\mathrm{C}=\mathrm{O})$. MS (ESI): $m / z(\%)=335(100)[\mathrm{M}+\mathrm{H}]^{+}$.

$\mathrm{C}_{17} \mathrm{H}_{22} \mathrm{~N}_{2} \mathbf{O}_{5}$ (334.37). 


\subsection{Synthese von 42}

\subsection{1. (3-Brompropyl)-carbaminsäure-tert-butylester (43)}

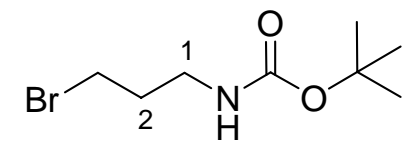

Eine Lösung von 63 (4.38 g, 20 mmol, 1.0 Äq.) in THF/MeOH (60 mL/30 mL) wurde mit $\mathrm{NEt}_{3}$ (2.52 g, 25 mmol, 1.3 Äq.) sowie $\mathrm{Boc}_{2} \mathrm{O}$ (5.24 g, 24 mmol, 1.2 Äq.) versetzt, $2 \mathrm{~h}$ bei Raumtemperatur gerührt. Nach Entfernen des Lösungsmittels wurde Wasser $(100 \mathrm{~mL})$ zugegeben. Die wässerige Phase wurde mit Ether $(2 \times 100 \mathrm{~mL})$ extrahiert. Die vereinigten organischen Phasen wurden über $\mathrm{Na}_{2} \mathrm{SO}_{4}$ getrocknet und das Lösungsmittel im Vakuum entfernt. Nach Säulenchromatographie an Kieselgel $(\mathrm{PE} / \mathrm{AcOEt}=50: 1 \rightarrow 2: 1)$ erhielt man die Titelverbindung als farbloses Öl (4.35 g, $0.54 \mathrm{mmol}, 91 \%)$.

$\mathbf{R}_{\mathbf{f}}=0.5(\mathrm{PE} / \mathrm{AcOEt}=10: 1)$.

${ }^{1} \mathbf{H}-\mathbf{N M R}\left(300 \mathrm{MHz}, \mathrm{CDCl}_{3}\right): \delta=1.45\left(\mathrm{~s}, 9 \mathrm{H}, \mathrm{C}\left(\mathrm{CH}_{3}\right)_{3}\right), 2.05\left(\mathrm{~m}_{\mathrm{c}}, 2 \mathrm{H}, 2-\mathrm{H}_{2}\right), 3.27\left(\mathrm{~s}_{\mathrm{br}}, 2 \mathrm{H}\right.$, $\left.1-\mathrm{H}_{2}\right), 3.45\left(\mathrm{t}, J=6.3 \mathrm{~Hz}, 2 \mathrm{H}, 3-\mathrm{H}_{2}\right), 4.72(\mathrm{~s} b r, 1 \mathrm{H}, \mathrm{NH})$.

${ }^{13}$ C-NMR $\left(75 \mathrm{MHz}, \mathrm{CDCl}_{3}\right): \delta=28.33\left(\mathrm{C}\left(\underline{\mathrm{CH}}_{3}\right)_{3}\right), 30.79(\mathrm{C}-3), 32.63(\mathrm{C}-2), 38.92(\mathrm{C}-1)$, $79.43\left(\underline{\mathrm{C}}\left(\mathrm{CH}_{3}\right)_{3}\right), 155.9(\mathrm{C}=\mathrm{O})$.

MS (DCI, $200 \mathrm{eV}): \mathrm{m} / \mathrm{z}(\%)=239.2(93)[\mathrm{M}+\mathrm{H}]^{+}$.

$\mathrm{C}_{8} \mathrm{H}_{16} \mathrm{BrNO}_{2}$ (238.12).

\subsubsection{5-(2-Methylaminoethoxy)-indol-2-carbonsäureethylester (64)}<smiles>CCOC(=O)c1cc2cc(OCCNC)ccc2[nH]1</smiles>

Zu einer Lösung der 50 (5.0g, 13.9 mmol, 1.0 Äq.) in THF (30 mL) wurden Methylamin (8 M in EtOH, $20 \mathrm{~mL})$ und $\mathrm{K}_{2} \mathrm{CO}_{3}(3.0 \mathrm{~g}, 21.7 \mathrm{mmol}, 1.6$ Äq.) gegeben. Die Reaktiongemisch wurde $12 \mathrm{~h}$ bei Raumtemperatur gerührt, mit Wasser versetzt, und mit AcOEt extrahiert. Die vereinigten organischen Phasen wurden über $\mathrm{Na}_{2} \mathrm{SO}_{4}$ getrocknet und das Lösungsmittel im 
Vakuum entfernt. Nach Säulenchromatographie an Kieselgel $\left(\mathrm{CH}_{2} \mathrm{Cl}_{2} / \mathrm{MeOH}=10: 1 \rightarrow 5: 1\right)$ erhielt man die Zielverbindung als braunen Feststoff (2.5 g, 9.5 mmol, 68 \%).

$\mathbf{R}_{\mathbf{f}}=0.2\left(\mathrm{CH}_{2} \mathrm{Cl}_{2} / \mathrm{MeOH}=10: 1\right)$.

${ }^{1} \mathbf{H}-\mathrm{NMR}\left(300 \mathrm{MHz}, \mathrm{DMSO}-\mathrm{d}_{6}\right): \delta=1.32\left(\mathrm{t}, J=6.9 \mathrm{~Hz}, 3 \mathrm{H}, \mathrm{CH}_{2} \mathrm{CH}_{3}\right), 2.45\left(\mathrm{~s}, 3 \mathrm{H}, \mathrm{NCH}_{3}\right)$, $3.00\left(\mathrm{t}, J=5.4 \mathrm{~Hz}, 2 \mathrm{H}, 2^{\prime}-\mathrm{H}_{2}\right), 4.06$ (t, $\left.J=5.4 \mathrm{~Hz}, 2 \mathrm{H}, 1^{\prime}-\mathrm{H}_{2}\right), 4.32$ (q, J=7.2 Hz, $2 \mathrm{H}$, $\left.\mathrm{C}_{2} \mathrm{CH}_{3}\right), 4.55\left(\mathrm{~s}_{\mathrm{br}}, 1 \mathrm{H}, \mathrm{NH}\right), 6.95(\mathrm{dd}, J=8.7,2.1 \mathrm{~Hz}, 1 \mathrm{H}, 6-\mathrm{H}), 7.05(\mathrm{~s}, 1 \mathrm{H}, 3-\mathrm{H}), 7.13(\mathrm{~d}$, $J=1.8 \mathrm{~Hz}, 1 \mathrm{H}, 4-\mathrm{H}), 7.38$ (d, $J=9.3 \mathrm{~Hz}, 1 \mathrm{H}, 7-\mathrm{H}), 11.73$ ( $\mathrm{s}_{\mathrm{br}}, 1 \mathrm{H}$, Indol-NH).

MS (EI, $70 \mathrm{eV}): m / z(\%)=262.0(21)[\mathrm{M}]^{+}$.

$\mathrm{C}_{14} \mathbf{H}_{18} \mathbf{N}_{2} \mathbf{O}_{3}(262.30)$.

\subsubsection{5-\{2-[(3-tert-Butoxycarbonylamino-propyl)-methyl-amino]-ethoxy\}- ]-indol-2-carbonsäure (42)}

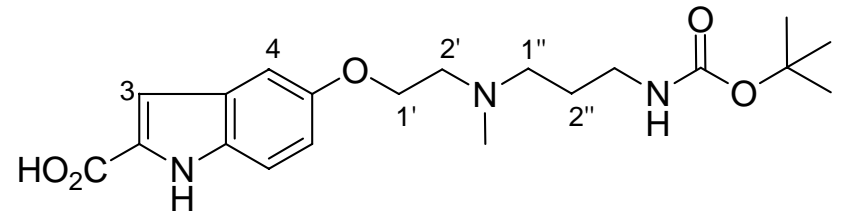

$\mathrm{Zu}$ einer Lösung von 64 (262 mg, $1.0 \mathrm{mmol}, 1.0$ Äq.) in DMF (5 mL) gab man $\mathrm{K}_{2} \mathrm{CO}_{3}$ (210 mg, $1.5 \mathrm{mmol}, 1.5$ Äq.) sowie 43 (360 mg, $1.5 \mathrm{mmol}, 1.5$ Äq.), ließ $12 \mathrm{~h}$ auf Raumtemperatur rühren. Nach Entfernen DMF im Vakuum, Wasser $(50 \mathrm{~mL})$ wurde zugegeben und mit AcOEt $(3 \times 50 \mathrm{~mL})$ extrahiert. Die vereinigten organischen Phasen wurden über $\mathrm{Na}_{2} \mathrm{SO}_{4}$ getrocknet und das Lösungsmittel im Vakuum entfernt. Nach Säulenchromatographie an Kieselgel $\left(\mathrm{CH}_{2} \mathrm{Cl}_{2} / \mathrm{MeOH}=50: 1 \rightarrow 10: 1\right)$ erhielt man das Zwischenprodukt (260 mg) als braunes Öl. Das Zwischenprodukt wurde in einem Lösungsgemisch aus $\mathrm{H}_{2} \mathrm{O} / \mathrm{MeOH} / \mathrm{THF}(3 \mathrm{~mL} / 1 \mathrm{~mL} / 3 \mathrm{~mL})$ gelöst, mit LiOH$\cdot \mathrm{H}_{2} \mathrm{O}(80 \mathrm{mg}, 2$ mmol, 3.0 Äq., bezug. des Zwischenprodukt) versetzt, 2 h bei Raumtemperatur gerührt. Nach Entfernen des Lösungsmittels wurde ges. $\mathrm{NaHCO}_{3}$-Lösung $(20 \mathrm{~mL})$ zugegeben, mit $n$ Butanol $(3 \times 30 \mathrm{~mL})$ extrahiert. Das nach Entfernen des n-Butanols erhaltene Rohprodukt wurde an Kieselgel adsorbiert und durch Säulenchromatographie $\left(\mathrm{CH}_{2} \mathrm{Cl}_{2} / \mathrm{MeOH}=5: 1 \rightarrow\right.$ 2:1) gereinigt. Man erhielt die Titelverbindung als blass-gelblichen Feststoff (160 mg, $0.41 \mathrm{mmol}, 41 \%$ über zwei Stufen). 
UV $\left(\mathrm{CH}_{3} \mathrm{CN}\right): \lambda_{\max }(\lg \varepsilon)=288.5 \mathrm{~nm}(2.988)$.

IR $(\mathrm{KBr}): \tilde{v}\left(\mathrm{~cm}^{-1}\right)=3322,2975,1692,1536,1407$.

${ }^{1} \mathbf{H}-\mathrm{NMR}\left(300 \mathrm{MHz}, \mathrm{DMSO}-\mathrm{d}_{6}\right): \delta=1.37\left(\mathrm{~s}, 9 \mathrm{H}, \mathrm{C}\left(\mathrm{CH}_{3}\right)_{3}\right), 1.56\left(\mathrm{~m}_{\mathrm{c}}, 2 \mathrm{H}, 2{ }^{\prime}{ }^{-} \mathrm{H}_{2}\right), 2.26(\mathrm{~s}$, $\left.3 \mathrm{H}, \mathrm{NCH}_{3}\right), 2.42$ (t, $J=6.9 \mathrm{~Hz}, 2 \mathrm{H}, 1$ '’- $\left.-\mathrm{H}_{2}\right), 2.72$ (t, $J=6.0 \mathrm{~Hz}, 2 \mathrm{H}, 2$ '- $-\mathrm{H}_{2}$ ), 2.97 (q, $J=6.3 \mathrm{~Hz}, 2 \mathrm{H}, 3$ '' $\left.-\mathrm{H}_{2}\right), 4.02$ (t, $\left.J=6.0 \mathrm{~Hz}, 2 \mathrm{H}, 1^{\prime}-\mathrm{H}_{2}\right), 6.75-6.77$ (m, $\left.3 \mathrm{H}, 3-\mathrm{H}, 6-\mathrm{H}, \mathrm{NH}\right)$, 7.02 (d, $J=2.4 \mathrm{~Hz}, 1 \mathrm{H}, 4-\mathrm{H}), 7.38$ (d, $J=8.7 \mathrm{~Hz}, 1 \mathrm{H}, 7-\mathrm{H}), 11.40$ (s, $1 \mathrm{H}$, Indol-NH).

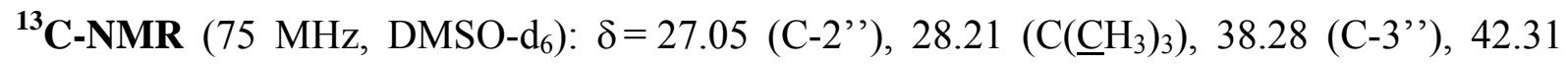
$\left(\mathrm{NCH}_{3}\right), 54.92$ (C-1'’), 55.91 (C-2'), 66.19 (C-1'), $77.27\left(\underline{\mathrm{C}}\left(\mathrm{CH}_{3}\right)_{3}\right), 103.0$ (C-4), 103.5 (C-3), 113.0 (C-7), 113.5 (C-6), 127.7, 131.5 (C-2, C-3a), 136.0 (C-7a), 152.4 (C-5), 155.5 (CONH), $165.6(\mathrm{C}=\mathrm{O})$.

MS (ESI): $m / z(\%)=392.2(100)[\mathrm{M}+\mathrm{H}]^{+}, 414.1(44)[\mathrm{M}+\mathrm{Na}]^{+}$.

$\mathbf{C}_{20} \mathbf{H}_{29} \mathbf{N}_{3} \mathbf{O}_{5}$ (391.46). $\quad$ Ber.: 392.21800 für $[\mathrm{M}+\mathrm{H}]^{+}$

Gef.: 392.21798 (ESI-HRMS).

\subsection{Synthese von 68}

\subsubsection{5-[2-(2-Cyanoethyl)-methyl-aminoethoxy]-indol-2-} carbonsäureethylester (67)

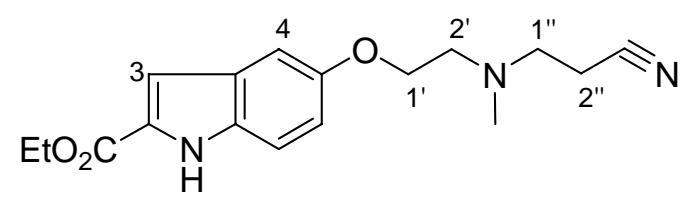

$\mathrm{Zu}$ einer Suspension von 64 (170 mg, $0.65 \mathrm{mmol}, 1.0$ Äq.) in Acrylsäurenitril (1 mL) und EtOH (1 mL) wurde DMAP (20 mg, 0.16 mmol, 0.25 Äq.) gegeben. Das Reaktionsgemisch wurde $2 \mathrm{~h}$ bei Raumtemperatur gerührt, mit Wasser $(20 \mathrm{~mL})$ beendet und mit AcOEt $(3 \times 30 \mathrm{~mL})$ extrahiert. Die vereinigten organischen Phasen wurden über $\mathrm{Na}_{2} \mathrm{SO}_{4}$ getrocknet und das Lösungsmittel im Vakuum entfernt. Nach Säulenchromatographie an Kieselgel $\left(\mathrm{CH}_{2} \mathrm{Cl}_{2} / \mathrm{MeOH}=50: 1 \rightarrow 20: 1\right)$ erhielt man die Titelverbindung als weißen Feststoff (170 mg, $0.54 \mathrm{mmol}, 83 \%)$.

$\mathbf{R}_{\mathbf{f}}=0.7\left(\mathrm{CH}_{2} \mathrm{Cl}_{2} / \mathrm{MeOH}=10: 1\right)$.

UV $\left(\mathrm{CH}_{3} \mathrm{CN}\right): \lambda_{\max }(\lg \varepsilon)=215.5 \mathrm{~nm}$ (4.473), 294.0 (4.323), 323.0 (3.733).

IR $(\mathrm{KBr}): \widetilde{v}\left(\mathrm{~cm}^{-1}\right)=3306,1688,1529,1341,1218$. 
${ }^{1} \mathbf{H}-\mathbf{N M R}\left(300 \mathrm{MHz}, \mathrm{DMSO}-\mathrm{d}_{6}\right): \delta=1.33\left(\mathrm{t}, J=7.2 \mathrm{~Hz}, 3 \mathrm{H}, \mathrm{OCH}_{2} \mathrm{CH}_{3}\right), 2.31(\mathrm{~s}, 3 \mathrm{H}$, $\left.\mathrm{NCH}_{3}\right), 2.61-2.78\left(\mathrm{~m}, 4 \mathrm{H}, 1\right.$ '’ $\left.-\mathrm{H}_{2}, 2{ }^{\prime}{ }^{\prime}-\mathrm{H}_{2}\right), 2.80$ (t, J=5.7 Hz, 2 H, 2'- $\left.-\mathrm{H}_{2}\right), 4.04$ (t, $J=6.0 \mathrm{~Hz}, 2 \mathrm{H}, 1$ ' $\left.-\mathrm{H}_{2}\right), 4.33\left(\mathrm{q}, J=7.2 \mathrm{~Hz}, 2 \mathrm{H}, \mathrm{OC}_{2} \mathrm{CH}_{3}\right), 6.93(\mathrm{dd}, J=9.0,2.4 \mathrm{~Hz}, 1 \mathrm{H}$, 6-H), 7.04 (d, $1 \mathrm{H}, J=1.5 \mathrm{~Hz}, 3-\mathrm{H}), 7.12$ (d, $1 \mathrm{H}, J=2.4 \mathrm{~Hz}, 4-\mathrm{H}), 7.36$ (d, $J=9.0 \mathrm{~Hz}, 1 \mathrm{H}$, 7-H), 11.69 (s, 1 H, Indol-NH).

${ }^{13}$ C-NMR (75 MHz, DMSO-d 6 ): $\delta=14.20\left(\mathrm{OCH}_{2} \mathrm{CH}_{3}\right), 15.26\left(\mathrm{C}-2\right.$ '”), $41.70\left(\mathrm{NCH}_{3}\right), 52.44$ (C-1'’), 55.06 (C-2'), $60.18\left(\mathrm{OCH}_{2} \mathrm{CH}_{3}\right), 66.24$ (C-1'), 103.1 (C-4), 107.2 (C-3), 113.4 (C-7), $116.4(\mathrm{C}-6), 119.9(\mathrm{C} \equiv \mathrm{N}), 127.0,127.6$ (C-2, C-3a), 132.8 (C-7a), $153.0(\mathrm{C}-5), 161.2(\mathrm{C}=\mathrm{O})$. MS (ESI): $m / z(\%)=338.1(18)[\mathrm{M}+\mathrm{Na}]^{+}, 652.9(100)[2 \mathrm{M}+\mathrm{Na}]^{+}, 314.2(100)[\mathrm{M}-\mathrm{H}]^{-}$.
$\mathrm{C}_{17} \mathrm{H}_{21} \mathbf{N}_{3} \mathbf{O}_{3}$ (315.37).
Ber.: C: 64.74
H: 6.71
$\mathrm{N}: 13.32$
Gef.: C: 64.69
H: 6.73
$\mathrm{N}: 13.12$

\subsubsection{5-[2-(2-Cyanoethyl)-methyl-aminoethoxy]-indol-2-carbonsäure (68)}<smiles>C[C](CC=N)N(C)CCOc1ccc2[nH]c(C(=O)O)cc2c1</smiles>

$\mathrm{Zu}$ einem Lösungsgemisch von $\mathrm{H}_{2} \mathrm{O} / \mathrm{MeOH} / \mathrm{THF}(3 \mathrm{~mL} / 1 \mathrm{~mL} / 3 \mathrm{~mL})$ gab man $67(270 \mathrm{mg}$, $0.86 \mathrm{mmol}, 1.0$ Äq.) sowie $\mathrm{LiOH} \cdot \mathrm{H}_{2} \mathrm{O}(110 \mathrm{mg}, 2.6 \mathrm{mmol}, 3.0$ Äq.), ließ $2 \mathrm{~h}$ bei Raumtemperatur rühren. Danach wurde Wasser $(20 \mathrm{~mL})$ zugegeben, mit $1 \mathrm{M} \mathrm{HCl}$ der pH-Wert der Lösung auf 5 eingestellt. Die wässrige Phase wurde mit $n$-Butanol $(3 \times 50 \mathrm{~mL})$ extrahiert. Das nach Entfernen des $n$-Butanols erhaltene Rohprodukt wurde an Kieselgel adsorbiert und durch Säulenchromatographie $\left(\mathrm{CH}_{2} \mathrm{Cl}_{2} / \mathrm{MeOH}=10: 1+0.1 \%\right.$ konz. Salzsäure $)$ gereinigt. Man erhielt die Titelverbindung als braunen Feststoff (230 mg, 0.8 mmol, 93 \%).

$\mathbf{R}_{\mathbf{f}}=0.6\left(\mathrm{CH}_{2} \mathrm{Cl}_{2} / \mathrm{MeOH}=10: 2+1 \% \mathrm{HOAc}\right)$.

${ }^{1} \mathbf{H}-\mathrm{NMR}\left(300 \mathrm{MHz}, \mathrm{DMSO}-\mathrm{d}_{6}\right): \delta=2.32\left(\mathrm{~s}, 3 \mathrm{H}, \mathrm{NCH}_{3}\right), 2.62-2.76\left(\mathrm{~m}, 4 \mathrm{H}, 1\right.$ ' '- $\mathrm{H}_{2}, 2$ ' '- $\left.\mathrm{H}_{2}\right)$, $2.80\left(\mathrm{t}, J=6.0 \mathrm{~Hz}, 2 \mathrm{H}, 2^{\prime}-\mathrm{H}_{2}\right), 4.03\left(\mathrm{t}, J=6.0 \mathrm{~Hz}, 2 \mathrm{H}, 1^{\prime}-\mathrm{H}_{2}\right), 6.81(\mathrm{dd}, J=9.0,2.4 \mathrm{~Hz}, 1 \mathrm{H}$, 6-H), $6.84(\mathrm{~d}, 1 \mathrm{H}, J=1.5 \mathrm{~Hz}, 3-\mathrm{H}), 7.06(\mathrm{~d}, 1 \mathrm{H}, J=2.1 \mathrm{~Hz}, 4-\mathrm{H}), 7.34$ (d, $J=8.7 \mathrm{~Hz}, 1 \mathrm{H}$, 7-H), 11.27 (s, 1 H, Indol-NH). 
${ }^{13}$ C-NMR (75 MHz, DMSO-d 6 ): $\delta=15.24\left(\mathrm{C}-2\right.$ '”), $41.72\left(\mathrm{NCH}_{3}\right), 52.43(\mathrm{C}-1$ '”), 55.12

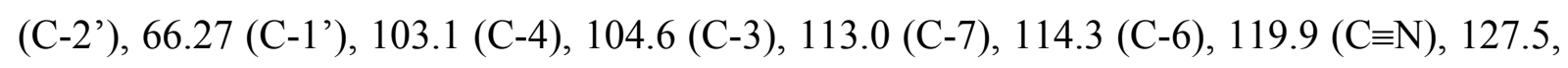
131.8 (C-2, C-3a), 133.7 (C-7a), 152.5 (C-5), $165.5(\mathrm{C}=\mathrm{O})$.

MS (EI, $70 \mathrm{eV}): m / z(\%)=287.3(13)[\mathrm{M}]^{+}$.

$\mathrm{C}_{15} \mathbf{H}_{17} \mathbf{N}_{3} \mathbf{O}_{3}(287.31)$.

\subsection{Synthese von 74}

\subsubsection{2-Acetylaminoethyl-p-nitrophenyl-ether (71)}<smiles>CC(=O)NCCOc1ccc([N+](=O)[O-])cc1</smiles>

$\mathrm{Zu}$ einer Suspension von $\mathrm{NaH}(0.48 \mathrm{~g}, 12.0 \mathrm{mmol}, 1.2$ Äq., mit Pentan dreimal gewaschen) in absolutem THF (20 ml) wurde eine Lösung von 69 (1.03 g, 10.0 mmol, 1.0 Äq.) in absolutem THF (20 ml) gegeben. Man erhitzte das Reaktionsgemisch zum Sieden, gab tropfenweise 70 (1.13 g, 8.0 mmol, 0.8 Äq.) hinzu und rührte für weitere 3.5 h am Rückfluss. Anschließend ließ man auf Raumtemperatur abkühlen. Wasser $(100 \mathrm{~mL})$ wurde zugegeben, die wässrige Phase mit Essigester $(2 \times 100 \mathrm{~mL})$ extrahiert, die vereinigten organischen Phasen über $\mathrm{Na}_{2} \mathrm{SO}_{4}$ getrocknet und das Lösungsmittel im Vakuum entfernt. Nach Säulenchromatographie an Kieselgel $(\mathrm{AcOEt} / \mathrm{MeOH}=40: 1 \rightarrow 20: 1)$ erhielt man die Titelverbindung als gelben Feststoff (1.02 g, $4.5 \mathrm{mmol}, 57 \%)$.

$\mathbf{R}_{\mathbf{f}}=0.3(\mathrm{AcOEt} / \mathrm{MeOH}=20: 1)$.

Smp.: $119^{\circ} \mathrm{C}$.

${ }^{1} \mathbf{H}-\mathrm{NMR}\left(300 \mathrm{MHz}, \mathrm{CDCl}_{3}\right): \delta=2.04\left(\mathrm{~s}, 3 \mathrm{H}, \mathrm{CH}_{3}\right), 3.71$ (q, $\left.J=5.4 \mathrm{~Hz}, 2 \mathrm{H}, 2-\mathrm{H}_{2}\right), 4.15$ (t, $\left.2 \mathrm{H}, J=5.4 \mathrm{~Hz}, 1-\mathrm{H}_{2}\right), 6.06$ ( $\mathrm{s}$ br, $\left.1 \mathrm{H}, \mathrm{NH}\right), 6.94-6.98$ (m, $2 \mathrm{H}, 2^{\prime}-\mathrm{H}, 6$ ' $\left.-\mathrm{H}\right), 8.18-8.21$ (m, $\left.2 \mathrm{H}, 3^{\prime}-\mathrm{H}, 5^{\prime}-\mathrm{H}\right)$.

${ }^{13}$ C-NMR (75 MHz, $\left.\mathrm{CDCl}_{3}\right): \delta=23.21\left(\mathrm{CH}_{3}\right), 38.73$ (C-2), 67.50 (C-1), 114.4(C-2', C-6'), 125.9 (C-3', C-5'), 141.7 (C-4'), 163.4 (C-1'), 170.4 (C=O).

MS (DCI, $200 \mathrm{eV}): \mathrm{m} / \mathrm{z}(\%)=242.3(100)\left[\mathrm{M}+\mathrm{NH}_{4}\right]^{+}, 466.4(14)\left[2 \mathrm{M}+\mathrm{NH}_{4}\right]^{+}$. 
$\mathrm{C}_{10} \mathbf{H}_{12} \mathbf{N}_{2} \mathbf{O}_{4}(224.21)$.

\subsubsection{N-[2-(4-Amino-phenoxy)-ethyl]-acetamidhydrochlorid (72)}

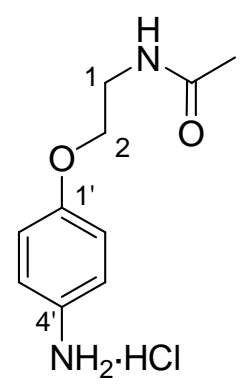

$\mathrm{Zu}$ einer Lösung von 71 (4.19 g, $18.7 \mathrm{mmol}, 1.0$ Äq.) in EtOH (100 mL) wurde bei Raumtemperatur Palladium auf Aktivkohle (10\%ig, $210 \mathrm{mg}$ ) gegeben. Die Reaktionsmischung wurde $2 \mathrm{~h}$ bei Raumtemperatur unter $\mathrm{H}_{2}$-Atmosphäre (4 bar) geschüttelt, der Feststoff durch Filtration über Celite abgetrennt, gründlich mit $\mathrm{CH}_{2} \mathrm{Cl}_{2} / \mathrm{MeOH}$ (2:1) nachgespült. Das Filtrat wurde im Vakuum eingeengt, $\mathrm{HCl} / \mathrm{EtOH}(1 \mathrm{M}, 20 \mathrm{~mL})$ wurde tropfenweise zugegeben. Die ausgefallenen Feststoff wurden abfiltriert und im Vakuum getrocknet. Die Titelverbindung (4.10 g, $17.8 \mathrm{mmol}$, $95 \%$ ) wurde als weißer Feststoff erhalten.

$\mathbf{R}_{\mathbf{f}}=0.1\left(\mathrm{CH}_{2} \mathrm{Cl}_{2} / \mathrm{MeOH}=10: 1\right)$.

Smp.: $188-190^{\circ} \mathrm{C}$ (zer.).

Zur NMR Analyse wurde die freie Base benutzt.

${ }^{1} \mathbf{H}-\mathbf{N M R}\left(300 \mathrm{MHz}, \mathrm{CDCl}_{3}\right): \delta=2.00\left(\mathrm{~s}, 3 \mathrm{H}, \mathrm{CH}_{3}\right), 3.43\left(\mathrm{~s}_{\mathrm{br}}, 2 \mathrm{H}, \mathrm{NH}_{2}\right), 3.61(\mathrm{q}, J=5.4 \mathrm{~Hz}$, $\left.2 \mathrm{H}, 1-\mathrm{H}_{2}\right), 3.95\left(\mathrm{t}, 2 \mathrm{H}, J=5.1 \mathrm{~Hz}, 2-\mathrm{H}_{2}\right), 6.07\left(\mathrm{~s}_{\mathrm{br}}, 1 \mathrm{H}, \mathrm{NH}\right), 6.62-6.65(\mathrm{~m}, 2 \mathrm{H}, 3$ '- $\mathrm{H}$, 5'-H), 6.71-6.74 (m, 2 H, 2'-H, 6'-H).

${ }^{13}$ C-NMR (75 MHz, $\left.\mathrm{CDCl}_{3}\right): \delta=23.24\left(\mathrm{CH}_{3}\right), 39.10$ (C-1), 67.36 (C-2), 115.5 (C-2', C-6'), 116.3 (C-3', C-5'), 140.4 (C-4'), 151.4 (C-1'), 170.2 (C=O).

MS (EI, $70 \mathrm{eV}): m / z(\%)=194.2(13)[\mathrm{M}-\mathrm{HCl}]^{+}$.

$\mathrm{C}_{10} \mathrm{H}_{15} \mathrm{ClN}_{2} \mathrm{O}_{2}$ (230.69). 


\subsubsection{5-(2-Acetylaminoethoxy)-indol-2-carbonsäureethylester (73)}

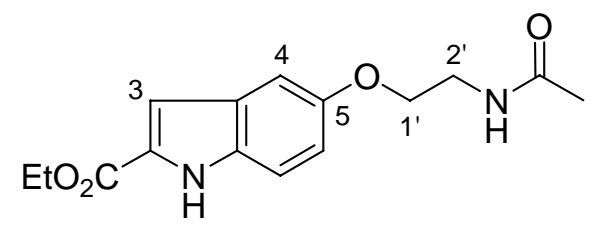

Zu einer Lösung von Anilinderivats 72 (4.44 g, 19.1 mmol, 1.0 Äq.) in Wasser (60 mL) und konzentrierter Salzsäure (1.6 mL) wurde bei $0{ }^{\circ} \mathrm{C}$ eine Lösung von $\mathrm{NaNO}_{2}(1.32 \mathrm{~g}$, $19.1 \mathrm{mmol}, 1.0$ Äq.) in Wasser $(27 \mathrm{~mL})$ getropft und die Reaktionsmischung 15 min bei $0{ }^{\circ} \mathrm{C}$ gerührt (Lösung A).

Eine Suspension aus NaOAc $(6.27 \mathrm{~g})$ in Ethanol $(85 \mathrm{~mL})$ wurde bei $0{ }^{\circ} \mathrm{C}$ tropfenweise mit 2-Methylacetessigsäureethylester (2.75 g, $19.1 \mathrm{mmol}, 1.0$ Äq.) versetzt. Nach Rühren bei $0{ }^{\circ} \mathrm{C}$ für 10 min wurde Wasser $(21 \mathrm{~mL}$ ) zugegeben (Lösung B).

Anschließend gab man Lösung A zügig zu Lösung B, erwärmte auf Raumtemperatur und rührte $2 \mathrm{~h}$. Nach Entfernen des Ethanols im Vakuum wurde die wässrige Phase mit $\mathrm{CH}_{2} \mathrm{Cl}_{2}$ $(2 \times 150 \mathrm{~mL})$ extrahiert, die vereinigten organischen Phasen über $\mathrm{Na}_{2} \mathrm{SO}_{4}$ getrocknet und das Lösungsmittel im Vakuum entfernt. Zu dem erhaltenen braunen Öl gab man eine Lösung von ges. $\mathrm{HCl} / \mathrm{HOAc}(60 \mathrm{~mL})$. Die Reaktionsmischung wurde $30 \mathrm{~min}$ bei $80^{\circ} \mathrm{C}$ gerührt. Anschließend wurde das Lösungsmittel im Vakuum entfernen, Wasser (100 mL) zugegeben, die wässrige Phase mit $\mathrm{CH}_{2} \mathrm{Cl}_{2}(2 \times 150 \mathrm{~mL})$ extrahiert, die vereinigten organischen Phasen über $\mathrm{Na}_{2} \mathrm{SO}_{4}$ getrocknet und das Lösungsmittel im Vakuum entfernt. Nach Säulenchromatographie an Kieselgel $\left(\mathrm{CH}_{2} \mathrm{Cl}_{2} / \mathrm{MeOH}=40: 1 \rightarrow 20: 1\right)$ erhielt man die Titelverbindung als weißen Feststoff (3.15 g, 10.9 mmol, 57 \%).

$\mathbf{R}_{\mathbf{f}}=0.5\left(\mathrm{CH}_{2} \mathrm{Cl}_{2} / \mathrm{MeOH}=10: 1\right)$.

Smp.: $175^{\circ} \mathrm{C}$.

UV $\left(\mathrm{CH}_{3} \mathrm{CN}\right): \lambda_{\max }(\lg \varepsilon)=215.5 \mathrm{~nm}$ (4.377), 293.5 (4.233), 321.5 (3.647).

IR $(\mathrm{KBr}): \tilde{v}\left(\mathrm{~cm}^{-1}\right)=3253,2939,1652,1529,1214$.

${ }^{1} \mathbf{H}-\mathbf{N M R}\left(300 \mathrm{MHz}, \mathrm{DMSO}-\mathrm{d}_{6}\right): \delta=1.33\left(\mathrm{t}, J=7.2 \mathrm{~Hz}, 3 \mathrm{H}, \mathrm{OCH}_{2} \mathrm{CH}_{3}\right), 1.84(\mathrm{~s}, 3 \mathrm{H}$, $\mathrm{CH}_{3} \mathrm{C}=\mathrm{O}$ ), 3.42 (q, $\left.J=5.7 \mathrm{~Hz}, 2 \mathrm{H}, 2^{\prime}-\mathrm{H}_{2}\right), 3.97$ (t, $\left.J=6.0 \mathrm{~Hz}, 2 \mathrm{H}, 1^{\prime}-\mathrm{H}_{2}\right), 4.32$ (q, $J=6.9$ $\left.\mathrm{Hz}, 2 \mathrm{H}, \mathrm{OCH}_{2} \mathrm{CH}_{3}\right), 6.92(\mathrm{dd}, J=9.0,2.4 \mathrm{~Hz}, 1 \mathrm{H}, 6-\mathrm{H}), 7.03(\mathrm{~d}, J=1.8 \mathrm{~Hz}, 1 \mathrm{H}, 3-\mathrm{H}), 7.11$ (d, $J=2.4 \mathrm{~Hz}, 1 \mathrm{H}, 4-\mathrm{H}), 7.36$ (d, $J=9.0 \mathrm{~Hz}, 1 \mathrm{H}, 7-\mathrm{H}), 8.04$ (s $\mathrm{br}, 1 \mathrm{H}, \mathrm{NH}), 11.68$ (s, $1 \mathrm{H}$, Indol-NH). 
${ }^{13}$ C-NMR (75 MHz, DMSO-d $\left.{ }_{6}\right): \delta=14.29\left(\mathrm{OCH}_{2} \mathrm{CH}_{3}\right), 22.53\left(\mathrm{CH}_{3} \mathrm{C}=\mathrm{O}\right), 38.38\left(\mathrm{C}-2^{\prime}\right)$, $60.30\left(\mathrm{O}^{-} \mathrm{H}_{2} \mathrm{CH}_{3}\right), 66.72$ (C-1'), 103.2 (C-4), 107.3 (C-3), 113.4 (C-7), 116.5 (C-6), 127.0, 127.6 (C-2, C-3a), 132.8 (C-7a), $153.0(\mathrm{C}-5), 161.2\left(\mathrm{CH}_{3} \mathrm{C}=\mathrm{O}\right), 169.5$ (COO).

MS (EI, $70 \mathrm{eV}): m / z(\%)=290.3(2)[\mathrm{M}]^{+}$.

$\mathbf{C}_{15} \mathbf{H}_{18} \mathbf{N}_{2} \mathbf{O}_{4}(290.32)$.

Ber.: $\quad 313.11588$ für $[\mathrm{M}+\mathrm{Na}]^{+}$

Gef.: 313.11562 (ESI-HRMS).

Ber.: C: $62.06 \quad$ H: $6.25 \quad \mathrm{~N}: 9.65$

Gef:: $\quad$ C: $61.75 \quad$ H: $6.26 \quad$ N: 9.47

\subsubsection{5-(2-tert-Butoxycarbonylaminoethoxy)-indol-2- carbonsäureethylester (74)}

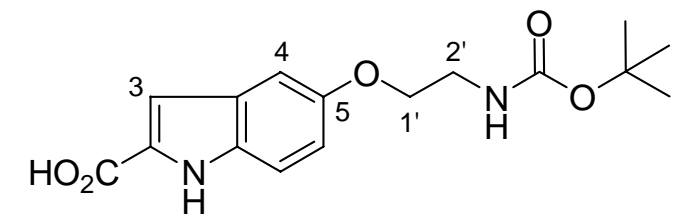

Eine Suspension von 73 (3.15 g, $10.9 \mathrm{mmol}, 1.0$ Äq) in $3 \mathrm{M} \mathrm{NaOH}(20 \mathrm{~mL}, 60 \mathrm{mmol})$ wurde $2 \mathrm{~h}$ am Rückfluss erhitzt. Nach Abkühlen auf Raumtemperatur wurde mit HOAc auf $\mathrm{pH}=8$ eingestellt. Nach Entfernen des Wassers im Vakuum, gab man $\mathrm{MeOH}$ (100 mL), $\mathrm{Boc}_{2} \mathrm{O}$ (3.08 g, $14.1 \mathrm{mmol}, 1.3$ Äq.), $\mathrm{NEt}_{3}(2.20 \mathrm{~g}, 21.7 \mathrm{mmol}, 2.0$ Äq.) hinzu und rührte $1 \mathrm{~h}$ bei Raumtemperatur. Anschließend wurde das Lösungsmittel im Vakuum entfernt, und der Rückstand mit Wasser $(50 \mathrm{~mL})$ versetzt. Die Wasser Phase wurde mit $1 \mathrm{M} \mathrm{HCl}$ auf $\mathrm{pH}=2$ gebracht, mit $\mathrm{CH}_{2} \mathrm{Cl}_{2}(2 \times 150 \mathrm{~mL})$ extrahiert. Die vereinigten organischen Phasen wurden über $\mathrm{Na}_{2} \mathrm{SO}_{4}$ getrocknet und das Lösungsmittel im Vakuum entfernt. Nach Säulenchromatographie an Kieselgel $\left(\mathrm{CH}_{2} \mathrm{Cl}_{2} / \mathrm{MeOH}=10: 1+0.1 \%\right.$ HOAc) erhielt man die Titelverbindung als weißen Feststoff (2.90 g, $9.1 \mathrm{mmol}, 83$ \%).

$\mathbf{R}_{\mathbf{f}}=0.6\left(\mathrm{CH}_{2} \mathrm{Cl}_{2} / \mathrm{MeOH}=10: 1+1 \% \mathrm{HOAc}\right)$.

Smp.: $150-153{ }^{\circ} \mathrm{C}$.

UV $\left(\mathrm{CH}_{3} \mathrm{CN}\right): \lambda_{\max }(\lg \varepsilon)=216.0 \mathrm{~nm}$ (4.420), 292.5 (4.221).

IR $(\mathrm{KBr}): \widetilde{v}\left(\mathrm{~cm}^{-1}\right)=3323,2978,1698,1526,1166$. 
${ }^{1} \mathbf{H}-\mathrm{NMR}\left(300 \mathrm{MHz}, \mathrm{DMSO}-\mathrm{d}_{6}\right): \delta=1.39\left(\mathrm{~s}, 9 \mathrm{H}, \mathrm{C}\left(\mathrm{CH}_{3}\right)_{3}\right), 3.30\left(\mathrm{q}, J=5.7 \mathrm{~Hz}, 2 \mathrm{H}, 2^{\prime}-\mathrm{H}_{2}\right)$, $3.94\left(\mathrm{t}, J=6.0 \mathrm{~Hz}, 2 \mathrm{H}, 1^{\prime}-\mathrm{H}_{2}\right), 6.85$ (dd, $\left.J=9.0,2.4 \mathrm{~Hz}, 1 \mathrm{H}, 6-\mathrm{H}\right), 6.89$ (d, $J=1.5 \mathrm{~Hz}, 1 \mathrm{H}$, 3-H), 6.94 ( $\left.\mathrm{s}_{\mathrm{br}}, 1 \mathrm{H}, \mathrm{NH}\right), 7.07$ (d, J=2.4 Hz, $\left.1 \mathrm{H}, 4-\mathrm{H}\right), 7.32$ (d, J=9.0 Hz, $\left.1 \mathrm{H}, 7-\mathrm{H}\right), 11.41$ (s, $1 \mathrm{H}$, Indol-NH).

${ }^{13}$ C-NMR (75 MHz, DMSO-d $\left.\mathrm{d}_{6}\right): \delta=28.15\left(\mathrm{C}\left(\underline{\mathrm{CH}}_{3}\right)_{3}\right), 39.60\left(\mathrm{C}-2\right.$ ') $66.89\left(\mathrm{C}-1^{\prime}\right), 77.63$ $\left(\underline{\mathrm{C}}\left(\mathrm{CH}_{3}\right)_{3}\right), 103.3$ (C-4), 104.6 (C-3), 112.9 (C-7), 114.4 (C-6), 127.5, 131.9 (C-2, C-3a), $133.2(\mathrm{C}-7 \mathrm{a}), 152.5(\mathrm{C}-5), 155.6(\mathrm{CON}), 164.2(\mathrm{COOH})$.

MS (ESI): $m / z(\%)=343(31)[\mathrm{M}+\mathrm{Na}]^{+}, 319(100)[\mathrm{M}-\mathrm{H}]^{-}$.

$\begin{array}{lllll}\mathbf{C}_{16} \mathbf{H}_{20} \mathbf{N}_{2} \mathbf{O}_{5} \text { (320.34). } & \text { Ber.: } & \text { C: } 59.99 & \text { H: } 6.29 & \text { N: } 8.74 \\ & \text { Gef.: } & \text { C: } 60.26 & \text { H: } 6.61 & \text { N: } 8.99\end{array}$

\subsection{Synthese von 76}

\subsubsection{1,2-bis-(4-Nitro-phenoxy)-ethan (46)}

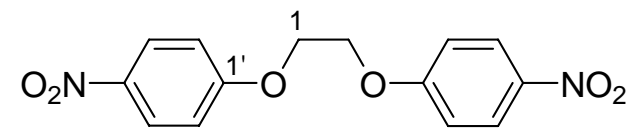

$\mathbf{R}_{\mathbf{f}}=0.2(\mathrm{PE} / \mathrm{AcOEt}=3: 1)$.

${ }^{1} \mathbf{H}-\mathbf{N M R}\left(300 \mathrm{MHz}, \mathrm{CDCl}_{3}\right): \delta=4.47\left(\mathrm{~s}, 4 \mathrm{H}, 1-\mathrm{H}_{2}, 2-\mathrm{H}_{2}\right), 7.01-7.04\left(\mathrm{~m}_{\mathrm{c}}, 4 \mathrm{H}, 2 \times 2{ }^{\prime}-\mathrm{H}, 2 \times\right.$ 6'-H), 8.22-8.25 (m, 4 H, $2 \times 3$ ' $\left.-\mathrm{H}, 2 \times 5^{\prime}-\mathrm{H}\right)$.

${ }^{13}$ C-NMR $\left(75 \mathrm{MHz}, \mathrm{CDCl}_{3}\right): \delta=66.74(\mathrm{C}-1, \mathrm{C}-2), 114.6(2 \times \mathrm{C}-2$ ', $2 \times \mathrm{C}-6$ '), 126.0 $\left(2 \times \mathrm{C}^{-3}{ }^{\prime}, 2 \times \mathrm{C}-5^{\prime}\right), 142.0\left(2 \times \mathrm{C}^{\prime} 4^{\prime}\right), 163.3\left(2 \times \mathrm{C}^{\prime} 1^{\prime}\right)$.

MS (EI, $70 \mathrm{eV}): m / z(\%)=304.0(100)[\mathrm{M}]^{+}$.

$\mathbf{C}_{14} \mathbf{H}_{12} \mathbf{N}_{2} \mathbf{O}_{6}$ (304.25). 


\subsubsection{1,2-bis-(2-Ethoxycarbo-indol-5-oxy)-ethan (76)}

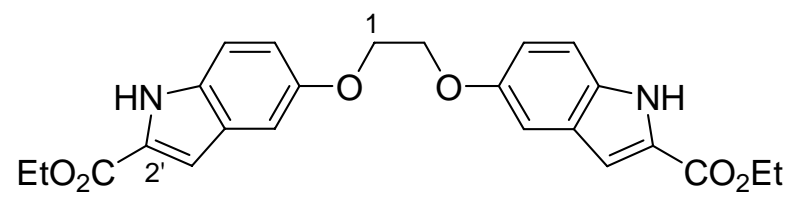

Eine Lösung von 46 (4.5 g, 14.8 mmol, 1.0 Äq.) in AcOEt/EtOH (60 mL/30 mL) wurde mit Palladium auf Aktivkohle (10\%ig, $0.18 \mathrm{~g}$ ) versetzt, $1 \mathrm{~h}$ bei Raumtemperatur unter $\mathrm{H}_{2}$ Atmosphäre (4 bar) geschüttelt. Der Feststoff wurde durch Filtration über Celite abgetrennt, gründlich mit Methanol nachgespült. Nach Entfernen des Lösungsmittels wurde die Zwischenverbindung 75 (3.3 g, 13.5 mmol, 92\%) als gelber Feststoff erhalten.

$\mathrm{Zu}$ einer Lösung von Anilinderivats 75 (2.0 g, $8.2 \mathrm{mmol}, 1.0$ Äq.) in Wasser (40 mL) und konzentrierter Salzsäure $(3 \mathrm{~mL})$ wurde bei $0{ }^{\circ} \mathrm{C}$ eine Lösung von $\mathrm{NaNO}_{2}(1.13 \mathrm{~g}, 16.4 \mathrm{mmol}$, 2.0 Äq.) in Wasser $(15 \mathrm{~mL})$ getropft und die Reaktionsmischung 15 min bei $0^{\circ} \mathrm{C}$ gerührt (Lösung A).

Eine Suspension aus NaOAc (4.04 g, $49.2 \mathrm{mmol}, 6.0$ Äq.) in Ethanol (30 mL) wurde bei $0{ }^{\circ} \mathrm{C}$ tropfenweise mit 2-Methylacetessigsäureethylester (2.36 g, $16.4 \mathrm{mmol}, 2.0$ Äq.) versetzt. Nach Rühren bei $0{ }^{\circ} \mathrm{C}$ für 10 min wurde Wasser $(7.5 \mathrm{~mL})$ zugegeben (Lösung B).

Anschließend gab man Lösung A zügig zu Lösung B, erwärmte auf Raumtemperatur und rührte $2 \mathrm{~h}$ bei Raumtemperatur. Nach Entfernen des Ethanols im Vakuum wurde die wässrige Phase mit AcOEt $(2 \times 100 \mathrm{~mL})$ extrahiert, die vereinigten organischen Phasen über $\mathrm{Na}_{2} \mathrm{SO}_{4}$ getrocknet und das Lösungsmittel im Vakuum entfernt. $\mathrm{Zu}$ dem erhaltenen braunen Öl gab man eine Lösung der $6 \mathrm{M} \mathrm{HCl} / i$-PrOH $(20 \mathrm{~mL})$. Die Reaktionsmischung wurde $20 \mathrm{~min}$ bei $70{ }^{\circ} \mathrm{C}$ gerührt. Anschließend ließ man auf Raumtemperatur abkühlen, das Lösungsmittel im Vakuum entfernen. Wasser $(100 \mathrm{~mL})$ wurde zugegeben, die wässrige Phase mit AcOEt $(2 \times 100 \mathrm{~mL})$ extrahiert, die vereinigten organischen Phasen über $\mathrm{Na}_{2} \mathrm{SO}_{4}$ getrocknet und das Lösungsmittel im Vakuum entfernt. Nach Säulenchromatographie an Kieselgel $\left(\mathrm{CH}_{2} \mathrm{Cl}_{2} / \mathrm{MeOH}=100: 1 \rightarrow 50: 1\right)$ erhielt man die Titelverbindung als blass-gelblichen Feststoff (2.0 g, $4.6 \mathrm{mmol}, 56 \%)$.

$\mathbf{R}_{\mathbf{f}}=0.3(\mathrm{PE} / \mathrm{AcOEt}=3: 1)$.

UV $\left(\mathrm{CH}_{3} \mathrm{CN}\right): \lambda_{\max }(\lg \varepsilon)=218.0 \mathrm{~nm}$ (4.701), 294.0 (4.581).

IR (KBr): $\tilde{v}\left(\mathrm{~cm}^{-1}\right)=3325,1678,1529,1447,1212$. 
${ }^{1}$ H-NMR (300 MHz, DMSO-d $\left.{ }_{6}\right): \delta=1.33\left(\mathrm{t}, J=7.2 \mathrm{~Hz}, 6 \mathrm{H}, 2 \times \mathrm{CH}_{3}\right), 4.30-4.37(\mathrm{~m}, 8 \mathrm{H}$, $\left.2 \times \underline{\mathrm{C}}_{2} \mathrm{CH}_{3}, 1-\mathrm{H}_{2}, 2-\mathrm{H}_{2}\right), 6.99\left(\mathrm{dd}, J=9.0,2.4 \mathrm{~Hz}, 2 \mathrm{H}, 2 \times 6^{\prime}-\mathrm{H}\right), 7.06(\mathrm{~d}, J=1.2 \mathrm{~Hz}, 2 \mathrm{H}$, $\left.2 \times 3^{\prime}-\mathrm{H}\right), 7.17\left(\mathrm{~d}, J=2.4 \mathrm{~Hz}, 2 \mathrm{H}, 2 \times 4^{\prime}-\mathrm{H}\right), 7.39\left(\mathrm{~d}, J=8.7 \mathrm{~Hz}, 2 \mathrm{H}, 2 \times 7^{\prime}-\mathrm{H}\right), 11.72(\mathrm{~s}$, $2 \mathrm{H}, 2 \times$ Indol-NH).

${ }^{13}$ C-NMR $\left(75 \mathrm{MHz}, \mathrm{DMSO}-\mathrm{d}_{6}\right): \delta=14.21\left(2 \times \mathrm{CH}_{3}\right), 60.21\left(2 \times \underline{\mathrm{CH}}_{2} \mathrm{CH}_{3}\right), 66.79(\mathrm{C}-1, \mathrm{C}-2)$,

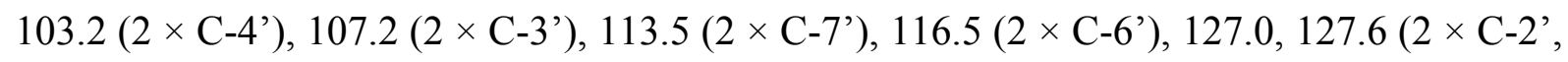
$\left.2 \times \mathrm{C}^{\prime} 3^{\prime} \mathrm{a}\right), 132.8\left(2 \times \mathrm{C}-7^{\prime}\right.$ 'a), $153.0\left(2 \times \mathrm{C}-5^{\prime}\right), 161.2(2 \times \mathrm{C}=\mathrm{O})$.

MS (ESI): $m / z(\%)=459.0(46)[\mathrm{M}+\mathrm{Na}]^{+}, 895.4(95)[2 \mathrm{M}+\mathrm{Na}]^{+}, 435.3(100)[\mathrm{M}-\mathrm{H}]^{-}$.

$\mathbf{C}_{24} \mathbf{H}_{24} \mathbf{N}_{2} \mathbf{O}_{6}(436.46)$.

Ber.: 437.17071 für $[\mathrm{M}+\mathrm{H}]^{+}$

Gef.: 437.17064 (ESI-HRMS). 


\section{Synthese des anti-Methyl-seco-CBI-Grundgerüstes}

\subsection{3-Amino-1-benzyloxy- $N$-(tert-butoxycarbonyl)-naphthalin (78)}<smiles>CC(C)(C)Nc1cc(Br)c2ccccc2c1</smiles>

$\mathrm{Zu}$ einer Suspension der Carbonsäure 77 (8.36 g, $30.0 \mathrm{mmol}, 1.0$ Äq.) in absolutem tertButylalkohol (0.24 L) gab man DPPA (9.08 g, 33.0 mmol, 1.1 Äq.) und Triethylamin (3.64 g, 36.0 mmol, 1.2 Äq.). Das Reaktionsgemisch wurde $3 \mathrm{~h}$ zum Sieden erhitzt. Nach Abkühlen auf Raumtemperatur in Wasser ( $200 \mathrm{~mL})$ gegossen, mit $\mathrm{CH}_{2} \mathrm{Cl}_{2}(2 \times 200 \mathrm{~mL})$ extrahiert. Die vereinigten organischen Phasen wurden über $\mathrm{Na}_{2} \mathrm{SO}_{4}$ getrocknet und das Lösungsmittel im Vakuum entfernt. Nach Säulenchromatographie an Kieselgel $(\mathrm{PE} / \mathrm{AcOEt}=10: 1 \rightarrow 5: 1)$ erhielt man die Zielverbindung als weißen Feststoff (8.66 g, 24.8 mmol, 83 \%).

$\mathbf{R}_{\mathbf{f}}=0.5(\mathrm{PE} / \mathrm{AcOEt}=10: 1)$.

Smp.: $130-133^{\circ} \mathrm{C}$.

${ }^{1}$ H-NMR $\left(300 \mathrm{MHz}, \mathrm{CDCl}_{3}\right): \delta=1.55\left(\mathrm{~s}, 9 \mathrm{H}, \mathrm{C}\left(\mathrm{CH}_{3}\right)_{3}\right), 5.21\left(\mathrm{~s}, 2 \mathrm{H}, \mathrm{C}_{2} \mathrm{Ph}\right), 6.64(\mathrm{~s}, 1 \mathrm{H}$, NH), $7.05(\mathrm{~d}, J=1.0 \mathrm{~Hz}, 1 \mathrm{H}, 2-\mathrm{H}), 7.30-7.53$ (m, $8 \mathrm{H}, 4-\mathrm{H}, 6-\mathrm{H}, 7-\mathrm{H}, 5 \times \mathrm{Ph}-\mathrm{H}), 7.68(\mathrm{~d}$, $J=8.1 \mathrm{~Hz}, 1 \mathrm{H}, 5-\mathrm{H}), 8.22(\mathrm{~d}, J=8.4 \mathrm{~Hz}, 1 \mathrm{H}, 8-\mathrm{H})$.

${ }^{13}$ C-NMR $\left(50 \mathrm{MHz}, \mathrm{CDCl}_{3}\right): \delta=28.36\left(\mathrm{C}\left(\underline{\mathrm{CH}}_{3}\right)_{3}\right), 70.11\left(\underline{\mathrm{C}}\left(\mathrm{CH}_{3}\right)_{3}\right), 80.62\left(\underline{\mathrm{CH}}_{2} \mathrm{Ph}\right), 99.15$ (C-2), 106.9 (C-4), 122.0 (C-8), 122.5 (C-8a), 123.7 (C-7), 126.8, 127.1, 128.0 (C-5, C-6, Ph- $\left.\mathrm{C}_{p}\right), 127.4\left(2 \times \mathrm{Ph}_{-} \mathrm{C}_{o}\right), 128.6\left(2 \times \mathrm{Ph}_{-} \mathrm{C}_{m}\right), 134.7(\mathrm{C}-4 \mathrm{a}), 136.2,136.8\left(\mathrm{C}-3, \mathrm{Ph}-\mathrm{C}_{i}\right), 152.8$ $(\mathrm{C}=\mathrm{O}), 155.2(\mathrm{C}-1)$.

$\mathrm{C}_{22} \mathrm{H}_{23} \mathrm{NO}_{3}$ (349.42). 


\subsection{2-Amino-4-benzyloxy-1-iod- $N$-(tert-butoxycarbonyl)-naphthalin (79)}

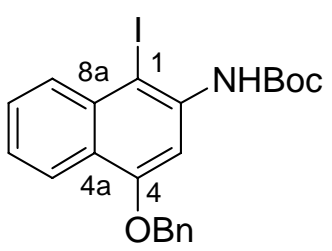

Zu einer Lösung des Naphthalinderivats 78 (3.64 g, 10.4 mmol, 1.0 Äq.) in $\mathrm{MeOH} / \mathrm{H}_{2} \mathrm{O}=4: 1$ (225mL) wurden $\mathrm{HIO}_{3}(0.37 \mathrm{~g}, 2.1 \mathrm{mmol}, 0.2$ Äq.) und Jod (1.06 g, $4.2 \mathrm{mmol}, 0.4$ Äq.) gegeben und $2 \mathrm{~h}$ unter Rückfluss erhitzt. Nach Entfernen des Methanols im Vakuum wurde die wässrige Phase mit $\mathrm{CH}_{2} \mathrm{Cl}_{2}(2 \times 100 \mathrm{~mL})$ extrahiert, die vereinigten organischen Phasen über $\mathrm{Na}_{2} \mathrm{SO}_{4}$ getrocknet und das Lösungsmittel im Vakuum entfernt. Nach Säulenchromatographie an Kieselgel $(\mathrm{PE} / \mathrm{AcOEt}=10: 1)$ erhielt man die Titelverbindung als braunen Feststoff (4.31 g, $9.1 \mathrm{mmol}, 87 \%$ ).

$\mathbf{R}_{\mathbf{f}}=0.7(\mathrm{PE} / \mathrm{AcOEt}=10: 1)$.

Smp.: $110^{\circ} \mathrm{C}$.

${ }^{1} \mathbf{H}-\mathbf{N M R}\left(300 \mathrm{MHz}, \mathrm{CDCl}_{3}\right): \delta=1.58\left(\mathrm{~s}, 9 \mathrm{H}, \mathrm{C}\left(\mathrm{CH}_{3}\right)_{3}\right), 5.28\left(\mathrm{~s}, 2 \mathrm{H}, \underline{\mathrm{C}}_{2} \mathrm{Ph}\right), 7.31\left(\mathrm{~s}_{\mathrm{br}}, 1 \mathrm{H}\right.$, NH), 7.36-7.57 (m, 7 H, 6-H, 7-H, $5 \times \mathrm{Ph}-\mathrm{H}), 8.02$ (d, J=6.9 Hz, $1 \mathrm{H}, 8-\mathrm{H}), 8.04$ (s, $1 \mathrm{H}$, $3-\mathrm{H}), 8.23$ (dd, $J=7.8,1.0 \mathrm{~Hz}, 1 \mathrm{H}, 5-\mathrm{H})$.

$\left.{ }^{13} \mathrm{C}-\mathrm{NMR}\left(75 \mathrm{MHz}, \mathrm{CDCl}_{3}\right): \delta=28.35\left(\mathrm{C}^{(} \underline{\mathrm{CH}}_{3}\right)_{3}\right), 70.35\left(\underline{\mathrm{C}}\left(\mathrm{CH}_{3}\right)_{3}\right), 80.23(\mathrm{C}-1), 81.18$ $\left(\underline{\mathrm{CH}}_{2} \mathrm{Ph}\right), 99.89$ (C-3), 122.7 (C-5), 123.7 (C-4a), 124.5 (C-6), 127.8 (2× $\left.\mathrm{Ph}-\mathrm{C}_{o}\right), 128.1$ $\left(\mathrm{Ph}-\mathrm{C}_{p}\right), 128.6\left(2 \times \mathrm{Ph}_{-} \mathrm{C}_{m}\right), 128.6(\mathrm{C}-7), 131.2(\mathrm{C}-8), 134.7(\mathrm{C}-8 \mathrm{a}), 136.6\left(\mathrm{Ph}-\mathrm{C}_{i}\right), 138.3$ (C-2), $152.8(\mathrm{C}=\mathrm{O}), 155.7(\mathrm{C}-4)$.

$\mathrm{C}_{22} \mathrm{H}_{22} \mathrm{INO}_{3}$ (475.32). 


\section{3 (E/Z)-2-Amino-4-benzyloxy- $N$-(tert-butyloxycarbonyl)- $N$-(3-chlor-2-} butenyl)-1-iod-naphthalin (81)<smiles>CC(Cl)=CCN(C(=O)OCc1ccccc1)c1cc(OCc2ccccc2)c2ccccc2c1I</smiles>

$\mathrm{Zu}$ einer Suspension von $\mathrm{NaH}(0.84 \mathrm{~g}, 21.1 \mathrm{mmol}, 2.5 \mathrm{Äq}$. als 60 \%ige Suspension in Mineralöl) in absolutem DMF $(50 \mathrm{~mL})$ wurde eine Lösung des Naphthalinderivates 79 (4.01 g, $8.4 \mathrm{mmol}, 1.0$ Äq.) in absolutem DMF $(30 \mathrm{~mL})$ gegeben. Man ließ $1 \mathrm{~h}$ bei Raumtemperatur rühren, gab (E/Z)-1,3-Dichlor-2-buten (2.0 g, 16.0 mmol, 1.9 Äq.) hinzu und rührte für weitere $3 \mathrm{~h}$ bei Raumtemperatur. Die Reaktion wurde durch vorsichtige Zugabe einer gesättigten $\mathrm{NH}_{4} \mathrm{Cl}$-Lösung $(60 \mathrm{~mL})$ beendet und die Reaktionsmischung mit Essigester $(2 \times 150 \mathrm{~mL})$ extrahiert. Die vereinigten organischen Phasen wurden über $\mathrm{Na}_{2} \mathrm{SO}_{4}$ getrocknet und das Lösungsmittel im Vakuum entfernt. Säulenchromatographie an Kieselgel (PE/AcOEt $=10: 1 \rightarrow 5: 1)$ lieferte die Titelverbindung als blass-gelblichen Feststoff (4.29 g, 7.6 mmol, $91 \%)$.

$\mathbf{R}_{\mathbf{f}}=0.5,0.6(\mathrm{PE} / \mathrm{AcOEt}=10: 1)$.

${ }^{1} \mathbf{H}-\mathbf{N M R}\left(300 \mathrm{MHz}, \mathrm{CDCl}_{3}\right): \delta=1.32,1.58\left(2 \times\right.$ s, zus. $\left.9 \mathrm{H}, \mathrm{C}\left(\mathrm{CH}_{3}\right)_{3}\right), 1.80,2.03(2 \times \mathrm{s}$, zus. $\left.3 \mathrm{H}, 4^{\prime}-\mathrm{CH}_{3}\right), 3.82-4.25\left(\mathrm{~m}, 1 \mathrm{H}, 1\right.$ '- $\left.-\mathrm{H}_{\mathrm{a}}\right), 4.48-4.55\left(\mathrm{~m}, 1 \mathrm{H}, 1\right.$ '- $\left.-\mathrm{H}_{\mathrm{b}}\right), 5.19-5.29(\mathrm{~m}, 2 \mathrm{H}$, OC$\left.{ }_{2} \mathrm{Ph}\right), 5.70-5.84$ (m, 1 H, 2'-H), 6.69-6.81 (m, 1 H, 3-H), 7.36-7.60 (m, 7 H, 6-H, 7-H, $5 \times \mathrm{Ph}-\mathrm{H}), 8.20-8.32(\mathrm{~m}, 2 \mathrm{H}, 5-\mathrm{H}, 8-\mathrm{H})$.

MS (ESI): $m / z(\%)=586(100)[\mathrm{M}+\mathrm{Na}]^{+}, 1149(40)[2 \mathrm{M}+\mathrm{Na}]^{+}$.

$\mathrm{C}_{26} \mathrm{H}_{27} \mathrm{ClINO}_{3}$ (563.86). 


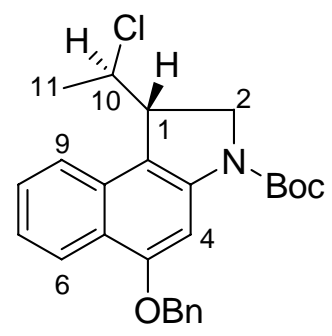

Der Iodaromat 81 (5.13 g, $9.1 \mathrm{mmol}, 1.0$ Äq.) wurde in Toluol (150 mL) gelöst und die Lösung gründlich durch Einleiten eines lebhaften Argon-Gasstromes entgast. Dann versetzte man mit Tris-(trimethylsilyl)-silan (2.48 g, 10.0 mmol, 1.1 Äq.) sowie AIBN ( $0.37 \mathrm{~g}$, $2.27 \mathrm{mmol}, 0.25$ Äq.) und rührte das Gemisch für $3 \mathrm{~h}$ bei $80^{\circ} \mathrm{C}$. Nach Entfernen des Toluols im Vakuum wurde wasser $(100 \mathrm{~mL})$ versetzt, die wässrige Phase mit Essigester $(2 \times 150 \mathrm{~mL})$ extrahiert, die vereinigten organischen Phasen über $\mathrm{Na}_{2} \mathrm{SO}_{4}$ getrocknet und das Lösungsmittel im Vakuum entfernt. Nach Säulenchromatographie an Kieselgel (PE/AcOEt $=100: 1 \rightarrow$ 8:1) erhielt man die Titelverbindung 82 als weißen Feststoff (1.76 g, 4.0 mmol, 44 \%) und das synDerivat 83 (1.50 g, $3.4 \mathrm{mmol}, 38 \%)$

$\mathbf{R}_{\mathbf{f}}=0.5(\mathrm{PE} / \mathrm{AcOEt}=10: 1)$.

Smp.: $171^{\circ} \mathrm{C}$.

${ }^{1} \mathbf{H}-\mathbf{N M R}\left(300 \mathrm{MHz}, \mathrm{CDCl}_{3}\right): \delta=1.58-1.63\left(\mathrm{~m}, 12 \mathrm{H}, \mathrm{C}\left(\mathrm{CH}_{3}\right)_{3}, 11-\mathrm{CH}_{3}\right), 3.82(\mathrm{~m}, 1 \mathrm{H}, 1-\mathrm{H})$, $4.07\left(\mathrm{~m}_{\mathrm{c}}, 1 \mathrm{H}, 2-\mathrm{H}_{\mathrm{a}}\right), 4.32\left(\mathrm{~m}_{\mathrm{c}}, 1 \mathrm{H}, 2-\mathrm{H}_{\mathrm{b}}\right), 4.60\left(\mathrm{~m}_{\mathrm{c}}, 1 \mathrm{H}, 10-\mathrm{H}\right), 5.26$ (s, $\left.2 \mathrm{H}, \mathrm{OC}_{2} \mathrm{Ph}\right), 7.29-$ 7.64 (m, 8 H, 7-H, 8-H, 9-H, $5 \times$ Ph-H), 7.88 ( $\left.\mathrm{s}_{\mathrm{br}}, 1 \mathrm{H}, 4-\mathrm{H}\right), 8.30$ (d, J=8.4 Hz, 1 H, 6-H).

$\left.{ }^{13} \mathrm{C}-\mathrm{NMR}\left(75 \mathrm{MHz}, \mathrm{CDCl}_{3}\right): \delta=23.73\left(11-\mathrm{CH}_{3}\right), 28.49\left(\mathrm{C}_{\left(\mathrm{CH}_{3}\right.}\right)_{3}\right), 46.10(\mathrm{C}-1), 50.80(\mathrm{C}-2)$, 60.19 (C-10), $70.20\left(\mathrm{OCH}_{2}\right), 80.89\left(\underline{\mathrm{C}}\left(\mathrm{CH}_{3}\right)_{3}\right), 96.27$ (C-4), 115.4 (C-9b), 122.1 (C-5a), 122.4, 122.9, 123.6 (C-6, C-7, C-9), 127.3 (C-8), 127.6, 128.0, 128.5 (5 × Ph- $\underline{\mathrm{CH}}$ ), 130.4 (C-9a), $136.9\left(\mathrm{Ph}-C_{i}\right), 142.0(\mathrm{C}-3 \mathrm{a}), 152.4(\mathrm{C}=\mathrm{O}), 155.8(\mathrm{C}-5)$.

MS (DCI, $200 \mathrm{eV}): \mathrm{m} / \mathrm{z}(\%)=455.3(100)\left[\mathrm{M}+\mathrm{NH}_{4}\right]^{+}, 438.3(62)[\mathrm{M}+\mathrm{H}]^{+}$.

$\mathrm{C}_{26} \mathrm{H}_{28} \mathrm{CINO}_{3}$ (437.97). 


\section{5 rac-\{(1,10)-syn-5-Benzyloxy-3-(tert-butyloxycarbonyl)-1-(10-chlor- ethyl)-1,2-dihydro-3H-benz[e]indol\} (83)}

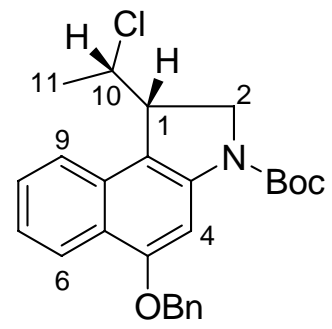

$\mathbf{R}_{\mathbf{f}}=0.6(\mathrm{PE} / \mathrm{EE}=10: 1)$.

${ }^{1}$ H-NMR $\left(300 \mathrm{MHz}, \mathrm{CDCl}_{3}\right): \delta=1.15\left(\mathrm{~d}, J=6.3 \mathrm{~Hz}, 3 \mathrm{H}, 11-\mathrm{CH}_{3}\right), 1.60\left(\mathrm{~s}, 9 \mathrm{H}, \mathrm{C}\left(\mathrm{CH}_{3}\right)_{3}\right)$, 4.03-4.18 (m, $\left.2 \mathrm{H}, 1-\mathrm{H}, 2-\mathrm{H}_{\mathrm{a}}\right), 4.36\left(\mathrm{~m}_{\mathrm{c}}, 1 \mathrm{H}, 2-\mathrm{H}_{\mathrm{b}}\right), 4.68\left(\mathrm{~m}_{\mathrm{c}}, 1 \mathrm{H}, 10-\mathrm{H}\right), 5.25(\mathrm{~s}, 2 \mathrm{H}$, $\left.\mathrm{OC}_{2} \mathrm{Ph}\right), 7.29-7.66(\mathrm{~m}, 8 \mathrm{H}, 7-\mathrm{H}, 8-\mathrm{H}, 9-\mathrm{H}, 5 \times \mathrm{Ph}-\mathrm{H}), 7.86\left(\mathrm{~s}_{\mathrm{br}}, 1 \mathrm{H}, 4-\mathrm{H}\right), 8.29(\mathrm{~d}, J=8.1$ $\mathrm{Hz}, 1 \mathrm{H}, 6-\mathrm{H})$.

${ }^{13}$ C-NMR $\left.\left(75 \mathrm{MHz}, \mathrm{CDCl}_{3}\right): \delta=17.88\left(11-\mathrm{CH}_{3}\right), 28.49\left(\mathrm{C}^{\left(\mathrm{CH}_{3}\right.}\right)_{3}\right), 46.06(\mathrm{C}-1), 49.91(\mathrm{C}-2)$, 58.24 (C-10), $70.26\left(\mathrm{OCH}_{2}\right), 81.04\left(\underline{\mathrm{C}}\left(\mathrm{CH}_{3}\right)_{3}\right), 96.36$ (C-4), 114.5 (C-9b), 121.9 (C-5a), 122.4, 123.1, 123.6 (C-6, C-7, C-9), 127.6, 127.8, 128.0, 128.6 (C-8, $5 \times$ Ph- $\underline{\mathrm{CH}}$ ), 130.2 (C-9a), $136.8\left(\mathrm{Ph}-\mathrm{C}_{i}\right), 142.0(\mathrm{C}-3 \mathrm{a}), 152.4(\mathrm{C}=\mathrm{O}), 156.0(\mathrm{C}-5)$.

$\mathrm{C}_{26} \mathrm{H}_{28} \mathrm{ClNO}_{3}$ (437.97).

\section{6 rac-(9,9a)-syn-2-(tert-Butyloxycarbonyl)-9-methyl-1,2,9,9a-} tetrahydro-cyclopropa $[c]$ benz $[e]$ indol-4-on (86)

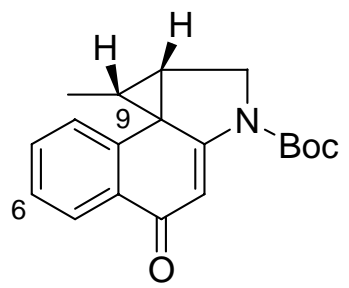

$\mathrm{Zu}$ einer Lösung von Benzylether 83 (265 mg, $0.61 \mathrm{mmol}, 1.0$ Äq.) in THF/MeOH = 3:2 $(50 \mathrm{~mL})$ wurde bei Raumtemperatur Palladium auf Aktivkohle (10\%ig, $50 \mathrm{mg})$ und HOAc $(0.1 \mathrm{~mL})$ gegeben. Die Reaktionsmischung wurde $2 \mathrm{~d}$ bei Raumtemperatur unter $\mathrm{H}_{2}$ Atmosphäre (1 bar) gerührt, der Feststoff durch Filtration über Celite abgetrennt und 
gründlich mit $\mathrm{CH}_{2} \mathrm{Cl}_{2} / \mathrm{MeOH}$ (2:1) nachgespült. Das Filtrat wurde im Vakuum eingeengt und das Zwischenprodukt (200 mg, $0.57 \mathrm{mmol}, 95$ \%) als weißer Feststoff erhalten.

$\mathrm{Zu}$ einer Lösung von Zwischenprodukt (40 mg, $0.11 \mathrm{mmol}, 1.0$ Äq.) in $\mathrm{CH}_{2} \mathrm{Cl}_{2}$ (2 mL) wurde bei Raumtemperatur DBU (25 mg, $0.16 \mathrm{mmol}, 1.5$ Äq.) gegeben. Man ließ $12 \mathrm{~h}$ bei Raumtemperatur rühren und beendete durch Zugabe einer gesättigten $\mathrm{NaHCO}_{3}$-Lösung $(20 \mathrm{~mL})$. Die wässrige Phase wurde mit Essigester $(2 \times 50 \mathrm{~mL})$ extrahiert, die vereinigten organischen Phasen über $\mathrm{Na}_{2} \mathrm{SO}_{4}$ getrocknet und das Lösungsmittel im Vakuum entfernt. Nach Säulenchromatographie an Kieselgel $(\mathrm{PE} / \mathrm{AcOEt}=10: 1 \rightarrow 3: 1)$ erhielt man die Titelverbindung als weißen Feststoff (30 mg, 0.096 mmol, $83 \%$ ).

$\mathbf{R}_{\mathbf{f}}=0.3(\mathrm{PE} / \mathrm{AcOEt}=3: 1)$.

${ }^{1} \mathbf{H}-\mathbf{N M R}\left(300 \mathrm{MHz}, \mathrm{CDCl}_{3}\right): \delta=1.08\left(\mathrm{~d}, J=6.0 \mathrm{~Hz}, 3 \mathrm{H}, \mathrm{CH}_{3}\right), 1.53\left(\mathrm{~s}, 9 \mathrm{H}, \mathrm{C}\left(\mathrm{CH}_{3}\right)_{3}\right)$, 1.73-1.79 (m, $1 \mathrm{H}, 9-\mathrm{H}), 2.74(\mathrm{dd}, J=7.8,5.4 \mathrm{~Hz}, 1 \mathrm{H}, 9 \mathrm{a}-\mathrm{H}), 3.88-4.06\left(\mathrm{~m}, 2 \mathrm{H}, 1-\mathrm{H}_{\mathrm{a}}\right.$, 1- $\left.\mathrm{H}_{\mathrm{b}}\right), 6.80(\mathrm{~d}, J=7.8 \mathrm{~Hz}, 1 \mathrm{H}, 8-\mathrm{H}), 6.84(\mathrm{~s} \mathrm{br}, 1 \mathrm{H}, 3-\mathrm{H}), 7.32(\mathrm{dt}, J=7.5,1.2 \mathrm{~Hz}, 1 \mathrm{H}, 6-\mathrm{H})$, $7.43(\mathrm{dt}, J=7.5,1.5 \mathrm{~Hz}, 1 \mathrm{H}, 7-\mathrm{H}), 8.15$ (dd, $J=7.2,1.2 \mathrm{~Hz}, 1 \mathrm{H}, 5-\mathrm{H})$.

${ }^{13} \mathrm{C}-\mathrm{NMR}\left(75 \mathrm{MHz}, \mathrm{CDCl}_{3}\right): \delta=6.83\left(\mathrm{CH}_{3}\right), 27.13(\mathrm{C}-9 \mathrm{a}), 28.15\left(\mathrm{C}\left(\underline{\mathrm{CH}}_{3}\right)_{3}\right), 34.24(\mathrm{C}-9)$, 37.72 (C-8b), 49.10 (C-1), $83.36\left(\underline{\mathrm{C}}\left(\mathrm{CH}_{3}\right)_{3}\right), 109.5$ (C-3), 120.5 (C-8), 126.1 (C-6), 126.6 (C-5), 131.6 (C-7), 132.7 (C-4a), 141.1 (C-8a), 150.8 (C=O), 157.5 (C-2a), 186.3 (C-4).

$\mathrm{C}_{19} \mathrm{H}_{21} \mathrm{NO}_{3}$ (311.37).

\section{7 rac-\{(1,10)-syn-1-(10-Chlor-ethyl)-5-hydroxy-1,2-dihydro-3H- benz[e]indol-hydrochlorid\} (143)}

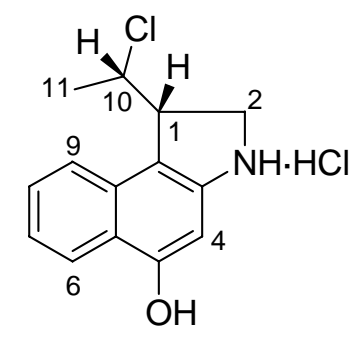

Das Edukt 86 (18 mg, $0.058 \mathrm{mmol}, 1.0$ Äq.) wurde in einem Lösungsmittelgemisch aus $6 \mathrm{M}$ $\mathrm{HCl} / i$-PrOH:AcOEt $=1: 1(2 \mathrm{~mL})$ gelöst und $1 \mathrm{~h}$ auf $60^{\circ} \mathrm{C}$ erhitzt. Anschließend ließ man auf Raumtemperatur abkühlen. Nach Entfernen des Lösungsmittels im Vakuum (durch azeotrope 
Destillation mit Toluol) wurde der Rückstand mit $\mathrm{Et}_{2} \mathrm{O}$ gewaschen. Man erhielt die Titelverbindung als grauen Feststoff (16 mg, $0.056 \mathrm{mmol}, 97 \%$ ).

${ }^{1}$ H-NMR $\left(300 \mathrm{MHz}\right.$, DMSO-d $\left.{ }_{6}\right): \delta=1.16\left(\mathrm{~d}, J=6.6 \mathrm{~Hz}, 3 \mathrm{H}, 11-\mathrm{CH}_{3}\right), 3.91-3.93(\mathrm{~m}, 2 \mathrm{H}$, 2- $\left.\mathrm{H}_{\mathrm{a}}, 2-\mathrm{H}_{\mathrm{b}}\right), 4.45\left(\mathrm{~m}_{\mathrm{c}}, 1 \mathrm{H}, 1-\mathrm{H}\right), 4.91\left(\mathrm{~m}_{\mathrm{c}}, 1 \mathrm{H}, 10-\mathrm{H}\right), 6.94(\mathrm{~s}, 1 \mathrm{H}, 4-\mathrm{H}), 7.50$ (t, J = $7.5 \mathrm{~Hz}$, $1 \mathrm{H}, 7-\mathrm{H}), 7.61$ (t, $J=7.5 \mathrm{~Hz}, 1 \mathrm{H}, 8-\mathrm{H}), 7.94(\mathrm{~d}, J=8.1 \mathrm{~Hz}, 1 \mathrm{H}, 9-\mathrm{H}), 8.20$ (d, $J=8.4 \mathrm{~Hz}$, $1 \mathrm{H}, 6-\mathrm{H}), 11.03\left(\mathrm{~s}_{\mathrm{br}}, 1 \mathrm{H}, \mathrm{NH}\right)$.

${ }^{13}$ C-NMR (75 MHz, DMSO-d 6 ): $\delta=19.14\left(11-\mathrm{CH}_{3}\right), 45.79$ (C-2), 47.93 (C-1), 58.58 (C-10), 98.97 (C-4), 119.1 (C-9b), 123.2 (C-6), 124.0 (C-9), 124.3 (C-5a), 125.0 (C-7), 128.0 (C-8), 129.6 (C-9a), 136.2 (C-3a), 155.4 (C-5).

$\mathbf{C}_{14} \mathbf{H}_{15} \mathbf{C l}_{2} \mathbf{N O}$ (284.18). 


\section{Synthese von anti-Methyl-seco-CBI-DNA-Binder}

\section{1 rac-\{3-[(2-\{2-[5-Benzyloxy-1-(10-chlor-ethyl)-1,2-dihydro-}

\section{benzo[e]indol-3-carbonyl]-indol-5-yloxy\}-ethyl)-methylamino]- propionsäure\} (88)}

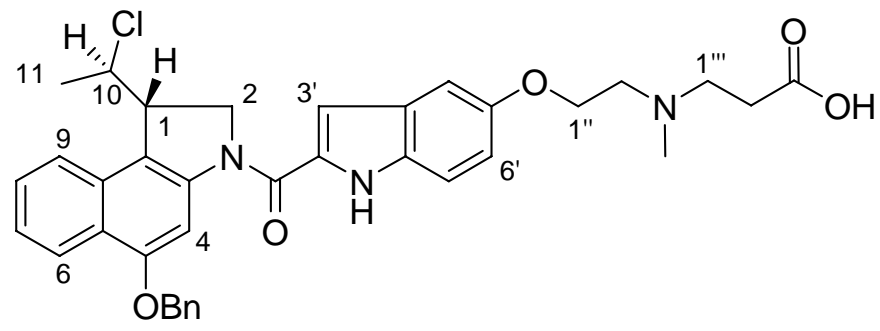

Das Indolderivat 62 (371 mg, 1.0 mmol, 1.0 Äq.) und 84 ( 440 mg, 1 mmol, 1.0 Äq.) wurden in DMF (50 mL) gelöst, mit EDC· $\mathrm{HCl}(382 \mathrm{mg}, 2 \mathrm{mmol}, 2.0$ Äq.) versetzt. Das Reaktionsgemisch wurde $12 \mathrm{~h}$ bei Raumtemperatur gerührt. Danach wurde das Lösungsmittel im Vakuum entfernt, Wasser $(50 \mathrm{~mL})$ zugegeben, die wässrige Phase mit AcOEt $(3 \times 80 \mathrm{~mL})$ extrahiert. Die vereinigten organischen Phasen wurden über $\mathrm{Na}_{2} \mathrm{SO}_{4}$ getrocknet und das Lösungsmittel im Vakuum entfernt. Der so erhaltene Feststoff $(710 \mathrm{mg})$ wurde in einem Lösungsgemisch von EtOH/ $\mathrm{H}_{2} \mathrm{O} / \mathrm{THF}=(20 \mathrm{~mL} / 20 \mathrm{~mL} / 40 \mathrm{~mL})$ gelöst und mit $\mathrm{LiOH} \cdot \mathrm{H}_{2} \mathrm{O}$ (126 mg, 3 mmol, 3.0 Äq.) versetzt. Das Reaktionsgemisch wurde 2 h bei Raumtemperatur gerührt, mit Wasser $(50 \mathrm{~mL})$ versetzt und der $\mathrm{pH}$-Wert der Lösung mit $1 \mathrm{M} \mathrm{HCl}$ auf $\mathrm{pH}=3$ gebracht. Die wässrige Phase wurde mit AcOEt $(3 \times 100 \mathrm{~mL})$ extrahiert, die vereinigten organischen Phasen über $\mathrm{Na}_{2} \mathrm{SO}_{4}$ getrocknet und das Lösungsmittel im Vakuum entfernt. Das Rohprodukt wurde aus Ethanol umkristallisiert, und die Titelverbindung als grauer Feststoff (550 mg, $0.88 \mathrm{mmol}, 88$ \% über zwei Stufen) erhalten.

$\mathbf{R}_{\mathbf{f}}=0.1\left(\mathrm{CH}_{2} \mathrm{Cl}_{2} / \mathrm{MeOH}=10: 1+1 \% \mathrm{HOAc}\right)$.

UV (MeOH): $\lambda_{\max }(\lg \varepsilon)=207.0 \mathrm{~nm}$ (4.710), 248.5 (4.362), 301.0 (4.435), 337.0 (4.362).

IR $(\mathrm{KBr}): \widetilde{v}\left(\mathrm{~cm}^{-1}\right)=3416,1624,1523,1408,1235$.

${ }^{1}$ H-NMR (300 MHz, DMSO-d $\left.)_{6}\right): \delta=1.65\left(\mathrm{~d}, J=6.9 \mathrm{~Hz}, 3 \mathrm{H}, 11-\mathrm{CH}_{3}\right), 2.86\left(\mathrm{~s}, 3 \mathrm{H}, \mathrm{NCH}_{3}\right)$,

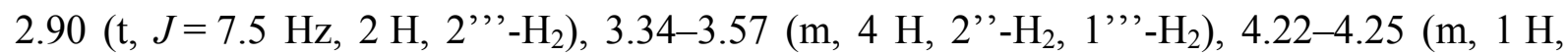
1-H), $4.43\left(\mathrm{~s}_{\mathrm{br}}, 2 \mathrm{H}, 1\right.$ '”- $\left.\mathrm{H}_{2}\right), 4.72-4.81\left(\mathrm{~m}, 3 \mathrm{H}, 2-\mathrm{H}_{2}, 10-\mathrm{H}\right), 5.31$ (s, $\left.2 \mathrm{H}, \mathrm{C}_{2} \mathrm{Ph}\right), 7.00$ (dd, $\left.J=8.7,2.1 \mathrm{~Hz}, 1 \mathrm{H}, 6^{\prime}-\mathrm{H}\right), 7.21$ (s, $\left.1 \mathrm{H}, 3^{\prime}-\mathrm{H}\right), 7.27$ (d, $\left.J=2.1 \mathrm{~Hz}, 1 \mathrm{H}, 4^{\prime}-\mathrm{H}\right), 7.34-7.60$ (m, 
8 H, 7-H, 8-H, 7'-H, $5 \times$ Ph-H), 7.97 (d, J=8.1 Hz, 1 H, 9-H), 8.13 (s, 1 H, 4-H), 8.23 (d, $J=8.4 \mathrm{~Hz}, 1 \mathrm{H}, 6-\mathrm{H}), 11.08\left(\mathrm{~s}_{\mathrm{br}}, 1 \mathrm{H}, \mathrm{COOH}\right), 11.71$ (s, $1 \mathrm{H}$, Indol-NH).

${ }^{13}$ C-NMR (75 MHz, DMSO-d $\left.{ }_{6}\right): \delta=23.33$ (C-11), $28.49\left(\mathrm{C}-2{ }^{\prime \prime \prime}\right), 40.06\left(\mathrm{NCH}_{3}\right), 45.88$ (C-1), 51.14 (C-1'”'), 52.00 (C-2), 53.94 (C-2'”), 61.33 (C-10), 62.87 (C-1'”), $69.64\left(\underline{C H}_{2} \mathrm{Ph}\right)$, 98.39 (C-4), 104.1 (C-4'), 105.4 (C-3’), 113.2 (C-7'), 115.6 (C-6’), 117.6 (C-9b), 122.6 (C-6), 123.1 (C-9), 123.8 (C-7), 127.4, 127.8, 128.4, 129.6, 131.2, 132.0, 136.8 (C-5a, C-8, C-9a, 6 $\times$ Ph-C, C-2', C-3'a, C-7'a), 142.1 (C-3a), 152.0, 154.2 (C-5, C-5'), 160.0 (CON), 171.4 $(\mathrm{COOH})$.

MS (ESI): $m / z(\%)=626.2(100)[\mathrm{M}+\mathrm{H}]^{+}$.

$\mathrm{C}_{36} \mathrm{H}_{36} \mathrm{CIN}_{3} \mathrm{O}_{5}$ (626.14). $\quad$ Ber.: 626.24163 für $[\mathrm{M}+\mathrm{H}]^{+}$

Gef.: 626.24158 (ESI-HRMS).

\section{2 rac-\{(1,10)-anti-5-Benzyloxy-1-(10-chlor-ethyl)-3-[(5-(2-cyanoethyl- methyl-aminoethoxy)-indol-2-yl)carbonyl]-1,2-dihydro-3H- benz[e]indol\} (89)}

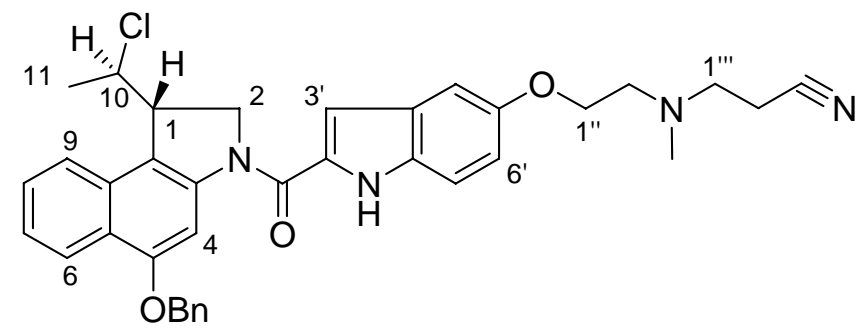

Eine Lösung von 84 (220 mg, 0.5 mmol, 1.0 Äq.) und 68 (200 mg, 0.7 mmol, 1.4 Äq.) in DMF (15 mL) wurde mit $\mathrm{EDC} \cdot \mathrm{HCl}(192 \mathrm{mg}, 1 \mathrm{mmol}, 2.0$ Äq.) versetzt. Das Reaktionsgemisch wurde $12 \mathrm{~h}$ bei Raumtemperatur gerührt. Danach wurde das Lösungsmittel im Vakuum entfernt, Wasser $(50 \mathrm{~mL})$ zugegeben und die wässrige Phase mit AcOEt $(3 \times 80$ $\mathrm{mL}$ ) extrahiert. Die vereinigten organischen Phasen wurden über $\mathrm{Na}_{2} \mathrm{SO}_{4}$ getrocknet und das Lösungsmittel im Vakuum entfernt. Nach Säulenchromatographie an Kieselgel $\left(\mathrm{CH}_{2} \mathrm{Cl}_{2} / \mathrm{MeOH}=100: 1 \rightarrow 25: 1\right)$ erhielt man die Titelverbindung als blass-grauen Feststoff (160 mg, $0.26 \mathrm{mmol}, 53 \%$ ).

$\mathbf{R}_{\mathbf{f}}=0.2\left(\mathrm{CH}_{2} \mathrm{Cl}_{2} / \mathrm{MeOH}=100: 3\right)$. 
UV $\left(\mathrm{CH}_{3} \mathrm{CN}\right): \lambda_{\max }(\lg \varepsilon)=207.0 \mathrm{~nm}$ (4.784), 250.0 (4.404), 290.0 (4.410), 300.0 (4.567), 339.5 (4.475).

IR $(\mathrm{KBr}): \widetilde{v}\left(\mathrm{~cm}^{-1}\right)=3392,2924,1622,1408,1266$.

${ }^{1}$ H-NMR (300 MHz, DMSO-d $\left.)_{6}\right): \delta=1.65\left(\mathrm{~d}, J=6.3 \mathrm{~Hz}, 3 \mathrm{H}, 11-\mathrm{CH}_{3}\right), 2.33\left(\mathrm{~s}, 3 \mathrm{H}, \mathrm{NCH}_{3}\right)$,

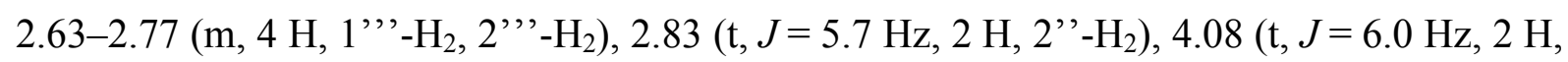
1 '’- $\left.\mathrm{H}_{2}\right), 4.21(\mathrm{~d}, J=8.7 \mathrm{~Hz}, 1 \mathrm{H}, 1-\mathrm{H}), 4.63\left(\mathrm{~d}, J=9.3 \mathrm{~Hz}, 1 \mathrm{H}, 2-\mathrm{H}_{\mathrm{a}}\right), 4.71(\mathrm{~d}, J=9.0 \mathrm{~Hz}$, $\left.1 \mathrm{H}, 2-\mathrm{H}_{\mathrm{b}}\right), 4.78-4.81(\mathrm{~m}, 1 \mathrm{H}, 10-\mathrm{H}), 5.30\left(\mathrm{~s}, 2 \mathrm{H}, \mathrm{C}_{2} \mathrm{Ph}\right), 6.95(\mathrm{dd}, J=8.7,2.1 \mathrm{~Hz}, 1 \mathrm{H}$, 6'-H), 7.18-7.20 (m, 2 H, 3'-H, 4'-H), 7.36-7.60 (m, 8 H, 7-H, 8-H, 7'-H, $5 \times$ Ph-H), 7.95 (d, $J=8.4 \mathrm{~Hz}, 1 \mathrm{H}, 9-\mathrm{H}), 8.14(\mathrm{~s}, 1 \mathrm{H}, 4-\mathrm{H}), 8.23$ (d, $J=8.1 \mathrm{~Hz}, 1 \mathrm{H}, 6-\mathrm{H}), 11.63$ (s, $1 \mathrm{H}$, Indol-NH).

${ }^{13}$ C-NMR (75 MHz, DMSO-d 6 ): $\delta=15.27$ (C-2 $\left.{ }^{\prime \prime \prime}\right), 23.32$ (C-11), $41.72\left(\mathrm{NCH}_{3}\right), 45.90$ (C-1), 51.99 (C-2), 52.45 (C-1','), 55.07 (C-2'’), 61.31 (C-10), 66.33 (C-1'’), 69.62 ( CH$\left._{2} \mathrm{Ph}\right)$, 98.38 (C-4), 103.3 (C-4'), 105.4 (C-3'), 113.1 (C-7'), 115.9 (C-6'), 117.5 (C-9b), 119.9 $(\mathrm{C} \equiv \mathrm{N}), 122.6$ (C-6), 123.0 (C-9), 123.7 (C-7), 127.3, 127.4, 127.5, 127.8, 128.4, 129.6, 130.9, 131.7, 136.8 (C-5a, C-8, C-9a, 6 × Ph-C, C-2', C-3'a, C-7'a), 142.1 (C-3a), 152.9, 154.2 (C-5, C-5'), 160.1 (CON).

$\mathbf{C}_{36} \mathbf{H}_{35} \mathrm{ClN}_{4} \mathbf{O}_{3}$ (607.17). $\quad$ Ber.: 607.24705 für $[\mathrm{M}+\mathrm{H}]^{+}$

Gef.: 607.24690 (ESI-HRMS).

\section{3 rac-\{(1,10)-anti-5-Benzyloxy-1-(10-chlor-ethyl)-3-[(5-(2-}

\section{hydroxylethoxy)-indol-2-yl)carbonyl]-1,2-dihydro-3 $\mathrm{H}$-benz[e]indol\}} (91)

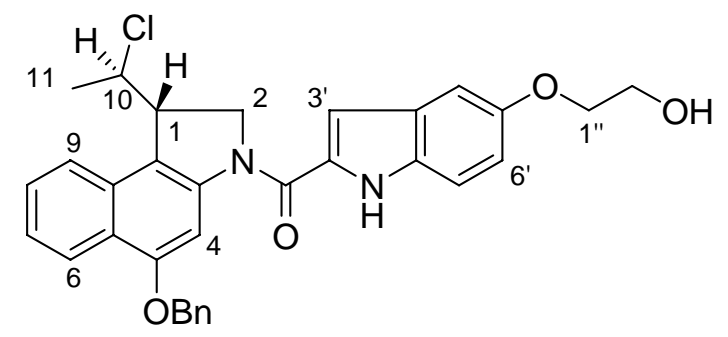

Eine Lösung von 84 ( 220 mg, 0.5 mmol, 1.0 Äq.) und 90 (221 mg, 0.5 mmol, 1.0 Äq.) in DMF (15 mL) wurde mit EDC·HCl (192 mg, $1 \mathrm{mmol}, 2.0$ Äq.) versetzt und anschließend $12 \mathrm{~h}$ bei Raumtemperatur gerührt. Danach wurde das Lösungsmittel im Vakuum entfernt, 
Wasser $(50 \mathrm{~mL})$ zugegeben und die wässrige Phase mit AcOEt $(3 \times 80 \mathrm{~mL})$ extrahiert. Die vereinigten organischen Phasen wurden über $\mathrm{Na}_{2} \mathrm{SO}_{4}$ getrocknet und das Lösungsmittel im Vakuum entfernt. Nach Säulenchromatographie an Kieselgel $\left(\mathrm{CH}_{2} \mathrm{Cl}_{2} / \mathrm{MeOH}=50: 1 \rightarrow 20: 1\right)$ erhielt man die Titelverbindung als blass-grauen Feststoff (145 mg, $0.27 \mathrm{mmol}, 54$ \%).

$\mathbf{R}_{\mathbf{f}}=0.2\left(\mathrm{CH}_{2} \mathrm{Cl}_{2} / \mathrm{MeOH}=100: 3\right)$.

UV $\left(\mathrm{CH}_{3} \mathrm{CN}\right): \lambda_{\max }(\lg \varepsilon)=207.0 \mathrm{~nm}$ (4.740), 250.0 (4.388), 290.0 (4.373), 300.0 (4.531), 339.5 (4.442).

IR $(\mathrm{KBr}): \widetilde{v}\left(\mathrm{~cm}^{-1}\right)=3427,2920,1620,1517,1409$.

${ }^{1} \mathbf{H}-\mathrm{NMR}\left(300 \mathrm{MHz}, \mathrm{DMSO}-\mathrm{d}_{6}\right): \delta=1.65\left(\mathrm{~d}, J=6.9 \mathrm{~Hz}, 3 \mathrm{H}, 11-\mathrm{CH}_{3}\right), 3.78(\mathrm{q}, J=5.4 \mathrm{~Hz}$, 2 H, 2' '- $\mathrm{H}_{2}$ ), 4.03 (t, J=5.4 Hz, 2 H, 1' '-H $)$, 4.19-4.22 (m, 1 H, 1-H), 4.61-4.87 (m, 3 H, 2-

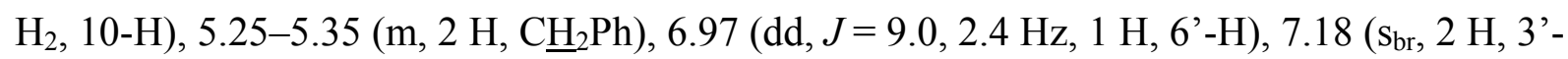
H, 4'-H), 7.33-7.60 (m, 8 H, 7-H, 8-H, 7'-H, $5 \times$ Ph-H), 7.95 (d, J=8.7 Hz, 1 H, 9-H), 8.14 (s, $1 \mathrm{H}, 4-\mathrm{H}), 8.23$ (d, J=7.8 Hz, $1 \mathrm{H}, 6-\mathrm{H}), 11.62$ (s, $1 \mathrm{H}, \mathrm{NH})$.

${ }^{13}$ C-NMR (75 MHz, DMSO-d 6 ): $\delta=23.33$ (C-11), 45.92 (C-1), 52.00 (C-2), 59.73 (C-2"'), 61.33 (C-10), 69.63 ( $\left.\underline{\mathrm{CH}}_{2} \mathrm{Ph}\right), 69.93$ (C-1’’), 98.40 (C-4), 103.3 (C-4'), 105.4 (C-3'), 113.1(C7'), 115.9 (C-6'), 117.5 (C-9b), 122.6 (C-6), 123.0 (C-9), 123.7 (C-7), 127.4, 127.4, 127.6, 127.7, 127.8, 128.4, 129.6, 130.8, 131.7, 136.8 (C-5a, C-8, C-9a, $6 \times$ Ph-C, C-2', C-3'a, C7’a), 142.2 (C-3a), 153.2, 154.2 (C-5, C-5'), $160.1(\mathrm{C}=\mathrm{O})$.

$\mathrm{C}_{32} \mathrm{H}_{29} \mathrm{CIN}_{2} \mathbf{O}_{4}(541.04)$.

Ber.: 541.18886 für $[\mathrm{M}+\mathrm{H}]^{+}$

Gef.: 541.18885 (ESI-HRMS). 


\section{4 rac-\{(1,10)-anti-5-Benzyloxy-3-[(5-(2-(tert-butyloxycarbonyl)- aminoethoxy)-indol-2-yl)carbonyl]-1-(10-chlor-ethyl)-1,2-dihydro- $3 H$-benz $[e]$ indol\} $(92)$}

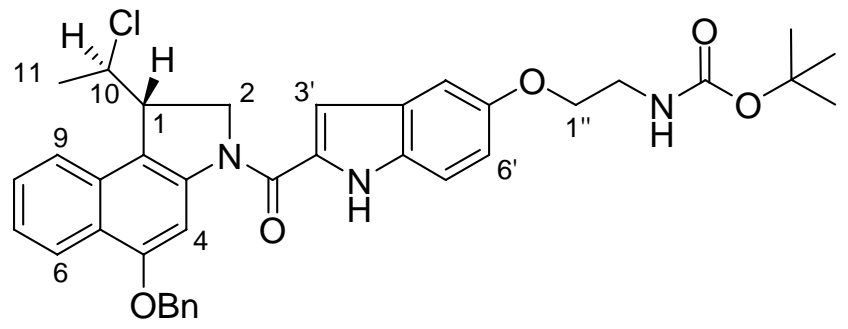

Eine Lösung von 84 ( 440 mg, 1.0 mmol, 1.0 Äq.) in DMF (50 mL) wurde mit 74 (320 mg, $1.0 \mathrm{mmol}, 1.0$ Äq.) und EDC.HCl (192 mg, $1.0 \mathrm{mmol}, 1.0$ Äq.) versetzt und $12 \mathrm{~h}$ bei Raumtemperatur gerührt. Danach wurde das Lösungsmittel im Vakuum entfernt, Wasser (50 $\mathrm{mL})$ zugegeben und die wässrige Phase mit AcOEt $(3 \times 80 \mathrm{~mL})$ extrahiert. Die vereinigten organischen Phasen wurden über $\mathrm{Na}_{2} \mathrm{SO}_{4}$ getrocknet und das Lösungsmittel im Vakuum entfernt. Nach Säulenchromatographie an Kieselgel $\left(\mathrm{CH}_{2} \mathrm{Cl}_{2} / \mathrm{MeOH}=50: 1 \rightarrow 20: 1\right)$ erhielt man die Titelverbindung als weißen Feststoff (300 mg, $0.47 \mathrm{mmol}, 47 \%$ ).

$\mathbf{R}_{\mathbf{f}}=0.5\left(\mathrm{CH}_{2} \mathrm{Cl}_{2} / \mathrm{MeOH}=100: 3\right)$.

UV $\left(\mathrm{CH}_{3} \mathrm{CN}\right): \lambda_{\max }(\lg \varepsilon)=207.0 \mathrm{~nm}$ (4.761), 250.0 (4.383), 290.0 (4.399), 300.0 (4.557), 339.5 (4.469).

IR $(\mathrm{KBr}): \widetilde{v}\left(\mathrm{~cm}^{-1}\right)=3450,1706,1618,1415,1170$.

${ }^{1}$ H-NMR $\left(300 \mathrm{MHz}, \mathrm{DMSO}_{-} \mathrm{d}_{6}\right): \delta=1.41\left(\mathrm{~s}, 9 \mathrm{H}, \mathrm{C}\left(\mathrm{CH}_{3}\right)_{3}\right), 1.65(\mathrm{~d}, J=6.6 \mathrm{~Hz}, 3 \mathrm{H}$, $11-\mathrm{CH}_{3}$ ), 3.44 (q, $J=5.7 \mathrm{~Hz}, 2 \mathrm{H}, 2$ ' '- $\mathrm{H}_{2}$ ), 4.00 (t, $J=6.0 \mathrm{~Hz}, 2 \mathrm{H}, 1$ ' '- $\left.\mathrm{H}_{2}\right), 4.22-4.25$ (m, $1 \mathrm{H}, 1-\mathrm{H}), 4.61-4.83$ (m, $\left.3 \mathrm{H}, 2-\mathrm{H}_{2}, 10-\mathrm{H}\right), 5.31$ (s, $\left.2 \mathrm{H}, \underline{\mathrm{C}}_{2} \mathrm{Ph}\right), 6.94$ (dd, J = 9.0, $2.7 \mathrm{~Hz}$, $1 \mathrm{H}, 6$ '-H), 6.96 (s $\mathrm{s}_{\mathrm{br}}, 1 \mathrm{H}, \mathrm{N}$ HBoc), 7.17 (s sr, 2 H, 3'-H, 4'-H), 7.36-7.60 (m, 8 H, 7-H, 8-H, 7’-H, $5 \times \mathrm{Ph}-\mathrm{H}), 7.96$ (d, J=8.4 Hz, $1 \mathrm{H}, 9-\mathrm{H}), 8.13$ (s, $1 \mathrm{H}, 4-\mathrm{H}), 8.23$ (d, J=8.4 Hz, $1 \mathrm{H}$, 6-H), 11.61 (s, 1 H, Indol-NH).

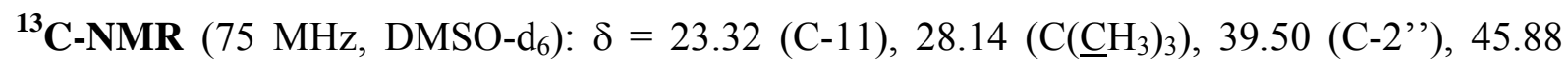
(C-1), 51.97 (C-2), 61.32 (C-10), 66.88 (C-1'’), $69.62\left(\underline{\mathrm{CH}}_{2} \mathrm{Ph}\right), 77.65\left(\underline{\mathrm{C}}\left(\mathrm{CH}_{3}\right)_{3}\right), 98.39$ (C-4), 103.4 (C-4'), 105.4 (C-3'), 113.1(C-7'), 115.8(C-6'), 117.5 (C-9b), 122.6 (C-6), 123.1 (C-9), 123.7(C-7), 127.3, 127.4, 127.5, 127.8, 128.4, 129.6, 130.9, 131.7, 136.8 (C-5a, C-8, C-9a, 6 
$\times$ Ph-C, C-2', C-3'a, C-7'a), 142.1(C-3a), 152.9, 154.2, 155.6 (C-5, C-5', CONH), 160.0 $(\mathrm{CON})$.

MS (ESI): $m / z(\%)=662.1(100)[\mathrm{M}+\mathrm{Na}]^{+}$.

$\mathrm{C}_{37} \mathrm{H}_{38} \mathrm{CIN}_{3} \mathrm{O}_{5}$ (640.17). $\quad$ Ber.: 640.25728 für $[\mathrm{M}+\mathrm{H}]^{+}$

Gef.: 640.25716 (ESI-HRMS).

\section{5 rac-\{3-[(2-\{2-[5-Benzyloxy-1-(10-chlor-ethyl)-1,2-dihydro-} benzo[e]indol-3-carbonyl]-indol-5-yloxy\}-ethyl)-amino]propionsäure\} (94)<smiles></smiles>

$\mathrm{Zu}$ einer Lösung von 92 (17 mg, $0.027 \mathrm{mmol}, 1.0$ Äq.) in $\mathrm{CH}_{2} \mathrm{Cl}_{2}(0.5 \mathrm{~mL})$ wurde tropfenweise eine ges. $\mathrm{HCl} / \mathrm{HOAc}(1 \mathrm{~mL})$ gegeben und $2 \mathrm{~h}$ bei Raumtemperatur gerührt. Der Niederschlag wurde abfiltriert, mit Ether gewaschen und im Vakuum getrocknet.

$\mathrm{Zu}$ einer Suspension des erhaltenen Niederschlags $(19 \mathrm{mg})$ in Ethanol $(3 \mathrm{~mL}) \mathrm{gab}$ man Natriumacetat (4 mg, 0.05 mmol, 2.0 Äq.) und Acrylsäureethylester (20 mg, 0.20 mmol, 7.4 Äq.) und rührte $8 \mathrm{~h}$ am Rückfluss. Nach Entfernen des Lösungsmittels wurde der Rückstand durch präparative $\mathrm{DC}\left(\mathrm{CH}_{2} \mathrm{Cl}_{2} / \mathrm{MeOH}=10: 1\right)$ gereinigt.

Das so erhaltene Esterderivat $(17 \mathrm{mg})$ wurde in $\mathrm{H}_{2} \mathrm{O} / \mathrm{THF}(0.5 \mathrm{~mL} / 1.5 \mathrm{~mL})$ gelöst, mit $\mathrm{LiOH} \cdot \mathrm{H}_{2} \mathrm{O}$ (1.5 mg, $0.036 \mathrm{mmol}, 1.3$ Äq.) versetzt und $12 \mathrm{~h}$ bei Raumtemperatur gerührt. Das Reaktionsgemisch wurde mit $1 \mathrm{M} \mathrm{HCl}$ auf $\mathrm{pH}=2$ eingestellt. Nach Entfernen des Lösungsmittels im Vakuum wurde der Rückstand durch präparative DC $\left(\mathrm{CH}_{2} \mathrm{Cl}_{2} / \mathrm{MeOH}\right.$ $=10: 2+5 \%$ HOAc) gereinigt und man erhielt die Titelverbindung (10 mg, $0.016 \mathrm{mmol}, 60 \%)$ als blass-gelben Feststoff.

$\mathbf{R}_{\mathbf{f}}=0.05\left(\mathrm{CH}_{2} \mathrm{Cl}_{2} / \mathrm{MeOH}=10: 1+1 \% \mathrm{HOAc}\right)$.

${ }^{1}$ H-NMR (300 MHz, DMSO-d $\left.{ }_{6}\right): \delta=1.65\left(\mathrm{~d}, J=6.6 \mathrm{~Hz}, 3 \mathrm{H}, 11-\mathrm{CH}_{3}\right), 2.49(\mathrm{t}, J=6.3 \mathrm{~Hz}$, $\left.2 \mathrm{H}, 2{ }^{\prime}{ }^{\prime}{ }^{-\mathrm{H}_{2}}\right), 2.86\left(\mathrm{t}, J=6.6 \mathrm{~Hz}, 2 \mathrm{H}, 1{ }^{\prime \prime}{ }^{\prime}-\mathrm{H}_{2}\right), 2.92\left(\mathrm{t}, J=5.4 \mathrm{~Hz}, 2 \mathrm{H}, 2{ }^{\prime}{ }^{\left.-\mathrm{H}_{2}\right),} 4.03\right.$ (t, 
$J=6.0 \mathrm{~Hz}, 2 \mathrm{H}, 1$ ' '- $\left.\mathrm{H}_{2}\right), 4.23(\mathrm{~d}, J=9.3 \mathrm{~Hz}, 1 \mathrm{H}, 1-\mathrm{H}), 4.62\left(\mathrm{~d}, J=11.1 \mathrm{~Hz}, 1 \mathrm{H}, 2-\mathrm{H}_{\mathrm{a}}\right), 4.72$ (d, $\left.J=9.9 \mathrm{~Hz}, 1 \mathrm{H}, 2-\mathrm{H}_{\mathrm{b}}\right), 4.77-4.82\left(\mathrm{~m}_{\mathrm{c}}, 1 \mathrm{H}, 10-\mathrm{H}\right), 5.31\left(\mathrm{~s}, 2 \mathrm{H}, \underline{\mathrm{C}}_{2} \mathrm{Ph}\right), 6.94$ (dd, $J=9.0$, $2.1 \mathrm{~Hz}, 1 \mathrm{H}, 6$ '-H), 7.17-7.18 ( $\mathrm{s}$ br, 2 H, 3'-H, 4'-H), 7.36-7.60 (m, 8 H, 7-H, 8-H, 7'-H, $5 \times \mathrm{Ph}-\mathrm{H}), 7.96(\mathrm{~d}, J=8.7 \mathrm{~Hz}, 1 \mathrm{H}, 9-\mathrm{H}), 8.13(\mathrm{~s}, 1 \mathrm{H}, 4-\mathrm{H}), 8.23(\mathrm{~d}, J=8.4 \mathrm{~Hz}, 1 \mathrm{H}, 6-\mathrm{H})$, 11.61 (s, $1 \mathrm{H}$, Indol-NH).

${ }^{13}$ C-NMR (75 MHz, DMSO-d 6 ): $\delta=23.33$ (C-11), 34.25 (C-2'”'), 44.70 (C-1'”'), 45.90 (C-1), 47.97 (C-2'’), 51.98 (C-2), 61.33 (C-10), 67.79 (C-1’'), 69.62 ( CH$\left._{2} \mathrm{Ph}\right), 98.39$ (C-4), 103.4 (C-4'), 105.4 (C-3'), 113.1 (C-7'), 115.9 (C-6'), 117.5 (C-9b), 122.6 (C-6), 123.1 (C-9), 123.7 (C-7), 127.4, 127.5, 127.8, 128.4, 129.6, 130.9, 131.7, 136.8 (C-5a, C-8, C-9a, $6 \times$ PhC, C-2', C-3'a, C-7'a), 142.1 (C-3a), 153.0, 154.2 (C-5, C-5'), 160.1 (CON), 172.4 (COOH). MS (ESI): $m / z(\%)=634.2(100)[\mathrm{M}+\mathrm{Na}]^{+}$.

$\mathrm{C}_{35} \mathbf{H}_{34} \mathrm{ClN}_{3} \mathbf{O}_{5}(612.11)$.

\section{6 rac-\{(1,10)-syn-5-Benzyloxy-1-(10-chlor-ethyl)-3-[(5-(2-chlorethoxy)- indol-2-yl)carbonyl]-1,2-dihydro-3H-benz[e]indol\} (96)}

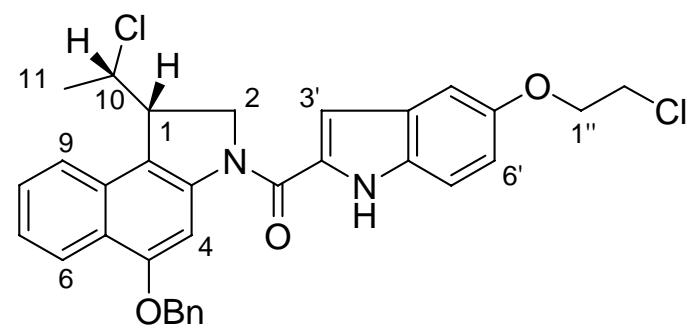

Eine Lösung von 85 ( 220 mg, 0.5 mmol, 1.0 Äq.) und 95 (120 mg, 0.5 mmol, 1.0 Äq.) in DMF (25 mL) wurde mit EDC·HCl (192 mg, $1 \mathrm{mmol}, 2.0$ Äq.) sowie $\mathrm{NaHCO}_{3}(84 \mathrm{mg}$, $1 \mathrm{mmol}, 2.0$ Äq.) versetzt und anschließend $12 \mathrm{~h}$ bei Raumtemperatur gerührt. Danach wurde das Lösungsmittel im Vakuum entfernt, Wasser $(50 \mathrm{~mL})$ zugegeben und die wässrige Phase mit AcOEt $(3 \times 80 \mathrm{~mL})$ extrahiert. Die vereinigten organischen Phasen wurden über $\mathrm{Na}_{2} \mathrm{SO}_{4}$ getrocknet und das Lösungsmittel im Vakuum entfernt. Nach Säulenchromatographie an Kieselgel $\left(\mathrm{CH}_{2} \mathrm{Cl}_{2} \rightarrow \mathrm{CH}_{2} \mathrm{Cl}_{2} / \mathrm{MeOH}=50: 1\right)$ erhielt man die Titelverbindung als blassgelblichen Feststoff (135 mg, 0.24 mmol, $48 \%$ ).

$\mathbf{R}_{\mathbf{f}}=0.2(\mathrm{PE} / \mathrm{AcOEt}=10: 1)$. 
${ }^{1} \mathbf{H}-\mathbf{N M R}\left(300 \mathrm{MHz}, \mathrm{CDCl}_{3}\right): \delta=1.13\left(\mathrm{~d}, J=7.2 \mathrm{~Hz}, 3 \mathrm{H}, 11-\mathrm{CH}_{3}\right), 3.82(\mathrm{t}, J=6.0 \mathrm{~Hz}, 2 \mathrm{H}$, 2'’- $\left.\mathrm{H}_{2}\right), 4.23$ (t, $J=5.7 \mathrm{~Hz}, 2 \mathrm{H}, 1$ '' $\left.-\mathrm{H}_{2}\right), 4.28$ (d, J=9.9 Hz, $\left.1 \mathrm{H}, 1-\mathrm{H}\right), 4.55$ (t, $J=10.2 \mathrm{~Hz}$, $\left.1 \mathrm{H}, 2-\mathrm{H}_{\mathrm{a}}\right), 4.71-4.74\left(\mathrm{~m}_{\mathrm{c}}, 1 \mathrm{H}, 10-\mathrm{H}\right), 4.89\left(\mathrm{~d}, J=10.8 \mathrm{~Hz}, 1 \mathrm{H}, 2-\mathrm{H}_{\mathrm{b}}\right), 5.21$ (d, $J=4.2 \mathrm{~Hz}, 2$ $\left.\mathrm{H}, \mathrm{CH}_{2} \mathrm{Ph}\right), 6.96$ (dd, J=8.7, $2.4 \mathrm{~Hz}, 1 \mathrm{H}, 6$ ' $\left.-\mathrm{H}\right), 7.06$ (d, J=1.2 Hz, 1 H, 3'-H), 7.14 (d, $\left.J=1.8 \mathrm{~Hz}, 1 \mathrm{H}, 4^{\prime}-\mathrm{H}\right), 7.33-7.56$ (m, $\left.8 \mathrm{H}, 7-\mathrm{H}, 8-\mathrm{H}, 7^{\prime}-\mathrm{H}, 5 \times \mathrm{Ph}-\mathrm{H}\right), 7.71$ (d, J=8.1 Hz, $1 \mathrm{H}, 9-\mathrm{H}), 8.27$ (s, $1 \mathrm{H}, 4-\mathrm{H}), 8.35$ (d, $J=8.7 \mathrm{~Hz}, 1 \mathrm{H}, 6-\mathrm{H}), 10.23$ (s, $1 \mathrm{H}, \mathrm{NH})$.

${ }^{13}$ C-NMR (75 MHz, $\mathrm{CDCl}_{3}$ ): $\delta=17.85$ (C-11), 42.03 (C-2’'), 47.37 (C-1), 52.29 (C-2), 57.92 (C-10), 68.80 (C-1’'), 70.30 ( (H$\left._{2} \mathrm{Ph}\right), 98.35$ (C-4), 104.4 (C-4'), 106.3 (C-3'), 112.9 (C-7'), 116.5 (C-9b), 117.1 (C-6'), 122.3 (C-9), 123.6 (C-6), 124.2 (C-7), 127.6, 127.8, 127.9, 128.1, 128.5, 129.7, 130.6, 131.9, 136.6 (C-5a, C-8, C-9a, $6 \times$ Ph-C, C-2', C-3'a, C-7'a), 142.3 (C3a), 153.1, 155.7 (C-5, C-5'), $160.4(\mathrm{C}=\mathrm{O})$.

$\mathrm{C}_{32} \mathrm{H}_{28} \mathrm{Cl}_{2} \mathbf{N}_{2} \mathrm{O}_{3}(559.48)$.

4.7 rac-\{(1,10)-syn-5-Benzyloxy-3-[(5-(2-(N,N-dimethylamino)-ethoxy)indol-2-yl)carbonyl]-1-(10-chlor-ethyl)-1,2-dihydro-3H-benz[e]indol\} (98)

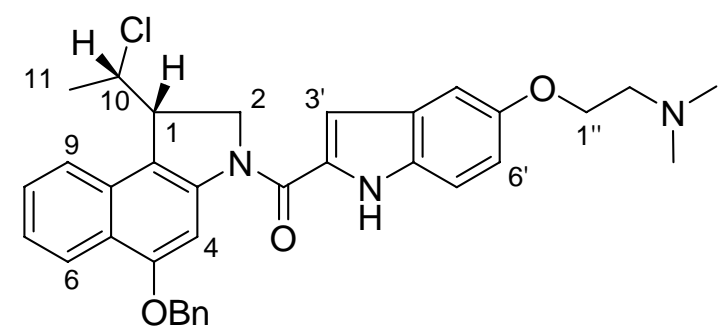

$\mathrm{Zu}$ einer Lösung von 96 (28 mg, $0.05 \mathrm{mmol}, 1.0$ Äq) in $\mathrm{CH}_{3} \mathrm{CN}$ (5mL) wurde NaI (300 mg, 2 mmol, 40 Äq.) gegeben, rührte 2 d am Rückfluss. Nach Abkühlen auf Raumtemperatur wurde Wasser $(30 \mathrm{~mL})$ zugegeben und mit AcOEt $(2 \times 50 \mathrm{~mL})$ extrahiert. Die vereinigten organischen Phasen wurden über $\mathrm{Na}_{2} \mathrm{SO}_{4}$ getrocknet und das Lösungsmittel im Vakuum entfernt. Der Rückstand wurde in THF $(0.2 \mathrm{~mL})$ gelöst, mit Kaliumcarbonat (40 mg, $0.29 \mathrm{mmol}, 5.8$ Äq.) und einer Lösung von Dimethylamin in Ethanol (5.6 M, $0.1 \mathrm{~mL}$ ) versetzt und $12 \mathrm{~h}$ bei Raumtemperatur gerührt. Danach wurde Wasser $(20 \mathrm{~mL})$ zugegeben und mit AcOEt $(2 \times 50 \mathrm{~mL})$ extrahiert. Die vereinigten organischen Phasen wurden über $\mathrm{Na}_{2} \mathrm{SO}_{4}$ getrocknet und das Lösungsmittel im Vakuum entfernt. Nach Säulenchromatographie an 
Kieselgel $\left(\mathrm{CH}_{2} \mathrm{Cl}_{2} / \mathrm{MeOH}=50: 1 \rightarrow 25: 1\right)$ erhielt man die Titelverbindung als blass-gelben Feststoff (19 mg, $0.033 \mathrm{mmol}, 66 \%)$.

$\mathbf{R}_{\mathbf{f}}=0.3\left(\mathrm{CH}_{2} \mathrm{Cl}_{2} / \mathrm{MeOH}=10: 1\right)$.

${ }^{1} \mathbf{H}-\mathrm{NMR}\left(300 \mathrm{MHz}, \mathrm{CDCl}_{3}\right): \delta=1.13\left(\mathrm{~d}, J=6.6 \mathrm{~Hz}, 3 \mathrm{H}, 11-\mathrm{CH}_{3}\right), 2.37\left(\mathrm{~s}, 6 \mathrm{H}, \mathrm{N}\left(\mathrm{CH}_{3}\right)_{2}\right)$, $2.78\left(\mathrm{t}, J=5.4 \mathrm{~Hz}, 2 \mathrm{H}, 2\right.$ ' '- $\left.\mathrm{H}_{2}\right), 4.11$ (t, $J=5.4 \mathrm{~Hz}, 2 \mathrm{H}, 1$ ' '- $\left.\mathrm{H}_{2}\right), 4.29$ (d, $J=8.1 \mathrm{~Hz}, 1 \mathrm{H}$, 1-H), $4.58\left(\mathrm{t}, J=10.2 \mathrm{~Hz}, 1 \mathrm{H}, 2-\mathrm{H}_{\mathrm{a}}\right), 4.70-4.73\left(\mathrm{~m}_{\mathrm{c}}, 1 \mathrm{H}, 10-\mathrm{H}\right), 4.90(\mathrm{~d}, J=11.4 \mathrm{~Hz}, 1 \mathrm{H}$, 2- $\left.\mathrm{H}_{\mathrm{b}}\right), 5.19-5.28\left(\mathrm{~m}_{\mathrm{c}}, 2 \mathrm{H}, \mathrm{CH}_{2} \mathrm{Ph}\right), 6.99$ (d, J=8.7 Hz, $\left.1 \mathrm{H}, 6^{\prime}-\mathrm{H}\right), 7.06$ (s, $\left.1 \mathrm{H}, 3^{\prime}-\mathrm{H}\right), 7.14$ (s, 1 H, 4'-H), 7.33-7.55 (m, 8 H, 7-H, 8-H, 7'-H, $5 \times \mathrm{Ph}-\mathrm{H}), 7.71$ (d, J=8.4 Hz, 1 H, 9-H), 8.26 (s, $1 \mathrm{H}, 4-\mathrm{H}), 8.34$ (d, $J=8.1 \mathrm{~Hz}, 1 \mathrm{H}, 6-\mathrm{H}), 10.06$ (s, $1 \mathrm{H}$, Indol-NH).

${ }^{13}$ C-NMR (75 MHz, $\left.\left.\mathrm{CDCl}_{3}\right): \delta=17.85(\mathrm{C}-11), 45.81\left(\mathrm{~N}_{\left(\mathrm{CH}_{3}\right)}\right)_{2}\right), 47.41(\mathrm{C}-1), 52.29(\mathrm{C}-2)$, 57.93 (C-10), 58.31 (C-2'”), 66.40 (C-1’”), 70.33 ( CH$\left._{2} \mathrm{Ph}\right), 98.38$ (C-4), 103.5 (C-4'), 106.3 (C-3'), 112.7 (C-7'), 116.5 (C-9b), 117.4 (C-6'), 122.3 (C-9), 123.6 (C-6), 124.1 (C-7), 127.5, 127.6, 127.8, 128.0, 128.2, 128.5, 129.7, 130.4, 131.5, 136.6 (C-5a, C-8, C-9a, $6 \times$ Ph-C, C2', C-3'a, C-7'a), 142.4 (C-3a), 153.8, 155.7 (C-5, C-5'), 160.4 (C=O).

$\mathrm{C}_{34} \mathrm{H}_{34} \mathrm{CIN}_{3} \mathrm{O}_{3}$ (568.11).

Ber.: $\quad 568.23615$ für $[\mathrm{M}+\mathrm{H}]^{+}$

Gef.: 568.23591 (ESI-HRMS). 


\section{5 Überführung zu den Drug-DNA-Bindern durch Debenzylierung}

5.1 rac-\{3-[(2-\{2-[1-(10-Chlor-ethyl)-5-hydroxy-1,2-dihydrobenzo[e]indol-3-carbonyl]-indol-5-yloxy\}-ethyl)-methylamino]propionsäure\} (100)

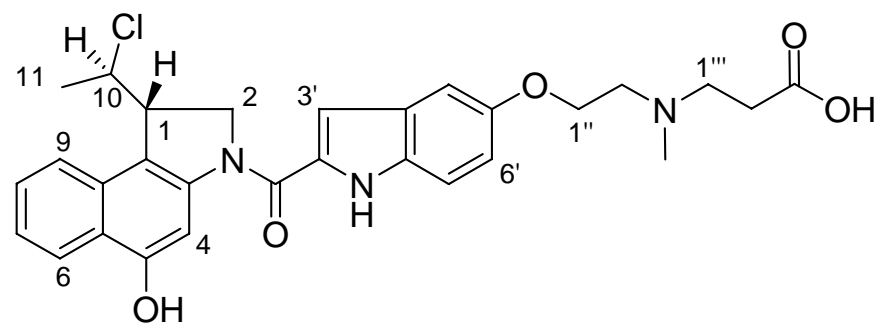

$\mathrm{Zu}$ einer Lösung von Benzylether 88 (31 mg, $0.05 \mathrm{mmol}, 1.0$ Äq.) in THF/MeOH = 1:1 $(6 \mathrm{~mL})$ wurde bei Raumtemperatur Palladium auf Aktivkohle (10\%ig, $6 \mathrm{mg})$ und HOAc (10 mg) gegeben. Die Reaktionsmischung wurde $2 \mathrm{~d}$ bei Raumtemperatur unter $\mathrm{H}_{2}$-Atmosphäre (1 bar) gerührt, der Feststoff durch Filtration über Celite abgetrennt und gründlich mit $\mathrm{CH}_{2} \mathrm{Cl}_{2} / \mathrm{MeOH}=2: 1$ nachgespült. Das Filtrat wurde im Vakuum eingeengt und die Titelverbindung (27 mg, $0.05 \mathrm{mmol}, 100 \%$ ) als gelber Feststoff erhalten.

$\mathbf{R}_{\mathbf{f}}=0.1\left(\mathrm{CH}_{2} \mathrm{Cl}_{2} / \mathrm{MeOH}=10: 2+1 \% \mathrm{HOAc}\right)$.

UV (MeOH): $\lambda_{\max }(\lg \varepsilon)=248.5$ (4.213), 303.0 (4.304), 339.5 (4.291).

IR $(\mathrm{KBr}): \widetilde{v}\left(\mathrm{~cm}^{-1}\right)=3417,1589,1518,1415$.

${ }^{1}$ H-NMR (300 MHz, DMSO-d 6 ): $\delta=1.63\left(\mathrm{~d}, J=6.3 \mathrm{~Hz}, 3 \mathrm{H}, 11-\mathrm{CH}_{3}\right), 2.50\left(\mathrm{~s}, 3 \mathrm{H}, \mathrm{NCH}_{3}\right)$, $2.64\left(\mathrm{t}, J=7.2 \mathrm{~Hz}, 2 \mathrm{H}, 2{ }^{\prime \prime}{ }^{-\mathrm{H}_{2}}\right), 3.08$ (t, $\left.J=6.9 \mathrm{~Hz}, 2 \mathrm{H}, 1{ }^{\prime \prime}{ }_{-}-\mathrm{H}_{2}\right), 3.17-3.19$ (s 2'’- $\left.\mathrm{H}_{2}\right), 4.15-4.18(\mathrm{~m}, 1 \mathrm{H}, 1-\mathrm{H}), 4.26$ ( $\mathrm{s}_{\mathrm{br}}, 2 \mathrm{H}, 1$ ' '- $\left.\mathrm{H}_{2}\right), 4.57-4.76$ (m, $\left.3 \mathrm{H}, 2-\mathrm{H}_{2}, 10-\mathrm{H}\right), 6.96$ (d, J=8.7 Hz, 1 H, 6'-H), 7.15 (s, 1 H, 3'-H), 7.21 (s, 1 H, 4'-H), 7.35 (t, J= 7.5 Hz, 1 H, 7H), 7.43 (d, $\left.J=8.7 \mathrm{~Hz}, 1 \mathrm{H}, 7^{\prime}-\mathrm{H}\right), 7.50$ (t, $\left.J=7.5 \mathrm{~Hz}, 1 \mathrm{H}, 8-\mathrm{H}\right), 7.88$ (d, $J=8.1 \mathrm{~Hz}, 1 \mathrm{H}, 9$ H), $7.98(\mathrm{~s}, 1 \mathrm{H}, 4-\mathrm{H}), 8.14(\mathrm{~d}, J=8.4 \mathrm{~Hz}, 1 \mathrm{H}, 6-\mathrm{H}), 10.42\left(\mathrm{~s}_{\mathrm{br}}, 1 \mathrm{H}, \mathrm{OH}\right), 11.61(\mathrm{~s}, 1 \mathrm{H}$, Indol-NH).

${ }^{13}$ C-NMR (75 MHz, DMSO-d 6 ): $\delta=23.39$ (C-11), 30.10 (C-2,"'), $40.78\left(\mathrm{NCH}_{3}\right), 45.88$ (C-1), 51.96 (C-1'”), 52.15 (C-2), 54.58 (C-2'’), 61.52 (C-10), 64.41 (C-1'’), 100.4 (C-4), 103.7 (C-4'), 105.3 (C-3'), 113.2 (C-7'), 115.6 (C-6’), 115.8 (C-9b), 122.8, 122.9, 123.1 (C-6, 
C-7, C-9), 127.0 (C-8), 122.2, 127.4, 129.8, 131.2, 131.8 (C-5a, C-9a, C-2', C-3'a, C-7'a), 142.2 (C-3a), 152.4, 153.9 (C-5, C-5'), 159.9 (CON), 172.5 (COOH).

MS (ESI): $m / z(\%)=536.1(100)[\mathrm{M}+\mathrm{H}]^{+}$.

$\mathrm{C}_{29} \mathrm{H}_{30} \mathrm{ClN}_{3} \mathrm{O}_{5}$ (536.02).

Ber.: 536.19468 für $[\mathrm{M}+\mathrm{H}]^{+}$

Gef.: 536.19464 (ESI-HRMS).

\section{2 rac-\{(1,10)-anti-1-(10-Chlor-ethyl)-3-[(5-(2-cyanoethyl-methyl- aminoethoxy)-indol-2-yl)carbonyl]-5-hydroxyl-1,2-dihydro-3H- benz[e]indol\} (101)}

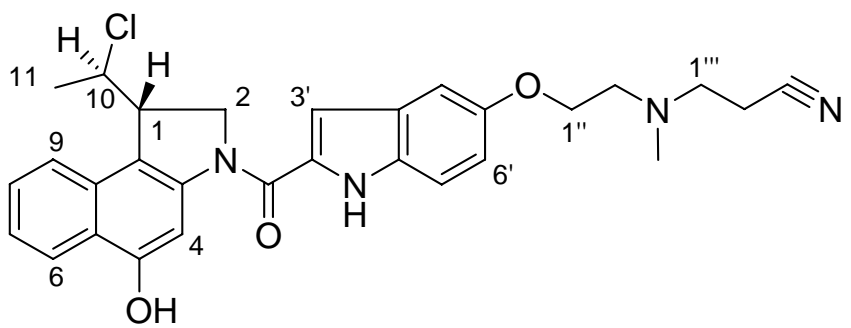

$\mathrm{Zu}$ einer Lösung von Benzylether 89 (30 mg, $0.05 \mathrm{mmol}, 1.0$ Äq.) in THF/MeOH = 1:1 $(6 \mathrm{~mL})$ wurde bei Raumtemperatur Palladium auf Aktivkohle (10\%ig, $6 \mathrm{mg})$ und HOAc (10 mg) gegeben. Die Reaktionsmischung wurde $1 \mathrm{~d}$ bei Raumtemperatur unter $\mathrm{H}_{2}$-Atmosphäre (1 bar) gerührt, der Feststoff durch Filtration über Celite abgetrennt und gründlich mit $\mathrm{CH}_{2} \mathrm{Cl}_{2} / \mathrm{MeOH}$ (2:1) nachgespült. Das Lösungsmittel wurde im Vakuum entfernt und Säulenchromatographie an Kieselgel $\left(\mathrm{CH}_{2} \mathrm{Cl}_{2} / \mathrm{MeOH}=50: 1 \rightarrow 25: 1\right)$ lieferte die Titelverbindung als blass-gelblicher Feststoff (23 mg, $0.044 \mathrm{mmol}, 88 \%$ ). Weitere Reinigung konnte durch Umkristallisierung aus Ethanol ermöglicht werden (15 mg, 0.029 mmol, 58 \%).

$\mathbf{R}_{\mathbf{f}}=0.3\left(\mathrm{CH}_{2} \mathrm{Cl}_{2} / \mathrm{MeOH}=20: 1\right)$.

UV $\left(\mathrm{CH}_{3} \mathrm{CN}\right): \lambda_{\max }(\lg \varepsilon)=206.0 \mathrm{~nm}$ (4.696), 249.0 (4.418), 301.0 (4.553), 339.5 (4.471).

IR $(\mathrm{KBr}): \widetilde{v}\left(\mathrm{~cm}^{-1}\right)=3432,1581,1517,1422,1178$.

${ }^{1}$ H-NMR (300 MHz, DMSO-d $\left.)_{6}\right): \delta=1.63\left(\mathrm{~d}, J=6.3 \mathrm{~Hz}, 3 \mathrm{H}, 11-\mathrm{CH}_{3}\right), 2.33\left(\mathrm{~s}, 3 \mathrm{H}, \mathrm{NCH}_{3}\right)$,

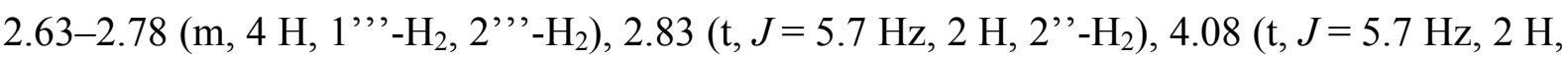
1' $\left.-\mathrm{H}_{2}\right), 4.16$ (d, $\left.J=9.0 \mathrm{~Hz}, 1 \mathrm{H}, 1-\mathrm{H}\right), 4.57-4.77$ (m, $\left.3 \mathrm{H}, 2-\mathrm{H}_{2}, 10-\mathrm{H}\right), 6.93$ (dd, $J=8.7,2.4$ Hz, 1 H, 6'-H), 7.15-7.19 (m, 2 H, 3'-H, 4'-H), 7.36 (t, $J=6.9$ Hz, 1 H, 7-H), 7.41 (d, J= 8.7 Hz, 1 H, 7'-H), 7.51 (t, J=7.2 Hz, 1 H, 8-H), 7.88 (d, J=8.4 Hz, 1 H, 9-H), 7.98 (s, 1 H, 4-H), 8.15 (d, $J=8.1 \mathrm{~Hz}, 1 \mathrm{H}, 6-\mathrm{H}), 10.35$ (s, $1 \mathrm{H}, \mathrm{OH}), 11.56$ (s, $1 \mathrm{H}, \mathrm{NH})$. 
${ }^{13}$ C-NMR (75 MHz, DMSO-d 6 ): $\delta=15.26$ (C-2 $\left.{ }^{\prime \prime \prime}\right), 23.35(\mathrm{C}-11), 41.73\left(\mathrm{NCH}_{3}\right), 45.87$ (C-1), 52.13 (C-2), 52.44 (C-1'’'), 55.08 (C-2'”), 61.47 (C-10), 66.33 (C-1’'), 100.3 (C-4),

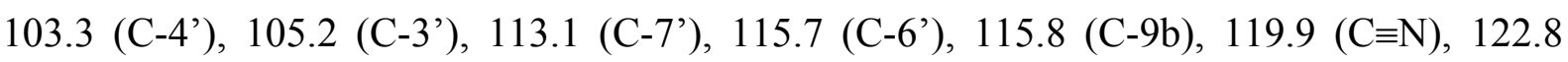
(C-7), 122.9 (C-9), 123.1 (C-6), 126.9 (C-8), 122.1, 127.5, 129.8, 131.0, 131.6 (C-5a, C-9a, C-2', C-3'a, C-7'a), 142.2 (C-3a), 152.9, 153.8 (C-5, C-5'), 159.9 (CON).

$\mathrm{C}_{29} \mathrm{H}_{29} \mathrm{CIN}_{4} \mathrm{O}_{3}(517.02)$.

Ber.: $\quad 517.20009$ für $[\mathrm{M}+\mathrm{H}]^{+}$

Gef.: 517.20011 (ESI-HRMS).

\section{3 rac-\{(1,10)-anti-1-(10-Chlor-ethyl)-5-hydroxyl-3-[(5-(2-} hydroxylethoxy)-indol-2-yl)carbonyl]-1,2-dihydro-3 $\mathrm{H}$-benz[e]indol\} (102)

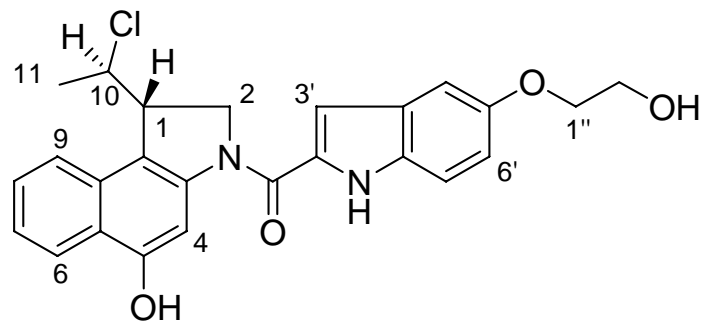

$\mathrm{Zu}$ einer Lösung von Benzylether 91 (27 mg, $0.05 \mathrm{mmol}, 1.0$ Äq.) in THF/MeOH = 1:1 $(6 \mathrm{~mL})$ wurde bei Raumtemperatur Palladium auf Aktivkohle (10\%ig, $5 \mathrm{mg})$ und HOAc (10 mg) gegeben. Die Reaktionsmischung wurde $1 \mathrm{~d}$ bei Raumtemperatur unter $\mathrm{H}_{2}$-Atmosphäre (1 bar) gerührt, der Feststoff durch Filtration über Celite abgetrennt und gründlich mit $\mathrm{CH}_{2} \mathrm{Cl}_{2} / \mathrm{MeOH}$ (2:1) nachgespült. Das Lösungsmittel wurde im Vakuum entfernt. Nach Säulenchromatographie an Kieselgel $\left(\mathrm{CH}_{2} \mathrm{Cl}_{2} / \mathrm{MeOH}=50: 1 \rightarrow\right.$ 25:1) lieferte die Titelverbindung als blass-gelblicher Feststoff (19 mg, $0.042 \mathrm{mmol}, 83 \%$ ). Weitere Reinigung konnte durch Umkristallisierung aus Ethanol ermöglicht werden (11 mg, $0.024 \mathrm{mmol}, 48 \%$ ).

$\mathbf{R}_{\mathbf{f}}=0.3\left(\mathrm{CH}_{2} \mathrm{Cl}_{2} / \mathrm{MeOH}=20: 1\right)$.

UV $\left(\mathrm{CH}_{3} \mathrm{CN}\right): \lambda_{\max }(\lg \varepsilon)=205.0 \mathrm{~nm}$ (4.650), 249.0 (4.377), 301.0 (4.502), 339.5 (4.411).

IR $(\mathrm{KBr}): \widetilde{v}\left(\mathrm{~cm}^{-1}\right)=3317,1580,1518,1428,1265$.

${ }^{1}$ H-NMR (600 MHz, DMSO-d 6 ): $\delta=1.63\left(\mathrm{~d}, J=6.6 \mathrm{~Hz}, 3 \mathrm{H}, 11-\mathrm{CH}_{3}\right), 3.76(\mathrm{q}, J=5.4 \mathrm{~Hz}$, $2 \mathrm{H}, 2$ '’ $\left.-\mathrm{H}_{2}\right), 4.01$ (t, $J=5.4 \mathrm{~Hz}, 2 \mathrm{H}, 1$ '’- $\left.\mathrm{H}_{2}\right), 4.17$ (d, J=9.6 Hz, $\left.1 \mathrm{H}, 1-\mathrm{H}\right), 4.60$ (dd, 
$\left.J=10.8,1.8 \mathrm{~Hz}, 1 \mathrm{H}, 2-\mathrm{H}_{\mathrm{a}}\right), 4.71\left(\mathrm{t}, J=10.8 \mathrm{~Hz}, 1 \mathrm{H}, 2-\mathrm{H}_{\mathrm{b}}\right), 4.73-4.77$ (m, $\left.1 \mathrm{H}, 10-\mathrm{H}\right), 4.82$ (t, $\left.J=6.0 \mathrm{~Hz}, 1 \mathrm{H}, \mathrm{CH}_{2} \mathrm{O} \underline{\mathrm{H}}\right), 6.94$ (dd, $J=9.0,1.8 \mathrm{~Hz}, 1 \mathrm{H}, 6$ ' $\left.-\mathrm{H}\right), 7.15-7.17$ (m, $2 \mathrm{H}, 3$ '- $-\mathrm{H}$, 4'-H), 7.36 (t, $J=7.5 \mathrm{~Hz}, 1 \mathrm{H}, 7-\mathrm{H}), 7.41$ (d, $\left.J=9.0 \mathrm{~Hz}, 1 \mathrm{H}, 7^{\prime}-\mathrm{H}\right), 7.51$ (t, $J=7.5 \mathrm{~Hz}, 1 \mathrm{H}$, 8-H), 7.88 (d, J=7.8 Hz, 1 H, 9-H), 7.97 (s, 1 H, 4-H), 8.14 (d, J=8.4 Hz, 1 H, 6-H), 10.34 (s, $1 \mathrm{H}, \mathrm{OH}), 11.54$ (s, $1 \mathrm{H}$, Indol-NH).

${ }^{13}$ C-NMR (150 MHz, DMSO-d ${ }_{6}$ ): $\delta=23.36$ (C-11), 45.89 (C-1), 52.14 (C-2), 59.72 (C-2"'), 61.48 (C-10), 69.92 (C-1'’), 100.4 (C-4), 103.3 (C-4'), 105.3 (C-3'), 113.0 (C-7'), 115.8 (C-6'), 115.9 (C-9b), 122.8 (C-7), 122.9 (C-9), 123.1 (C-6), 127.0 (C-8), 122.2, 127.5, 129.8, 131.0, 131.6 (C-5a, C-9a, C-2', C-3'a, C-7'a), 142.2 (C-3a), 153.1, 153.8 (C-5, C-5'), 159.9 $(\mathrm{C}=\mathrm{O})$.

$\mathrm{C}_{25} \mathrm{H}_{23} \mathrm{ClN}_{2} \mathrm{O}_{4}$ (450.91).

Ber.: $\quad 451.14191$ für $[\mathrm{M}+\mathrm{H}]^{+}$

Gef.: 451.14189 (ESI-HRMS). 


\section{Synthese von Tetragastrin}

\subsection{N-(tert-Butyloxycarbonyl)-L-tryptophyl-L-methionin (110)}

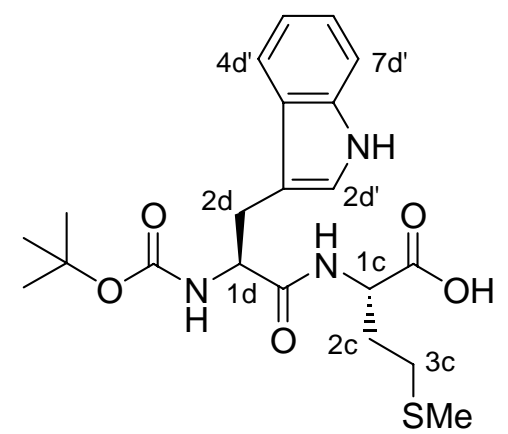

$\mathrm{Zu}$ einer Lösung von Boc-L-Tryptophan (3.04 g, 10.0 mmol, 1.0 Äq.) in $\mathrm{CH}_{2} \mathrm{Cl}_{2}$ (80 mL) bei $0{ }^{\circ} \mathrm{C}$ gab man HOSu (1.15 g, $10.0 \mathrm{mmol}, 1.0$ Äq.) und EDC. $\mathrm{HCl}(1.92 \mathrm{~g}, 10 \mathrm{mmol}, 1.0$ Äq.) und rührte für $4 \mathrm{~h}$ bei Raumtemperatur. Nach Entfernen des Lösungsmittels wurde der Rückstand mit THF (100 mL) versetzt und anschließend zu einer Lösung von L-Methionin (1.49 g, 10.0 mmol, 1.0 Äq.) und DIEA (1.29 g, 10 mmol, 1.0 Äq.) in Wasser (100 mL) gegeben. Das Reaktionsgemisch wurde $12 \mathrm{~h}$ bei Raumtemperatur gerührt und anschließend das THF im Vakuum entfernt. Der Rückstand wurde mit $1 \mathrm{M} \mathrm{HCl}$ auf $\mathrm{pH} 2$ eingestellt und mit $\mathrm{Et}_{2} \mathrm{O}(2 \times 100 \mathrm{~mL})$ extrahiert. Die vereinigten organischen Phasen wurden mit ges. NaCl-Lösung $(40 \mathrm{~mL})$ gewaschen, über $\mathrm{Na}_{2} \mathrm{SO}_{4}$ getrocknet und das Lösungsmittel im Vakuum entfernt. Der so erhaltene weiße Feststoff (3.16 g, $7.2 \mathrm{mmol}, 72 \%$ ) wurde nicht weiter gereinigt.

$\mathbf{R}_{\mathbf{f}}=0.3\left(\mathrm{CH}_{2} \mathrm{Cl}_{2} / \mathrm{MeOH}=15: 1+0.5 \% \mathrm{HOAc}\right)$.

Drehwert: $[\alpha]_{\mathrm{D}}^{20}=-16.6^{\circ}(c=0.5$ in $\mathrm{MeOH})$.

${ }^{1} \mathbf{H}-\mathbf{N M R}\left(300 \mathrm{MHz}, \mathrm{DMSO}_{6}, 100{ }^{\circ} \mathrm{C}\right): \delta=1.33\left(\mathrm{~s}, 9 \mathrm{H}, \mathrm{C}\left(\mathrm{CH}_{3}\right)_{3}\right), 1.85-2.03(\mathrm{~m}, 2 \mathrm{H}$, $\left.2 \mathrm{c}-\mathrm{H}_{2}\right), 2.06\left(\mathrm{~s}, 3 \mathrm{H}, \mathrm{SCH}_{3}\right), 2.47-2.52\left(\mathrm{~m}, 2 \mathrm{H}, 3 \mathrm{c}-\mathrm{H}_{2}\right), 2.97(\mathrm{dd}, J=14.7,8.7 \mathrm{~Hz}, 1 \mathrm{H}$, 2d-Ha $), 3.16\left(\mathrm{dd}, J=14.7,4.8 \mathrm{~Hz}, 1 \mathrm{H}, 2 \mathrm{~d}-\mathrm{H}_{\mathrm{a}}\right), 4.26-4.33(\mathrm{~m}, 1 \mathrm{H}, 1 \mathrm{~d}-\mathrm{H}), 4.38-4.45(\mathrm{~m}, 1 \mathrm{H}$, $1 \mathrm{c}-\mathrm{H}), 6.27(\mathrm{~d}, J=6.0 \mathrm{~Hz}, 1 \mathrm{H}, \mathrm{BocN} \underline{\mathrm{H}}), 6.98$ (t, $J=6.6 \mathrm{~Hz}, 1 \mathrm{H}, 5 \mathrm{~d}-\mathrm{H}), 7.06$ (t, $J=6.9 \mathrm{~Hz}$, $1 \mathrm{H}, 6 \mathrm{~d} '-\mathrm{H}), 7.12$ (d, J=2.1 Hz, $1 \mathrm{H}, 2 \mathrm{~d}-\mathrm{H}), 7.33$ (d, J=8.1 Hz, $1 \mathrm{H}, 7 \mathrm{~d}-\mathrm{H}), 7.57$ (d, $\left.J=7.5 \mathrm{~Hz}, 1 \mathrm{H}, 4 \mathrm{~d}^{\prime}-\mathrm{H}\right), 7.75$ (d, $\left.J=7.5 \mathrm{~Hz}, 1 \mathrm{H}, \mathrm{NH}\right), 10.53$ ( $\mathrm{s}_{\mathrm{br}}, 1 \mathrm{H}$, Indol-NH).

${ }^{13} \mathrm{C}-\mathrm{NMR}\left(75 \mathrm{MHz}, \mathrm{DMSO}_{\mathrm{d}}, 100{ }^{\circ} \mathrm{C}\right): \delta=14.14\left(\mathrm{SCH}_{3}\right), 27.31(\mathrm{C}-2 \mathrm{~d}), 27.62\left(\mathrm{C}\left(\underline{\mathrm{CH}}_{3}\right)_{3}\right)$, 29.25 (C-3c), 30.94 (C-2c), 50.73 (C-1c), 54.95 (C-1d), $77.78\left(\underline{\mathrm{C}}\left(\mathrm{CH}_{3}\right)_{3}\right), 109.75(\mathrm{C}-3 \mathrm{~d})$, 110.70 (C-7d'), 117.65, 117.81 (C-4d', C-5d'), 120.24 (C-6d'), 123.06 (C-2d'), 127.16 (C-3ad'), $135.83\left(\mathrm{C}-7 \mathrm{ad}^{\prime}\right), 154.46(\underline{\mathrm{C}}(\mathrm{O}) \mathrm{O} t \mathrm{Bu}), 171.28,172.12(2 \times \mathrm{C}=\mathrm{O})$. 
MS (DCI, $\left.\mathrm{NH}_{3}\right): m / z(\%)=453.4(52)\left[\mathrm{M}+\mathrm{NH}_{4}\right]^{+}$.

$\mathrm{C}_{21} \mathrm{H}_{29} \mathrm{~N}_{3} \mathrm{O}_{5} \mathrm{~S}$ (435.54).

\subsection{L-Asparaginsäure- $\beta$-methylester Hydrochlorid (116)}<smiles>COC(=O)C[C@H]([NH3+])C(=O)O</smiles>

$\mathrm{Zu}$ einer bei Raumtemperatur gerührten Suspension von L-Asparaginsäure 115 (3.99 g, 30.0 $\mathrm{mmol})$ in Methanol (30 mL) wurde über $10 \mathrm{~min} \mathrm{TMSCl}(4.7 \mathrm{~mL}, 36.0 \mathrm{mmol})$ gegeben und weitere $24 \mathrm{~h}$ gerührt. Zur Aufarbeitung wurde die Reaktionsmischung in $\mathrm{Et}_{2} \mathrm{O}(300 \mathrm{~mL})$ gegossen, wobei das Hydrochlorid 116 als farbloser Feststoff ausfiel. Dieser wurde abgesaugt, mit $\mathrm{Et}_{2} \mathrm{O}$ gewaschen und im Vakuum getrocknet (5.01 g, $27.3 \mathrm{mmol}$, 91\%).

Smp.: $186^{\circ} \mathrm{C}$ (zers.).

${ }^{1}$ H-NMR (300 MHz, DMSO-d $\left.{ }_{6}\right): \delta=2.97\left(\mathrm{~d}, J=5.7 \mathrm{~Hz}, 2 \mathrm{H}, 3-\mathrm{H}_{2}\right), 3.64\left(\mathrm{~s}, 3 \mathrm{H}, \mathrm{OCH}_{3}\right)$, $4.16(\mathrm{t}, J=5.4 \mathrm{~Hz}, 1 \mathrm{H}, 2-\mathrm{H}), 8.57\left(\mathrm{~s}_{\mathrm{br}}, 3 \mathrm{H}, \mathrm{NH}_{3}\right)$.

$\mathrm{C}_{5} \mathrm{H}_{10} \mathrm{CINO}_{4}(183.59)$.

\section{3 $\quad N$-(tert-Butyloxycarbonyl)-L-aspartyl-( $\beta$-O-methyl)-L-phenyl- alaninamid (122)}<smiles>COC(=O)C[C@H](NC(=O)OC(C)(C)C)C(=O)N[C@@H](Cc1ccccc1)C(N)=O</smiles>

Zur Lösung des Hydrochlorides 116 (5.51 g, $30.0 \mathrm{mmol})$ in $\mathrm{MeOH}(150 \mathrm{~mL})$ wurden bei Raumtemperatur Di-tert-butyldicarbonat (7.86 g, $36.0 \mathrm{mmol})$ und $\mathrm{NaHCO}_{3}$ (5.04 g, 60.0 $\mathrm{mmol}) / \mathrm{H}_{2} \mathrm{O}(150 \mathrm{~mL})$ gegeben und $2 \mathrm{~h}$ gerührt. Nach Entfernen des Methanols im Vakuum wurde die wässrige Phase mit Ether $(50 \mathrm{~mL})$ extrahiert. Dann wurde die wässrige Phase mit $0.5 \mathrm{M} \mathrm{HCl}$ auf $\mathrm{pH} 2$ eingestellt und mit EtOAc $(2 \times 100 \mathrm{~mL})$ extrahiert. Die vereinigten 
organischen Phasen (AcOEt) wurden über $\mathrm{Na}_{2} \mathrm{SO}_{4}$ getrocknet und das Lösungsmittel im Vakuum entfernt. Man erhielt 117 als farbloses Ö1 (4.24 g, 17.1 mmol, 57 \%).

$\mathrm{Zu}$ einer Lösung der Aminosäure 117 (0.12 g, 0.5 mmol, 1.0 Äq.) in trocknem THF (22 mL) bei $-18.0^{\circ} \mathrm{C}$ gab man DIEA (65 mg, $0.5 \mathrm{mmol}, 1.0$ Äq.) und Chlorameisensäureethylester (54 mg, $0.5 \mathrm{mmol}, 1.0$ Äq.) und rührte $30 \mathrm{~min}$ bei $-10^{\circ} \mathrm{C}$. Anschließend wurde einer Lösung von L-Phenylalaninamid (82 mg, $0.5 \mathrm{mmol}, 1.0$ Äq.) in Wasser (20 mL) zugegeben und $2 \mathrm{~h}$ bei Raumtemperatur gerührt. Nach Abdestillieren des THF im Vakuum wurde der Niederschlag abfiltriert, mit $\mathrm{Et}_{2} \mathrm{O}$ gewaschen und getrocknet im Vakuum. Man erhielt das Zielverbindung als weißen Feststoff (0.12 g, $0.3 \mathrm{mmol}, 60 \%)$.

$\mathbf{R}_{\mathbf{f}}=0.3\left(\mathrm{CH}_{2} \mathrm{Cl}_{2} / \mathrm{MeOH}=15: 1+0.5 \% \mathrm{HOAc}\right)$.

Drehwert: $[\alpha]_{\mathrm{D}}^{20}=-30.3^{\circ}(c=0.35$ in $\mathrm{MeOH})$.

${ }^{1} \mathbf{H}-\mathbf{N M R}\left(300 \mathrm{MHz}\right.$, DMSO-d $\left.6,100{ }^{\circ} \mathrm{C}\right): \delta=1.37\left(9 \mathrm{H}, \mathrm{C}_{6}\left(\mathrm{CH}_{3}\right)_{3}\right), 2.51(\mathrm{dd}, J=15.9,7.8 \mathrm{~Hz}$, $\left.1 \mathrm{H}, 2 \mathrm{~b}-\mathrm{H}_{\mathrm{a}}\right), 2.65\left(\mathrm{dd}, J=15.6,7.8 \mathrm{~Hz}, 1 \mathrm{H}, 2 \mathrm{~b}-\mathrm{H}_{\mathrm{b}}\right), 2.87$ (dd, $\left.J=13.5,7.8 \mathrm{~Hz}, 1 \mathrm{H}, 2 \mathrm{a}-\mathrm{H}_{\mathrm{a}}\right)$, $3.03\left(\mathrm{dd}, J=14.1,5.4 \mathrm{~Hz}, 1 \mathrm{H}, 2 \mathrm{a}-\mathrm{H}_{\mathrm{b}}\right), 3.57\left(\mathrm{~s}, 3 \mathrm{H}, \mathrm{CH}_{3}\right), 4.27(\mathrm{dt}, J=7.5,6.0 \mathrm{~Hz}, 1 \mathrm{H}$, 1b-H), 4.45 (dt, $J=7.5,5.7 \mathrm{~Hz}, 1 \mathrm{H}, 1 \mathrm{a}-\mathrm{H}), 6.65(\mathrm{~d}, J=6.3 \mathrm{~Hz}, 1 \mathrm{H}, \mathrm{BocN} \underline{\mathrm{H}}), 6.90\left(\mathrm{~s}_{\mathrm{br}}, 2 \mathrm{H}\right.$, $\left.\mathrm{NH}_{2}\right), 7.11-7.27$ (m, $\left.5 \mathrm{H}, 5 \times \mathrm{Ph}-\mathrm{H}\right), 7.49(\mathrm{~d}, J=7.2 \mathrm{~Hz}, 1 \mathrm{H}, \mathrm{NH})$.

MS (ESI): $m / z(\%)=416.2(40)[\mathrm{M}+\mathrm{Na}]^{+}, 809.0(100)[2 \mathrm{M}+\mathrm{Na}]^{+}$.

$\mathrm{C}_{19} \mathbf{H}_{27} \mathbf{N}_{3} \mathbf{O}_{6}$ (393.43).

\subsection{L-Asparaginsäure- $\beta$-allylester Hydrochlorid (118)}<smiles>C=CCOC(=O)C[C@H](N)C(=O)O</smiles>

$\mathrm{Zu}$ einer bei Raumtemperatur gerührten Suspension von L-Asparaginsäure 115 (2.66 g, 20.0 mmol) in Allylalkohol (30 mL) wurde über 6 min TMSCl (3.9 mL, $30.0 \mathrm{mmol})$ gegeben und weitere $24 \mathrm{~h}$ gerührt. Zur Aufarbeitung wurde die Reaktionsmischung in $\mathrm{Et}_{2} \mathrm{O}(150 \mathrm{~mL})$ gegossen, wobei das Hydrochlorid 118 als farbloser Feststoff ausfiel. Dieser wurde abgesaugt, mit $\mathrm{Et}_{2} \mathrm{O}$ gewaschen und im Vakuum getrocknet (2.96 g, $14.1 \mathrm{mmol}, 71 \%$ ).

Smp.: $180^{\circ} \mathrm{C}$ (zers.). 
${ }^{1}$ H-NMR $\left(200 \mathrm{MHz}, \mathrm{D}_{2} \mathrm{O}\right): \delta=3.03\left(\mathrm{~d}, J=5.4 \mathrm{~Hz}, 2 \mathrm{H}, 3-\mathrm{H}_{2}\right), 4.36(\mathrm{t}, J=5.4 \mathrm{~Hz}, 1 \mathrm{H}, 2-\mathrm{H})$, $4.63\left(\mathrm{~d}, J=5.4 \mathrm{~Hz}, 2 \mathrm{H}, 1^{\prime}-\mathrm{H}_{2}\right), 5.27$ (d, $J=9.8 \mathrm{~Hz}, 1 \mathrm{H}, 3$ ' $\left.-\mathrm{H}_{\mathrm{a}}\right), 5.34(\mathrm{dd}, J=15.4,1.5 \mathrm{~Hz}$, $\left.1 \mathrm{H}, 3^{\prime}-\mathrm{H}_{\mathrm{b}}\right), 5.91-5.95$ (m, $1 \mathrm{H}, 2^{\prime}$ '-H).

$\mathrm{C}_{7} \mathrm{H}_{12} \mathrm{CINO}_{4}$ (209.63).

\section{5 $\quad N$-(tert-Butyloxycarbonyl)-L-aspartyl-( $\beta$-O-allyl)-L-phenyl- alaninamid (123)}

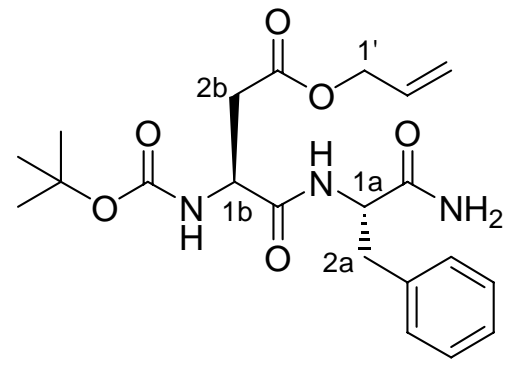

Zur Lösung des Hydrochlorides $118(2.10 \mathrm{~g}, 10.0 \mathrm{mmol})$ in THF/MeOH $(50 \mathrm{~mL} / 50 \mathrm{~mL})$ wurden bei Raumtemperatur Di-tert-butyldicarbonat (2.80 g, $13.0 \mathrm{mmol})$ und NEtiPr $\operatorname{Pr}_{2}(3.88 \mathrm{~g}$, $30.0 \mathrm{mmol}$ ) gegeben und $2 \mathrm{~h}$ gerührt. Nach Entfernen des Lösungsmittels wurde Wasser $(50 \mathrm{~mL})$ zugegeben, mit Ether $(30 \mathrm{~mL})$ extrahiert. Die wässrige Phase wurde mit $0.5 \mathrm{M} \mathrm{HCl}$ auf $\mathrm{pH} 2$ eingestellt und mit EtOAc $(2 \times 100 \mathrm{~mL})$ extrahiert. Die vereinigten organischen Phasen (AcOEt) wurden über $\mathrm{Na}_{2} \mathrm{SO}_{4}$ getrocknet und das Lösungsmittel im Vakuum entfernt. Man erhielt 119 als farbloses Öl (2.80 g, $10.0 \mathrm{mmol}, 100 \%)$.

$\mathrm{Zu}$ einer Lösung der Aminosäure 119 (2.80 g, $10.0 \mathrm{mmol}, 1.0$ Äq.) in trocknem THF $(100 \mathrm{~mL})$ bei $-18.0{ }^{\circ} \mathrm{C}$ gab man DIEA (1.29 g, $10.0 \mathrm{mmol}, 1.0$ Äq.) und Chlorameisensäureethylester $\left(1.09 \mathrm{~g}, 10.0 \mathrm{mmol}, 1.0\right.$ Äq.) und rührte $1 \mathrm{~h}$ bei $-10^{\circ} \mathrm{C}$. Anschließend wurde eine Lösung von L-Phenylalaninamid (1.64 g, 10.0 mmol, 1.0 Äq.) in Wasser $(40 \mathrm{~mL})$ zugegeben und $2 \mathrm{~h}$ bei Raumtemperatur gerührt. Nach Abdestillieren des THF im Vakuum goss man den Rückstand in $1 \mathrm{M} \mathrm{HCl}(50 \mathrm{~mL})$ und extrahierte mit EtOAc $(2 \times 100 \mathrm{~mL})$. Die vereinigten organischen Phasen wurden über $\mathrm{Na}_{2} \mathrm{SO}_{4}$ getrocknet und das Lösungsmittel im Vakuum entfernt. Nach Umkristallisierung aus EtOH/ $\mathrm{H}_{2} \mathrm{O}$ erhielt man das Zielverbindung als weißen Feststoff (3.95 g, 94 \%).

$\mathbf{R}_{\mathbf{f}}=0.8\left(\mathrm{CH}_{2} \mathrm{Cl}_{2} / \mathrm{MeOH}=10: 1+1 \% \mathrm{HOAc}\right)$.

Drehwert: $[\alpha]_{\mathrm{D}}^{20}=-26.9^{\circ}(c=0.45$ in $\mathrm{MeOH})$. 
${ }^{1}$ H-NMR (300 MHz, DMSO-d $\left.{ }_{6}\right): \delta=1.37\left(9 \mathrm{H}, \mathrm{C}\left(\mathrm{CH}_{3}\right)_{3}\right), 2.55(\mathrm{dd}, J=15.9,9.0 \mathrm{~Hz}, 1 \mathrm{H}$, 2b- $\left.\mathrm{H}_{\mathrm{a}}\right), 2.67$ (dd, $\left.J=16.2,5.1 \mathrm{~Hz}, 1 \mathrm{H}, 2 \mathrm{~b}-\mathrm{H}_{\mathrm{b}}\right), 2.85$ (dd, $\left.J=13.8,8.4 \mathrm{~Hz}, 1 \mathrm{H}, 2 \mathrm{a}-\mathrm{H}_{\mathrm{a}}\right), 3.01$ $\left(\mathrm{dd}, J=13.8,4.8 \mathrm{~Hz}, 1 \mathrm{H}, 2 \mathrm{a}-\mathrm{H}_{\mathrm{b}}\right), 4.28(\mathrm{dt}, J=8.1,5.1 \mathrm{~Hz}, 1 \mathrm{H}, 1 \mathrm{~b}-\mathrm{H}), 4.42(\mathrm{dt}, J=7.8$, $5.1 \mathrm{~Hz}, 1 \mathrm{H}, 1 \mathrm{a}-\mathrm{H}), 4.54\left(\mathrm{dd}, J=5.4,1.5 \mathrm{~Hz}, 2 \mathrm{H}, 1^{\prime}-\mathrm{H}_{2}\right), 5.20(\mathrm{dd}, J=10.5,1.2 \mathrm{~Hz}, 1 \mathrm{H}$, 3'- $\left.\mathrm{H}_{\mathrm{a}}\right), 5.30\left(\mathrm{dd}, J=17.1,1.5 \mathrm{~Hz}, 1 \mathrm{H}, 3^{\prime}-\mathrm{H}_{\mathrm{b}}\right), 5.83-5.96\left(\mathrm{~m}, 1 \mathrm{H}, 2^{\prime}-\mathrm{H}\right), 7.08$ (s, $\left.2 \mathrm{H}, \mathrm{NH}_{2}\right)$, 7.11-7.27 (m, 5 H, $5 \times \mathrm{Ph}-\mathrm{H})$, ), 7.35 (s, $1 \mathrm{H}, \mathrm{BocN} \underline{\mathrm{H}}), 7.69$ (d, J=8.1 Hz, $1 \mathrm{H}, \mathrm{NH})$.

MS (ESI): $m / z(\%)=442.1(58)[\mathrm{M}+\mathrm{Na}]^{+}, 860.9(100)[2 \mathrm{M}+\mathrm{Na}]^{+}$.

$\mathbf{C}_{21} \mathbf{H}_{29} \mathbf{N}_{3} \mathbf{O}_{6}$ (419.47).

\section{6 $\quad N$-(tert-Butyloxycarbonyl)-L-aspartyl-( $\beta$-O-benzyl)-L-phenyl- alaninamid (124)}

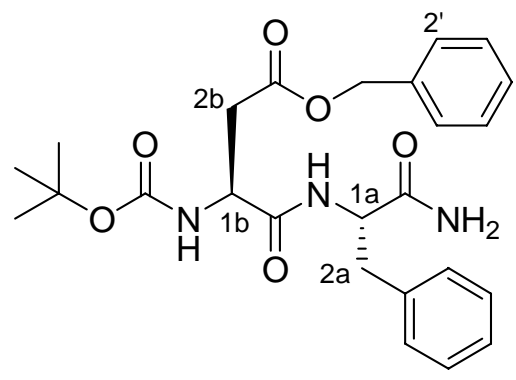

Zu einer Lösung der Aminosäure 120 (1.0 g, 3.1 mmol, 1.0 Äq.) in trocknem THF (50 mL) bei $-18.0^{\circ} \mathrm{C}$ gab man Triethylamin $(0.37$ g, 3.7 mmol, 1.2 Äq. $)$ und Chlorameisensäureethylester $(0.35 \mathrm{~g}, 3.2 \mathrm{mmol}, 1.0$ Äq. $)$ und rührte $1 \mathrm{~h}$ bei $-10^{\circ} \mathrm{C}$. Anschließend wurde eine Lösung von L-Phenylalaninamid (0.51 g, $3.1 \mathrm{mmol}, 1.0$ Äq.) in Wasser $(20 \mathrm{~mL})$ zugegeben und $12 \mathrm{~h}$ bei Raumtemperatur gerührt. Nach Abdestillieren des THF im Vakuum wurde der Rückstand mit $\mathrm{CH}_{2} \mathrm{Cl}_{2}(2 \times 50 \mathrm{~mL})$ extrahiert und die vereinigten organischen Phasen über $\mathrm{Na}_{2} \mathrm{SO}_{4}$ getrocknet. Nach Säulenchromatographie $\left(\mathrm{CH}_{2} \mathrm{Cl}_{2} / \mathrm{MeOH}=100: 3 \rightarrow 100: 5\right)$ erhielt man das Dipeptid 124 als weißen Schaum (1.19 g, $2.5 \mathrm{mmol}, 82 \%)$.

$\mathbf{R}_{\mathbf{f}}=0.2\left(\mathrm{CH}_{2} \mathrm{Cl}_{2} / \mathrm{MeOH}=40: 1\right)$.

Drehwert: $[\alpha]_{\mathrm{D}}^{20}=-29.8^{\circ}(c=1.0$ in DMF $)$.

${ }^{1} \mathbf{H}-\mathrm{NMR}\left(300 \mathrm{MHz}, \mathrm{DMSO}_{6}, 100{ }^{\circ} \mathrm{C}\right): \delta=1.41\left(9 \mathrm{H}, \mathrm{C}\left(\mathrm{CH}_{3}\right)_{3}\right), 2.48(\mathrm{dd}, J=17.4,6.0 \mathrm{~Hz}$, $\left.1 \mathrm{H}, 2 \mathrm{~b}-\mathrm{H}_{\mathrm{a}}\right), 2.91\left(\mathrm{dd}, J=17.4,6.3 \mathrm{~Hz}, 1 \mathrm{H}, 2 \mathrm{~b}-\mathrm{H}_{\mathrm{b}}\right), 3.19\left(\mathrm{dd}, J=13.8,10.2 \mathrm{~Hz}, 1 \mathrm{H}, 2 \mathrm{a}-\mathrm{H}_{\mathrm{a}}\right)$, $3.47\left(\mathrm{dd}, J=14.1,4.8 \mathrm{~Hz}, 1 \mathrm{H}, 2 \mathrm{a}-\mathrm{H}_{\mathrm{b}}\right), 4.16-4.24(\mathrm{~m}, J=1 \mathrm{H}, 1 \mathrm{~b}-\mathrm{H}), 4.52(\mathrm{~d}, J=4.5 \mathrm{~Hz}$, 
$\left.2 \mathrm{H}, \underline{\mathrm{C}}_{2} \mathrm{Ph}\right), 4.68(\mathrm{dd}, J=10.2,4.5 \mathrm{~Hz}, 1 \mathrm{H}, 1 \mathrm{a}-\mathrm{H}), 4.79$ (t, $\left.1 \mathrm{H}, \mathrm{NH}\right), 6.96\left(\mathrm{~s}, 2 \mathrm{H}, \mathrm{NH}_{2}\right)$, 7.16-7.33 (m, $11 \mathrm{H}, 10 \times \mathrm{Ph}-\mathrm{H}, \mathrm{NH})$.

MS (DCI, $\left.\mathrm{NH}_{3}\right): m / z(\%)=487.4(52)\left[\mathrm{M}+\mathrm{NH}_{4}\right]^{+}$.

$\mathrm{C}_{25} \mathbf{H}_{31} \mathbf{N}_{3} \mathbf{O}_{6}$ (469.53).

\subsection{N-(tert-Butyloxycarbonyl)-L-aspartyl-L-phenylalaninamid (129)}

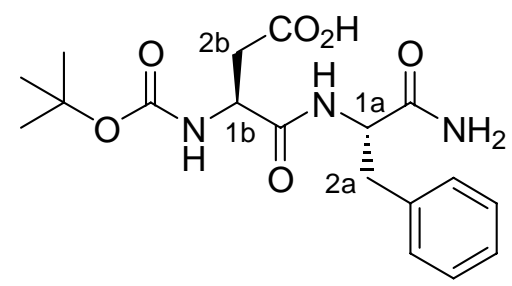

Eine Lösung des benzylgeschützten Dipeptids 124 (390 mg, $0.83 \mathrm{mmol}$ ) in einem Gemisch aus THF/MeOH = 1:1 (16 mL) versetzte man mit Palladium auf Aktivkohle (10\%ig, $40 \mathrm{mg})$ und rührte $12 \mathrm{~h}$ bei Raumtemperatur unter $\mathrm{H}_{2}$-Atmosphäre (1 bar). Der Feststoff wurde durch Filtration über Celite abgetrennt und gründlich mit $\mathrm{CH}_{2} \mathrm{Cl}_{2} / \mathrm{MeOH}$ (2:1) nachgespült. Das Filtrat wurde im Vakuum eingeengt und die Titelverbindung (264 mg, $0.70 \mathrm{mmol}, 84 \%$ ) als weißer Feststoff erhalten.

$\mathbf{R}_{\mathbf{f}}=0.4\left(\mathrm{CH}_{2} \mathrm{Cl}_{2} / \mathrm{MeOH}=10: 1+1 \% \mathrm{HOAc}\right)$.

${ }^{1} \mathbf{H}-\mathrm{NMR}\left(300 \mathrm{MHz}, \mathrm{DMSO}-\mathrm{d}_{6}, 80^{\circ} \mathrm{C}\right): \delta=1.39\left(\mathrm{~s}, 9 \mathrm{H}, \mathrm{C}\left(\mathrm{CH}_{3}\right)_{3}\right), 2.45(\mathrm{dd}, J=16.5$, $\left.7.8 \mathrm{~Hz}, 1 \mathrm{H}, 2 \mathrm{~b}-\mathrm{H}_{\mathrm{a}}\right), 2.60\left(\mathrm{dd}, J=16.2,5.4 \mathrm{~Hz}, 1 \mathrm{H}, 2 \mathrm{~b}-\mathrm{H}_{\mathrm{b}}\right), 2.89(\mathrm{dd}, J=13.8,7.8 \mathrm{~Hz}, 1 \mathrm{H}$, $\left.2 \mathrm{a}-\mathrm{H}_{\mathrm{a}}\right), 3.05\left(\mathrm{dd}, J=13.8,5.1 \mathrm{~Hz}, 1 \mathrm{H}, 2 \mathrm{a}-\mathrm{H}_{\mathrm{b}}\right), 4.21-4.28(\mathrm{~m}, 1 \mathrm{H}, 1 \mathrm{~b}-\mathrm{H}), 4.46(\mathrm{td}, J=8.1$, $5.4 \mathrm{~Hz}, 1 \mathrm{H}, 1 \mathrm{a}-\mathrm{H}), 6.71\left(\mathrm{~s}_{\mathrm{br}}, 1 \mathrm{H}, \mathrm{BocN} \underline{\mathrm{H}}\right), 6.99\left(\mathrm{~s}_{\mathrm{br}}, 2 \mathrm{H}, \mathrm{NH}_{2}\right), 7.18-7.27(\mathrm{~m}, 5 \mathrm{H}$, $5 \times \mathrm{Ph}-\mathrm{H}), 7.53(\mathrm{~d}, J=8.1 \mathrm{~Hz}, 1 \mathrm{H}, \mathrm{NH})$.

${ }^{13} \mathrm{C}-\mathrm{NMR}\left(75 \mathrm{MHz}, \mathrm{DMSO}-\mathrm{d}_{6}, 80{ }^{\circ} \mathrm{C}\right): \delta=27.82\left(\mathrm{C}^{\left.\left(\mathrm{CH}_{3}\right)_{3}\right)}\right), 35.96,37.24(\mathrm{C}-2 \mathrm{a}, \mathrm{C}-2 \mathrm{~b})$, $51.25(\mathrm{C}-1 \mathrm{~b}), 53.30(\mathrm{C}-1 \mathrm{a}), 78.25\left(\underline{\mathrm{C}}\left(\mathrm{CH}_{3}\right)_{3}\right), 125.80\left(\mathrm{Ph}-\mathrm{C}_{p}\right), 127.60,128.81(4 \times \mathrm{Ph}-\mathrm{C})$, $137.31\left(\mathrm{Ph}-\mathrm{C}_{i}\right), 154.53(\underline{\mathrm{C}}(\mathrm{O}) \mathrm{O} t \mathrm{Bu}), 170.21,171.38,172.09(3 \times \mathrm{C}=\mathrm{O})$.

MS (ESI): $m / z(\%)=402.1(74)[\mathrm{M}+\mathrm{Na}]^{+}, 378.0(100)[\mathrm{M}-\mathrm{H}]^{-}$.

$\mathbf{C}_{18} \mathbf{H}_{25} \mathbf{N}_{3} \mathbf{O}_{6}(379.41)$. 


\subsection{L-Aspartyl-L-phenylalaninamid-trifluoracetat (130)}

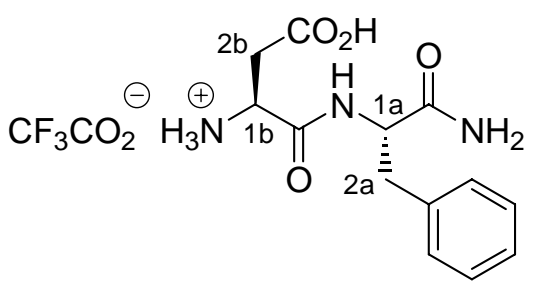

Eine Suspension des geschützten Dipeptids 129 (244 mg, $0.64 \mathrm{mmol})$ in $\mathrm{CH}_{2} \mathrm{Cl}_{2}(1.8 \mathrm{~mL})$ versetzte man mit Wasser $(0.3 \mathrm{~mL})$ und TFA $(1.8 \mathrm{~mL})$ und rührte $3 \mathrm{~h}$ bei Raumtemperatur. Anschließend wurde die TFA unter Zugabe von Toluol durch azeotrope Destillation im Vakuum entfernt und der Rückstand im Vakuum getrocknet. Man erhielt das TFA-Salz des Dipeptids als weißes Pulver, das direkt weiter eingesetzt wurde (250 mg, $0.64 \mathrm{mmol}, 99 \%)$.

Drehwert: $[\alpha]_{D}^{20}=+17.8^{\circ}\left(c=0.45\right.$ in $\left.\mathrm{H}_{2} \mathrm{O}\right)$.

${ }^{1}$ H-NMR $\left(300 \mathrm{MHz}, \mathrm{DMSO}_{\mathrm{d}}, 80^{\circ} \mathrm{C}\right): \delta=2.76\left(\mathrm{dd}, J=17.7,7.8 \mathrm{~Hz}, 1 \mathrm{H}, 2 \mathrm{~b}-\mathrm{H}_{\mathrm{a}}\right), 2.85-$ $2.92\left(\mathrm{~m}, 2 \mathrm{H}, 2 \mathrm{~b}-\mathrm{H}_{\mathrm{b}}, 2 \mathrm{a}-\mathrm{H}_{\mathrm{a}}\right), 3.09$ (dd, $\left.J=14.7,5.1 \mathrm{~Hz}, 1 \mathrm{H}, 2 \mathrm{a}-\mathrm{H}_{\mathrm{b}}\right), 4.08(\mathrm{dd}, J=7.5,4.5 \mathrm{~Hz}$, $1 \mathrm{H}, 1 \mathrm{~b}-\mathrm{H}), 4.47-4.51\left(\mathrm{~m}_{\mathrm{c}}, 1 \mathrm{H}, 1 \mathrm{a}-\mathrm{H}\right), 7.03\left(\mathrm{~s}_{\mathrm{br}}, 2 \mathrm{H}, \mathrm{NH}_{2}\right), 7.20-7.28(\mathrm{~m}, 5 \mathrm{H}, 5 \times \mathrm{Ph}-\mathrm{H})$, $8.43(\mathrm{~d}, J=5.1 \mathrm{~Hz}, 1 \mathrm{H}, \mathrm{NH}), 8.63\left(\mathrm{~s} b \mathrm{r}, 1 \mathrm{H}, \mathrm{NH}^{+}\right)$.

${ }^{13}$ C-NMR (75 MHz, DMSO-d $\left.6,80{ }^{\circ} \mathrm{C}\right): \delta=35.08$ (C-2b), 37.09 (C-2a), 48.79 (C-1b), 54.27 (C-1a), $125.98\left(\mathrm{Ph}_{-} \mathrm{C}_{p}\right), 127.77,128.76(4 \times \mathrm{Ph}-\mathrm{C}), 137.38\left(\mathrm{Ph}^{-C_{i}}\right), 167.19,170.60,171.81$ $(3 \times \mathrm{C}=\mathrm{O})$.

MS (ESI): $m / z(\%)=280.0(100)\left[\mathrm{M}-\mathrm{CF}_{3} \mathrm{CO}_{2}\right]^{+}$.

$\mathbf{C}_{15} \mathbf{H}_{18} \mathbf{F}_{3} \mathbf{N}_{3} \mathbf{O}_{6}$ (393.32). 


\subsection{N-(tert-Butyloxycarbonyl)-L-tryptophyl-L-methionyl- L-aspartyl-( $\beta$-O-methyl)-L-phenylalaninamid (125)}

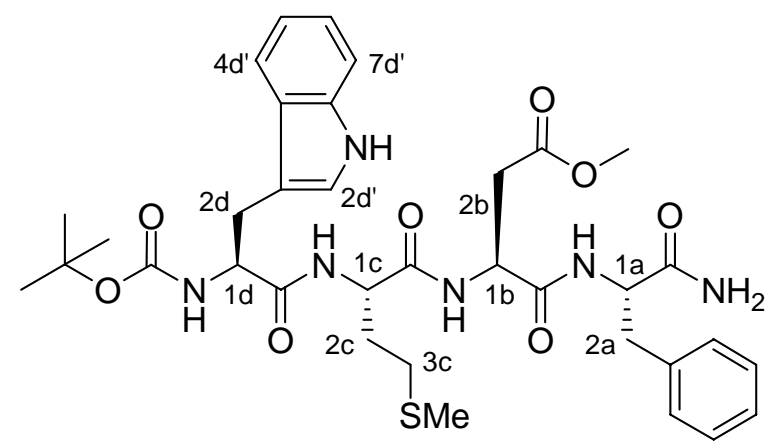

$\mathrm{Zu}$ einer Suspension von Dipeptid 122 (708 mg, $1.8 \mathrm{mmol}, 1.0$ Äq.) in $\mathrm{CH}_{2} \mathrm{Cl}_{2}$ (10 mL) und Wasser $(1 \mathrm{~mL})$ gab man tropfenweise TFA $(10 \mathrm{~mL})$ und rührte $2 \mathrm{~h}$ bei Raumtemperatur. Anschließend wurde die TFA unter Zugabe von Toluol durch azeotrope Destillation im Vakuum entfernt und der Rückstand in Wasser $(40 \mathrm{~mL})$ gelöst sowie mit DIEA (465 mg, 3.6 mmol, 2.0 Äq.) versetzt (Lösung A).

Zu einer Lösung des Dipeptids 110 (784 mg, 1.8 mmol, 1.0 Äq.) in $\mathrm{CH}_{2} \mathrm{Cl}_{2}$ (40 mL) bei $0{ }^{\circ} \mathrm{C}$ gab man HOSu (207 mg, $1.8 \mathrm{mmol}, 1.0$ Äq.) und $\mathrm{EDC} \cdot \mathrm{HCl}(345 \mathrm{mg}, 1.8 \mathrm{mmol}$, 1.0 Äq.) und rührte bei Raumtemperatur für 2 h. Nach Entfernen des Lösungsmittels wurde der Rückstand mit THF (40 mL) versetzt und die entstandene Lösung zu Lösung A getropft. Das Reaktionsgemisch wurde $2 \mathrm{~h}$ bei Raumtemperatur gerührt und anschließend THF im Vakuum entfernt. Nach Abkühlen auf $0{ }^{\circ} \mathrm{C}$ wurde der entstandene Niederschlag abfiltriert, mit Ether gewaschen und im Vakuum getrocknet. Man erhielt die Titelverbindung als weißen Feststoff (0.838 g, $1.2 \mathrm{mmol}, 66 \%)$.

$\mathbf{R}_{\mathbf{f}}=0.3\left(\mathrm{CH}_{2} \mathrm{Cl}_{2} / \mathrm{MeOH}=15: 1+5 \% \mathrm{HOAc}\right)$.

Drehwert: $[\alpha]_{\mathrm{D}}^{20}=-21.6^{\circ}(c=0.45$ in $\mathrm{MeOH})$.

${ }^{1} \mathbf{H}-N M R\left(300 \mathrm{MHz}, \mathrm{DMSO}_{-} \mathrm{d}_{6}, 100{ }^{\circ} \mathrm{C}\right): \delta=1.31\left(\mathrm{~s}, 9 \mathrm{H}, \mathrm{C}\left(\mathrm{CH}_{3}\right)_{3}\right), 1.77-1.98(\mathrm{~m}, 2 \mathrm{H}$, $\left.2 \mathrm{c}-\mathrm{H}_{2}\right), 2.03\left(\mathrm{~s}, 3 \mathrm{H}, \mathrm{SCH}_{3}\right), 2.40-2.46\left(\mathrm{~m}, 2 \mathrm{H}, 3 \mathrm{c}-\mathrm{H}_{2}\right), 2.57(\mathrm{dd}, J=16.2,7.2 \mathrm{~Hz}, 1 \mathrm{H}$, 2b-Ha $), 2.74$ (dd, $\left.J=16.2,6.0 \mathrm{~Hz}, 1 \mathrm{H}, 2 \mathrm{~b}-\mathrm{H}_{\mathrm{b}}\right), 2.85-3.09$ (m, $3 \mathrm{H}, 2 \mathrm{a}-\mathrm{H}_{2}, 2 \mathrm{~d}-\mathrm{H}_{\mathrm{a}}$ ), 3.15 (dd, $\left.J=14.7,4.8 \mathrm{~Hz}, 1 \mathrm{H}, 2 \mathrm{~d}-\mathrm{H}_{\mathrm{b}}\right), 3.58\left(\mathrm{~s}, 3 \mathrm{H}, \mathrm{OCH}_{3}\right), 4.23-4.30\left(\mathrm{~m}_{\mathrm{c}}, 1 \mathrm{H}, 1 \mathrm{~d}-\mathrm{H}\right), 4.31-4.48$ (m, $2 \mathrm{H}, 1 \mathrm{c}-\mathrm{H}, 1 \mathrm{a}-\mathrm{H}), 4.56-4.63\left(\mathrm{~m}_{\mathrm{c}}, 1 \mathrm{H}, 1 \mathrm{~b}-\mathrm{H}\right), 6.87\left(\mathrm{~s}_{\mathrm{br}}, 2 \mathrm{H}, \mathrm{NH}\right), 6.96(\mathrm{t}, J=7.2 \mathrm{~Hz}, 1 \mathrm{H}$, 5d'-H), 7.05 (t, J=7.2 Hz, 1 H, 6d'-H), 7.10-7.34 (m, 7 H, 2d'-H, 7d'-H, $5 \times$ Ph-H), 7.55-7.57 
(d, $J=7.8 \mathrm{~Hz}, 2 \mathrm{H}, \mathrm{NH}, 4 \mathrm{~d} '-\mathrm{H}), 7.72(\mathrm{~d}, J=7.2 \mathrm{~Hz}, 1 \mathrm{H}, \mathrm{NH}), 7.91\left(\mathrm{~s}_{\mathrm{br}}, 1 \mathrm{H}, J=7.8 \mathrm{~Hz}, 1 \mathrm{H}\right.$, $\mathrm{NH}), 10.51$ (s, $1 \mathrm{H}$, Indol-NH).

${ }^{13}$ C-NMR $\left.\left(75 \mathrm{MHz}, \mathrm{DMSO}-\mathrm{d}_{6}, 100{ }^{\circ} \mathrm{C}\right): \delta=14.16\left(\mathrm{SCH}_{3}\right), 27.16(\mathrm{C}-2 \mathrm{~d}), 27.62\left(\mathrm{C}_{\left(\mathrm{CH}_{3}\right.}\right)_{3}\right)$, 29.08 (C-3c), 31.46 (C-2c), 35.37 (C-2b), 37.03 (C-2a), 49.34 (C-1b), $50.79\left(\mathrm{OCH}_{3}\right), 51.71$ (C-1c), 53.52 (C-1a), 55.07 (C-1d), $77.87\left(\underline{\mathrm{C}}\left(\mathrm{CH}_{3}\right)_{3}\right), 109.8\left(\mathrm{C}-3 \mathrm{~d}^{\prime}\right), 110.7\left(\mathrm{C}-7 \mathrm{~d}^{\prime}\right), 117.7$, 117.8 (C-4d', C-5d'), 120.3 (C-6d'), 123.0 (C-2d'), 125.6, 127.1, 127.5, 128.5 (C-3ad', $5 \times \mathrm{Ph}-\mathrm{C}), 135.8\left(\mathrm{C}-7 \mathrm{ad}^{\prime}\right), 137.2\left(\mathrm{Ph}-\mathrm{C}_{i}\right), 154.6(\underline{\mathrm{C}}(\mathrm{O}) \mathrm{O} t \mathrm{Bu}), 169.0,169.9,170.5,171.6,171.8$ $(5 \times \mathrm{C}=\mathrm{O})$.

MS (ESI): $m / z(\%)=733.5(43)[\mathrm{M}+\mathrm{Na}]^{+}, 1443.4(100)[2 \mathrm{M}+\mathrm{Na}]^{+}$.

$\mathrm{C}_{35} \mathbf{H}_{46} \mathbf{N}_{6} \mathbf{O}_{8} \mathbf{S}(710.84)$.

\subsection{N-(tert-Butyloxycarbonyl)-L-tryptophyl-L-methionyl-L-aspartyl-L- phenylalaninamid (109)}

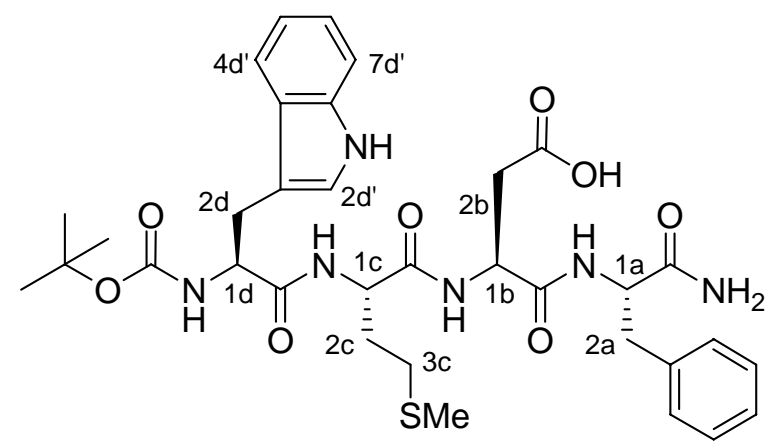

$\mathrm{Zu}$ einer Lösung von 125 (10 mg, 0.014 mmol, 1.0Äq.) wurde bei Raumtemperatur eine Lösung von $\mathrm{LiOH} \cdot \mathrm{H}_{2} \mathrm{O}(1.0 \mathrm{mg}, 0.024 \mathrm{mmol}, 2.0$ Äq.) in Wasser (1 mL) getropft und $5 \mathrm{~min}$ bei Raumtemperatur gerührt. Anschließend wurde mit $0.5 \mathrm{M} \mathrm{HCl}$ auf $\mathrm{pH} 2$ eingestellt und mit EtOAc $(2 \times 30 \mathrm{~mL})$ extrahiert. Die vereinigten organischen Phasen wurden über $\mathrm{Na}_{2} \mathrm{SO}_{4}$ getrocknet und das Lösungsmittel im Vakuum entfernt. Man erhielt 119 als weißen Feststoff (9 mg, $0.013 \mathrm{mmol}, 90 \%$ ).

$\mathbf{R}_{\mathbf{f}}=0.2\left(\mathrm{CH}_{2} \mathrm{Cl}_{2} / \mathrm{MeOH}=10: 1+0.5 \% \mathrm{HOAc}\right)$.

${ }^{13} \mathrm{C}-\mathrm{NMR}\left(75.5 \mathrm{MHz}, \mathrm{DMSO}-\mathrm{d}_{6}, 80^{\circ} \mathrm{C}\right): \delta=14.28\left(\mathrm{SCH}_{3}\right), 27.27(\mathrm{C}-2 \mathrm{~d}), 27.77\left(\mathrm{C}\left(\underline{\mathrm{CH}}_{3}\right)_{3}\right)$, 28.94 (C-3c), 32.14 (C-2c), 36.74 (C-2b), 37.09 (C-2a), 48.70 (C-1b), 51.51 (C-1c), 53.64 (C-1a), 55.11 (C-1d), $77.91\left(\underline{\mathrm{C}}\left(\mathrm{CH}_{3}\right)_{3}\right), 110.0$ (C-3d'), 110.9 (C-7d'), 117.8 (C-5d'), 118.0 (C-4d'), 120.4 (C-6d'), 123.2 (C-2d'), $125.7\left(\mathrm{Ph}_{-} \mathrm{C}_{p}\right), 127.2$ (C-3ad'), 127.6, 128.7 (4 × Ph-C), 
$135.9\left(\mathrm{C}-7 \mathrm{ad}^{\prime}\right), 137.7\left(\mathrm{Ph}_{-} \mathrm{C}_{i}\right), 154.6(\underline{\mathrm{C}}(\mathrm{O}) \mathrm{O} t \mathrm{Bu}), 168.7,170.2,171.3,171.9,172.5$ $(5 \times \mathrm{C}=\mathrm{O})$.

MS (ESI): $m / z(\%)=719.3(100)[\mathrm{M}+\mathrm{Na}]^{+}, 1415.1(24)[2 \mathrm{M}+\mathrm{Na}]^{+}, 695.3(100)[\mathrm{M}-\mathrm{H}]^{-}$.

$\mathbf{C}_{34} \mathbf{H}_{44} \mathbf{N}_{6} \mathbf{O}_{8} \mathbf{S}(696.81)$.

\subsection{N-(tert-Butyloxycarbonyl)-L-tryptophyl-L-methionyl-}

\section{L-aspartyl-( $\beta$-O-allyl)-L-phenylalaninamid (126)}

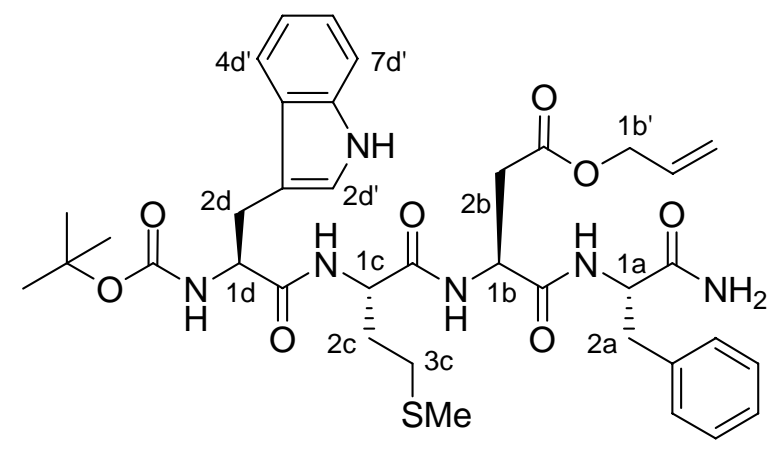

$\mathrm{Zu}$ einer Suspension von Dipeptid 123 (838 mg, $2.0 \mathrm{mmol}, 1.0$ Äq.) in $\mathrm{CH}_{2} \mathrm{Cl}_{2}$ (6 mL) und Wasser $(0.6 \mathrm{~mL})$ gab man tropfenweise TFA $(6 \mathrm{~mL})$ und rührte $2 \mathrm{~h}$ bei Raumtemperatur. Anschließend wurde die TFA unter Zugabe von Toluol durch azeotrope Destillation im Vakuum entfernt und der Rückstand in Wasser (40 mL) gelöst sowie mit DIEA (517 mg, 4.0 mmol, 2.0 Äq.) versetzt (Lösung A).

$\mathrm{Zu}$ einer Lösung des Dipeptids 110 (871 mg, $2.0 \mathrm{mmol}, 1.0$ Äq.) in $\mathrm{CH}_{2} \mathrm{Cl}_{2}(20 \mathrm{~mL})$ bei $0{ }^{\circ} \mathrm{C}$ gab man HOSu (230 mg, $2.0 \mathrm{mmol}, 1.0$ Äq.) und EDC.HCl (383 mg, $2.0 \mathrm{mmol}, 1.0$ Äq.) und rührte bei Raumtemperatur für $2 \mathrm{~h}$. Nach Entfernen des Lösungsmittels wurde der Rückstand mit THF (40 mL) versetzt und die entstandene Lösung zu Lösung A getropft. Das Reaktionsgemisch wurde $2 \mathrm{~h}$ bei Raumtemperatur gerührt und anschließend THF im Vakuum entfernt. Nach Abkühlen auf $0{ }^{\circ} \mathrm{C}$ wurde der entstandene Niederschlag abfiltriert, mit Ether gewaschen und im Vakuum getrocknet. Man erhielt die Titelverbindung als weißen Feststoff (1.26 g, $1.7 \mathrm{mmol}, 85 \%)$.

$\mathbf{R}_{\mathbf{f}}=0.3\left(\mathrm{CH}_{2} \mathrm{Cl}_{2} / \mathrm{MeOH}=15: 1+5 \% \mathrm{HOAc}\right)$.

Drehwert: $[\alpha]_{\mathrm{D}}^{20}=-16.0^{\circ}(c=0.35$ in $\mathrm{MeOH})$.

${ }^{1}$ H-NMR (300 MHz, DMSO-d $\left.{ }_{6}\right): \delta=1.32\left(\mathrm{~s}, 9 \mathrm{H}, \mathrm{C}\left(\mathrm{CH}_{3}\right)_{3}\right), 1.77-1.94$ (m, $\left.2 \mathrm{H}, 2 \mathrm{c}-\mathrm{H}_{2}\right), 2.02$ (s, $\left.3 \mathrm{H}, \mathrm{SCH}_{3}\right), 2.39-2.44\left(\mathrm{~m}, 2 \mathrm{H}, 3 \mathrm{c}-\mathrm{H}_{2}\right), 2.59$ (dd, $\left.J=16.2,7.8 \mathrm{~Hz}, 1 \mathrm{H}, 2 \mathrm{~b}-\mathrm{H}_{\mathrm{a}}\right), 2.76-3.12$ 
(m, $\left.5 \mathrm{H}, 2 \mathrm{~b}-\mathrm{H}_{\mathrm{b}}, 2 \mathrm{a}-\mathrm{H}_{2}, 2 \mathrm{~d}-\mathrm{H}_{2}\right), 4.20-4.26\left(\mathrm{~m}_{\mathrm{c}}, 1 \mathrm{H}, 1 \mathrm{~d}-\mathrm{H}\right), 4.35-4.44(\mathrm{~m}, 2 \mathrm{H}, 1 \mathrm{c}-\mathrm{H}, 1 \mathrm{a}-\mathrm{H})$, 4.51-4.54 (m, 2 H, 1b'- $\left.\mathrm{H}_{2}\right), 4.58-4.65\left(\mathrm{~m}_{\mathrm{c}}, 1 \mathrm{H}, 1 \mathrm{~b}-\mathrm{H}\right), 5.18$ (d, J=10.2 Hz, $\left.1 \mathrm{H}, 3 \mathrm{~b}^{\prime}-\mathrm{H}_{\mathrm{a}}\right)$, $5.28\left(\mathrm{~d}, J=17.8 \mathrm{~Hz}, 1 \mathrm{H}, 3 \mathrm{~b}^{\prime}-\mathrm{H}_{\mathrm{b}}\right), 5.82-5.95\left(\mathrm{~m}, 1 \mathrm{H}, 2 \mathrm{~b}^{\prime}-\mathrm{H}\right), 6.85(\mathrm{~d}, J=7.8 \mathrm{~Hz}, 1 \mathrm{H}$, BocNH), 6.97 (t, $J=7.2 \mathrm{~Hz}, 1 \mathrm{H}, 5 \mathrm{~d}$ '-H), 7.06 (t, $J=7.8 \mathrm{~Hz}, 1 \mathrm{H}, 6 \mathrm{~d} '-\mathrm{H}), 7.14-7.34$ (m, 9 H, 2d'-H, 7d'-H, $\left.5 \times \mathrm{Ph}-\mathrm{H}, \mathrm{NH}_{2}\right), 7.59$ (d, $\left.J=7.2 \mathrm{~Hz}, 1 \mathrm{H}, 4 \mathrm{~d} '-\mathrm{H}\right), 7.86$ (d, $\left.J=7.8 \mathrm{~Hz}, 1 \mathrm{H}, \mathrm{NH}\right)$, 7.99 (d, $J=7.2 \mathrm{~Hz}, 1 \mathrm{H}, \mathrm{NH}), 8.24$ (d, $J=7.5 \mathrm{~Hz}, 1 \mathrm{H}, \mathrm{NH}), 10.76$ (s, $1 \mathrm{H}$, Indol-NH).

${ }^{13}$ C-NMR (75 MHz, DMSO-d $\left.{ }_{6}\right): \delta=14.57\left(\mathrm{SCH}_{3}\right), 27.29(\mathrm{C}-2 \mathrm{~d}), 28.05\left(\mathrm{C}\left(\mathrm{CH}_{3}\right)_{3}\right), 29.26$ (C-3c), 31.99 (C-2c), 35.75 (C-2b), 37.35 (C-2a), 49.44 (C-1b), 51.80 (C-1c), 53.87 (C-1a), 55.21 (C-1d), 64.63 (C-1b'), $78.10\left(\underline{\mathrm{C}}\left(\mathrm{CH}_{3}\right)_{3}\right), 110.2$ (C-3d'), $111.2\left(\mathrm{C}-7 \mathrm{~d}^{\prime}\right), 117.7,117.8$ (C-4d', C-5d'), 118.4 (C-3b'), 120.7 (C-6d'), 123.6 (C-2d'), 126.2, 127.3, 128.0, 129.1 (C-3ad', $5 \times \mathrm{Ph}-\mathrm{C}), 132.4$ (C-2b'), 136.0 (C-7ad'), $137.6\left(\mathrm{Ph}_{-} \mathrm{C}_{i}\right), 155.3(\underline{\mathrm{C}}(\mathrm{O}) \mathrm{O} t \mathrm{Bu}), 169.6,169.8$, 171.0, 172.1, $172.4(5 \times \mathrm{C}=\mathrm{O})$.

MS (ESI): $m / z(\%)=759.3(100)[\mathrm{M}+\mathrm{Na}]^{+}, 1495.1(68)[2 \mathrm{M}+\mathrm{Na}]^{+}$.

$\mathrm{C}_{37} \mathrm{H}_{48} \mathbf{N}_{6} \mathbf{O}_{8} \mathrm{~S}(736.88)$.

\subsection{L-Tryptophyl-L-methionyl-L-aspartyl-L-phenylalaninamid- trifluoracetat (131)}

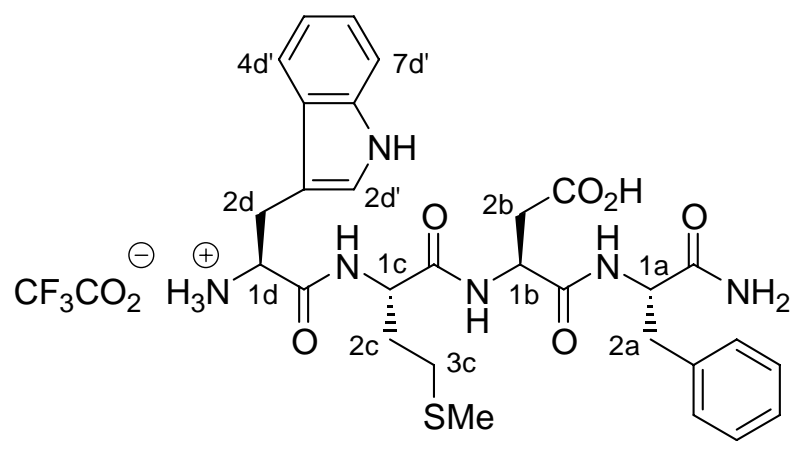

Zu einer Lösung des Dipeptids 110 (218 mg, 0.5 mmol, 1.0 Äq.) in DMF (4 mL) gab man HOBt (68 mg, $0.5 \mathrm{mmol}, 1.0$ Äq.) und $\mathrm{EDC} \cdot \mathrm{HCl}(96 \mathrm{mg}, 0.5 \mathrm{mmol}, 1.0$ Äq.) und rührte bei Raumtemperatur für $30 \mathrm{~min}$. Anschließend tropfte man eine Lösung von 130 (200 mg, 0.5 mmol, 1.0 Äq.) und DIEA (195 mg, 1.5 mmol, 1.0 Äq.) in DMF (4 mL) zu und rührte bei Raumtemperatur für $3 \mathrm{~h}$. Das Reaktionsgemisch wurde mit $0.5 \mathrm{M} \mathrm{HCl}$ auf $\mathrm{pH} 2$ eingestellt und mit EtOAc $(2 \times 50 \mathrm{~mL})$ extrahiert. Die vereinigten organischen Phasen wurden über $\mathrm{Na}_{2} \mathrm{SO}_{4}$ getrocknet und das Lösungsmittel im Vakuum entfernt. Nach Säulenchromatographie 
$\left(\mathrm{CH}_{2} \mathrm{Cl}_{2} / \mathrm{MeOH}=20: 1 \rightarrow 10: 1+0.1 \%\right.$ HOAc$)$ erhielt man das geschützte Tetrapeptid 109 (280 mg, $0.4 \mathrm{mmol}$ ). Eine Suspension des erhaltenen Tetrapeptids 109 (280 mg, $0.4 \mathrm{mmol}$ ) in $\mathrm{CH}_{2} \mathrm{Cl}_{2}(2 \mathrm{~mL})$ versetzte man mit Wasser $(0.4 \mathrm{~mL})$ und TFA $(2 \mathrm{~mL})$ und rührte $2 \mathrm{~h}$ bei Raumtemperatur. Anschließend wurde die TFA unter Zugabe von Toluol durch azeotrope Destillation im Vakuum entfernt und der Rückstand im Vakuum getrocknet. Nach präparativer HPLC erhielt man das TFA-Salz des Tetrapeptids 131 als weißes Pulver (120 $\mathrm{mg}, 0.17 \mathrm{mmol}, 34 \%$ über zwei Stufen).

${ }^{1}$ H-NMR (600 MHz, DMSO-d $\left.{ }_{6}, 80{ }^{\circ} \mathrm{C}\right): \delta=1.81-1.87\left(\mathrm{~m}, 1 \mathrm{H}, 2 \mathrm{c}-\mathrm{H}_{\mathrm{a}}\right), 1.94-2.00(\mathrm{~m}, 1 \mathrm{H}$, $\left.2 \mathrm{c}-\mathrm{H}_{\mathrm{b}}\right), 2.05\left(\mathrm{~s}, 3 \mathrm{H}, \mathrm{SCH}_{3}\right), 2.42-2.52\left(\mathrm{~m}, 2 \mathrm{H}, 3 \mathrm{c}-\mathrm{H}_{2}\right), 2.55(\mathrm{dd}, J=16.2,6.6 \mathrm{~Hz}, 1 \mathrm{H}$, 2b- $\left.\mathrm{H}_{\mathrm{a}}\right), 2.71\left(\mathrm{dd}, J=16.2,6.6 \mathrm{~Hz}, 1 \mathrm{H}, 2 \mathrm{~b}-\mathrm{H}_{\mathrm{b}}\right), 2.89$ (dd, $\left.J=13.8,7.8 \mathrm{~Hz}, 1 \mathrm{H}, 2 \mathrm{a}-\mathrm{H}_{\mathrm{a}}\right), 3.06$ $\left(\mathrm{dd}, J=13.8,5.4 \mathrm{~Hz}, 1 \mathrm{H}, 2 \mathrm{a}-\mathrm{H}_{\mathrm{b}}\right), 3.12\left(\mathrm{dd}, J=15.0,8.4 \mathrm{~Hz}, 1 \mathrm{H}, 2 \mathrm{~d}-\mathrm{H}_{\mathrm{a}}\right), 3.29(\mathrm{dd}, J=15.0$, $\left.5.4 \mathrm{~Hz}, 1 \mathrm{H}, 2 \mathrm{~d}-\mathrm{H}_{\mathrm{b}}\right), 4.11-4.14\left(\mathrm{~m}_{\mathrm{c}}, 1 \mathrm{H}, 1 \mathrm{~d}-\mathrm{H}\right), 4.44-4.47$ (m, $\left.2 \mathrm{H}, 1 \mathrm{c}-\mathrm{H}, 1 \mathrm{a}-\mathrm{H}\right), 4.57-4.60$ $\left(\mathrm{m}_{\mathrm{c}}, 1 \mathrm{H}, 1 \mathrm{~b}-\mathrm{H}\right), 7.01\left(\mathrm{~s}_{\mathrm{br}}, 2 \mathrm{H}, \mathrm{NH}_{2}\right), 7.02$ (t, $\left.J=7.2 \mathrm{~Hz}, 1 \mathrm{H}, 5 \mathrm{~d}^{\prime}-\mathrm{H}\right), 7.10$ (t, $J=7.2 \mathrm{~Hz}$, $1 \mathrm{H}, 6 \mathrm{~d}-\mathrm{H}), 7.17-7.27$ (m, 6 H, 2d'-H, $5 \times \mathrm{Ph}-\mathrm{H}), 7.38$ (d, J=7.2 Hz, 1 H, 7d'-H), 7.68 (d, $\left.J=7.8 \mathrm{~Hz}, 2 \mathrm{H}, 4 \mathrm{~d}^{\prime}-\mathrm{H}, \mathrm{NH}\right), 8.02\left(\mathrm{~s}, 1 \mathrm{H}, \mathrm{NH}^{+}\right), 8.12(\mathrm{~d}, J=7.2 \mathrm{~Hz}, 1 \mathrm{H}, \mathrm{NH}), 8.58$ (d, $J=7.8 \mathrm{~Hz}, 1 \mathrm{H}, \mathrm{NH}), 10.80$ (s, $1 \mathrm{H}$, Indol-NH).

${ }^{13} \mathrm{C}-\mathrm{NMR}\left(150 \mathrm{MHz}, \mathrm{DMSO}-\mathrm{d}_{6}, 80{ }^{\circ} \mathrm{C}\right): \delta=14.28\left(\mathrm{SCH}_{3}\right), 26.96(\mathrm{C}-2 \mathrm{~d}), 29.20(\mathrm{C}-3 \mathrm{c}), 31.87$ (C-2c), 35.71 (C-2b), 37.18 (C-2a), 49.52 (C-1b), 51.97 (C-1c), 52.54 (C-1d), 53.62 (C-1a), 106.7 (C-3d'), 111.1 (C-7d'), 118.1 (C-4d'), 118.1 (C-5d'), 120.8 (C-6d'), 124.6 (C-2d'), 125.8 $\left(\mathrm{Ph}-\mathrm{C}_{p}\right), 126.9\left(\mathrm{C}-3 \mathrm{ad}^{\prime}\right), 127.7,128.7$ (4 × Ph-C), $136.2\left(\mathrm{C}-7 \mathrm{ad}^{\prime}\right), 137.4\left(\mathrm{Ph}_{-} \mathrm{C}_{i}\right), 168.1,169.6$, $170.1,171.3,172.1(5 \times \mathrm{C}=\mathrm{O})$.

$\mathbf{C}_{31} \mathbf{H}_{37} \mathbf{F}_{3} \mathbf{N}_{6} \mathbf{O}_{8} \mathbf{S}(710.72)$. $\quad$ Ber.: 597.24898 für $\left[\mathrm{M}-\mathrm{CF}_{3} \mathrm{COO}\right]^{+}$

Gef.: 597.24893 (ESI-HRMS).

HPLC (präparative Säule, Kromasil $100 \mathrm{C} 18$; Eluent A: $\mathrm{H}_{2} \mathrm{O}, 0.1 \%$ TFA; Eluent B: $\mathrm{CH}_{3} \mathrm{CN}$; Gradient: $20 \%$ in $5 \mathrm{~min}$, auf $60 \%$ in $20 \mathrm{~min}$; Flow: $10 \mathrm{~mL} / \mathrm{min}$ ): $\mathrm{R}_{\mathrm{t}}: 19 \mathrm{~min}$. 


\subsection{L-tryptophyl-L-methionyl-L-aspartyl-( $\beta$-O-benzyl)-L- phenylalaninamid-trifluoracetat (128)}

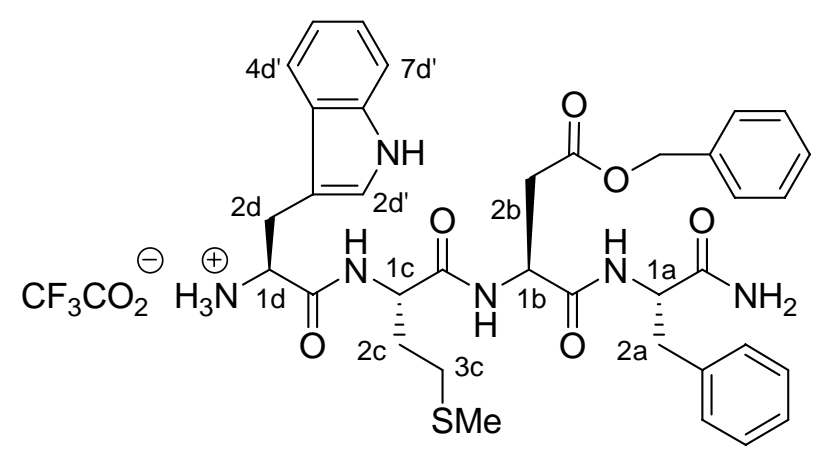

$\mathrm{Zu}$ einer Lösung von Dipeptid 124 (118 mg, 0.25 mmol, 1.2 Äq.) in $\mathrm{CH}_{2} \mathrm{Cl}_{2}$ (1 mL) und Wasser $(0.05 \mathrm{~mL})$ gab man tropfenweise TFA $(1 \mathrm{~mL})$ und rührte $2 \mathrm{~h}$ bei Raumtemperatur. Anschließend wurde die TFA unter Zugabe von Toluol durch azeotrope Destillation im Vakuum entfernt und der Rückstand mit $\mathrm{CH}_{2} \mathrm{Cl}_{2}(2 \mathrm{~mL})$ sowie DIEA (78 mg, $0.6 \mathrm{mmol}$, 3.0 Äq.) versetzt (Lösung A).

$\mathrm{Zu}$ einer Lösung des Dipeptids 110 (88 mg, $0.2 \mathrm{mmol}, 1.0$ Äq.) in $\mathrm{CH}_{2} \mathrm{Cl}_{2}(2 \mathrm{~mL})$ gab man HOBt (34 mg, $0.25 \mathrm{mmol}, 1.2$ Äq.) und EDC·HCl (48 mg, $0.25 \mathrm{mmol}, 1.2$ Äq.) und rührte bei Raumtemperatur für $30 \mathrm{~min}$. Anschließend tropfte man Lösung $\mathrm{A}$ zu und rührte bei Raumtemperatur für $12 \mathrm{~h}$. Das Reaktionsgemisch wurde mit $0.5 \mathrm{M} \mathrm{HCl}$ auf $\mathrm{pH} 2$ eingestellt und mit EtOAc $(2 \times 50 \mathrm{~mL})$ extrahiert. Die vereinigten organischen Phasen wurden mit ges. $\mathrm{NaHCO}_{3}$-Lösung $(30 \mathrm{~mL})$ gewaschen, über $\mathrm{Na}_{2} \mathrm{SO}_{4}$ getrocknet und das Lösungsmittel im Vakuum entfernt. Der Rückstand wurde in $\mathrm{CH}_{2} \mathrm{Cl}_{2}(2 \mathrm{~mL})$ gelöst, mit Wasser $(0.2 \mathrm{~mL})$ und TFA ( $2 \mathrm{~mL})$ versetzt und $2 \mathrm{~h}$ bei Raumtemperatur gerührt. Anschließend wurde die TFA unter Zugabe von Toluol durch azeotrope Destillation im Vakuum entfernt und der Rückstand im Vakuum getrocknet. Nach präparativer HPLC erhielt man das TFA-Salz des Tetrapeptids 128 als weißes Pulver (70 mg, $0.087 \mathrm{mmol}, 44 \%$ über zwei Stufen).

${ }^{1} \mathbf{H}-\mathbf{N M R}\left(600 \mathrm{MHz}, \mathrm{DMSO}-\mathrm{d}_{6}, 100{ }^{\circ} \mathrm{C}\right): \delta=1.83-1.89\left(\mathrm{~m}, 1 \mathrm{H}, 2 \mathrm{c}-\mathrm{H}_{\mathrm{a}}\right), 1.97-2.02(\mathrm{~m}, 1 \mathrm{H}$, $\left.2 \mathrm{c}-\mathrm{H}_{\mathrm{b}}\right), 2.05\left(\mathrm{~s}, 3 \mathrm{H}, \mathrm{SCH}_{3}\right), 2.44-2.54\left(\mathrm{~m}, 2 \mathrm{H}, 3 \mathrm{c}-\mathrm{H}_{2}\right), 2.67(\mathrm{dd}, J=16.2,7.2 \mathrm{~Hz}, 1 \mathrm{H}$, 2b-Ha $), 2.84\left(\mathrm{dd}, J=16.2,6.6 \mathrm{~Hz}, 1 \mathrm{H}, 2 \mathrm{~b}-\mathrm{H}_{\mathrm{b}}\right), 2.90$ (dd, $\left.J=13.8,7.2 \mathrm{~Hz}, 1 \mathrm{H}, 2 \mathrm{a}-\mathrm{H}_{\mathrm{a}}\right), 3.06$ $\left(\mathrm{dd}, J=13.8,5.4 \mathrm{~Hz}, 1 \mathrm{H}, 2 \mathrm{a}-\mathrm{H}_{\mathrm{b}}\right), 3.12\left(\mathrm{dd}, J=15.0,7.8 \mathrm{~Hz}, 1 \mathrm{H}, 2 \mathrm{~d}-\mathrm{H}_{\mathrm{a}}\right), 3.30$ (dd, $J=14.4$, $\left.5.1 \mathrm{~Hz}, 1 \mathrm{H}, 2 \mathrm{~d}-\mathrm{H}_{\mathrm{b}}\right), 4.13-4.15\left(\mathrm{~m}_{\mathrm{c}}, 1 \mathrm{H}, 1 \mathrm{~d}-\mathrm{H}\right), 4.45-4.50(\mathrm{~m}, 2 \mathrm{H}, 1 \mathrm{c}-\mathrm{H}, 1 \mathrm{a}-\mathrm{H}), 4.66-4.69$ $\left(\mathrm{m}_{\mathrm{c}}, 1 \mathrm{H}, 1 \mathrm{~b}-\mathrm{H}\right), 5.09\left(\mathrm{~s}, 2 \mathrm{H}, \mathrm{OCH}_{2}\right), 6.91(\mathrm{~s} b \mathrm{r}, 2 \mathrm{H}, \mathrm{NH}), 7.01(\mathrm{t}, J=7.2 \mathrm{~Hz}, 1 \mathrm{H}, 5 \mathrm{~d}-\mathrm{H})$, 
$7.09\left(\mathrm{t}, J=7.2 \mathrm{~Hz}, 1 \mathrm{H}, 6 \mathrm{~d}^{\prime}-\mathrm{H}\right), 7.16-7.38\left(\mathrm{~m}, 12 \mathrm{H}, 2 \mathrm{~d}^{\prime}-\mathrm{H}, 7 \mathrm{~d}^{\prime}-\mathrm{H}, 10 \times \mathrm{Ph}-\mathrm{H}\right), 7.63$ $(J=7.8 \mathrm{~Hz}, 1 \mathrm{H}, \mathrm{NH}), 7.67$ (d, $J=7.8 \mathrm{~Hz}, 1 \mathrm{H}, 4 \mathrm{~d}-\mathrm{H}), 8.07$ (d, $J=7.2 \mathrm{~Hz}, 1 \mathrm{H}, \mathrm{NH}), 8.50$ ( $\left.\mathrm{s}_{\mathrm{br}}, 1 \mathrm{H}, \mathrm{NH}\right), 10.75$ (s, $1 \mathrm{H}$, Indol-NH).

${ }^{13} \mathrm{C}-\mathrm{NMR}\left(150 \mathrm{MHz}, \mathrm{DMSO}-\mathrm{d}_{6}, 100{ }^{\circ} \mathrm{C}\right): \delta=14.15\left(\mathrm{SCH}_{3}\right), 26.88(\mathrm{C}-2 \mathrm{~d}), 29.13(\mathrm{C}-3 \mathrm{c})$, 31.64 (C-2c), 35.61 (C-2b), 37.17 (C-2a), 49.38 (C-1b), 51.98 (C-1c), 52.52 (C-1d), 53.51 (C-1a), $65.33\left(\mathrm{OCCH}_{2}\right), 106.7$ (C-3d'), 111.0 (C-7d'), 117.9 (C-4d'), 118.0 (C-5d'), 120.7 (C-6d'), 124.4 (C-2d'), $125.7\left(\mathrm{Ph}_{-} \mathrm{C}_{p}\right), 126.8$ (C-3ad'), 127.3, 127.5, 127.8, 128.6 (8 × Ph-C), $127.4\left(\mathrm{Ph}-\mathrm{C}_{p}\right), 135.5\left(\mathrm{Ph}-\mathrm{C}_{i}\right), 136.1\left(\mathrm{C}-7 \mathrm{ad}^{\prime}\right), 137.2\left(\mathrm{Ph}-\mathrm{C}_{i}\right), 168.1,169.0,169.5,170.0,171.8$ $(5 \times \mathrm{C}=\mathrm{O})$.

$\mathrm{C}_{38} \mathrm{H}_{43} \mathrm{~F}_{3} \mathbf{N}_{6} \mathrm{O}_{8} \mathrm{~S}$ (800.84).

Ber.: $\quad 687.29593$ für $\left[\mathrm{M}-\mathrm{CF}_{3} \mathrm{COO}\right]^{+}$

Gef.: 687.29597 (ESI-HRMS)

HPLC (präparative Säule, Kromasil $100 \mathrm{C} 18$; Eluent A: $\mathrm{H}_{2} \mathrm{O}, 0.1 \%$ TFA; Eluent B: $\mathrm{CH}_{3} \mathrm{CN}$; 55\% A, 45\% B ; Flow: $12 \mathrm{~mL} / \mathrm{min}$ ): $\mathrm{R}_{\mathrm{t}}: 14 \mathrm{~min}$. 


\section{$7 \quad$ Synthese der anti-Methyl-seco-CBI-DNA-Binder-}

\section{Tetragastrin-Derivate}

\section{1 (1S, 10R/1R, 10S)-3-[(2-\{2-[5-Benzyloxy-1-(10-chlor-ethyl)-1,2- \\ dihydro-benzo[e]indol-3-carbonyl]-indol-5-yloxy\}-ethyl)- \\ methylamino]-propionsäure-[L-tryptophyl-L-methionyl-L- \\ aspartyl-( $\beta$-O-methyl)-L-phenylalaninamidyl]-amid (133)}

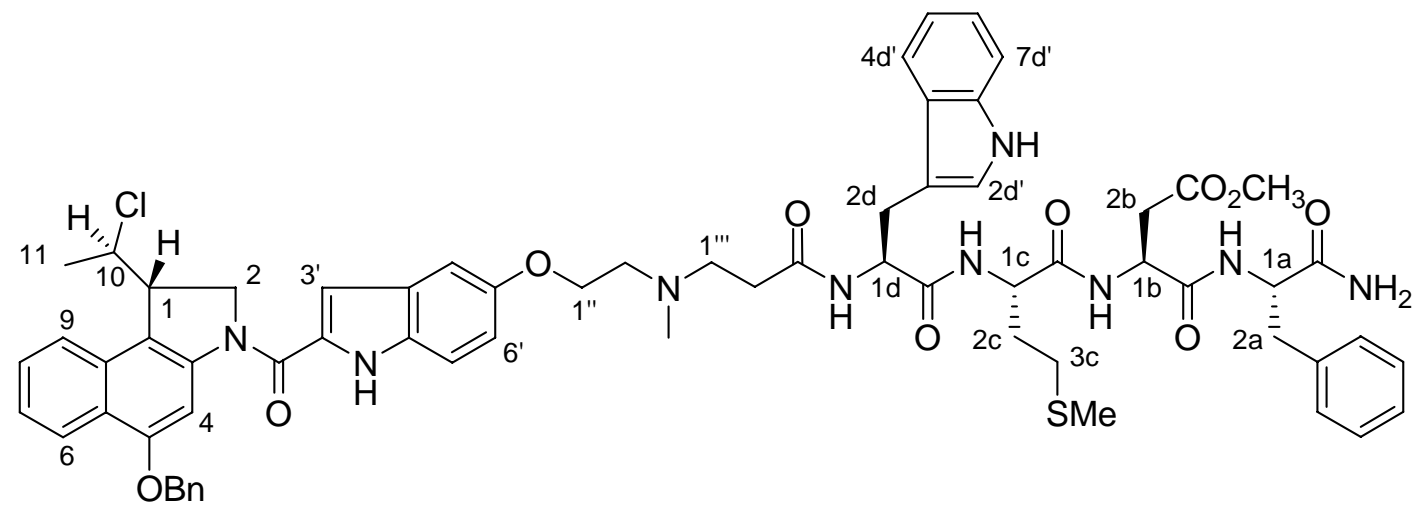

Zu einer Lösung von 88 (25 mg, 0.04 mmol, 1.0 Äq.) in DMF (1.5 mL) gab man HOBt (8 mg, $0.06 \mathrm{mmol}, 1.5 \mathrm{Äq}$.) und $\mathrm{EDC} \cdot \mathrm{HCl}(12 \mathrm{mg}, 0.06 \mathrm{mmol}, 1.5 \mathrm{Äq}$.) und rührte bei Raumtemperatur für 15 min (Lösung A).

$\mathrm{Zu}$ einer Lösung von 132 (29 mg, $0.04 \mathrm{mmol}, 1.0$ Äq.) und DIEA (16 mg, $0.12 \mathrm{mmol}, 3.0$ Äq.) in DMF ( $1 \mathrm{~mL})$ tropfte man Lösung A und rührte bei Raumtemperatur für $12 \mathrm{~h}$. Das Reaktionsgemisch wurde mit Wasser $(30 \mathrm{~mL})$ versetzt und mit EtOAc $(2 \times 50 \mathrm{~mL})$ extrahiert. Die vereinigten organischen Phasen wurden über $\mathrm{Na}_{2} \mathrm{SO}_{4}$ getrocknet und das Lösungsmittel im Vakuum entfernt. Nach Säulenchromatographie $\left(\mathrm{CH}_{2} \mathrm{Cl}_{2} / \mathrm{MeOH}=20: 1 \rightarrow 10: 1\right)$ erhielt man das Molekül 133 als blass-gelben Feststoff ( 24 mg, 0.02 mmol, $49 \%$ ).

${ }^{1}$ H-NMR $\left(600 \mathrm{MHz}\right.$, DMSO-d $\left.\mathrm{d}_{6}\right): \delta=1.65\left(\mathrm{~d}, J=6.0 \mathrm{~Hz}, 3 \mathrm{H}, 11-\mathrm{CH}_{3}\right), 1.77-1.83\left(\mathrm{~m}_{\mathrm{c}}, 1 \mathrm{H}\right.$, 2c- $\left.\mathrm{H}_{\mathrm{a}}\right), 1.88-2.04\left(\mathrm{~m}_{\mathrm{c}}, 1 \mathrm{H}, 2 \mathrm{c}-\mathrm{H}_{\mathrm{b}}\right), 2.01\left(\mathrm{~s}, 3 \mathrm{H}, \mathrm{SCH}_{3}\right), 2.21\left(\mathrm{~s}, 3 \mathrm{H}, \mathrm{NCH}_{3}\right), 2.28(\mathrm{t}, J=7.5$ $\mathrm{Hz}, 2 \mathrm{H}, 2$ "' $-\mathrm{H}_{2}$ ), 2.34-2.44 (m, $2 \mathrm{H}, 3 \mathrm{c}-\mathrm{H}_{2}$ ), 2.56-2.60 (m, $3 \mathrm{H}, 1$ '"'- $\mathrm{H}_{2}, 2 \mathrm{~b}-\mathrm{H}_{\mathrm{a}}$ ), 2.71-2.77 (m, $3 \mathrm{H}, 2$ ' '- $\left.\mathrm{H}_{2}, 2 \mathrm{~b}-\mathrm{H}_{\mathrm{b}}\right), 2.84-2.88$ (m, $\left.1 \mathrm{H}, 2 \mathrm{a}-\mathrm{H}_{\mathrm{a}}\right), 2.97-3.05$ (m, $2 \mathrm{H}, 2 \mathrm{a}-\mathrm{H}_{\mathrm{b}}, 2 \mathrm{~d}-\mathrm{H}_{\mathrm{a}}$ ), 3.153.17 (m, $\left.1 \mathrm{H}, 2 \mathrm{~d}-\mathrm{H}_{\mathrm{b}}\right), 3.57$ (s, $\left.3 \mathrm{H}, \mathrm{OCH}_{3}\right), 4.01\left(\mathrm{~s}_{\mathrm{br}}, 2 \mathrm{H}, 1\right.$ '”- $\left.\mathrm{H}_{2}\right), 4.22-4.25(\mathrm{~m}, 1 \mathrm{H}, 1-\mathrm{H})$, 4.32-4.35 ( $\left.\mathrm{m}_{\mathrm{c}}, 1 \mathrm{H}, 1 \mathrm{c}-\mathrm{H}\right), 4.39-4.42\left(\mathrm{~m}_{\mathrm{c}}, 1 \mathrm{H}, 1 \mathrm{a}-\mathrm{H}\right), 4.59-4.64\left(\mathrm{~m}, 3 \mathrm{H}, 1 \mathrm{~b}-\mathrm{H}, 1 \mathrm{~d}-\mathrm{H}, 2-\mathrm{H}_{\mathrm{a}}\right)$, 4.73-4.76 (m, $\left.1 \mathrm{H}, 2-\mathrm{H}_{\mathrm{b}}\right), 4.79-4.82\left(\mathrm{~m}_{\mathrm{c}}, 1 \mathrm{H}, 10-\mathrm{H}\right), 5.30-5.33\left(\mathrm{~m}_{\mathrm{c}}, 2 \mathrm{H}, \mathrm{C}_{2} \mathrm{Ph}\right), 6.92(\mathrm{~d}$, 
$J=8.4 \mathrm{~Hz}, 1 \mathrm{H}, 6$ '-H), 6.97 (t, $\left.J=7.2 \mathrm{~Hz}, 1 \mathrm{H}, 5 \mathrm{~d}^{\prime}-\mathrm{H}\right), 7.06$ (t, $\left.J=7.2 \mathrm{~Hz}, 1 \mathrm{H}, 6 \mathrm{~d}-\mathrm{H}\right), 7.10$ 7.45 (m, 18 H, 3'-H, 4'-H, 7'-H, 7-H, $10 \times$ Ph-H, NH $\left.2,2 d^{\prime}-H, 7 d^{\prime}-H\right)$, 7.57-7.59 (m, 2 H, 8-H, 4d'-H), 7.84 (d, $J=7.8 \mathrm{~Hz}, 1 \mathrm{H}, \mathrm{NH}), 7.97$ (d, $J=8.4 \mathrm{~Hz}, 1 \mathrm{H}, 9-\mathrm{H}), 8.07$ (d, $J=7.2 \mathrm{~Hz}, 1 \mathrm{H}$, NH), 8.14-8.15 (m, 2 H, 4-H, NH), 8.24 (d, $J=8.4$ Hz, 1 H, 6-H), 8.27 (d, J=7.2 Hz, 1 H, $\mathrm{NH}), 10.78$ (s, $1 \mathrm{H}$, Indol-NH $\mathrm{Trp}), 11.61$ (s, $1 \mathrm{H}$, Indol-NH).

${ }^{13}$ C-NMR (125 MHz, DMSO-d $\left.{ }_{6}\right): \delta=14.54\left(\mathrm{SCH}_{3}\right), 23.32$ (C-11), 27.20 (C-2d), 29.37 (C-3c), 31.47 (C-2c), 33.04 (C-2','), 35.63 (C-2b), 37.29 (C-2a), $41.78\left(\mathrm{NCH}_{3}\right), 45.90$ (C-1), 49.51 (C-1b), $51.39\left(\mathrm{OCH}_{3}\right), 51.98,51.98$ (C-1c, C-2), 53.31, 53.43 (C-1d, C-1','), 53.89 (C-1a), 55.30 (C-2'’), 61.31 (C-10), 66.05 (C-1'’), 69.64 ( $\left.\underline{\mathrm{CH}}_{2} \mathrm{Ph}\right), 98.41$ (C-4), 103.3 (C-4'), 105.4 (C-3'), 110.0 (C-3d'), 111.2 (C-7d'), 113.1 (C-7'), 115.9 (C-6'), 117.6 (C-9b), 118.1, 118.3 (C-4d', C-5d'), 120.7 (C-6d'), 122.6 (C-6), 123.1 (C-9), 123.5 (C-7), 123.7 (C-2d'), $126.1,127.3,127.4,127.5,127.8,127.9,128.1,128.4,128.8,129.0,129,6,130.8,131.7$ (Ph-C ${ }_{p}$, Ph-C ${ }_{p}$ Phe, C-3ad', C-5a, C-8, C-9a, C-2', C-3'a, C-7'a, $8 \times$ Ph-C), 136.0, 136.8, 137.6 (C-7ad', Ph-C $i$, Ph-C ${ }_{i \text { Phe }}$ ), 142.1 (C-3a), 152.9, 154.2 (C-5, C-5'), 160.1 (CON), 169.6, 170.5, $171.0,171.5,171.9,172.3(6 \times \mathrm{C}=\mathrm{O})$.

$\mathrm{C}_{66} \mathrm{H}_{72} \mathrm{CIN}_{9} \mathrm{O}_{10} \mathrm{~S}(1217.48)$.

Ber.: 1218.48841 für $[\mathrm{M}+\mathrm{H}]^{+}$

Gef.: 1218.48931 (ESI-HRMS)

HPLC (analytische Säule, Kromasil $100 \mathrm{C} 18$; Eluent A: $\mathrm{H}_{2} \mathrm{O}, 0.1 \%$ TFA; Eluent B: $\mathrm{CH}_{3} \mathrm{CN}$; Gradient: $30 \%$ in $5 \mathrm{~min}$, auf $90 \%$ in $25 \mathrm{~min}$; Flow: $0.8 \mathrm{~mL} / \mathrm{min}$ ): $\mathrm{R}_{\mathrm{t}}: 28 \mathrm{~min}$. 


\section{$7.2 \quad(1 S, 10 R / 1 R, 10 S)-3-[(2-\{2-[5-B e n z y l o x y-1-(10-c h l o r-e t h y l)-1,2-$}

dihydro-benzo[e]indol-3-carbonyl]-indol-5-yloxy\}-ethyl)methylamino]-propionsäure-[L-tryptophyl-L-methionyl-Laspartyl-( $\beta$-O-benzyl)-L-phenylalaninamidyl]-amid (134)<smiles>[3H]CN(C)[CH]CCC(=O)N[C@@H](Cc1c[nH]c2c1C=C[CH+]2)C(=O)N[C@@H](CCSC)C(=O)N[C@@H](CC(=O)OCc1ccccc1)C(=O)N[C@@H](Cc1ccccc1)C(N)=O</smiles>

Zu einer Lösung von 88 (25 mg, 0.04 mmol, 1.0 Äq.) in DMF (1 mL) gab man HOBt (8 mg, $0.06 \mathrm{mmol}, 1.5$ Äq.) und EDC. $\mathrm{HCl}(12 \mathrm{mg}, 0.06 \mathrm{mmol}, 1.5 \mathrm{Äq}$.) und rührte bei Raumtemperatur für 30 min (Lösung A).

Zu einer Lösung von 128 (32 mg, 0.04 mmol, 1.0 Äq.) und DIEA (16 mg, 0.12 mmol, 3.0 Äq.) in DMF ( $1 \mathrm{~mL})$ tropfte man Lösung A und rührte bei Raumtemperatur für $12 \mathrm{~h}$. Das Reaktionsgemisch wurde mit Wasser $(30 \mathrm{~mL})$ versetzt und mit EtOAc $(2 \times 50 \mathrm{~mL})$ extrahiert. Die vereinigten organischen Phasen wurden über $\mathrm{Na}_{2} \mathrm{SO}_{4}$ getrocknet und das Lösungsmittel im Vakuum entfernt. Nach Säulenchromatographie $\left(\mathrm{CH}_{2} \mathrm{Cl}_{2} / \mathrm{MeOH}=20: 1 \rightarrow 10: 1\right)$ erhielt man 132 als blass-gelben Feststoff (37 mg, 0.029 mmol, $71 \%$ ).

${ }^{1}$ H-NMR (600 MHz, DMSO-d $\left.)_{6}\right): \delta=1.65\left(\mathrm{~d}, J=6.0 \mathrm{~Hz}, 3 \mathrm{H}, 11-\mathrm{CH}_{3}\right), 1.76-1.85\left(\mathrm{~m}_{\mathrm{c}}, 1 \mathrm{H}\right.$, $\left.2 \mathrm{c}-\mathrm{H}_{\mathrm{a}}\right), 1.85-1.95\left(\mathrm{~m}_{\mathrm{c}}, 1 \mathrm{H}, 2 \mathrm{c}-\mathrm{H}_{\mathrm{b}}\right), 2.00\left(\mathrm{~s}, 3 \mathrm{H}, \mathrm{SCH}_{3}\right), 2.20\left(\mathrm{~s}, 3 \mathrm{H}, \mathrm{NCH}_{3}\right), 2.28(\mathrm{t}, J=7.2$

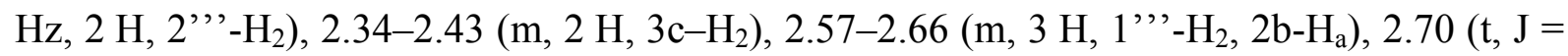
$7.2 \mathrm{~Hz}, 2 \mathrm{H}, 2$ '’- $\left.\mathrm{H}_{2}\right), 2.77-2.89\left(\mathrm{~m}, 2 \mathrm{H}, 2 \mathrm{~b}-\mathrm{H}_{\mathrm{b}}, 2 \mathrm{a}-\mathrm{H}_{\mathrm{a}}\right), 2.98-3.05\left(\mathrm{~m}, 2 \mathrm{H}, 2 \mathrm{a}-\mathrm{H}_{\mathrm{b}}, 2 \mathrm{~d}-\mathrm{H}_{\mathrm{a}}\right)$, 3.12-3.19 (m, $\left.1 \mathrm{H}, 2 \mathrm{~d}-\mathrm{H}_{\mathrm{b}}\right), 4.00\left(\mathrm{t}, J=6.0 \mathrm{H}, 1\right.$ '’- $\left.\mathrm{H}_{2}\right), 4.23$ (d, $\left.J=9.0 \mathrm{H}, 1 \mathrm{H}, 1-\mathrm{H}\right), 4.33-4.37$ $\left(\mathrm{m}_{\mathrm{c}}, 1 \mathrm{H}, 1 \mathrm{c}-\mathrm{H}\right), 4.40-4.44\left(\mathrm{~m}_{\mathrm{c}}, 1 \mathrm{H}, 1 \mathrm{a}-\mathrm{H}\right), 4.57-4.61\left(\mathrm{~m}_{\mathrm{c}}, 1 \mathrm{H}, 1 \mathrm{~d}-\mathrm{H}\right), 4.63-4.70(\mathrm{~m}, 2 \mathrm{H}$, 1b-H, 2-H $\left.\mathrm{a}_{\mathrm{a}}\right), 4.73-4.76\left(\mathrm{~m}, 1 \mathrm{H}, 2-\mathrm{H}_{\mathrm{b}}\right), 4.80-4.81\left(\mathrm{~m}_{\mathrm{c}}, 1 \mathrm{H}, 10-\mathrm{H}\right), 5.05-5.10\left(\mathrm{~m}_{\mathrm{c}}, 2 \mathrm{H}\right.$, $\mathrm{CO}_{2} \underline{\mathrm{H}}_{2} \mathrm{Ph}$ ), 5.29-5.34 (m $\left.\mathrm{m}_{\mathrm{c}}, 2 \mathrm{H}, \mathrm{OC}_{2} \mathrm{Ph}\right), 6.92$ (dd, J=9.0, $2.4 \mathrm{~Hz}, 1 \mathrm{H}, 6$ ' $\left.-\mathrm{H}\right), 6.97$ (t, $\left.J=7.2 \mathrm{~Hz}, 1 \mathrm{H}, 5 \mathrm{~d}^{\prime}-\mathrm{H}\right), 7.05$ (t, $J=7.2 \mathrm{~Hz}, 1 \mathrm{H}, 6 \mathrm{~d}$ '-H), 7.11-7.45 (m, 23 H, 3'-H, 4'-H, 7'-H, 7-H, $15 \times \mathrm{Ph}-\mathrm{H}, \mathrm{NH}_{2}, 2 \mathrm{~d}$ '-H, 7d'-H), 7.57-7.58 (m, $\left.2 \mathrm{H}, 8-\mathrm{H}, 4 \mathrm{~d}^{\prime}-\mathrm{H}\right), 7.84$ (d, J= 7.8 Hz, $1 \mathrm{H}$, 
NH), 7.96 (d, $J=9.0 \mathrm{~Hz}, 1 \mathrm{H}, 9-\mathrm{H}), 8.07$ (d, $J=7.8 \mathrm{~Hz}, 1 \mathrm{H}, \mathrm{NH}), 8.14$ (s $\left.\mathrm{s}_{\mathrm{br}}, 1 \mathrm{H}, 4-\mathrm{H}\right), 8.20$ (d, $J=7.8 \mathrm{~Hz}, 1 \mathrm{H}, \mathrm{NH}), 8.24$ (d, $J=8.4 \mathrm{~Hz}, 1 \mathrm{H}, 6-\mathrm{H}), 8.28$ (d, $J=7.2 \mathrm{~Hz}, 1 \mathrm{H}, \mathrm{NH}), 10.78$ (s, $1 \mathrm{H}$, Indol-NH $\left.\mathrm{Nr}_{\mathrm{Tr}}\right), 11.61$ (s, $1 \mathrm{H}$, Indol-NH).

${ }^{13}$ C-NMR (125 MHz, DMSO-d $\left.{ }_{6}\right): \delta=14.57\left(\mathrm{SCH}_{3}\right), 23.34$ (C-11), 27.21 (C-2d), 29.41 (C-3c), 31.52 (C-2c), 33.10 (C-2'”'), 35.66 (C-2b), 37.35 (C-2a), $41.81\left(\mathrm{NCH}_{3}\right), 45.93$ (C-1), 49.52 (C-1b), 52.05 (C-1c, C-2), 53.34 (C-1','), 53.50 (C-1d), 53.94 (C-1a), 55.32 (C-2’'), 61.32 (C-10), $65.71\left(\mathrm{CO}_{2} \underline{\mathrm{CH}}_{2} \mathrm{Ph}\right), 66.10$ (C-1'’), $69.66\left(\mathrm{O}_{\mathrm{CH}}{ }_{2} \mathrm{Ph}\right), 98.43$ (C-4), 103.3 (C-4'), 105.4 (C-3'), 110.0 (C-3d'), 111.2 (C-7d'), 113.1 (C-7'), 115.9 (C-6'), 117.6 (C-9b), 118.1, 118.4 (C-4d', C-5d'), 120.8 (C-6d'), 122.7 (C-6), 123.1 (C-9), 123.5 (C-7), 123.8 (C-2d'), 126.2, 127.4, 127.6, 127.8, 127.9, 128.0, 128.3, 128.4, 129.1, 129,6, 130.9, 131.7 (C-3ad', C5a, C-8, C-9a, C-2', C-3'a, C-7'a, $15 \times$ Ph-C), 136.2, 136.8, 137.6 (C-7ad', $3 \times$ Ph-C $), 142.2$ (C-3a), 153.0, 154.2 (C-5, C-5'), 160.1 (CON), 169.6, 170.0, 171.1, 171.6, 171.9, 172.4 (6 $\times \mathrm{C}=\mathrm{O})$.

$\mathrm{C}_{72} \mathrm{H}_{76} \mathrm{CIN}_{9} \mathrm{O}_{10} \mathrm{~S}$ (1294.95).

Ber.: 1294.51971 für $[\mathrm{M}+\mathrm{H}]^{+}$

Gef.: 1294.51973 (ESI-HRMS)

HPLC (analytische Säule, Kromasil $100 \mathrm{C} 18$; Eluent A: $\mathrm{H}_{2} \mathrm{O}, 0.1 \%$ TFA; Eluent B: $\mathrm{CH}_{3} \mathrm{CN}$; Gradient: $45 \%$ in $5 \mathrm{~min}$, auf $85 \%$ in $20 \mathrm{~min}$; Flow: $0.8 \mathrm{~mL} / \mathrm{min}$ ): $\mathrm{R}_{\mathrm{t}}: 23 \mathrm{~min}$. 


\section{$7.3 \quad(1 S, 10 R / 1 R, 10 S)-3-[(2-\{2-[5-B e n z y l o x y-1-(10-c h l o r-e t h y l)-1,2-$}

dihydro-benzo[e]indol-3-carbonyl]-indol-5-yloxy\}-ethyl)methylamino]-propionsäure-[L-tryptophyl-L-methionyl-Laspartyl-L-phenylalaninamidyl]-amid-trifluoracetat (136)

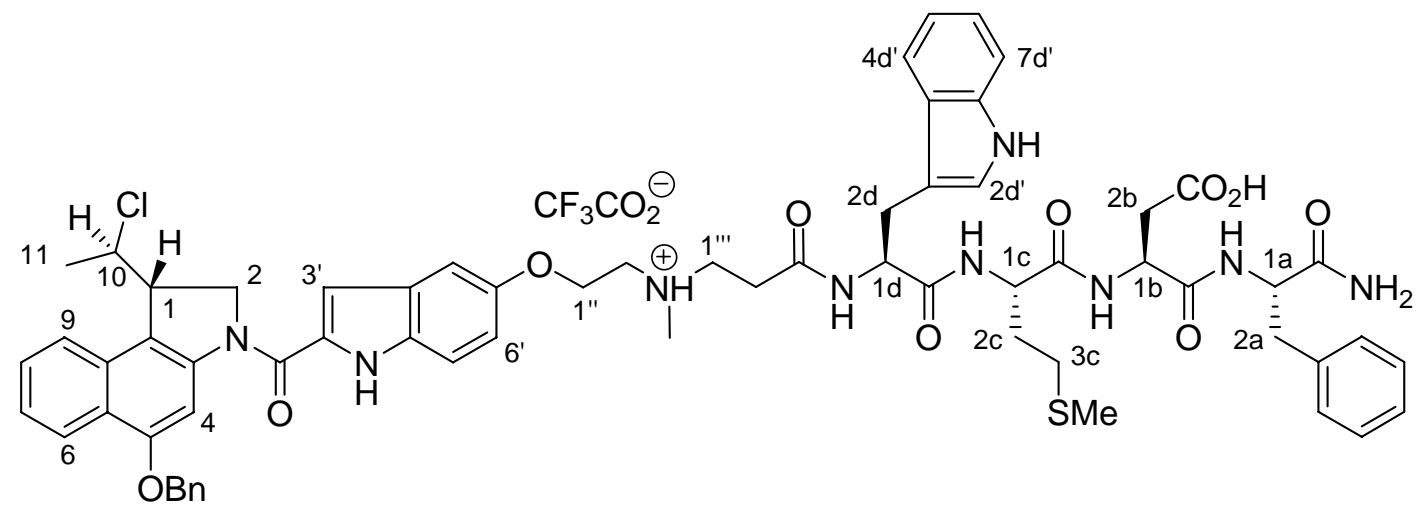

Eine Suspension des geschützten Tetrapeptids $126(30 \mathrm{mg}, 0.04 \mathrm{mmol})$ in $\mathrm{CH}_{2} \mathrm{Cl}_{2}(0.5 \mathrm{~mL})$ versetzte man mit Wasser $(0.05 \mathrm{~mL})$ und TFA $(0.5 \mathrm{~mL})$ und rührte $1.5 \mathrm{~h}$ bei Raumtemperatur. Anschließend wurde die TFA unter Zugabe von Toluol durch azeotrope Destillation im Vakuum entfernt und der Rückstand in DMF (5 mL) gelöst (Lösung A).

Zu einer Lösung von 88 (25 mg, 0.04 mmol, 1.0 Äq.) in DMF (1.0 mL) gab man HOBt (8 mg, $0.06 \mathrm{mmol}, 1.5$ Äq.) und $\mathrm{EDC} \cdot \mathrm{HCl}(12 \mathrm{mg}, 0.06 \mathrm{mmol}, 1.5 \mathrm{Äq}$.), rührte bei Raumtemperatur für 15 min (Lösung B).

Zu Lösung A gab man DIEA (16 mg, 0.12 mmol, 3.0 Äq), tropfte anschließend Lösung B zu und rührte $12 \mathrm{~h}$ bei Raumtemperatur. Das Reaktionsgemisch wurde mit Wasser $(30 \mathrm{~mL})$ versetzt und mit EtOAc $(2 \times 50 \mathrm{~mL})$ extrahiert. Die vereinigten organischen Phasen wurden über $\mathrm{Na}_{2} \mathrm{SO}_{4}$ getrocknet und das Lösungsmittel im Vakuum entfernt. Nach Säulenchromatographie $\left(\mathrm{CH}_{2} \mathrm{Cl}_{2} / \mathrm{MeOH}=20: 1 \rightarrow 10: 1\right)$ erhielt man 135 als blass-gelben Feststoff (30 mg, $0.024 \mathrm{mmol})$.

Zu einer Lösung von 135 (30 mg, 0.024 mmol, 1.0 Äq.), Pd(PPh $)_{4}(8$ mg, $6.9 \mu$ mmol, 0.3 Äq.) und Triphenylphosphan (16 mg, $61 \mu \mathrm{mmol}, 2.5$ Äq.) in einem Gemisch aus trocknem und entgastem $\mathrm{CH}_{3} \mathrm{CN}(1 \mathrm{~mL})$ und DMF $(1 \mathrm{~mL})$ wurde Pyrrolidin $(60 \mu \mathrm{l}, 0.73 \mathrm{mmol}$, 30 Äq.) gegeben und $2 \mathrm{~h}$ bei Raumtemperatur gerührt. Das Reaktionsgemisch wurde mit Wasser $(30 \mathrm{~mL})$ versetzt, mit $1.0 \mathrm{M} \mathrm{HCl}$ auf $\mathrm{pH} 3$ eingestellt und mit EtOAc $(2 \times 50 \mathrm{~mL})$ extrahiert. Die vereinigten organischen Phasen wurden über $\mathrm{Na}_{2} \mathrm{SO}_{4}$ getrocknet und das 
Lösungsmittel im Vakuum entfernt. Der Rückstand wurde zuerst mit $\mathrm{Et}_{2} \mathrm{O}$ gewaschen, dann mit präparativer HPLC gereinigt. Man erhielt die Titelverbindung 136 (10 mg, $8.3 \mu \mathrm{mmol}$, $21 \%$ über drei Stufen).

${ }^{1} \mathbf{H}-N M R\left(600 \mathrm{MHz}\right.$, DMSO-d 6 ): $\delta=1.65\left(\mathrm{~d}, J=7.2 \mathrm{~Hz}, 3 \mathrm{H}, 11-\mathrm{CH}_{3}\right), 1.76-1.82\left(\mathrm{~m}_{\mathrm{c}}, 1 \mathrm{H}\right.$, $\left.2 \mathrm{c}-\mathrm{H}_{\mathrm{a}}\right), 1.88-1.94\left(\mathrm{~m}_{\mathrm{c}}, 1 \mathrm{H}, 2 \mathrm{c}-\mathrm{H}_{\mathrm{b}}\right), 2.01\left(\mathrm{~s}, 3 \mathrm{H}, \mathrm{SCH}_{3}\right), 2.38-2.49\left(\mathrm{~m}, 2 \mathrm{H}, 3 \mathrm{c}-\mathrm{H}_{2}\right), 2.50-$ $2.52\left(\mathrm{~m}, 1 \mathrm{H}, 2 \mathrm{~b}-\mathrm{H}_{\mathrm{a}}\right), 2.67-2.70\left(\mathrm{~m}, 3 \mathrm{H}, 2\right.$ ' ' $\left.-\mathrm{H}_{2}, 2 \mathrm{~b}-\mathrm{H}_{\mathrm{b}}\right), 2.77$ (s, $\left.3 \mathrm{H}, \mathrm{NCH}_{3}\right), 2.85$ (dd, $J=$ 13.8, 8.4 Hz, $\left.1 \mathrm{H}, 2 \mathrm{a}-\mathrm{H}_{\mathrm{a}}\right), 2.97$ (dd, $\left.J=14.4,9.0 \mathrm{~Hz}, 1 \mathrm{H}, 2 \mathrm{~d}-\mathrm{H}_{\mathrm{a}}\right), 3.04(\mathrm{dd}, J=13.8,4.8 \mathrm{~Hz}$, $\left.1 \mathrm{H}, 2 \mathrm{a}-\mathrm{H}_{\mathrm{b}}\right), 3.16\left(\mathrm{dd}, J=14.4,4.5 \mathrm{~Hz}, 1 \mathrm{H}, 2 \mathrm{~d}-\mathrm{H}_{\mathrm{b}}\right), 3.37-3.42\left(\mathrm{~s}_{\mathrm{br}}, 4 \mathrm{H}, 1\right.$ ',' $-\mathrm{H}_{2}, 2$ ' '- $\left.\mathrm{H}_{2}\right)$, 4.24-4.28 (m, 3 H, 1'’-H, $1-\mathrm{H}), 4.36-4.39$ (m, 2 H, 1a-H, 1c-H), 4.54 (m, 1 H, 1b-H), 4.61$4.63\left(\mathrm{~m}, 2 \mathrm{H}, 1 \mathrm{~d}-\mathrm{H}, 2-\mathrm{H}_{\mathrm{a}}\right), 4.76-4.80\left(\mathrm{~m}, 1 \mathrm{H}, 2-\mathrm{H}_{\mathrm{b}}\right), 4.80-4.81\left(\mathrm{~m}_{\mathrm{c}}, 1 \mathrm{H}, 10-\mathrm{H}\right), 5.30-5.33$ $\left(\mathrm{m}_{\mathrm{c}}, 2 \mathrm{H}, \mathrm{CH}_{2} \mathrm{Ph}\right), 6.97-6.99$ (m, 2 H, 6'-H, 5d'-H), 7.06 (t, J=7.2 Hz, $\left.1 \mathrm{H}, 6 \mathrm{~d}^{\prime}-\mathrm{H}\right), 7.10$ 7.45 (m, 16 H, 3'-H, 4'-H, 7'-H, 7-H, $10 \times$ Ph-H, NH $\left.2,2 d^{\prime}-H, 7 d^{\prime}-H\right)$, 7.57-7.65 (m, 3 H, 8-H, 4d'-H, NH), 7.84 (d, J=7.8 Hz, $1 \mathrm{H}, \mathrm{NH}), 7.97$ (d, J=8.4 Hz, $1 \mathrm{H}, 9-\mathrm{H}), 8.13$ ( $\left.\mathrm{s}_{\mathrm{br}}, 1 \mathrm{H}, 4-\mathrm{H}\right)$, $8.16(\mathrm{~d}, J=7.2 \mathrm{~Hz}, 1 \mathrm{H}, \mathrm{NH}), 8.23$ (d, $J=7.8 \mathrm{~Hz}, 1 \mathrm{H}, 6-\mathrm{H}), 8.35$ (d, $J=7.8 \mathrm{~Hz}, 1 \mathrm{H}, \mathrm{NH})$, $9.60\left(\mathrm{~s}_{\mathrm{br}}, 1 \mathrm{H}, \mathrm{NH}^{+}\right), 10.79$ (s, $1 \mathrm{H}$, Indol-NH $\left.\mathrm{NH}_{\mathrm{Trp}}\right), 11.69$ (s, $1 \mathrm{H}$, Indol-NH), 12.39 ( $\mathrm{s}_{\mathrm{br}}, 1 \mathrm{H}$, $\mathrm{COOH})$.

${ }^{13}$ C-NMR (125 MHz, DMSO-d 6 ): $\delta=14.55\left(\mathrm{SCH}_{3}\right), 23.33$ (C-11), 27.62 (C-2d), 29.38 (C2','), 29.39 (C-3c), 31.73 (C-2c), 35.81 (C-2b), 37.23 (C-2a), $40.09\left(\mathrm{NCH}_{3}\right), 45.88$ (C-1), 49.52 (C-1b), 51.85, 51.89, 51.98 (C-1c, C-2, C-1','), 53.58 (C-1d), 53.83 (C-1a), 54.18 (C2'’), 61.33 (C-10), 62.65 (C-1'), $69.63\left(\underline{\mathrm{CH}}_{2} \mathrm{Ph}\right), 98.37$ (C-4), 104.1 (C-4'), 105.4 (C-3'), 109.9 (C-3d'), 111.2 (C-7d'), 113.2 (C-7'), 115.6 (C-6'), 117.6 (C-9b), 118.1, 118.4 (C-4d', C-5d'), 120.8 (C-6d'), 122.6 (C-6), 123.1 (C-9), 123.7 (C-7), 123.8 (C-2d'), 126.1, 127.3, 127.4, 127.5, 127.8, 127.9, 128.1, 128.4, 128.8, 129.0, 129,6, 131.2, 132.0 (Ph- $\mathrm{C}_{p}, \mathrm{Ph}-\mathrm{C}_{p \text { Phe, }}$ C-3ad', C-5a, C-8, C-9a, C-2', C-3'a, C-7'a, $8 \times$ Ph-C), 136.0, 136.8, 137.7 (C-7ad', Ph-C Ph-C $\left.C_{i P h e}\right), 142.1$ (C-3a), 151.9, 154.2 (C-5, C-5'), 160.0 (CON), 169.0, 169.9, 171.0, 171.5, $171.8,172.4(6 \times \mathrm{C}=\mathrm{O})$.

$\mathrm{C}_{67} \mathrm{H}_{71} \mathrm{ClF}_{3} \mathrm{~N}_{9} \mathrm{O}_{12} \mathrm{~S}(1318.85)$.

Ber.: $\quad 1204.47276$ für $\left[\mathrm{M}-\mathrm{CF}_{3} \mathrm{COO}\right]^{+}$

Gef.: 1204.47254 (ESI-HRMS)

HPLC (präparative Säule, Kromasil $100 \mathrm{C} 18$; Eluent A: $\mathrm{H}_{2} \mathrm{O}, 0.1 \%$ TFA; Eluent B: $\mathrm{CH}_{3} \mathrm{CN}$; Gradient: $36 \%$ in $5 \mathrm{~min}$, auf $90 \%$ in $20 \mathrm{~min}$; Flow: $10 \mathrm{~mL} / \mathrm{min}$ ): $\mathrm{R}_{\mathrm{t}}: 23 \mathrm{~min}$. 


\section{Synthese des anti-Methyl-seco-CBI-DMAI-Carbamat- Derivats}

\section{1 rac-\{(1,10)-anti-1-(10-Chlor-ethyl)-3-[(5-(2-( $N, N$-dimethylamino)- ethoxy)-indol-2-yl)carbonyl]-5-hexylaminocarbonyloxy-1,2-dihydro- $3 H$-benz[e]indol $\}(140)$}

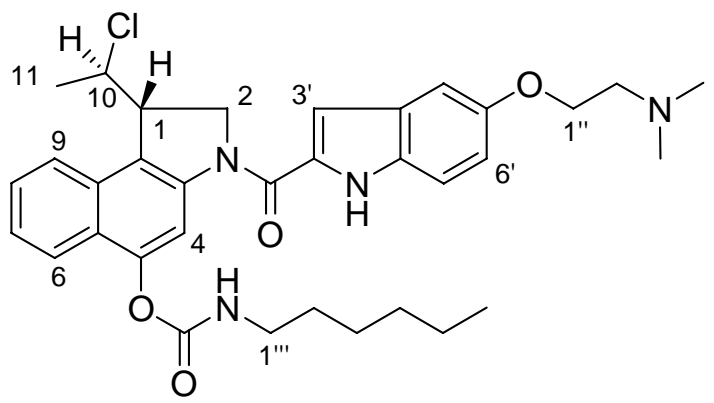

$\mathrm{Zu}$ einer Suspension von 22 (44 mg, $86 \mu \mathrm{mol}, 1.0$ Äq.) in $\mathrm{CH}_{3} \mathrm{CN}$ (16 mL) wurde 138 (36 mg, $179 \mu \mathrm{mol}, 2.1$ Äq.) sowie DIPEA (56 mg, $433 \mu \mathrm{mol}, 5.0$ Äq.) gegeben und $2.5 \mathrm{~h}$ bei Raumtemperatur gerührt. Nach Entfernen des Lösungsmittels wurde der Rückstand mit Toluol gewaschen, mit einer Lösung des Hexylamin (90 mg, $889 \mu \mathrm{mol}, 10.0$ Äq.) in $\mathrm{CH}_{3} \mathrm{CN}$ $(15 \mathrm{~mL})$ versetzt und $1 \mathrm{~h}$ bei Raumtemperatur gerührt. Danach wurde ges. $\mathrm{NaHCO}_{3}$-Lösung $(20 \mathrm{~mL})$ zugegeben und mit AcOEt $(2 \times 30 \mathrm{~mL})$ extrahiert. Die vereinigten organischen Phasen wurden über $\mathrm{Na}_{2} \mathrm{SO}_{4}$ getrocknet und das Lösungsmittel im Vakuum entfernt. Nach Säulenchromatographie an Kieselgel $\left(\mathrm{CH}_{2} \mathrm{Cl}_{2} / \mathrm{MeOH}=10: 1\right)$ erhielt man die Titelverbindung als blass-gelblichen Feststoff ( $24 \mathrm{mg}, 40 \mu \mathrm{mol}, 47 \%$ über zwei Stufen).

$\mathbf{R}_{\mathbf{f}}=0.3\left(\mathrm{CH}_{2} \mathrm{Cl}_{2} / \mathrm{MeOH}=10: 1\right)$.

${ }^{1}$ H-NMR $\left(300 \mathrm{MHz}\right.$, Acetone-d $\left.\mathrm{d}_{6}\right): \delta=0.87-0.92\left(\mathrm{~m}, 3 \mathrm{H}, 6{ }^{\prime \prime}{ }^{-}-\mathrm{CH}_{3}\right), 1.33-1.44(\mathrm{~m}, 6 \mathrm{H}$,

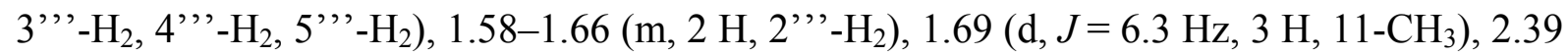

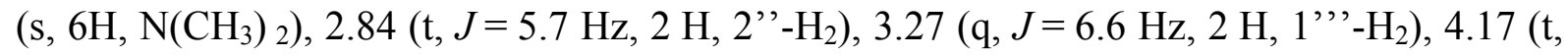
$J=5.7 \mathrm{~Hz}, 2 \mathrm{H}, 1$ ' '- $\left.\mathrm{H}_{2}\right), 4.20-4.25(\mathrm{~m}, 1 \mathrm{H}, 1-\mathrm{H}), 4.63-4.86$ (m, $\left.3 \mathrm{H}, 2-\mathrm{H}_{2}, 10-\mathrm{H}\right), 6.93$ (dd, $J=9.0,2.4 \mathrm{~Hz}, 1 \mathrm{H}, 6$ '-H), 7.16-7.19 (m, 3 H, 4'-H, 3'-H, CONH), 7.37-7.50 (m, 3 H, 7-H, 8-H, 7'-H), 7.91-7.98 (m, 2 H, 6-H, 9-H), 8.44 (s, 1 H, 4-H), 10.84 (s, 1 H, Indol-NH).

${ }^{13}$ C-NMR (75 MHz, Acetone- $\mathrm{d}_{6}$ ): $\delta=14.30$ (C-6"'), 23.24, 27.14, 32.22 (C-3"', C-4"', C-5','), 23.95 (C-11), 30.52 (C-2'”'), 41.87 (C-1','), $45.82\left(\mathrm{~N}^{\prime}\left(\mathrm{CH}_{3}\right)_{2}\right), 47.61$ (C-1), 52.95 (C-2), 58.74 (C-2'’), 61.53 (C-10), 66.94 (C-1'’), 104.16 (C-4'), 106.65 (C-3'), 112.07 (C-4), 113.87 (C-7'), 117.22 (C-6'), 123.4, 124.1 (C-6, C-9), 123.6 (C- 9b), 125.3 (C-7), 126.2 
(C-5a), 127.9 (C-8), 129.2, 130.8, 131.9, 132.8 (C-9a, C-2', C-3'a, C-7'a), 142.9 (C-3a), 148.6, 154.4, 155.5 (C-5, C-5', CONH), $160.9(\mathrm{CON})$.

MS (ESI): $m / z(\%)=605.4(100)[\mathrm{M}+\mathrm{H}]^{+}$.

$\mathrm{C}_{34} \mathrm{H}_{41} \mathrm{ClN}_{4} \mathrm{O}_{3}(605.2)$. 


\section{Abkürzungen und Akronyme}

A

Ac

ADEPT Antibody Directed Enzyme Prodrug Therapy

Äq.

AIBN

APT

Asp

$\beta$-Ala

Ber.

$\mathrm{Bn}$

Boc

Bsp.

$\mathrm{Bu}$

CBI

CBQ

$\mathrm{Cbz}$

CCK

CI

CPI

CPyI

DA

DSA

DC

DCI

DCC

DIEA

DMAI

DMAP

DMEM

DMF

DMSO

DPPA

Adenin

Acetyl

Äquivalente

$\alpha, \alpha^{\prime}$-Azabisisobutyronitril

Attached Proton Test

Asparaginsäure

$\beta$-Alanin

Berechnet

Benzyl

tert-Butoxycarbonyl

Beispiel

Butyl

Cyclopropabenzoindol

Cyclopropabenzochinolin

Benzyloxycarbonyl

Cholecystokinin

Cyclopropaindol

Cyclopropapyrroloindol

7-Methoxycarbonyl-cyclopropapyridoindol

Duocarmycin A

Duocarmycin Stable A

Dünnschichtchromatographie

direkte chemische Ionisation

Dicyclohexylcarbodiimid

Diisopropylethylamin

5-[2-( $N, N$-Dimethylamino)ethoxy]-indol

4-(N,N-Dimethylamino)-pyridin

Dulbecco's Modified Eagles Medium

Dimethylformamid

Dimethylsulfoxid

Diphenylphosphorylazid 
EDC $\quad N$-(3-Dimethylaminopropyl)- $N$ '-ethylcarbodiimid-hydrochlorid

$\mathrm{ED}_{50} \quad$ Effektive Dosis; Toxinkonzentration, bei der das Zellwachstum $50 \%$

unterbunden wird

EI Elektronenstoßionisation

ESI Elektronensprayionisation

Et Ethyl

EtOAc Essigsäureethylester

EtOH Ethanol

FKS Fötales Kälberserum

FT-ICR Fourier-Transformation-Ion-Cyclotron-Resonanz

Gef. Gefunden

ges. gesättigt

HATU $\quad O$-(7-Azabenzotriazol-1-yl)- $N, N, N^{\prime}, N^{\prime}$-tetramethyluronium-hexafluorophosphat

HOAt 1-Hydroxy-7-azabenzo-triazol

HOBt 1-Hydroxy-benzotriazol

HOCP 2,4,5-Trichlorphenol

HONB $\quad N$-Hydroxy-5-norbornen-2,3-dicarboximid

$\mathrm{HOSu} \quad N$-Hydroxysuccinimid

HPLC High Performance Liquid Chromatography

HRMS hochaufgelöstes Massenspektrum

HTCFA Human Tumor Colony Forming Ability

$\mathrm{Hz} \quad$ Hertz

$i \quad$ ipso

IR Infrarot-Spektroskopie

kat. katalytische Mengen

Kat. Katalysator

konz. konzentriert

$m \quad$ meta

$\max$ maximal

MCBI 7-Methoxy-CBI

MCCPI Methoxycarbonyl-CPI

Me Methyl

$\mathrm{MeOH} \quad$ Methanol

Met Methionin 


\begin{tabular}{|c|c|}
\hline MMI & 5-Methoxyindol \\
\hline MS (4 Å) & Molekularsieb (4 Å) \\
\hline MS & Massenspektrometrie \\
\hline NBS & $N$-Bromsuccinimid \\
\hline$n \mathrm{Bu}$ & n-Butyl \\
\hline NIS & $N$-Iodsuccinimid \\
\hline NMR & Nuclear Magnetic Resonance \\
\hline$o$ & ortho \\
\hline$p$ & para \\
\hline PDE & Pyrrolodihydroindol \\
\hline $\mathrm{PE}$ & $n$-Pentan \\
\hline $\mathrm{Ph}$ & Phenyl \\
\hline Phe & Phenylalanin \\
\hline $\mathrm{R}_{\mathrm{f}}$ & Retentionsfaktor \\
\hline $\mathrm{R}_{\mathrm{t}}$ & Retentionszeit \\
\hline RT & Raumtemperatur \\
\hline Sdp. & Siedepunkt \\
\hline$t \mathrm{Bu}$ & tert-Butyl \\
\hline $\mathrm{T}$ & Thymin \\
\hline tert & tertiär \\
\hline TFA & Trifluoressigsäure \\
\hline THF & Tetrahydrofuran \\
\hline TMEDA & Tetramethylethylendiamin \\
\hline TMI & 5,6,7-Trimethoxyindol \\
\hline TMS & Trimethylsilyl \\
\hline TOCSY & Total Correlation Spectroscopy \\
\hline $\operatorname{Trp}$ & Tryptophan \\
\hline TTMSS & Tris-(trimethylsilyl)-silan \\
\hline UV & Ultraviolett-Spektroskopie \\
\hline
\end{tabular}




\section{Literatur}

1 Daten aus Eurostat Jahrbuch 2005;

http://epp.eurostat.cec.eu.int/cache/ITY_OFFPUB/KS-CD-05-001-2/DE/KS-CD-05-0012-DE.PDF.

2 V. Schirrmacher, Krebs - Tumoren, Zellen, Gene, Spektrum der Wissenschaft Verlagsgesellschaft, Heidelberg, 1990.

3 W. Burkart, Spektrum der Wissenschaft 1994, 12, 112.

4 P. Erbar, Onkologie - Einführung in Pathophysiologie, Klinik und Therapie maligner Tumoren, 2. Aufl., Schattauer Verlag, Stuttgart, 1995.

5 siehe http://www.krebsinformation.de/tnm-system.html und dortige Verweise.

6 R. A. Weinberg, Spezial: Krebsmedizin, Spektrum der Wissenschaft 1996, 7-17.

7 H. Varmus, R. A. Weinberg, Gene und Krebs - Biologische Wurzeln der Tumorentstehung, Spektrum Akademischer Verlag, Heidelberg, 1996.

$8 \quad$ R. A. Weinberg, Science 1985, 230, 770-776.

9 O. M. Friedman, A. M. Seligman, J. Am. Chem. Soc. 1954, 76, 655-658; H. Arnold, F. Bourseaux, Angew. Chem. 1958, 70, 539-544; H. Arnold, F. Bourseaux, N. Brock, Nature 1958, 181, 931-931.

10 E. Wiltshaw, Platinum Metals Rev. 1979, 23, 90-98; S. E. Sherman, S. J. Lippard, Chem. Rev. 1987, 87, 1153-1181; T. Boulikas, M. Vougiouka, Oncology Reports 2003, 10, 1663-1682.

11 C. Bystroff, S. J. Oatley, J. Kraut, Biochemistry 1990, 29, 3263-3277.

12 E. K. Rowinsky, R. C. Donehower, Pharmac. Ther. 1991, 52, 35-84.

13 J. Rohr, Angew. Chem. 1997, 109, 2284-2289; K. C. Nicolaou, R. K. Guy, P. Potier, Sci. Am. 1996, 272, 84-88; M. E. Wall, M. C. Wani, Cancer Res. 1995, 55, 753-760; K. C. Nicolaou, W.-M. Dai, R. K. Guy, Angew. Chem. Int. Ed. Engl. 1994, 33, 15-44; A. G. Chaudhary, M. M. Gharpure, J. M. Rimoldi, M. D. Chordia, A. A. L. Gunatilaka, D. G. I. Kingston, S. Grover, C. M. Lin, E. Hamel, J. Am. Chem. Soc. 1994, 116, 4097-4098; K. C. Nicolaou, W.-M. Dai, R. K. Guy, Angew. Chem. 1994, 106, 38-69; D. G. I. Kingston, Pharmac. Ther. 1991, 52, 1-34; S. B. Horwitz, I. Ringel, J. Nat. Cancer Inst. 1991, 83, 288-291; M. C. Wani, H. L. Taylor, M. E. Wall, P. Coggon, A. T. McPhail, J. Am. Chem. Soc. 1971, 93, 2325-2327.

14 R. C, Young, R. F. Ozols, C. E. Myers, New Eng. J. Med. 1981, 305, 139-153. 
H. zur Hausen in Krebs-Forschung, Diagnostik, Therapie, Spektrum Akademischer Verlag, Heidelberg, 1992.

\section{H. Ringert, Nat. Med. 2000, 6, 332-336.}

Ullrich, C. A. Müller, V. Becker, A. J. Gross, B. Hemmerlein, L. Kanz, G. A. Müller, R. 301-387; G. A. Piertersz, I. F. C. McKenzie, Immun. Rev. 1992, 129, 57-80.

N. Jungheim, T. A. Shepherd, Chem. Rev. 1994, 94, 1553-1566.

W. J. Kruper, W. Fordyce, W. Goeckeler, Cancer 1994, 73, 993-998; D. J. Buchsbaum, T. S. Lawrence, Targeted Diagn. Ther. 1990, 3, 215-255.

M. Hallek, H. Buening, M. Ried, U. Hacker, Ch. Kurzeder, C.M. Wendtner, Der Internist 2001, 42, 1306-1313.

F. Selz, C. Hue, S. Certain, J. L. Casanova, P, Bousso, F. Le Deist, A. Fischer, Science, 2000, 288, 669-672.

Naturwissenschaften 1959, 46, 25-29; O. Warburg, The Metabolism of Tumors, Constable, London 1930.

F. Schneider, Die Naturwissenschaften 1981, 68, 20-27.

M. von Ardenne, P. G. Reitnauer, D. Schmidt, Acta Biol. Med. Germ. 1969, 22, 35-36.

M. von Ardenne, P. G. Reitnauer, Arch. Geschwulstforschung 1975, 45, 135-145; E. Jähde, M. F. Rajewsky, Cancer Res. 1982, 42, 1505-1512; S. P. Osinsky, G. V. Evtushenko, E. A. Annin, L. N. Bubnovskaja, Med. Oncol. Tumor Phar. 1990, 7, 249256; S. P. Osinsky, L. N. Bubnovskaja, T. Sergienko, Anticancer Res. 1987, 7, 199-201. 
L. F. Tietze, Nachr. Chem. Tech. Lab. 1988, 36, 728-737; L. F. Tietze, Molecular Aspects of Chemotherapy, E. Borowski, D. Shugar (Hrsg.), Pergamon Press, New York, 1990.

L. F. Tietze, R. Fischer, Angew. Chem. 1981, 93, 1002; Angew. Chem. Int. Ed. Engl. 1981, 20, 969-970; L. F. Tietze, R. Fischer, H. J. Guder, A. Goerlach, M. Neumann, T. Krach, Carbohydr. Res. 1987, 164, 177-194; L. F. Tietze, R. Fischer, H. J. Guder, M. Neumann, Liebigs Ann. 1987, 847-856; L. F. Tietze, M. Beller, R. Fischer, M. Lögers, E. Jähde, K. H. Glüsenkamp, M. F. Rajewsky, Angew. Chem. 1990, 102, 812-813; Angew. Chem. Int. Ed. Engl. 1990, 29, 782-783; L. F. Tietze, R. Fischer, M. Beller, R. Seele, Liebigs Ann. Chem. 1990, 151-157.

C. J. Springer, P. Antoniw, K. D. Bagshawe, F. Searle, G. M. F. Bisset, M. Jarman, J. Med. Chem. 1990, 33, 677-681.

E. Bakina, Z. Wu, M. Rosenblum, D. Farquhar, J. Med. Chem. 1997, 40, 4013-4018.

V. M. Vrudhula, H. P. Svensson, K. A. Kennedy, P. D. Senter, P. M. Wallace, J. Bioconjugate Chem. 1993, 4, 334-340.

R. Hannemann, Dissertation, Universität Göttingen, 1993.

W. Buhr, Dissertation, Universität Göttingen, 1995.

L.F. Tietze, M. Lieb, T. Herzig, F. Haunert, I. Schuberth, Bioorg. Med. Chem. 2001, 9, 1929-1939; L. F. Tietze, T. Herzig, A. Fecher, F. Haunert, I. Schuberth, ChemBioChem 2001, 758-765.

W. A. Denny, Eur. J. Med. Chem. 2001, 36, 577-595; M. de Graaf, E. Boven, H. W. Scheeren, H. J. Haisma, H. M. Pinedo, Curr. Pharm. Design 2002, 8, 1391-1403, W. A. Denny, Curr. Pharm. Design 2002, 8, 1349-1361.

40 A. P. Mazar, Anti-Cancer Drugs 2001, 12, 387-400.

41 F. M. H. de Groot, L. W. A. van Berkom, H. W. Scheeren, J. Med. Chem. 2000, 43, 3093-3102.

42 L. J. Hanka, A. Dietz, S. A. Gerpheide, S. L. Kuentzel, D. G. Martin, J. Antibiot. 1978, 31, 1211-1217; D. G. Martin, C. Biles, S. A. Gerpheide, L. J. Hanka, W. C. Krueger, J. P. McGovren, S. A. Mizsak, G. L. Neil, J. C. Stewart, J. Visser, J. Antibiot. 1981, 34, 1119-1125.

43 J. P. McGroven, G. L. Clarke, E. A. Pratt, T. F. DeKoning, J. Antibiot. 1984, 37, 63-70.

44 M. Ichimura, T. Ogawa, K. Takahashi, E. Kobayashi, I. Kawamoto, T. Yasuzawa, I. Takahashi, H. Nakano, J. Antibiot. 1990, 43, 1037-1038. 

787-828; b) D. L. Boger, D. S. Johnson, Angew. Chem. 1996, 108, 1542-1580; S. E. Wolkenberg, D. L. Boger, Chem. Rev. 2002, 102, 2477-2496. Med. Chem. 2003, 11, 3815-3838. 1929-1939; M. P. Hay, R. F. Anderson, D. M. Ferry, W. R. Wilson, W. A. Denny, J. Med. Chem. 2003, 46, 5533-5545.

L. F. Tietze, R. Hannemann, W. Buhr, M. Lögers, P. Menningen, M. Lieb, D. Starck, T. Grote, A. Döring, I. Schuberth, Angew. Chem. 1996, 108, 2840-2842; Angew. Chem. Int. Ed. Engl. 1996, 35, 2674-2677; L. F. Tietze, T. Feuerstein, Aust. J. Chem. 2003, 56, 841854.

A. Fecher, Dissertation, Göttingen 2000; T. Herzig, Dissertation, Göttingen 2000;

T. Feuerstein, Dissertation, Göttingen 2003.

F. Major, Diplomarbeit, Göttingen 2003. 
60

A. Sato, L. McNulty, K. Cox, S. Kim, A. Scott, K. Daniell, K. Summerville, C. Price, S. Hudson, K. Kiakos, J. A. Hartley, T. Asoa, M. Lee, J. Med. Chem., 2005, 48, 3903-3918 und hierin zitierte Literatur.

61 W. Maison, J. V. Frangioni, Angew. Chem. 2003, 115, 4874-4876. Herzig, Ger. Offen. 2001, DE10021335; L. F. Tietze, T. Herzig, A. Fecher, F. Haunert, I. Schuberth, ChemBioChem 2001, 758-765; L. F. Tietze, T. Feuerstein, Aust. J. Chem. 2003, 56, 841-854; L. F. Tietze, T. Feuerstein, Curr. Pharm. Des. 2003, 9, 2155-2175.

M. Langer, A. G. Beck-Sickinger, Curr. Med. Chem. Anti Cancer Agents 2001, 1, 71-93.

T. W. Moody, S. A. Mantey, T. K. Pradhan, M. Schumann, T. Nakagawa, A. Martinez, J. Fuselier, D. H. Coy, R. T. Jensen, J. Bio. Chem. 2004, 279, 23580-23589.

J.-C. Schaer, J. C. Reubi, J. Clin. Endocrinol. Metab. 1999, 84, 233-239.

H. J. Tracy, R. A. Gregory, Nature 1964, 204, 935-938; J. S. Morley, H. J. Tracy, R. A. Gregory, Nature 1965, 207, 1356-1359.

J. C. Reubi, J.-C. Schaer, B. Waser, Cancer Res. 1997, 57, 1377-1386.

N. I. Tarasova, S. A. Wank, E. A. Hudson, V. I. Romanov, G. Czerwinski, J. H. Resau, C. J. Michejda, Cell Tissue Res. 1997, 287, 325-333.

T. M. Behr, N. Jenner, S. Radetzky, M. Béhé, S. Gratz, S. Yücekent, F. Raue, W. Becker, Eur. J. Nucl. Med. 1998, 25, 424-430; T. M. Behr, N. Jenner, M. Béhé, C. Angerstein, S. Gratz, F. Raue, W. Becker, J. Nucl. Med. 1999, 40, 6, 1029-1044; T. M. Behr, M. Béhé, C. Angerstein, S. Gratz, R. Mach, L. Hagemann, N. Jenner, M. Stiehler, K. Frank-Raue, F. Raue, W. Becker, Clin. Cancer Res. 1999, 5, 3124s-3138s.

B. F. Schmidt, L. Hernandez, C. Rouzer, G. Czerwinski, G. Chmurny, C. J. Michejda, J. Med. Chem. 1994, 37, 3812-3818.

O. Panknin, Dissertation, Göttingen, 2004.

R. R. Phillips, Organic Reactions (New York), 1959, 10, 143-78.

S. N. Georgiades, J. Clardy, Org. Lett., 2005, 19, 4091 - 4094.

D. Bensa, J. Rodriguez, Synthetic Communications, 2004, 34, 1515-1533.

J. Skarzewski, Z. Skrowaczewska, Tetrahedron, 1976, 32, 1221-1224.

D. Spiegl, Diplomarbeit, Göttingen 2004.

T. Herzig, Dissertation, Göttingen 2000.

L. F. Tietze, A. Fecher, T. Herzig, PCT Int. Appl. 2001, WO2001083448; L. F. Tietze, T. D. L. Boger, J. A. McKie, J. Org. Chem. 1995, 50, 1271-1275; D. L. Boger, W. Han, C. M. Tarby, C. W. Boyce, H. Cai, Q. Jin, P. A. Kitos, J. Org. Chem. 1996, 61, 4894-4912. 

8990

A. Fecher, Dissertation, Göttingen 2000.

H. O. Wirth, O. Königstein, W. Kern, Ann. Chem. 1960, 643, 84-104.

J. P. Parrish, D. B. Kastrinsky, I. Hwang, D. L. Boger, J. Org. Chem. 2003, 68, 8984-

B. Krewer, Diplomarbeit, Göttingen 2005.

K. Ninomiya, T.Shioiri, S. Yamada, Tetrahedron 1974, 30, 2151-2157.

S. Ram, L. D. Spicer, Tetrahedron Lett. 1987, 28, 515-516; T. Bieg, W. Szeja, Synthesis 1985, 76-77.

H. Gregory, P. M. Hardy, D. S. Jones, G. W. Kenner, R. C. Sheppard, Nature 1964, 204, 931-933; J. C. Anderson, M. A. Barton, R. A. Gregory, P. M. Hardy, G. W. Kenner, J. K. MacLeod, J. Preston, R. C. Sheppard, J. S. Morley, Nature 1964, 204, 933-934.

86 J. M. Davey, A. H. Laird, J. S. Morley, J. Chem. Soc. C 1966, 555-566.

87 P. Henklein, M. Boomgaarden, E.-M. Nieke, M. Georgi, H. Niedrich, Pharmazie 1988, $43,10-12$.

U. Griesbach, Dissertation, Göttingen, 2002.

P. J. Belshaw, S. Mzengeza, G. A. Lajoie, Synth. Commun. 1990, 20, 3157-3160.

Das Peptid ist von Firma Bachem.

E. Didier, D. C. Horwell, M. C. Pritchard, Tetrahedron 1992, 48, 8471-8490.

D. R. Coulson, Inorg. Synth. 1975, 13, 121-124.

R. Deziel, Tetrahedron Lett. 1987, 28, 4371-4372.

F. Guibé, Tetrahedron 1997, 54, 2967-3042; H. Kunz, H. Waldmann, Angew. Chem. 1984, 96, 49-50; Angew. Chem. Int. Ed. Engl. 1984, 23, 71-72.

B. ElAmin, G. M. Anantharamaiah, G.P. Royer, G. E. Means, J. Org. Chem. 1979, 44, 3442-3444; D. C. Gowda, Indian Journal of Chemistry, Section B: Organic Chemistry Including Medicinal Chemistry 2002, 41B, 1064-1067.

S. Ray, D. Chaturvedi, Drugs of the Future 2004, 29, 343-357.

D. L. Boger, C. W. Boyce, R. M. Garbaccio, M. Searcey, Q. Jin, Synthesis 1999, 15051509. 


\section{Danksagung}

Zunächst gilt mein Dank der NMR-Abteilung des Instituts für Organische und Biomolekulare Chemie mit Herrn U. Leonhardt, Frau C. Siebert, Herrn M. Weitemeyer, Frau C. Zolke und ganz besonders ihrem Leiter Herrn R. Machinek. Frau G. Udvarnoki und Herrn Dr. Holm Frauendorf danke ich für die Aufnahme von Massenspektren, Herrn F. Hambloch für die Anfertigung von Elementaranalysen. Mein besonderer Dank gilt Frau Dr. Ingrid Schuberth, Anja Herdlitschke und Angela Rübeling für die Durchführung der in vitroZytotoxizitätsuntersuchungen. Ebenso danke ich Frau E. Pfeil für die Aufnahme zahlreiche IR- und UV-Spektren. Unserer IT-Experten Frau M. Pretor, T. Kinzel und S. Hellkamp, schulde ich ebenfalls großen Dank.

Für das sorgfältige Korrekturlesen dieser Arbeit bedanke ich mich bei O. Elsner, H.Schuster, F. Lotz, L. Nacke, T. Redert, D. Spiegel und C. Brazel.

Der Abteilung von Prof. Dr. Dr. h.c. L. F. Tietze danke ich für die stete Hilfsbereitschaft und das gute Arbeitsklima. Besonders danke ich O. Elsner, H. Schuster, F. Major, Dr. O. Panknin, Dr. C. Vock, Dr. R. Singidi, S. Hampel, C. Noll, F. Stecker, C. Raith und D-S. Liu für grenzenlosen Ideenaustausch im Labor und Hilfe im Leben.

Dem DFG-Graduiertenkolleg 782 danke ich für die finanzielle Förderung während meiner Promotion.

Ich danke meiner Familie für das Verständnis und Unterstützung in den Jahren der Promotion. 


\section{Lebenslauf}

$\begin{array}{ll}\text { 20.09.1974 } & \text { Geboren als Sohn von Shu-Hong Chen und seiner Frau } \\ & \text { WenZhen Sun in Shanghai, China } \\ & \text { Besuch der Grundschule in Shanghai, China } \\ 1980-1986 & \text { Besuch der Mittelschule in Shanghai, China } \\ 1986-1992 & \text { Studium im Fachbereich Chemie der Ostchinesischen } \\ 1992-1996 & \text { Pädagogischen Universität in Shanghai, China } \\ & \text { Abschluß : Bachelor of Science } \\ & \text { Forschungsassistent im Shanghai Institut für Pharmazeutische } \\ & \text { Industrie } \\ & \text { Studium im Fachbereich Chemie der Peking Universität in } \\ & \text { Peking, China } \\ & \text { Abschluß : Master of Science } \\ & \text { Forschungsassistent im Shanghai Institut für Pharmazeutische } \\ & \text { Industrie } \\ & \text { Dissertation am Institut für Organische und Biomolekulare } \\ & \text { Chemie der Georg-August-Universität in Göttingen unter der } \\ \text { März 2003- April. 2006 } & \text { Leitung von Prof. Dr. Dr. h.c. L. F. Tietze über die "Synthese } \\ & \text { von Tetragastrin-CC-1065-Konjugaten und verwandten } \\ & \text { Verbindungen für eine selektive Krebstherapie" } \\ & \text { Mündliche Promotionsprüfung }\end{array}$

